\title{
DYSSYNCHRONOPATHY
}

\author{
and the role of \\ cardiac resynchronization therapy
}

Kevin Vernooy 
Copyright (C) Kevin Vernooy, Maastricht 2006

ISBN-10: 90-5278-576-7

ISBN-13: 978-90-5278-576-9

Datawyse / Universitaire Pers Maastricht 


\title{
DYSSYNCHRONOPATHY
}

\section{and the role of \\ cardiac resynchronization therapy}

\author{
PROEFSCHRIFT \\ Ter verkrijging van de graad van doctor \\ aan de Universiteit Maastricht, \\ op gezag van de Rector Magnificus, \\ Prof. mr. G.P.M.F. Mols \\ volgens het besluit van Collega van Decanen, \\ in het openbaar te verdedigen \\ op vrijdag 24 november 2006 om 14:00 uur \\ door \\ Kevin Vernooy \\ Geboren op 29 juli 1978 \\ te St. Oedenrode
}

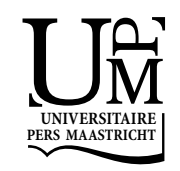




\section{Promotores}

Prof. dr. H.J.G.M. Crijns

Prof. dr. T. Arts

\section{Co-promotores}

Dr. F.W. Prinzen

Dr. B. Dijkman

\section{Beoordelingscommissie}

Prof. dr. G.J. van der Vusse (voorzitter)

Prof. dr. M.A. Allessie

Dr. A. Auricchio, Fondazione Cardiocentro Ticino, Lugano, Switzerland

Prof. dr. J.J. Bax, Leids Universitair Medisch Centrum

Prof. dr. J.G. Maessen

The studies described in this thesis were supported by the Netherlands Organization for Health, Research and development (Zon-MW).

Financial support by stichting RESCAR Maastricht for the publication of this thesis is gratefully acknowledged.

Additional support was granted by: Medtronic Bakken Research Center, Guidant Nederland, Astellas Pharma, Pfizer, Novartis and AstraZeneca 


\section{Contents}

$\begin{array}{ll}\text { Abbreviations } & 7\end{array}$

Chapter 1

Introduction

Chapter 2

Dyssynchronopathy

15

Chapter 3

Review on CRT

27

Chapter 4

Left bundle branch block induces ventricularremodeling and functional septal Hypoperfusion

Chapter 5

Intra-ventricular resynchronization for optimal left ventricular function during pacing in experimental left bundle branch block

\section{Chapter 6}

Calculating an effective VV-interval in order to optimize $\mathrm{AV}$-delay and $\mathrm{VV}$-interval in cardiac resynchronization therapy

\section{Chapter 7}

Cardiac resynchronization therapy cures dyssynchronopathy

in canine LBBB hearts

\section{Chapter 8}

Ventricular remodeling during long-term right ventricular pacing following His bundle ablation

Chapter 9

General discussion

Summary

Samenvatting

Dankwoord 



\section{Abbreviations}

AV-delay:

BiV pacing:

BiV0 pacing:

BiVS pacing:

BVP:

CRT:

CSsys:

ECG:

HBA:

HR:

interVA:

intraVA:

LBBB:

LV:

LVdP/dt|max:

LVdP/dt|min:

LV EF:

LV EDP:

LV EDV:

LV ESV:

LV FS:

LV SP:

MRI:

NYHA fc

PM:

RV:

$\mathrm{RVdP} / \mathrm{dt} \mid \max$ :

SPWMD:

SV:

SW:

TA-LVpace:

TA-RVpace:

TLV:

TRV:

TDI:

VV-interval:

VVeff: atrio-ventricular delay

biventricular pacing

simultaneous $\mathrm{BiV}$ pacing

sequential $\mathrm{BiV}$ pacing

biventricular pacing

cardiac resynchronization therapy

systolic circumferential strain

electrocardiogram

His bundle ablation

heart rate

inter-ventricular asynchrony (RV-LV asynchrony)

intra-ventricular asynchrony (intra-LV asynchrony)

left bundle branch block

left ventricle, left ventricular

maximum rate of $\mathrm{LV}$ pressure rise

maximum rate of $\mathrm{LV}$ pressure decline

LV ejection fraction

LV end-diastolic pressure

LV end-diastolic volume

LV end-systolic volume

LV franctional shortening

LV systolic pressure

magnetic resonance imaging

New York heart association functional class

pacemaker

right ventricle, right ventricular

maximum rate $\mathrm{RV}$ pressure rise

septal-to-posterior wall motion delay

stroke volume

stroke work

programmed delay from right atrial sensing to LV pacing

programmed delay from right atrial sensing to RV pacing

time from atrial sensing to onset of electrical activation of the LV lateral wall by intrinsic activation

time from atrial sensing to onset of electrical activation of the RV by intrinsic activation

tissue Doppler imaging

time interval between RV and LV pacing

effective VV-interval 


\section{Chapter 1}

\section{Introduction}

Kevin Vernooy, MD

Department of Physiology and Cardiology, Cardiovascular Research Institute Maastricht, Maastricht, the Netherlands 


\section{$10 \mid$ Chapter 1}

Synchronous, coordinate ventricular contraction is an important determinant of cardiac pump function. The coordinate contraction is achieved by almost synchronous activation of the ventricular muscle due to impulse conduction through the specialized ventricular rapid-conduction system. Conduction through the Purkinje fibers is approximately 4 times faster than in the normal myocardium.

Abnormal ventricular impulse conduction, such as left bundle branch block (LBBB), ${ }^{1,2}$ Wolff-Parkinson-White syndrome ${ }^{3}$ or ventricular pacing, ${ }^{4}$ results in asynchronous ventricular activation and contraction, because the Purkinje system is bypassed, to various degrees, and activation spreads by slow conduction in the normal myocardium. The resulting asynchronous ventricular activation and discoordinate contraction leads to adverse hemodynamic effects and abnormal distribution of myocardial workload and blood flow. ${ }^{5,6}$ Studies using ventricular pacing have shown that asynchronous ventricular activation immediately deteriorates left ventricular (LV) function. ${ }^{7}$ Moreover, evidence is increasing that asynchronous ventricular activation is associated with structural changes in the long run. Animal studies have shown that long-term LV pacing induces LV remodeling, including LV dilatation and asymmetric hypertrophy, as well as molecular changes, all processes known to predispose for heart failure. ${ }^{8,9}$ An increasing number of clinical studies indicate that right ventricular (RV) pacing and LBBB are associated with increased morbidity and mortality. ${ }^{10-13}$ It appears that all abovementioned abnormalities originate from the asynchronous ventricular activation and contraction. If that is the case, this combination of derangements would deserve its own name: dyssynchronopathy.

Recognition of dyssynchronopathy is relevant, because during the last decade considerable attention has emerged for cardiac resynchronization therapy (CRT). CRT aims to improve cardiac pump function by restoration of synchronous ventricular activation by electrical stimulation of the RV and LV (biventricular pacing). The RV pacing electrode usually is positioned in the RV apex and the LV pacing electrode is positioned via the coronary sinus in one of the descending postero-lateral veins, being the latest activated region. Various clinical studies have shown that, in patients with heart failure and LBBB, CRT improves cardiac pump function, quality of life, exercise tolerance and hospitalizations for heart failure, ${ }^{14,15}$ and reduces the risk of death. ${ }^{16}$ Moreover, longterm CRT can even decrease LV cavity dimensions, referred to as reverse remodeling. ${ }^{16,17}$

Although CRT has had great success, various issues are not clear. The effect of CRT varies widely between patients, both acute and long-term. Several studies have recognized that up to $30 \%$ of the patients who receive a CRT device do not respond to this therapy, even after careful examination and following current guidelines. In addition, within the category of responders, the benefit of CRT varies widely, ranging from small improvement to sensational func- 
tional recovery. A similarly wide variability is noticed with respect to the approach of cardiologists in the use of CRT. While some cardiologists regard CRT as last resort to current therapies, others believe that CRT should be applied in each patient with any sign of a ventricular conduction abnormality.

These inconsistencies suggest that we still lack important knowledge on the consequences of LBBB for the heart, how to resynchronize LBBB hearts in order to achieve the largest improvement in pump function, and to what extent acute improvements also relate to long-term effects.

\section{OVERVIEW OF THE THESIS}

The overall aim of this thesis is to investigate the effect of induced asynchronous ventricular activation on ventricular function and structure in healthy hearts and its reversal by CRT. Furthermore, we investigated how optimal resynchronization can be achieved and predicted from electrocardiographic and hemodynamic indices of asynchrony. In this thesis, we recognize inter- and intra-ventricular asynchrony, being the asynchrony between the RV and LV and the asynchrony within the LV, respectively. Inter-ventricular asynchrony was determined by the time delay between the upslope of the LV and RV pressure curves. Intra-ventricular asynchrony was determined based on electrical activation (the time delay of LV endocardial electrical activation) and mechanical signals (the time delay of circumferential midwall strain).

In patients, LBBB has been associated with LV dilatation, hypertrophy and reduced LV ejection fraction, ${ }^{9}$ as well as myocardial perfusion defects. ${ }^{18}$ However, in all of these studies LBBB patients have considerable co-morbidity, hampering the conclusion that these abnormalities are related to dyssynchronopathy. The rationale of the study described in chapter 4 is to obtain better insights into the etiology of myocardial adaptations during LBBB. To this purpose, we investigated the effects of LBBB on LV pump function, contraction, myocardial perfusion and structural changes during chronic (4 months) of experimental LBBB.

Although it is well established that pacing at the LV can improve synchrony of activation in LBBB hearts, confusion exists about the optimal site of the LV lead, as well as whether pacing should occur at the LV alone or at the LV and RV together. ${ }^{19,20}$ Moreover, various determinants have been proposed for prediction of optimal resynchronization. In chapter 5, we describe a study in canine LBBB hearts on the effect of LV and BiV pacing on LV pump function, QRS duration, and estimates of intra- and inter-ventricular asynchrony.

In current CRT, sequential biventricular pacing is advocated, although proper timing of RV and LV pacing is not well understood. ${ }^{21}$ Therefore, we investigated in Chapter 6 whether the effective VV-interval (VVeff), the actual 


\section{2 \\ Chapter 1}

time difference between LV and RV activation, can be used to optimize timing between the atria and ventricles (AV-delay) and timing between the RV and LV (VV-interval).

The observation that long-term asynchronous ventricular activation induces ventricular remodeling ${ }^{5,9}$ and the subsequent indication for CRT has raised the question to what extent CRT can reverse the ventricular adaptations induced by LBBB. In chapter 7, we used animals with chronic LBBB in order to explore to what extent CRT leads to reversal of the LBBB induced adaptations.

While chapters 4 and 7 describe the natural history of animal hearts with LBBB, knowledge of the natural history of patients with LBBB is hampered by the silent onset of LBBB and co-morbidity. However, onset of asynchronous ventricular activation is exactly known in patients receiving a ventricular pacemaker. Therefore, we analyzed LV remodeling in a population of patients undergoing His bundle ablation and pacemaker implantation for atrial arrhythmias (Chapter 8). We hypothesize that ventricular pacing could have a dual effect in this category of patients: a beneficial effect on cardiac pump function by heart rate regularization, and a negative effect by inducing asynchronous ventricular conduction.

The thesis starts with a survey of literature on LBBB and CRT (chapter 2 and 3, respectively) and ends with a general discussion (chapter 9). In the latter chapter, the findings of the abovementioned studies are discussed with special emphasis on the clinical implications and future studies.

\section{REFERENCES}

1 Grines CL, Bashore TM, Boudoulas H, Olson S, Shafer P, Wooley CF. Functional abnormalities in isolated left bundle branch block. The effect of interventricular asynchrony. Circulation. 1989;79:845-853.

2 Vassallo JA, Cassidy DM, Marchlinski FE, Buxton AE, Waxman HL, Doherty JU, Josephson ME. Endocardial activation of left bundle branch block. Circulation. 1984;69:914-923.

3 Durrer D, Roos JP. Epicardial excitation of the ventricles in a patient with wolff-ParkinsonWhite syndrome ( type B). Circulation. 1967;35:15-21.

4 Vassallo JA, Cassidy DM, Miller JM, Buxton AE, Marchlinski FE, Josephson ME. Left ventricular endocardial activation during right ventricular pacing: effect of underlying heart disease. J Am Coll Cardiol. 1986;7:1228-1233.

5 van Oosterhout MF, Prinzen FW, Arts T, Schreuder JJ, Vanagt WY, Cleutjens JP, Reneman RS. Asynchronous electrical activation induces asymmetrical hypertrophy of the left ventricular wall. Circulation. 1998;98:588-595.

6 Prinzen FW, Hunter WC, Wyman BT, McVeigh ER. Mapping of regional myocardial strain and work during ventricular pacing: experimental study using magnetic resonance imaging tagging. J Am Coll Cardiol. 1999;33:1735-1742.

7 Peschar M, de Swart H, Michels KJ, Reneman RS, Prinzen FW. Left ventricular septal and apex pacing for optimal pump function in canine hearts. J Am Coll Cardiol. 2003;41:12181226. 
8 van Oosterhout MF, Arts T, Muijtjens AM, Reneman RS, Prinzen FW. Remodeling by ventricular pacing in hypertrophying dog hearts. Cardiovasc Res. 2001;49:771-778.

9 Prinzen FW, Cheriex EC, Delhaas T, van Oosterhout MF, Arts T, Wellens HJ, Reneman RS. Asymmetric thickness of the left ventricular wall resulting from asynchronous electric activation: a study in dogs with ventricular pacing and in patients with left bundle branch block. Am Heart J. 1995;130:1045-1053.

10 Nielsen JC, Kristensen L, Andersen HR, Mortensen PT, Pedersen OL, Pedersen AK. A randomized comparison of atrial and dual-chamber pacing in 177 consecutive patients with sick sinus syndrome: echocardiographic and clinical outcome. J Am Coll Cardiol. 2003;42:614623.

11 Andersen HR, Nielsen JC, Thomsen PE, Thuesen L, Mortensen PT, Vesterlund T, Pedersen AK. Long-term follow-up of patients from a randomised trial of atrial versus ventricular pacing for sick-sinus syndrome. Lancet. 1997;350:1210-1216.

12 Wilkoff BL, Cook JR, Epstein AE, Greene HL, Hallstrom AP, Hsia H, Kutalek SP, Sharma A. Dual-chamber pacing or ventricular backup pacing in patients with an implantable defibrillator: the Dual Chamber and VVI Implantable Defibrillator (DAVID) Trial. Jama. 2002;288:3115-3123.

13 Sweeney MO, Prinzen FW. A new paradigm for physiologic ventricular pacing. J Am Coll Cardiol. 2006;47:282-288.

14 Kass DA, Chen CH, Curry C, Talbot M, Berger R, Fetics B, Nevo E. Improved left ventricular mechanics from acute VDD pacing in patients with dilated cardiomyopathy and ventricular conduction delay. Circulation. 1999;99:1567-1573.

15 Auricchio A, Stellbrink C, Sack S, Block M, Vogt J, Bakker P, Huth C, Schondube F, Wolfhard U, Bocker D, Krahnefeld O, Kirkels H. Long-term clinical effect of hemodynamically optimized cardiac resynchronization therapy in patients with heart failure and ventricular conduction delay. J Am Coll Cardiol. 2002;39:2026-2033.

16 Cleland JG, Daubert JC, Erdmann E, Freemantle N, Gras D, Kappenberger L, Tavazzi L. The effect of cardiac resynchronization on morbidity and mortality in heart failure. N Engl J Med. 2005;352:1539-1549.

17 Yu CM, Chau E, Sanderson JE, Fan K, Tang MO, Fung WH, Lin H, Kong SL, Lam YM, Hill MR, Lau CP. Tissue Doppler echocardiographic evidence of reverse remodeling and improved synchronicity by simultaneously delaying regional contraction after biventricular pacing therapy in heart failure. Circulation. 2002;105:438-445.

18 Hasegawa S, Sakata Y, Ishikura F, Hirayama A, Kusuoka H, Nishimura T, Kodama K. Mechanism for abnormal thallium-201 myocardial scintigraphy in patients with left bundle branch block in the absence of angiographic coronary artery disease. Ann Nucl Med. 1999; 13:253-259.

19 Butter C, Auricchio A, Stellbrink C, Fleck E, Ding J, Yu Y, Huvelle E, Spinelli J. Effect of resynchronization therapy stimulation site on the systolic function of heart failure patients. Circulation. 2001;104:3026-3029.

20 Ansalone G, Giannantoni P, Ricci R, Trambaiolo P, Fedele F, Santini M. Doppler myocardial imaging to evaluate the effectiveness of pacing sites in patients receiving biventricular pacing. J Am Coll Cardiol. 2002;39:489-499.

21 Perego GB, Chianca R, Facchini M, Frattola A, Balla E, Zucchi S, Cavaglia S, Vicini I, Negretto M, Osculati G. Simultaneous vs. sequential biventricular pacing in dilated cardiomyopathy: an acute hemodynamic study. Eur J Heart Fail. 2003;5:305-313. 


\section{Chapter 2}

\section{Relation between abnormal ventricular impulse conduction and heart failure: dyssynchronopathy}

Kevin Vernooy, MD, Xander A.A.M. Verbeek, PhD, Maaike Peschar, $\mathrm{PhD}$, and Frits W. Prinzen

Department of Physiology, Cardiovascular Research Institute Maastricht, Maastricht University, Maastricht, the Netherlands

Based on: J Interv Cardiol. 2003 Dec;16(6):557-62. Review 
$16 \mid$ Chapter 2

\section{INTRODUCTION}

Many abnormalities can lead to heart failure, either acutely or chronically: valvular dysfunction, tachy- and bradycardia, hypertrophy, infarction. During the last decennium, a new factor emerged: abnormal impulse conduction in the ventricles, leading to asynchronous electrical activation and contraction. This factor is quickly gaining interest due to the rapid progress of cardiac resynchronization therapy (CRT). Abnormal impulse conduction can occur due to disturbed function of the ventricular rapid conduction ("Purkinje") system and/or due to pacing the ventricles.

In this chapter, we will review the literature about left bundle branch block (LBBB) and right ventricular (RV) pacing with respect to their a) immediate effect on cardiac function, b) long-term structural and functional effect and c) the clinical and epidemiological evidence for a relation between abnormal conduction and heart failure. Information on RV pacing and LBBB is combined, because their electrical activation patterns are very similar. Both conditions are relevant to cardiovascular healthcare. In 2000 more than 150.000 pacemakers were implanted in the U.S. alone, ${ }^{1}$ most of them in combination with an RV pacing electrode. LBBB is the most common kind of abnormal ventricular conduction disturbance in patients with heart failure $(\sim 30 \%){ }^{2}$

\section{HEMODYNAMIC EFFECTS OF RV PACING}

Already in 1925, Wiggers and colleagues recognized the importance of the sequence of electrical activation of the ventricles for cardiac pump function using artificial electrical stimulation of the ventricles. ${ }^{3}$ Kosowsky and colleagues showed that RV apex pacing reduces pump function, but His-bundle pacing, maintaining the normal activation sequence, does not. ${ }^{4}$ Several animal studies showed that the site of pacing significantly affects cardiac pump function. ${ }^{5-9}$ Importantly, hemodynamic deterioration is usually most pronounced when pacing at the RV apex, the site commonly used in the clinic.

Ventricular pacing reduces systolic and diastolic function, independent of preload and afterload. ${ }^{5,10-13}$ With respect to systolic function, the maximal rate of rise of left ventricular pressure (LVdP/dt|max) appears to be the most sensitive marker of reduced systolic function. ${ }^{7,9,14}$ The sensitivity of this isovolumic measure of contractility may be due to the large differences in muscle fiber length changes during this phase: rapid shortening near the pacing site but pronounced stretching in remote areas (figure 1). ${ }^{6,15}$ Therefore, forces generated by the already activated fibers are dissipated by internal resistances of 


\section{Early activated Normal Late activated}
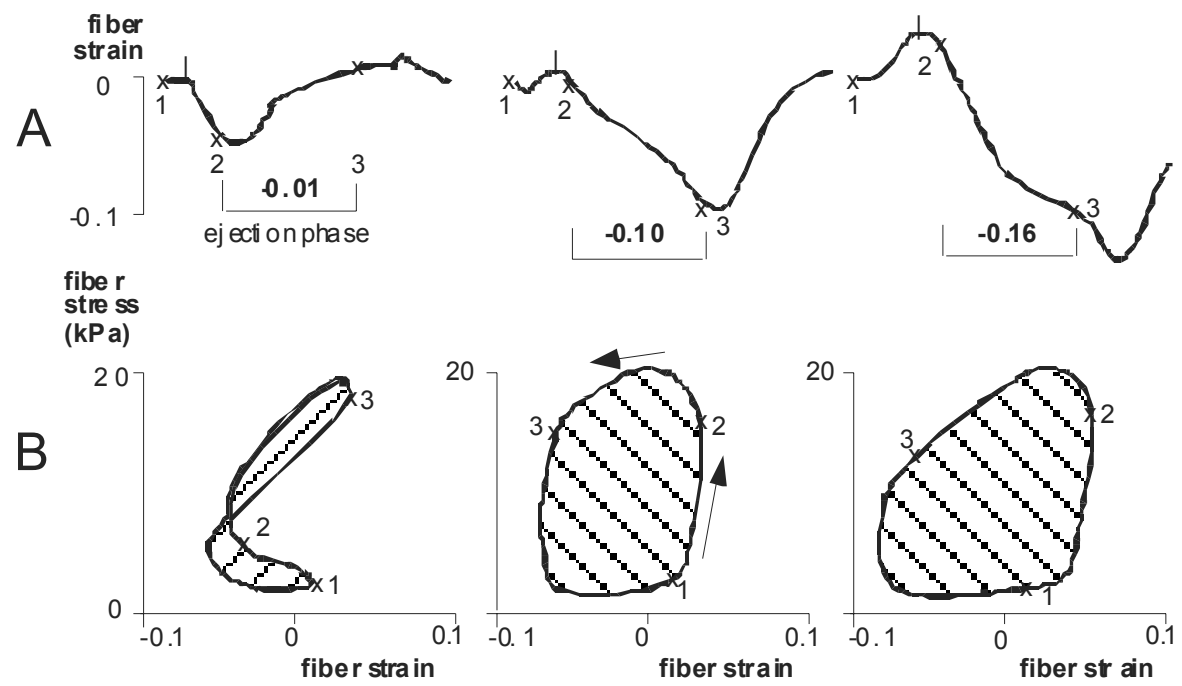

Figure 1. Regional strain and stress-strain relations during ventricular pacing in regions close to (early-activated) and remote from the pacing site (late-activated). Negative strain indicates shortening (A). Hatched areas of the loops indicate regional external work (B). 1, 2 and 3 indicate end-diastole, begin-ejection and end-ejection, respectively. Data derived from references. ${ }^{6,15}$

not yet activated fibers. Stroke volume is also affected, because the total duration of systole is hardly influenced by pacing, ${ }^{10}$ the isovolumic phases last longer, thus limiting the time for ejection. ${ }^{16}$ The negative inotropic effect of pacing has also been characterized using the LV function curve, i.e. output at varying preload ${ }^{11}$ and is expressed as a rightward shift of the end-systolic P-V relation (figure 2), indicating that a larger ventricular end-diastolic volume is required to obtain the same pressure development. ${ }^{5,12,13}$ Ventricular pacing may compromise effective forward stroke volume further by inducing mitral valve regurgitation. ${ }^{17,18}$ Ventricular pacing also impairs ventricular relaxation. Especially isovolumic relaxation parameters, like $\mathrm{LVdP} / \mathrm{dt} \mid \mathrm{min}$ and Tau, are strongly influenced by ventricular pacing. ${ }^{7,14,19}$

While ventricular pacing decreases mechanical output, it does not change ${ }^{12}$ or even increases myocardial oxygen consumption. ${ }^{20}$ Therefore, the efficiency of conversion of metabolic to mechanical energy becomes $20-30 \%$ lower. Moreover, within the LV wall large differences in mechanical work during pac- 


\section{8 \\ Chapter 2}

ing (Figure 1) result in significant regional differences in perfusion and oxygen consumption. ${ }^{21}$

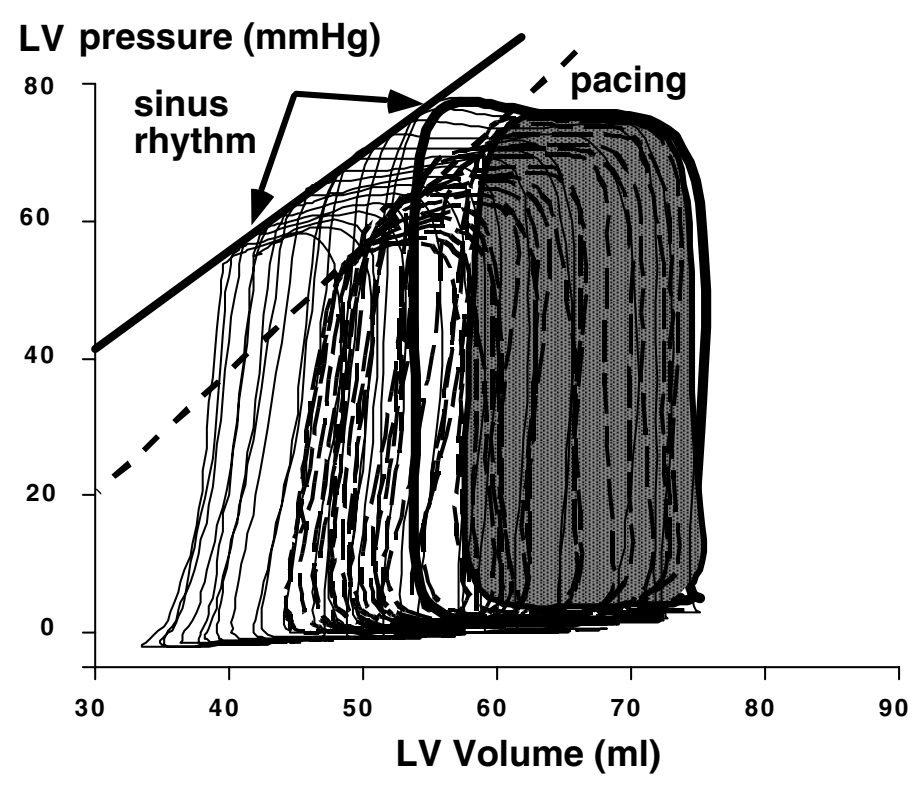

Figure 2. Pressure-volume (P-V) diagrams during sinus rhythm (drawn lines) and ventricular pacing (broken lines). Thickly drawn lines represent loops during steady state while thin lines represent loops during caval vein occlusion. The end-systolic P-V relation (straight lines) shifts rightward during ventricular pacing. Because pacing does not change the end-diastolic P-V relation, ventricular pacing reduces stroke work (gray area). Modified from reference. ${ }^{13}$

\section{HEMODYNAMIC EFFECTS OF LBBB}

Because LBBB usually starts silently, knowledge on the direct hemodynamic effects of LBBB are limited to studies on patients with intermittent LBBB. While the reduction in cardiac pump function after onset of LBBB is clear, the interpretation of these data is hampered by the fact that the onset of LBBB usually coincides with an increase in heart rate, elicited by an exercise test. The exercise test itself may confound the LBBB effect of cardiac function, because it can induce myocardial ischemia. ${ }^{22}$ Understanding LBBB is further complicated by its frequent coincidence with other cardiovascular derangements. Recently an animal model of LBBB has been developed. LBBB is created by abla- 
tion of the proximal part of the left bundle branch. ${ }^{23}$ After ablation of the left bundle branch the duration of the QRS complex, the asynchrony of contraction between RV and LV increased and LV function decreased, ${ }^{23}$ to a similar degree as in LBBB patients. ${ }^{24,25}$ These data suggest that, although in patients LBBB is supposedly the result of more diffuse conduction disturbances, this LBBB model resembles the LBBB patients quite well. The ablation model is also better than when using RV pacing as model for LBBB, ${ }^{22,26}$ because RV pacing requires a higher heart rate and/or shorter AV-delay to guarantee activation of the entire ventricles by the pacing stimulus. Moreover, during LBBB RV activation is normal whereas it is abnormal during RV pacing. The animal model of LBBB so far shows that LBBB reduces systolic and diastolic LV function. ${ }^{23}$. Hearts with experimental LBBB also show the paradoxical septal wall motion, ${ }^{23}$ which is so characteristic for LBBB hearts. ${ }^{27-30}$ The paradoxical motion may be caused by the asynchrony between RV and LV, producing dynamic alterations in transseptal pressure differences ${ }^{28,31}$ and by pre-systolic shortening of septal muscle fibers. ${ }^{32}$ Furthermore results the abnormal septal motion in a diminished contribution of the interventricular septum to LV ejection. ${ }^{33}$

\section{LONG-TERM STRUCTURAL AND FUNCTIONAL EFFECT OF RV PACING AND LBBB}

Asynchronous electrical activation not only has acute mechanical consequences, but also influences cardiac structure and function on the long run. Longer lasting ventricular pacing leads to major structural changes, such as ventricular dilatation and asymmetric hypertrophy, referred to as remodeling. ${ }^{13,34}$ The various aspects of this remodeling are most likely related to the effects on global and regional contraction, described above. Ventricular pacing leads to ventricular dilatation and asymmetric hypertrophy, ${ }_{3,3}^{13,35}$ fiber disarray, ${ }^{36,37}$ increased myocardial catecholamine concentrations ${ }^{38}$ and altered perfusion distribution. ${ }^{39,40}$ The asymmetry of hypertrophy, disturbed perfusion and fiber disarray appear the result of the abnormal contraction patterns and mechanical loading under these conditions, whereas the ventricular dilatation and increased catecholamine concentrations may be related to the reduced pump function (Figure $3)$. 
$20 \mid$ Chapter 2

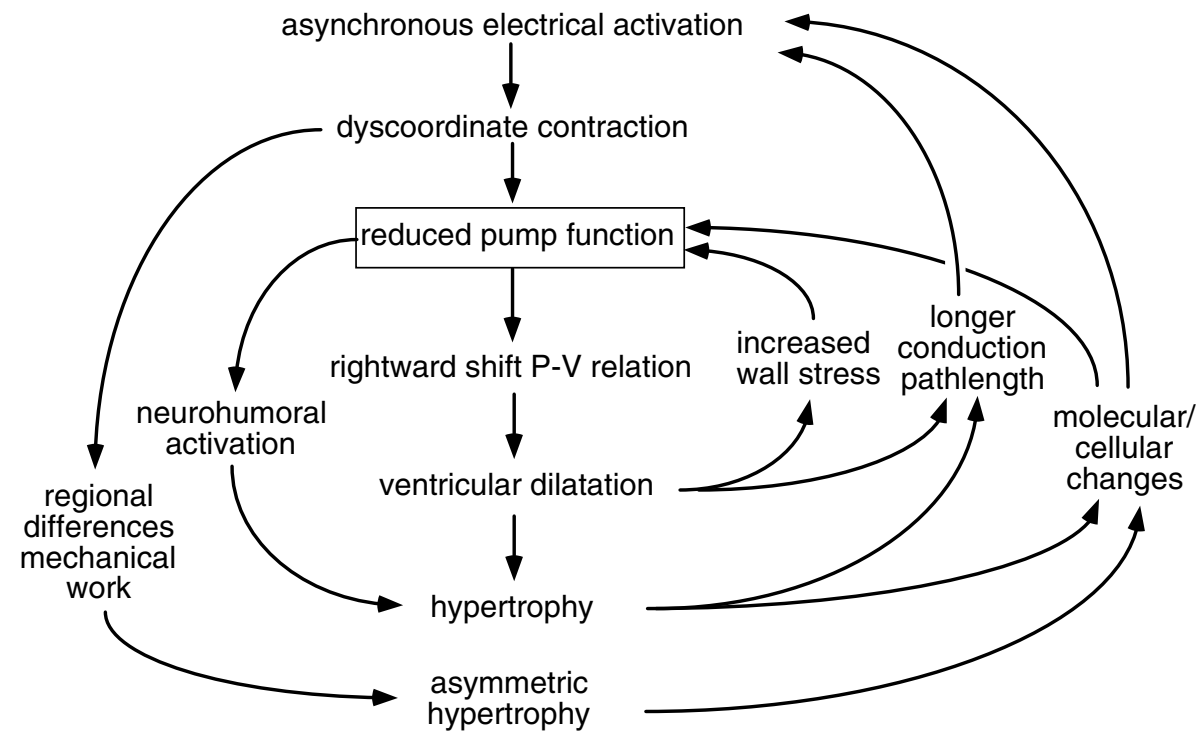

Figure 3. The vicious circle of dyssynchronopathy. Relation between events following onset of asynchronous electrical activation, partly based on experimental findings in animal experiments with ventricular pacing. For details, see text.
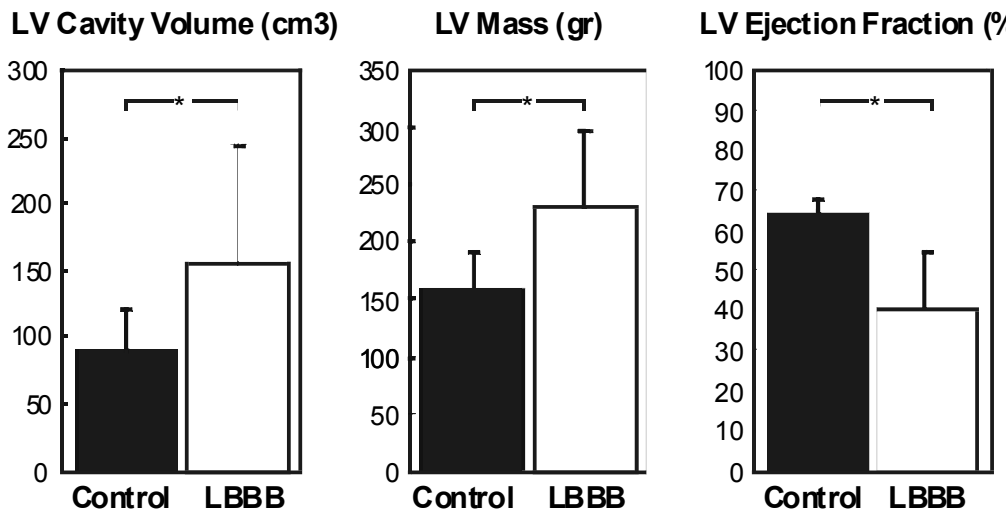

Figure 4. LV cavity volume, LV mass and LV ejection fraction in patients with LBBB as compared with control patients, obtained in a retrospective echocardiographic study. ${ }^{35}$ 
Information on remodeling in $\mathrm{LBBB}$ is, until now, only available from retrospective, cross sectional, studies in patients. In general, LBBB patients have dilated and hypertrophied ventricles with reduced ejection fraction, as compared with control subjects (figure 4). However, part of these differences may be due to the extensive co-morbidity present in the group of LBBB patients. ${ }^{33,35}$

In diseases like infarction and hypertension ventricular remodeling appears, at least initially, meant to compensate for the loss of function or the increased load, respectively. However, dilatation and hypertrophy do not reduce at all the asynchronous activation induced by pacing or LBBB, but rather increase asynchrony, ${ }^{13}$ because they increase the pathway and/or mass of myocardium to be activated and can reduce expression of gap-junction channels. ${ }^{41}$ Moreover, in chronically paced dogs, ${ }^{13}$ and patients with $\mathrm{LBBB}^{35}$ the ratio of LV cavity to wall volume or cavity radius to wall thickness was reduced, indicating that wall stress is higher in these hearts. Ventricular hypertrophy may facilitate the development of heart failure also by altering the expression of genes, among others involved in contractile function (figure 3 ). ${ }^{42}$ All these processes may lead to a vicious circle, where dilatation and hypertrophy further reduce LV pump function, directly or by increasing asynchrony of activation (figure 3 ). Because of their close functional relationship, we think it is justified to regard the combination of these abnormalities as a single derangement and to refer to it as dyssynchronopathy.

\section{CLINICAL AND EPIDEMIOLOGICAL EVIDENCE FOR A RELATION BE- TWEEN ABNORMAL CONDUCTION AND HEART FAILURE}

An increasing number of studies suggest that dyssynchronopathy may at least contribute to the development of heart failure. In patients with chronic RV apex pacing morbidity and mortality are higher than in patients with atrial pacing. ${ }^{9,43,44}$ In a prospective study on patients with sinus node disease and normal heart function, after a follow-up of up to 8 years, survival was higher and heart failure, atrial fibrillation and thrombo-embolic events occurred less in the atrial pacing than in the ventricular pacing group. ${ }^{43}$ In a large population of sinus node disease patients, the MOST trial showed a strong association between the percentage of (single- as well as dual chamber) ventricular pacing and the development of heart failure. ${ }^{45}$ Even more dramatic effects of RV pacing were shown by the DAVID trial, a large randomized trial performed in patients with an implantable cardioverter defibrillator, and compromised ventricular pump function. In this trial, dual-chamber pacing with a lower rate of $70 \mathrm{bpm}$ (DDD 70) was compared with ventricular backup pacing at a lower rate of $40 \mathrm{bpm}$ (VVI 40). The hypothesis was that AV sequential pacing with the dual-chamber 


\section{2 \\ Chapter 2}

pacemaker had a better outcome than solely ventricular pacing. However, these pacing configurations resulted in a much higher percentage ventricular paced beats in the dual chamber pacing group as compared to the ventricular backup pacing group. As a result, within 12 months a significantly higher degree of combined hospitalization and mortality due to heart failure was found in the dual chamber pacing group. ${ }^{46}$

With respect to LBBB, several population studies showed a poorer prognosis for LBBB patients than for those without. After correction for confounding factors, mortality due to cardiac causes is up to 10 times higher in patients with LBBB. ${ }^{47,48}$ This epidemiological evidence is also expressed in the prevalence of LBBB: while at age 65 years in the general population 1-3\% of subjects has LBBB, this number is $\sim 30 \%$ in the category of patients with heart failure. ${ }^{2}$

Such epidemiological findings do not proof a relation between LBBB and heart failure. A recent preliminary study showed that LBBB may be a consequence of poor cardiac function and ventricular dilatation, because appropriate (mechanical or pharmacological) treatment of heart failure was able to resolve the LBBB in $\sim 35 \%$ of the patients. ${ }^{49}$ The information from the consequences of ventricular pacing, mentioned above, however, suggest that LBBB also may be an important determinant of heart failure. The beneficial effects of cardiac resynchronization therapy further support this idea. CRT immediately improves LV pump function ${ }^{50,51}$ and efficiency ${ }^{51}$ in patients with heart failure in combination with LBBB-like conduction abnormalities and also leads, on the long run, to (partial) reversal of the remodeling process, ${ }^{52}$ and reduction of the degree of heart failure. Therefore, CRT may reverse the vicious circle of dyssynchronopathy depicted in figure 3. CRT is discussed in more detail in chapter 4 . The question whether isolated LBBB could lead to dyssynchronopathy is addressed in chapter 5, using the animal model of LBBB.

\section{REFERENCES}

1 American Heart Association. Heart Disease and Stroke Statistics - 2003 update. Dallas, TX, 2002.

2 Baldasseroni S, Opasich C, Gorini M, Lucci D, Marchionni N, Marini M, Campana C, Perini G, Deorsola A, Masotti G, Tavazzi L, Maggioni AP. Left bundle-branch block is associated with increased 1-year sudden and total mortality rate in 5517 outpatients with congestive heart failure: a report from the Italian network on congestive heart failure. Am Heart $\mathrm{J}$. 2002;143:398-405.

3 Wiggers CJ. The muscular reactions of the mammalian ventricles to artificial surface stimuli. Am J Physiol 1925;73:346-378.

4 Kosowsky BD, Scherlag BJ, Damato AN. Re-evaluation of the atrial contribution to ventricular function: study using His bundle pacing. Am J Cardiol. 1968;21:518-524. 
5 Park RC, Little WC, O'Rourke RA. Effect of alteration of left ventricular activation sequence on the left ventricular end-systolic pressure-volume relation in closed-chest dogs. Circ Res. 1985;57:706-717.

6 Prinzen FW, Augustijn CH, Arts T, Allessie MA, Reneman RS. Redistribution of myocardial fiber strain and blood flow by asynchronous activation. Am J Physiol. 1990;259:H300-308.

7 Prinzen FW, Van Oosterhout MF, Vanagt WY, Storm C, Reneman RS. Optimization of ventricular function by improving the activation sequence during ventricular pacing. Pacing Clin Electrophysiol. 1998;21:2256-2260.

8 Peschar M, de Swart H, Michels KJ, Reneman RS, Prinzen FW. Left ventricular septal and apex pacing for optimal pump function in canine hearts. J Am Coll Cardiol. 2003;41:12181226.

9 Rosenqvist M, Bergfeldt L, Haga Y, Ryden J, Ryden L, Owall A. The effect of ventricular activation sequence on cardiac performance during pacing. Pacing Clin Electrophysiol. 1996;19:1279-1286.

10 Boerth RC, Covell JW. Mechanical performance and efficiency of the left ventricle during ventricular stimulation. Am J Physiol. 1971;221:1686-1691.

11 Gilmore JP, Sarnoff SJ, Mitchell JH, Linden RJ. Synchronicity of ventricular contraction: observations comparing haemodynamic effects of atrial and ventricular pacing. Br Heart J. 1963;25:299-307.

12 Owen CH, Esposito DJ, Davis JW, Glower DD. The effects of ventricular pacing on left ventricular geometry, function, myocardial oxygen consumption, and efficiency of contraction in conscious dogs. Pacing Clin Electrophysiol. 1998;21:1417-1429.

13 van Oosterhout MF, Prinzen FW, Arts T, Schreuder JJ, Vanagt WY, Cleutjens JP, Reneman RS. Asynchronous electrical activation induces asymmetrical hypertrophy of the left ventricular wall. Circulation. 1998;98:588-595.

14 Zile MR, Blaustein AS, Shimizu G, Gaasch WH. Right ventricular pacing reduces the rate of left ventricular relaxation and filling. J Am Coll Cardiol. 1987;10:702-709.

15 Prinzen FW, Hunter WC, Wyman BT, McVeigh ER. Mapping of regional myocardial strain and work during ventricular pacing: experimental study using magnetic resonance imaging tagging. J Am Coll Cardiol. 1999;33:1735-1742.

16 Zhou Q, Henein M, Coats A, Gibson D. Different effects of abnormal activation and myocardial disease on left ventricular ejection and filling times. Heart. 2000;84:272-276.

17 Maurer G, Torres MA, Corday E, Haendchen RV, Meerbaum S. Two-dimensional echocardiographic contrast assessment of pacing-induced mitral regurgitation: relation to altered regional left ventricular function. J Am Coll Cardiol. 1984;3:986-991.

18 Mark JB, Chetham PM. Ventricular pacing can induce hemodynamically significant mitral valve regurgitation. Anesthesiology. 1991;74:375-377.

19 Blaustein AS, Gaasch WH. Myocardial relaxation. VI. Effects of beta-adrenergic tone and asynchrony on LV relaxation rate. Am J Physiol. 1983;244:H417-422.

20 Baller D, Wolpers HG, Zipfel J, Bretschneider HJ, Hellige G. Comparison of the effects of right atrial, right ventricular apex and atrioventricular sequential pacing on myocardial oxygen consumption and cardiac efficiency: a laboratory investigation. Pacing Clin Electrophysiol. 1988;11:394-403.

21 Delhaas T, Arts T, Prinzen FW, Reneman RS. Regional fibre stress-fibre strain area as an estimate of regional blood flow and oxygen demand in the canine heart. J Physiol. 1994;477 ( Pt 3):481-496.

22 Hirzel HO, Senn M, Nuesch K, Buettner C, Pfeiffer A, Hess OM, Krayenbuehl HP. Thallium-201 scintigraphy in complete left bundle branch block. Am J Cardiol. 1984;53:764-769.

23 Liu L, Tockman B, Girouard S, Pastore J, Walcott G, KenKnight B, Spinelli J. Left ventricular resynchronization therapy in a canine model of left bundle branch block. Am J Physiol Heart Circ Physiol. 2002;282:H2238-2244. 


\section{4 \\ Chapter 2}

24 Vassallo JA, Cassidy DM, Marchlinski FE, Buxton AE, Waxman HL, Doherty JU, Josephson ME. Endocardial activation of left bundle branch block. Circulation. 1984;69:914-923.

25 Rouleau F, Merheb M, Geffroy S, Berthelot J, Chaleil D, Dupuis JM, Victor J, Geslin P. Echocardiographic assessment of the interventricular delay of activation and correlation to the QRS width in dilated cardiomyopathy. Pacing Clin Electrophysiol. 2001;24:1500-1506.

26 Ono S, Nohara R, Kambara H, Okuda K, Kawai C. Regional myocardial perfusion and glucose metabolism in experimental left bundle branch block. Circulation. 1992;85:1125-1131.

27 Dillon JC, Chang S, Feigenbaum H. Echocardiographic manifestations of left bundle branch block. Circulation. 1974;49:876-880.

28 Grines CL, Bashore TM, Boudoulas H, Olson S, Shafer P, Wooley CF. Functional abnormalities in isolated left bundle branch block. The effect of interventricular asynchrony. Circulation. 1989;79:845-853.

29 Fujino M, Arakawa K. Echocardiographic assessment of left ventricular function in patients with complete left bundle branch block. Jpn Circ J. 1984;48:119-126.

30 Fujii J, Wantanabe H, Watanabe T, Takahashi N, Ohta A, Kato K. M-mode and crosssectional echocardiographic study of the left ventricular wall motions in complete left bundle-branch block. Br Heart J. 1979;42:255-260.

31 Little WC, Reeves RC, Arciniegas J, Katholi RE, Rogers EW. Mechanism of abnormal interventricular septal motion during delayed left ventricular activation. Circulation. 1982;65:1486-1491.

32 Leclercq C, Faris O, Tunin R, Johnson J, Kato R, Evans F, Spinelli J, Halperin H, McVeigh E, Kass DA. Systolic improvement and mechanical resynchronization does not require electrical synchrony in the dilated failing heart with left bundle-branch block. Circulation. 2002;106:1760-1763.

33 Bavelaar-Croon CD, Wahba FF, Van Hecke MV, Atsma DE, Stokkel MP, Pauwels EK, Van der Wall EE. Perfusion and functional abnormalities outside the septal region in patients with left bundle branch block assessed with gated SPECT. Q J Nucl Med. 2001;45:108-114.

34 van Oosterhout MF, Arts T, Muijtjens AM, Reneman RS, Prinzen FW. Remodeling by ventricular pacing in hypertrophying dog hearts. Cardiovasc Res. 2001;49:771-778.

35 Prinzen FW, Cheriex EC, Delhaas T, van Oosterhout MF, Arts T, Wellens HJ, Reneman RS. Asymmetric thickness of the left ventricular wall resulting from asynchronous electric activation: a study in dogs with ventricular pacing and in patients with left bundle branch block. Am Heart J. 1995;130:1045-1053.

36 Adomian GE, Beazell J. Myofibrillar disarray produced in normal hearts by chronic electrical pacing. Am Heart J. 1986;112:79-83.

37 Karpawich PP, Justice CD, Cavitt DL, Chang CH. Developmental sequelae of fixed-rate ventricular pacing in the immature canine heart: an electrophysiologic, hemodynamic, and histopathologic evaluation. Am Heart J. 1990;119:1077-1083.

38 Lee MA, Dae MW, Langberg JJ, Griffin JC, Chin MC, Finkbeiner WE, O'Connell JW, Botvinick E, Scheinman MM, Rosenqvist $M$. Effects of long-term right ventricular apical pacing on left ventricular perfusion, innervation, function and histology. J Am Coll Cardiol. 1994;24:225-232.

39 van Oosterhout MF, Arts T, Bassingthwaighte JB, Reneman RS, Prinzen FW. Relation between local myocardial growth and blood flow during chronic ventricular pacing. Cardiovasc Res. 2002;53:831-840.

40 Nielsen JC, Bottcher M, Nielsen TT, Pedersen AK, Andersen HR. Regional myocardial blood flow in patients with sick sinus syndrome randomized to long-term single chamber atrial or dual chamber pacing--effect of pacing mode and rate. J Am Coll Cardiol. 2000;35:1453-1461. 
41 Patel PM, Plotnikov A, Kanagaratnam P, Shvilkin A, Sheehan CT, Xiong W, Danilo P, Jr., Rosen MR, Peters NS. Altering ventricular activation remodels gap junction distribution in canine heart. J Cardiovasc Electrophysiol. 2001;12:570-577.

42 Swynghedauw B. Molecular mechanisms of myocardial remodeling. Physiol Rev. 1999;79:215-262.

43 Andersen HR, Nielsen JC, Thomsen PE, Thuesen L, Mortensen PT, Vesterlund T, Pedersen AK. Long-term follow-up of patients from a randomised trial of atrial versus ventricular pacing for sick-sinus syndrome. Lancet. 1997;350:1210-1216.

44 Nielsen JC, Andersen HR, Thomsen PE, Thuesen L, Mortensen PT, Vesterlund T, Pedersen AK. Heart failure and echocardiographic changes during long-term follow-up of patients with sick sinus syndrome randomized to single-chamber atrial or ventricular pacing. Circulation. 1998;97:987-995.

45 Sweeney MO, Hellkamp AS, Ellenbogen KA, Greenspon AJ, Freedman RA, Lee KL, Lamas GA. Adverse effect of ventricular pacing on heart failure and atrial fibrillation among patients with normal baseline QRS duration in a clinical trial of pacemaker therapy for sinus node dysfunction. Circulation. 2003;107:2932-2937.

46 Wilkoff BL, Cook JR, Epstein AE, Greene HL, Hallstrom AP, Hsia H, Kutalek SP, Sharma A. Dual-chamber pacing or ventricular backup pacing in patients with an implantable defibrillator: the Dual Chamber and VVI Implantable Defibrillator (DAVID) Trial. Jama. 2002;288:3115-3123.

47 Casiglia E, Spolaore P, Ginocchio G, Marchioro M, Mazza A, di Menza G, Maniati G, Daskalakis C, Colangeli G, Ambrosio GB. Mortality in relation to Minnesota code items in elderly subjects. Sex-related differences in a cardiovascular study in the elderly. Jpn Heart J. 1993;34:567-577.

48 Schneider JF, Thomas HE, Jr., Kreger BE, McNamara PM, Kannel WB. Newly acquired left bundle-branch block: the Framingham study. Ann Intern Med. 1979;90:303-310.

49 Neimann P, Robbins R, Shinn J, Liang D, Friday KS. Left bundle branch block resolution with left ventricular remodeling in heart failure. Pacing Clin Electrophysiol. 2003;26:1050 (abstract).

50 Auricchio A, Stellbrink C, Block M, Sack S, Vogt J, Bakker P, Klein H, Kramer A, Ding J, Salo R, Tockman B, Pochet T, Spinelli J. Effect of pacing chamber and atrioventricular delay on acute systolic function of paced patients with congestive heart failure. The Pacing Therapies for Congestive Heart Failure Study Group. The Guidant Congestive Heart Failure Research Group. Circulation. 1999;99:2993-3001.

51 Nelson GS, Curry CW, Wyman BT, Kramer A, Declerck J, Talbot M, Douglas MR, Berger $\mathrm{RD}, \mathrm{McVeigh}$ ER, Kass DA. Predictors of systolic augmentation from left ventricular preexcitation in patients with dilated cardiomyopathy and intraventricular conduction delay. Circulation. 2000;101:2703-2709.

52 St John Sutton MG, Plappert T, Abraham WT, Smith AL, DeLurgio DB, Leon AR, Loh E, Kocovic DZ, Fisher WG, Ellestad M, Messenger J, Kruger K, Hilpisch KE, Hill MR. Effect of cardiac resynchronization therapy on left ventricular size and function in chronic heart failure. Circulation. 2003;107:1985-1990. 


\section{Chapter 3}

\section{Review on Cardiac Resynchronization therapy}

Kevin Vernooy, MD

Department of Physiology and Cardiology, Cardiovascular Research Institute Maastricht, Maastricht, the Netherlands 


\section{$28 \mid$ Chapter 3}

\section{INTRODUCTION}

During the last decade, cardiac resynchronization therapy (CRT) has emerged as an effective therapy for patients with advanced systolic heart failure and ventricular conduction disturbances, mainly left bundle branch block (LBBB). CRT restores a synchronous ventricular activation and contraction using combined right ventricular (RV) and left ventricular (LV) pacing, also referred to as biventricular (BiV) pacing (figure 1). Large clinical trials have shown that CRT improves symptoms, quality of life, and exercise tolerance and lowers mortality in patients with refractory heart failure. Nevertheless, a significant number of patients do not improve after CRT, the non-responders.

This chapter reviews the literature on CRT with special emphasis on rationale and benefit of CRT. Attention is paid to the potential cause of lack of response to CRT, patient selection, pacing site(s) and timing of pacing. In addition, we discuss whether advances in programming the BiV pacing device could increase LV pump function.

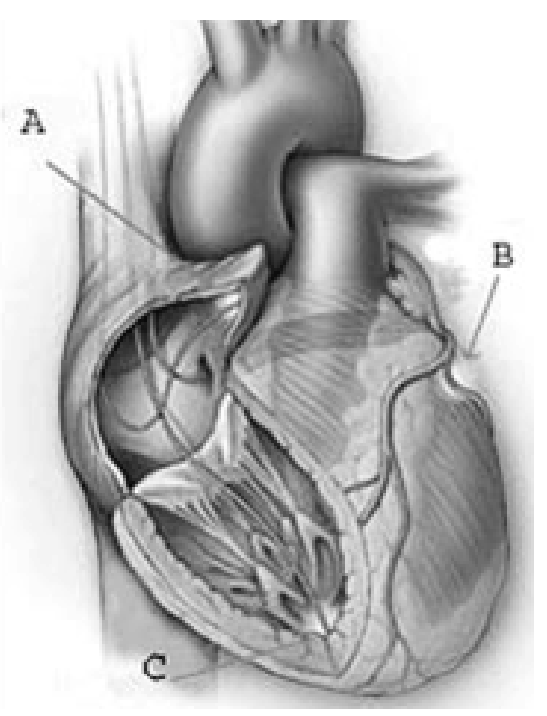

Figure 1. Positioning of pacing electrodes in biventricular pacing. Conventional pacemakers are equipped with two pacing electrodes (or "leads") that conduct pacing signals to specific regions of the heart (the right atrial lead, position $\mathbf{A}$; the right ventricle, position C). Biventricular pacing devices use a third lead, positioned at the left ventricle (position B). The atrial lead usually senses atrial activity and the two ventricular leads deliver synchronized stimulation to the two ventricles. Therefore, combination of all three leads aims to create a synchronized contraction of the ventricles. Modified from www.heartfailure.org. 


\section{HEART FAILURE AND BIVENTRICULAR PACING}

Heart failure is one of the major health problems in the western world, affecting 22 million people worldwide and approximately 6.5 million persons in Europe alone. Management of patients with this problem represents the largest single expense to medical care. Heart failure is a progressive disease characterized by LV dilatation and loss of pump function. The severity of LV dilatation, referred to as ventricular remodeling, is known to be an independent contributor to poor outcome in patients with heart failure. ${ }^{1}$

In up to $30 \%$ of the patients with NYHA functional class III or IV, ventricular conduction disturbances are present, especially LBBB. LBBB is characterized by spread of ventricular activation from the right bundle and slow conduction from the septum throughout the LV to the LV poster-lateral wall. As mentioned in the previous chapter, it is plausible, but insufficiently proven, that LBBB induces dyssynchronopathy and contributes to the development of heart failure.

Irrespective of whether LBBB contributes to heart failure, the evidence that asynchronous activation reduces pump function makes it highly plausible that resynchronization can improve cardiac pump function. Evidence for decreased cardiac function during pacing appeared in the literature around $1920 .^{2}$ It may therefore be considered surprising that the first study on BiV pacing was performed as recent as $1994 .{ }^{3}$ Ever since that moment, large amounts of clinical studies have been published with promising results.

Since the approval of BiV pacing by the United States Food and Drug Administration in 2001, it has been recommended in the 2002 update of the American College of Cardiology/American Heart Association/North American Society of Pacing and Electrophysiology Heart Rhythm Society (ACC/AHA/NASPE). ${ }^{4}$ The recommendations for the guidelines are based on convincing evidence of the beneficial effects of CRT as an adjunctive therapy for the treatment of patients with heart failure. ${ }^{4}$ The number of CRT devices implanted is still increasing. In the Netherlands alone, 2000 patients received a CRT device in 2005. 
$30 \mid$ Chapter 3
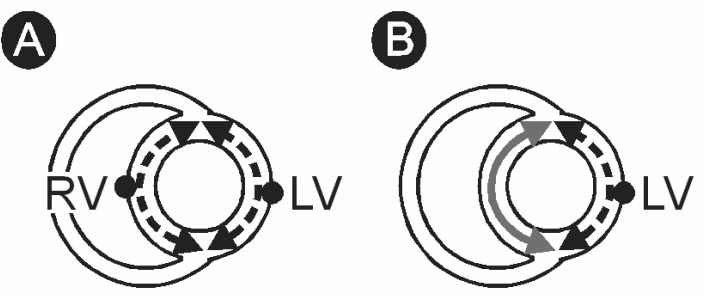

Figure 2. Schematic presentation of ventricular resynchronization during (A) biventricular pacing, and during (B) fusion of the LV pacing activation wave front with the intrinsic activation through the right bundle.

\section{RATIONALE AND BENEFIT}

With CRT, cardiac pacing entered a new application field. While conventional pacemakers are meant to maintain heart rhythm, pacing the RV in combination with the LV intends to restore ventricular mechanical synchrony at essentially unchanged heart rhythm. In addition, new techniques have been developed in order to position the LV pacing electrode transvenously on the epicardial LV postero-lateral wall

Ventricular resynchronization can be achieved in two ways (Figure 2). First, stimulation of the RV and LV eslectrodes results in two activation wave fronts, which merge approximately halfway. Secondly, pacing the LV using a proper atrio-ventricular (AV-) delay results in fusion of the intrinsic activation wave with the activation wave front induced by LV pacing.

It is important to realize, that for proper cardiac pump function it is not the electrical resynchronization that is important, but the concomitant recoordinated contraction. This recoordinated contraction during BiV pacing has been elegantly demonstrated by Wyman and colleagues. ${ }^{5}$ Using tagged magnetic resonance imaging, they showed that atrial pacing induces uniform contraction, illustrated by a uniform distribution of myocardial strain throughout systole (figure 3, upper row). RV apex pacing, on the other hand, shows a slow wave of contraction moving throughout the heart (figure3, lower row). BiV pacing induces two contraction waves resulting in a more synchronous ventricular contraction (figure 3, middle row). Various experimental studies confirmed that during LBBB simultaneous RV and LV pacing creates a more synchronous contraction pattern. ${ }^{6-10}$ This is accompanied by marked, beat-to-beat hemodynamic improvement, as derived from $\mathrm{LVdP} / \mathrm{dt} \mid \mathrm{max}$, pulse pressure, cardiac output and ejection fraction (figure 4). ${ }^{6-10}$ 


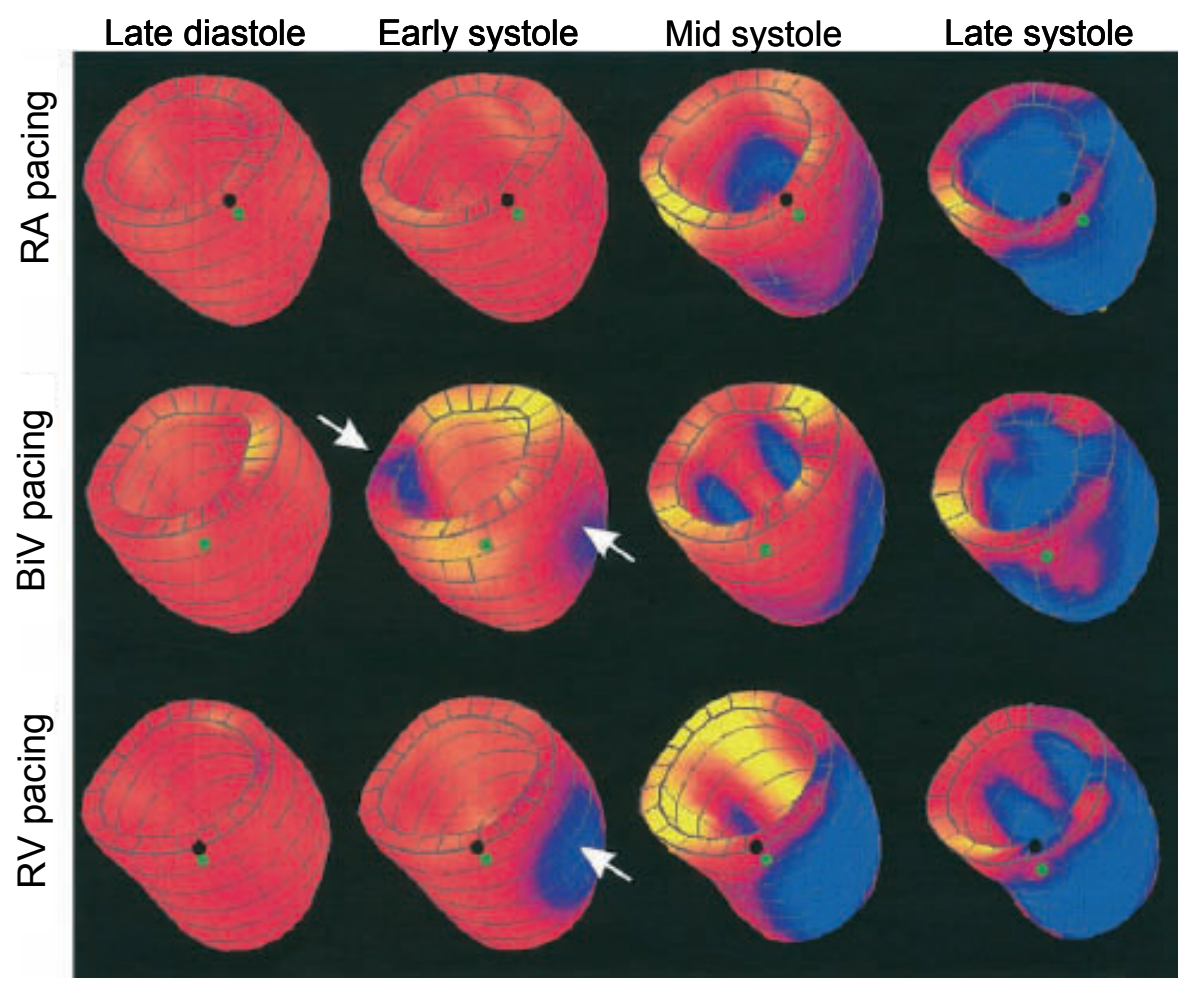

Figure 3. Three-dimensional reconstruction of the LV wall with myocardial strain represented in color. Data was obtained using magnetic resonance tagging in a normal dog heart. Blue indicates contraction (negative circumferential strain), red indicates the zero strain (end diastole), and yellow indicates stretch (positive circumferential strain). Data is shown for late diastole and early, mid and late systole using right atrial (RA) pacing, biventricular (BV) pacing, and right ventricular (RV) pacing. The black dot indicates the location of the mid-septum and the white arrows indicate the ventricular pacing sites. Please note the considerable regional strain differences during RV pacing in early and mid systole between the septum and lateral wall. BV pacing reduces these differences, but differences are still more pronounced than during RA pacing. Modified from reference. ${ }^{5}$

Improvement of LV pump function is achieved at unchanged or even decreased filling pressures, indicating a true improvement of ventricular contractility due to improved coordination of contraction. Furthermore, BiV pacing was shown to result in a uniform myocardial blood flow distribution and to increase the efficiency of LV pump function. ${ }^{11}$ Further improvement in LVdP/dt|max can be attributed to the reduction of mitral regurgitation, which occurred immediately after onset of BiV pacing. ${ }^{12,13}$ 


\section{2 \\ Chapter 3}

Besides acute hemodynamic studies, various clinical trials have studied the long-term effects of CRT on LV pump function, LV dimensions and clinical parameters in patients with heart failure and LBBB. Early observational studies demonstrated that improved LV pump function was maintained over time., ${ }^{7,14}$ These studies also showed that CRT improved heart failure symptoms. Since the completion of these initial studies, many patients have been evaluated in randomized single- or double blinded controlled trials on CRT. ${ }^{6,15-20}$ These studies consistently demonstrated improvements in quality of life, exercise tolerance, and heart failure symptoms, fewer hospitalizations for heart failure. Moreover, the CARE-HF study recently showed that CRT reduces the risk of death as compared to standard medical therapy (figure 5). ${ }^{20}$
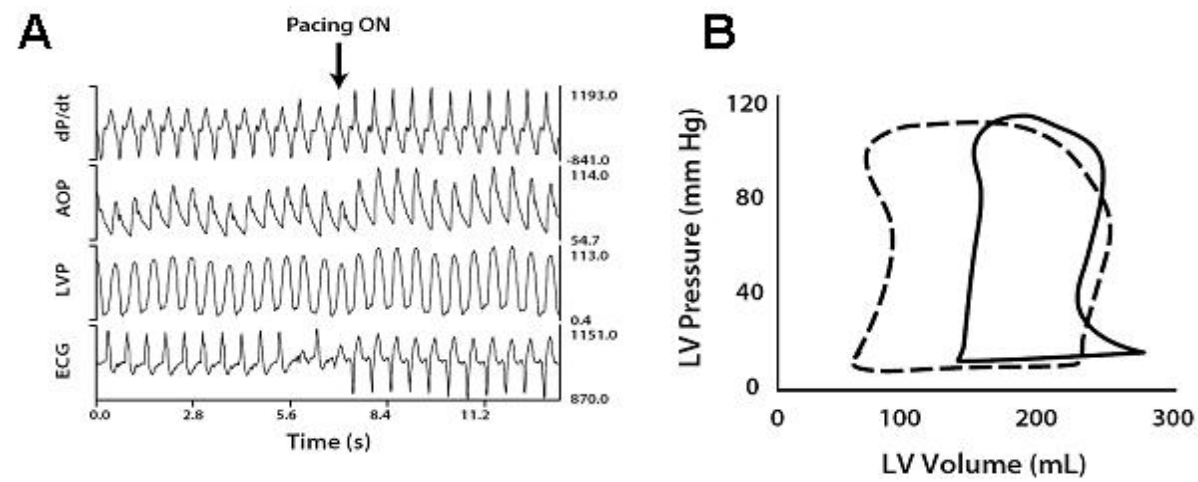

Figure 4. A. Acute hemodynamic response in LBBB patient before and after biventricular pacing. After onset of biventricular pacing there is an abrupt rise in pressure development and rate of development, and an increase in the arterial pulse pressure indicative of enhanced cardiac output. B. Similar data displayed as pressure-volume loops. Biventricular pacing induces a left shift of the pressure-volume loop, increasing the width and area, and reducing end-systolic volume. Modified from reference. ${ }^{73}$

Also, various clinical studies have shown that $\mathrm{BiV}$ pacing causes regression of LV end-diastolic and end-systolic volume on the long run, usually referred to as LV reverse remodeling. ${ }^{20-22}$ Obviously, in clinical studies it is impossible to investigate to what extent $\mathrm{BiV}$ pacing is able to reverse the vicious circle of dyssynchronopathy, as proposed in chapter 2 . Moreover, clinical studies did not report on changes in (regional) LV wall mass during BiV pacing. The response of hypertrophy to $\mathrm{BiV}$ pacing is interesting because in canine hearts long-term asynchronous LV pacing induces ventricular remodeling, consisting, besides LV dilatation, of significant hypertrophy in the latest activated regions. ${ }^{23,24}$ It is likely that the asymmetric hypertrophy was caused by regional differences in 
myocardial work because of the asynchronous ventricular activation. The overall ventricular dilatation and hypertrophy may be related to the loss in pump function. ${ }^{5,25,26}$ Therefore, the effect of long-term asynchronous LV activation due to LBBB on LV function and LV dimensions is studied in chapter 4. In chapter 7, the changes in LV dimensions and LV ejection fraction are studied during BiV pacing in animals with chronic LBBB.

$\mathrm{RV}$ pacing is known to result in an asynchronous ventricular activation similar to $\mathrm{LBBB}^{27}$ Like LBBB, there is increasing evidence that RV pacing increases the risk for developing heart failure. ${ }^{28-30}$ It has been proposed that the asynchronous ventricular activation due to RV pacing could be the electrophysiological basis for recommending $\mathrm{BiV}$ pacing in patients with heart failure and permanent RV pacing. The first studies investigating heart failure symptoms and LV pump function after the upgrade from a RV pacing system to a $\mathrm{BiV}$ pacing system showed good results. ${ }^{3-33}$ As a result, CRT is recommended in current guidelines for patients with heart failure (New York Heart Association functional class III and IV), presence of LBBB or RV pacing, poor LV ejection fraction $(<35 \%)$, and increased LV end-diastolic dimensions $(>55$ $\mathrm{mm}){ }^{4}$ However, the question arises whether these selection criteria are appropriate.

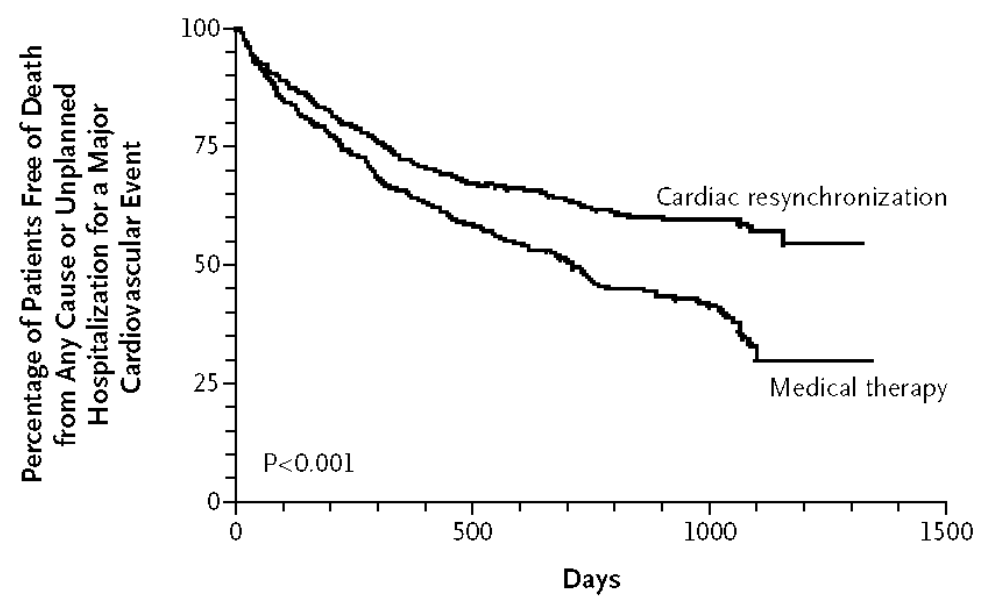

Figure 5. Kaplan-Meier estimates of the time to primary endpoint of the CARE-HF trial. ${ }^{20}$ death from any cause or an unplanned hospitalization for a major cardiovascular event. 
Table. Overview of clinical studies investigating the role of indices of mechanical asynchrony to predict response to CRT. Table is modified from reference. ${ }^{39}$

\begin{tabular}{|c|c|c|c|}
\hline Authors & Echo technique & $\begin{array}{l}\text { Methodology of asyn- } \\
\text { chrony }\end{array}$ & Main findings \\
\hline Pitzalis et al. ${ }^{43}$ & M-mode & $\begin{array}{l}\text { Septal-to-posterior } \\
\text { wall motion delay } \\
\text { (SPWMD) }\end{array}$ & $\begin{array}{c}\text { SPWMD } \geq 130 \text { ms predicts } L V \\
\text { reverse remodeling }\end{array}$ \\
\hline Pitzalis et al. ${ }^{44}$ & M-mode & SPWMD & $\begin{array}{c}\text { SPWMD } \geq 130 \text { ms predicts } \\
\text { event-free survival }\end{array}$ \\
\hline Marcus et al. ${ }^{45}$ & M-mode & SPWMD & $\begin{array}{c}\text { SPWMD } \geq 130 \text { ms insufficient } \\
\text { to predict LV reverse remodel- } \\
\text { ing }\end{array}$ \\
\hline Penicka et al. ${ }^{66}$ & Pulsed-wave TDI & $\begin{array}{l}\text { Ts(onset) of } 3 \text { basal } \\
\text { LV and } 1 \text { basal RV } \\
\text { segments }\end{array}$ & $\begin{array}{l}\text { Summation of inter- and intra- } \\
\text { ventricular delay }>102 \mathrm{~ms} \\
\text { predicts increased LV EF }\end{array}$ \\
\hline Ansalone et al. ${ }^{67}$ & Pulsed-wave TDI & $\begin{array}{l}\text { Systolic dyssynchrony } \\
\text { among } 5 \text { basal seg- } \\
\text { ments }\end{array}$ & $\begin{array}{l}\text { Extensive LV dyssynchrony } \\
\text { results in increased symptoms } \\
\text { and decreased LVEF }\end{array}$ \\
\hline Garrigue et al. ${ }^{68}$ & Pulsed-wave TDI & $\begin{array}{c}\text { Ts(onset) between } \\
\text { septum and lateral wall }\end{array}$ & $\begin{array}{l}\text { Post-CRT reduction in LV } \\
\text { dyssynchrony and improve- } \\
\text { ment in symptoms }\end{array}$ \\
\hline Bordacher et al. ${ }^{69}$ & $\begin{array}{l}\text { Pulsed-wave TDI, } \\
\text { M-mode, pulsed- } \\
\text { wave Doppler }\end{array}$ & $\begin{array}{l}\text { Maximal difference in } \\
12 \text { LV segments for } \\
\text { Ts, TS(onset), Ts-SD, } \\
\text { and DLC }\end{array}$ & $\begin{array}{l}\text { Maximal difference in } 12 \mathrm{LV} \\
\text { segments for Ts, T(onset), Ts- } \\
\text { SD closely correlates with } \\
\text { improvement of MR and CO, } \\
\text { but not inter-ventricular delay } \\
\text { by pulsed-wave Doppler echo }\end{array}$ \\
\hline Yu et al. ${ }^{22}$ & Color-coded TDI & $\begin{array}{l}\text { Ts of } 12 \mathrm{LV} \text { segments } \\
\text { in ejection phase }\end{array}$ & $\begin{array}{c}\text { Improve LV dyssynchrony by } \\
\text { delaying Ts in } 12 \text { LV segments } \\
\text { globally resulting in homoge- } \\
\text { nous Ts }\end{array}$ \\
\hline Bax et al. ${ }^{36}$ & Color-coded TDI & $\begin{array}{l}\text { Septal-to-lateral delay } \\
\text { of Ts in ejection phase }\end{array}$ & $\begin{array}{c}\text { Septal-to-lateral delay of } \\
\text { Ts }>60 \mathrm{~ms} \text { predicts increased } \\
\text { LV EF }\end{array}$ \\
\hline Yu et al. ${ }^{12}$ & Color-coded TDI & $\begin{array}{l}\text { Ts-SD of } 12 \mathrm{LV} \text { seg- } \\
\text { ments in ejection phase }\end{array}$ & $\begin{array}{c}\text { Ts-SD of } 12 \text { segments }>33 \mathrm{~ms} \\
\text { predicts LV reverse remodel- } \\
\text { ing }\end{array}$ \\
\hline Bax et $\mathrm{L}^{35}$ & Color-coded TDI & $\begin{array}{l}\text { Septal-to-lateral delay } \\
\text { of Ts in ejection phase }\end{array}$ & $\begin{array}{l}\text { Septal-to-lateral delay of } \\
\text { Ts }>65 \mathrm{~ms} \text { predicts LV reverse }\end{array}$ \\
\hline
\end{tabular}


Table. Overview of clinical studies investigating the role of indices of mechanical asynchrony to predict response to CRT. Table is modified from reference. ${ }^{39}$

\begin{tabular}{|c|c|c|c|}
\hline Authors & Echo technique & $\begin{array}{l}\text { Methodology of asyn- } \\
\text { chrony }\end{array}$ & Main findings \\
\hline & & & $\begin{array}{l}\text { remodeling; and is associated } \\
\text { with lower event rate }\end{array}$ \\
\hline Yu et al. ${ }^{70}$ & $\begin{array}{l}\text { Color-coded } \\
\text { TDIA, SRI }\end{array}$ & $\begin{array}{l}\text { Ts-SD of } 12 \mathrm{LV} \text { seg- } \\
\text { ments in ejection phase }\end{array}$ & $\begin{array}{c}\text { Ts-SD of } 12 \text { LV segments }>31 \\
\text { ms predicts LV reverse remod- } \\
\text { eling }\end{array}$ \\
\hline Sogaard et al. ${ }^{21}$ & $\begin{array}{l}\text { Color-coded TDI, } \\
\text { SRI }\end{array}$ & DLC & $\begin{array}{l}\text { Number of basal segments with } \\
\text { DLC predicts improved LV EF }\end{array}$ \\
\hline Sogaard et al. ${ }^{64}$ & $\begin{array}{l}\text { Color-coded TDI, } \\
\text { SRI, TT }\end{array}$ & TT and DLC & $\begin{array}{l}\text { Optimization of VV-timing by } \\
\text { TT results in decreased DLC } \\
\text { and improved LV EF }\end{array}$ \\
\hline Breithardt et al. ${ }^{47}$ & Strain, SRI & $\begin{array}{l}\text { Strain and SRI at sep- } \\
\text { tal and lateral wall }\end{array}$ & $\begin{array}{l}\text { Baseline: lateral wall strain and } \\
\text { strain rate higher than septal; } \\
\text { CRT: septal wall strain and } \\
\text { strain rate higher than lateral }\end{array}$ \\
\hline Yu et al. ${ }^{71}$ & TSI & $\begin{array}{l}\text { Ts-SD of } 12 \text { LV seg- } \\
\text { ments in ejection phase } \\
\text { (inclusion of post- } \\
\text { systolic shortening) }\end{array}$ & $\begin{array}{l}\text { Ts-SD of } 12 \mathrm{LV} \text { segments in } \\
\text { ejection phase }>34 \text { ms predicts } \\
\text { reverse remodeling }\end{array}$ \\
\hline Zhang et al. ${ }^{72}$ & 3D echo & $\begin{array}{l}\text { Time to minimal sys- } \\
\text { tolic volume (Tmsc) in } \\
6,12 \text {, and } 16 \mathrm{LV} \mathrm{seg-} \\
\text { ments }\end{array}$ & $\begin{array}{l}\text { Improvement of Tmsv parame- } \\
\text { ters during CRT Tmsv of } 16 \\
\text { LV segments by 3D echo cor- } \\
\text { relate closely with Ts-SD of } 12 \\
\text { LV segments by TDI }\end{array}$ \\
\hline
\end{tabular}

$\mathrm{CO}=$ Cardiac output; $\mathrm{CRT}=$ Cardiac resynchronization therapy; $\mathrm{DLC}=$ delayed longitudinal contraction; $\mathrm{LV}=$ left ventricular; $\mathrm{LV} E F=\mathrm{LV}$ ejection fraction; $\mathrm{MR}=$ Mitral regurgitation; $\mathrm{RV}=$ right ventricular; $\mathrm{SRI}=$ strain rate imaging; $\mathrm{TDI}=$ tissue doppler imaging; $\mathrm{Tmsv}=$ time to minimal systolic volume; Ts= time to peak myocardial systolic velocity; TSI= tissue synchronization imaging; $\mathrm{Ts}($ onset $)=$ time to onset of myocardial systolic velocity; $\mathrm{Ts}-\mathrm{SD}=$ standard deviation of time to peak myocardial systolic velocity; $\mathrm{TT}=$ tissue tracking; $\mathrm{VV}=$ interventricular.

\section{SELECTION FOR TREATMENT WITH CRT}

Despite the clear evidence for the benefits of CRT in the majority of patients with heart failure and ventricular conduction disturbances, about one-third of 


\section{6 \\ Chapter 3}

the patients do not respond to this therapy. ${ }^{34,35}$ Exact estimation of the percentage of patients not responding to CRT is hampered by the use of different criteria to identify responders. Parameters to identify lack of response to CRT include improvement in heart failure symptoms, improvement in 6 minute walking test or in peak VO2 exercise test or a decrease in LV end-diastolic volume. ${ }^{36,37}$ Avoiding patients not responding to CRT is important because it reduces unnecessary procedure risks and medical expenses.

To reduce the amount of non-responders of CRT, proper patient selection is most important. The current criteria for selecting patients eligible for CRT are primarily determined by the inclusion/exclusion criteria of the large clinical trials. ${ }^{15,17,19,20}$ For instance, QRS duration is one of the current selection criteria for the presence of ventricular electrical asynchrony. However, QRS duration of more than $130 \mathrm{~ms}$ appeared not always an indicator of inhomogeneities in myocardial contraction within the LV. The MIRACLE trial showed that patients with right bundle branch block have less benefit from CRT than patients with LBBB. $^{18}$

Various studies have assessed the prognostic value of mechanical ventricular asynchrony for CRT. In first instance, ventricular asynchrony was examined by tagged magnetic resonance imaging. These tagged images provided a full three dimensional myocardial strain measurement of the LV (figure 1). ${ }^{5,10,14,25,38}$ However, magnetic resonance imaging is complex and time-consuming. The various echocardiographic techniques for patient selection have been extensively reviewed elsewhere. ${ }^{39}$ In short, in the literature, distinction is made between inter- and intra-ventricular asynchrony (table 1).

Inter-ventricular asynchrony represents the time difference between RV and LV contraction. Inter-ventricular delay can be measured by the timing difference in opening of the aortic and pulmonary valve, ${ }^{40}$ and by time difference of peak velocity in the RV and LV wall, using tissue Doppler imaging (TDI). Other approaches to measure inter-ventricular asynchrony are determination of phase difference between the RV and LV wall motion using nuclear imaging ${ }^{41}$ or time difference between upslope of LV and RV pressure curves (used in this thesis).$^{42}$ For practical reasons the echocardiographic approach is mostly used in clinical practice.

Intra-ventricular asynchrony is defined as the asynchrony within the LV. A simple echocardiographic method to measure intra-ventricular asynchrony was proposed by Pitzalis and colleagues. ${ }^{43,44}$ They measured the septal-to-posteriorwall motion delay (SPWMD) as the delay between the maximal inward movement of the septum and the LV lateral wall with M-mode echocardiography (figure 6a). The SPWMD predicted the response on reverse remodeling and reduced risk of heart failure progression in patients with CRT. ${ }^{43,44}$ However, other investigators have questioned the use of SPWMD,${ }^{45}$ because assessment of 
maximal inward septal movement is often not reliable in patients with ischemic heart disease and previous anterior wall myocardial infarction.

Intra-ventricular asynchrony has most frequently been studied by time to peak or time to onset of myocardial motion, obtained with color-coded or pulsed-wave TDI measurements, respectively (figure 6b, table 1). ${ }^{22,36}$ Although, various studies showed that LV intra-ventricular asynchrony determined with TDI was a good predictor of response to CRT, ${ }^{22,35,46}$ TDI has several inherent technical limitations. It measures the velocity of displacement of a myocardial segment relative to the ultrasound transducer in the direction of the ultrasound beam. Likewise, the longitudinal velocity, as usually determined in basal regions, is the sum of all velocity contributions in the regions in between transducer and the particular area of interest. Local contraction can be estimated by subtraction of velocities in nearby regions. Such analysis yields myocardial strain and strain-rate in the longitudinal direction. ${ }^{47}$ Compared with TDI, strain measurements differentiate better between active systolic contraction and passive displacement. However, the related image acquisition and analysis are time-consuming and operator-dependent. Therefore, the clinical applicability of strain rate imaging is currently limited. In a simpler, user-friendlier approach, the display of myocardial displacement, by so called Tissue Tracking, provides crude information on distribution of regional myocardial motion. This technique also has proven to be helpful in assessment of BiV pacing. ${ }^{21}$

Table 1 gives a summary of studies on the predictive value of the most common echocardiographic indices of asynchrony for a positive response to CRT. The overall impression is that mechanical asynchrony is a relevant parameter for patient selection. However, the large variability in the indices and in the observed threshold values for a positive CRT response indicates that there is a need for standardization.

Despite evidence that BiV pacing is beneficial, LBBB morphology on the surface ECG does not necessarily result in asynchronous LV contraction. In up to 30 to 40 percent of the patients with wide QRS complexes no intraventricular asynchrony was present. ${ }^{48}$ A possible explanation is a discrepancy between ventricular electrical activation and mechanical contraction. In addition, previous myocardial infarctions may influence regional TDI measurements. Interestingly, intra-ventricular asynchrony has been found in about 30 percent of the patients with heart failure and narrow QRS complex. ${ }^{48,49}$

Prediction of response to CRT appears to be especially difficult in patients with ischemic dilated cardiomyopathy. ${ }^{50}$ An explanation for the poor response to CRT in patients with ischemic dilated cardiomyopathy may be due to a possible interaction between myocardial infarct and intra-ventricular asynchrony. Moreover, infarcted regions may block ventricular conduction impairing proper resynchronization. It seems likely that, especially in patients with ischemic di- 
lated cardiomyopathy, pacing site and timing of stimulation have to be tailored individually.

\section{PaCing Site(S) AND CONFIGURATION}

From a theoretical point of view, the sites of pacing which may be considered optimal are those that determine the greatest reduction in total activation time, i.e. those pacing sites that generate two activation wave fronts starting from opposite positions. Because in LBBB the basal part of the LV postero-lateral wall is usually the latest activated part, ${ }^{51,52}$ this is often regarded as the preferred LV pacing site. Recently, Gasparini and colleagues showed a significant improvement in cardiac function and increase in exercise capacity over time, regardless of the LV stimulation sites. ${ }^{53}$ These data confirmed earlier observations by Butter and colleagues who showed that pacing at anterior and lateral wall both increase LV contractility and pump function. ${ }^{54}$ However, pacing from the lateral wall resulted in a significantly larger increase in LV contractility.

An important issue for selection of the best pacing site is, however, that catheterization of the appropriate coronary vein cannot be achieved in all patients because of the coronary vein anatomy. Also, lead positioning in some veins leads to phrenic nerve stimulation and/or unacceptable pacing and sensing thresholds. In those cases, the cardiac surgeon can perform thoracotomy for LV lead placement. Studies have shown that LV epicardial lead implantation by minimal invasive thoracotomy is feasible and is believed to be a valuable option to achieve BiV pacing. ${ }^{8,55,56}$

An interesting and partly unexplained finding is that LV pacing alone is also beneficial in patients with heart failure. While BiV pacing is usually used in clinical practice, acute hemodynamic studies show that single LV pacing can improve cardiac function as least as good. ${ }^{6,757}$ Also, long term results are similar for $\mathrm{LV}$ and BiV pacing. ${ }^{58}$ In contrast to the good results of single LV pacing, it is know from animal studies that LV pacing resulted in decreased LV function and LV dilatation on the long run. ${ }^{23} \mathrm{LV}$ pacing in this animal study was however performed with very short AV-delays introducing significant inter- and intra-ventricular asynchrony. ${ }^{59,60}$ 

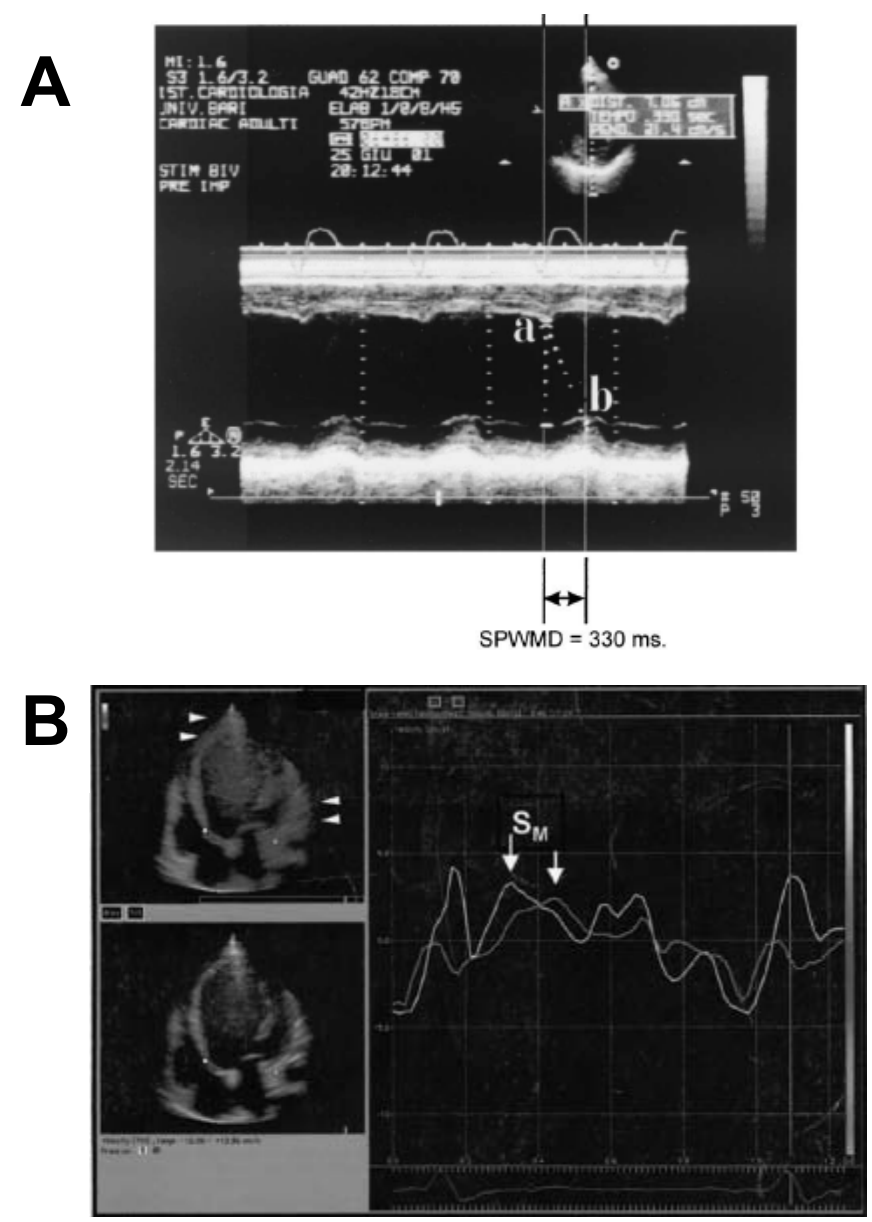

Figure 6. A. Mono-dimensional short-axis view of the echocardiographic image taken at the level of the papillary muscles. Calculation of septal-to-posterior wall motion delay (SPWMD) obtained by measuring the shortest interval between the maximal posterior displacement of the septum (a) and the posterior wall (b). Modified from reference. ${ }^{43} \mathbf{B}$. Regional myocardial velocity curves obtained by tissue Doppler imaging in a LBBB patient at the basal septal (yellow) and basal lateral (green) segments. In the color twodimensional pictures, movement of the myocardium toward the probe (during contraction) is shown in red, whereas movement away from the probe (during relaxation) is shown in blue. There was delay in the onset and peak systolic motion (SM) in the LV lateral wall compared with the septal wall. Modified from reference. ${ }^{22}$ 


\section{0 \\ Chapter 3}

A possible explanation for the good results of single LV pacing in CRT in patients with LBBB is fusion of the LV pacing wave front with the intrinsic activation through the right bundle branch. ${ }^{61}$ The fact that cardiac pump function is sometimes better during LV pacing than during BiV pacing ${ }^{62}$ could even be attributed to the advantageous use of the normal RV activation through the right bundle branch, as opposed to artificial RV pacing. After all, RV pacing requires myocardial tissue conduction, thus introducing asynchronous RV activation.

However, fusion can not explain why in patients with atrial fibrillation ${ }^{63}$ and even in patients with narrow QRS complex improvements in cardiac function by LV pacing are reported. ${ }^{61}$ Moreover, in LBBB patients with sinus rhythm, LV pacing at short AV-delay improves LV function more than expected from the degree of electrical resynchronization. ${ }^{6,12}$ The relatively good hemodynamic performance of single LV pacing has also been shown in a canine model of heart failure and LBBB. There it was found that during LV pacing in failing hearts, in contrast to normal hearts, ${ }^{25}$ electrical asynchrony within the LV coincides with mechanical synchrony. ${ }^{10}$ One possible explanation is that during LV pacing the septum is less prestretched in the failing than in the normal heart. ${ }^{25}$ This could be due to larger stiffness of the septum or to the high diastolic RV pressure. The early systolic prestretch gives rise to pronounced shortening later during systole. The lack of prestretch could therefore reduce the amount of mechanical asynchrony.

Another explanation for the good results of single site LV pacing is provided by work of Bleasdale and colleagues. ${ }^{61}$ These investigators measured LV pressure-volume relations in patients with both narrow and wide QRS complex and with varying levels of venous pressures. In patients with central venous pressure of more than $15 \mathrm{mmHg}$, LV pacing at short AV-delays increased LV filling through a mechanism called interventricular coupling or diastolic ventricular interaction. During high central venous pressure, the RV occupies more of the pericardial space at the expense of the LV. Therefore, single LV pacing may cause earlier LV relaxation and better LV filling. In accordance with the Frank-Starling mechanism, this resulted in an increase in LV stroke volume and stroke work.

Besides pacing site(s), timing of RV and LV stimulation is important. It is still not clear which pacing configuration results in best acute hemodynamic improvement during $\mathrm{BiV}$ pacing. For the pacing configuration resulting in best ventricular synchrony and best LV pump function, pacing one should realize that three distinct levels of asynchrony can be distinguished during $\mathrm{BiV}$ pacing: (1) the atrio-ventricular asynchrony due to slow AV conduction, (2) the interventricular asynchrony due to abnormal impulse propagation between both ventricles, and (3) intra-ventricular asynchrony due to regions of delayed activation within the LV itself. 
Atrio-ventricular asynchrony can be tuned with the AV-delay, timing of atrial and ventricular contraction for optimal ventricular filling en minimal enddiastolic mitral regurgitation. AV-delay, however, not only influences ventricular filling time, but also the degree of inter- and intra-ventricular asynchrony and consequently hemodynamic improvement ${ }^{6}$. After all, the moment of ventricular stimulation in relation to that of intrinsic activation determines the degree of fusion between intrinsic activation and pacing stimulus.

BiV pacing systems also have the option to vary the timing of RV and LV stimulation, i.e. VV-interval. Several studies report small, but significant, beneficial hemodynamic effects of sequential over simultaneous BiV pacing. ${ }^{64,65}$ Varying the VV-interval may lead to different degrees of inter- and intraventricular asynchrony. However, extensive hemodynamic testing need to be performed in order to find the pacing configuration that results in best inter- and intra-ventricular synchrony and best LV pump function. We, therefore, studied in chapter 6 a non-invasive method to optimize AV-delay and VV-interval in canine hearts with LBBB

\section{REFERENCES}

1 Lee TH, Hamilton MA, Stevenson LW, Moriguchi JD, Fonarow GC, Child JS, Laks H, Walden JA. Impact of left ventricular cavity size on survival in advanced heart failure. Am J Cardiol. 1993;72:672-676.

2 Wiggers CJ. The muscular reactions of the mammalian ventricles to artificial surface stimuli. Am J Physiol 1925;73:346-378.

3 Bakker P, de Jonge N, Klopping C, Meijburg HW, Barmen 't Loo C, Wittkampf F, Van Mechelen R, Mower MM, Thomas AC. Biventricular pacing in congestive heart failure. Clinical Research. 1994;42:327A.

4 Gregoratos G, Abrams J, Epstein AE, Freedman RA, Hayes DL, Hlatky MA, Kerber RE, Naccarelli GV, Schoenfeld MH, Silka MJ, Winters SL, Gibbons RJ, Antman EM, Alpert JS, Gregoratos G, Hiratzka LF, Faxon DP, Jacobs AK, Fuster V, Smith SC, Jr. ACC/AHA/NASPE 2002 guideline update for implantation of cardiac pacemakers and antiarrhythmia devices: summary article: a report of the American College of Cardiology/American Heart Association Task Force on Practice Guidelines (ACC/AHA/NASPE Committee to Update the 1998 Pacemaker Guidelines). Circulation. 2002;106:2145-2161.

5 Wyman BT, Hunter WC, Prinzen FW, Faris OP, McVeigh ER. Effects of single- and biventricular pacing on temporal and spatial dynamics of ventricular contraction. Am J Physiol Heart Circ Physiol. 2002;282:H372-379.

6 Auricchio A, Stellbrink C, Block M, Sack S, Vogt J, Bakker P, Klein H, Kramer A, Ding J, Salo R, Tockman B, Pochet T, Spinelli J. Effect of pacing chamber and atrioventricular delay on acute systolic function of paced patients with congestive heart failure. The Pacing Therapies for Congestive Heart Failure Study Group. The Guidant Congestive Heart Failure Research Group. Circulation. 1999;99:2993-3001.

7 Kass DA, Chen CH, Curry C, Talbot M, Berger R, Fetics B, Nevo E. Improved left ventricular mechanics from acute VDD pacing in patients with dilated cardiomyopathy and ventricular conduction delay. Circulation. 1999;99:1567-1573. 


\section{2 \\ Chapter 3}

8 Dekker AL, Phelps B, Dijkman B, van der Nagel T, van der Veen FH, Geskes GG, Maessen JG. Epicardial left ventricular lead placement for cardiac resynchronization therapy: optimal pace site selection with pressure-volume loops. J Thorac Cardiovasc Surg. 2004;127:16411647.

9 Liu L, Tockman B, Girouard S, Pastore J, Walcott G, KenKnight B, Spinelli J. Left ventricular resynchronization therapy in a canine model of left bundle branch block. Am J Physiol Heart Circ Physiol. 2002;282:H2238-2244.

10 Leclercq C, Faris O, Tunin R, Johnson J, Kato R, Evans F, Spinelli J, Halperin H, McVeigh E, Kass DA. Systolic improvement and mechanical resynchronization does not require electrical synchrony in the dilated failing heart with left bundle-branch block. Circulation. 2002;106:1760-1763.

11 Nelson GS, Berger RD, Fetics BJ, Talbot M, Spinelli JC, Hare JM, Kass DA. Left ventricular or biventricular pacing improves cardiac function at diminished energy cost in patients with dilated cardiomyopathy and left bundle-branch block. Circulation. 2000;102:30533059 .

12 Yu CM, Fung WH, Lin H, Zhang Q, Sanderson JE, Lau CP. Predictors of left ventricular reverse remodeling after cardiac resynchronization therapy for heart failure secondary to idiopathic dilated or ischemic cardiomyopathy. Am J Cardiol. 2003;91:684-688.

13 Breithardt OA, Sinha AM, Schwammenthal E, Bidaoui N, Markus KU, Franke A, Stellbrink C. Acute effects of cardiac resynchronization therapy on functional mitral regurgitation in advanced systolic heart failure. J Am Coll Cardiol. 2003;41:765-770.

14 Nelson GS, Curry CW, Wyman BT, Kramer A, Declerck J, Talbot M, Douglas MR, Berger $\mathrm{RD}, \mathrm{McVeigh}$ ER, Kass DA. Predictors of systolic augmentation from left ventricular preexcitation in patients with dilated cardiomyopathy and intraventricular conduction delay. Circulation. 2000;101:2703-2709.

15 Cazeau S, Leclercq C, Lavergne T, Walker S, Varma C, Linde C, Garrigue S, Kappenberger L, Haywood GA, Santini M, Bailleul C, Daubert JC. Effects of multisite biventricular pacing in patients with heart failure and intraventricular conduction delay. $\mathrm{N}$ Engl J Med. 2001;344:873-880.

16 Linde C, Leclercq C, Rex S, Garrigue S, Lavergne T, Cazeau S, McKenna W, Fitzgerald M, Deharo JC, Alonso C, Walker S, Braunschweig F, Bailleul C, Daubert JC. Long-term benefits of biventricular pacing in congestive heart failure: results from the MUltisite STimulation in cardiomyopathy (MUSTIC) study. J Am Coll Cardiol. 2002;40:111-118.

17 Abraham WT, Fisher WG, Smith AL, Delurgio DB, Leon AR, Loh E, Kocovic DZ, Packer M, Clavell AL, Hayes DL, Ellestad M, Trupp RJ, Underwood J, Pickering F, Truex C, McAtee P, Messenger J. Cardiac resynchronization in chronic heart failure. N Engl J Med. 2002;346:1845-1853.

18 St John Sutton MG, Plappert T, Abraham WT, Smith AL, DeLurgio DB, Leon AR, Loh E, Kocovic DZ, Fisher WG, Ellestad M, Messenger J, Kruger K, Hilpisch KE, Hill MR. Effect of cardiac resynchronization therapy on left ventricular size and function in chronic heart failure. Circulation. 2003;107:1985-1990.

19 Bristow MR, Saxon LA, Boehmer J, Krueger S, Kass DA, De Marco T, Carson P, DiCarlo L, DeMets D, White BG, DeVries DW, Feldman AM. Cardiac-resynchronization therapy with or without an implantable defibrillator in advanced chronic heart failure. N Engl J Med. 2004;350:2140-2150.

20 Cleland JG, Daubert JC, Erdmann E, Freemantle N, Gras D, Kappenberger L, Tavazzi L. The effect of cardiac resynchronization on morbidity and mortality in heart failure. N Engl $\mathrm{J}$ Med. 2005;352:1539-1549.

21 Sogaard P, Egeblad H, Kim WY, Jensen HK, Pedersen AK, Kristensen BO, Mortensen PT. Tissue Doppler imaging predicts improved systolic performance and reversed left ventricular 
remodeling during long-term cardiac resynchronization therapy. J Am Coll Cardiol. 2002;40:723-730.

22 Yu CM, Chau E, Sanderson JE, Fan K, Tang MO, Fung WH, Lin H, Kong SL, Lam YM, Hill MR, Lau CP. Tissue Doppler echocardiographic evidence of reverse remodeling and improved synchronicity by simultaneously delaying regional contraction after biventricular pacing therapy in heart failure. Circulation. 2002;105:438-445.

23 van Oosterhout MF, Prinzen FW, Arts T, Schreuder JJ, Vanagt WY, Cleutjens JP, Reneman RS. Asynchronous electrical activation induces asymmetrical hypertrophy of the left ventricular wall. Circulation. 1998;98:588-595.

24 Peschar M, Vernooy K, Vanagt WY, Reneman RS, Vos MA, Prinzen FW. Absence of reverse electrical remodeling during regression of volume overload hypertrophy in canine ventricles. Cardiovasc Res. 2003;58:510-517.

25 Prinzen FW, Hunter WC, Wyman BT, McVeigh ER. Mapping of regional myocardial strain and work during ventricular pacing: experimental study using magnetic resonance imaging tagging. J Am Coll Cardiol. 1999;33:1735-1742.

26 Delhaas T, Arts T, Prinzen FW, Reneman RS. Regional fibre stress-fibre strain area as an estimate of regional blood flow and oxygen demand in the canine heart. J Physiol. 1994;477 ( Pt 3):481-496.

27 Ono S, Nohara R, Kambara H, Okuda K, Kawai C. Regional myocardial perfusion and glucose metabolism in experimental left bundle branch block. Circulation. 1992;85:1125-1131.

28 Sweeney MO, Hellkamp AS, Ellenbogen KA, Greenspon AJ, Freedman RA, Lee KL, Lamas GA. Adverse effect of ventricular pacing on heart failure and atrial fibrillation among patients with normal baseline QRS duration in a clinical trial of pacemaker therapy for sinus node dysfunction. Circulation. 2003;107:2932-2937.

29 Sweeney MO, Prinzen FW. A new paradigm for physiologic ventricular pacing. J Am Coll Cardiol. 2006;47:282-288.

30 Wilkoff BL, Cook JR, Epstein AE, Greene HL, Hallstrom AP, Hsia H, Kutalek SP, Sharma A. Dual-chamber pacing or ventricular backup pacing in patients with an implantable defibrillator: the Dual Chamber and VVI Implantable Defibrillator (DAVID) Trial. Jama. 2002;288:3115-3123.

31 Baker CM, Christopher TJ, Smith PF, Langberg JJ, Delurgio DB, Leon AR. Addition of a left ventricular lead to conventional pacing systems in patients with congestive heart failure: feasibility, safety, and early results in 60 consecutive patients. Pacing Clin Electrophysiol. 2002;25:1166-1171.

32 Leon AR, Greenberg JM, Kanuru N, Baker CM, Mera FV, Smith AL, Langberg JJ, DeLurgio DB. Cardiac resynchronization in patients with congestive heart failure and chronic atrial fibrillation: effect of upgrading to biventricular pacing after chronic right ventricular pacing. J Am Coll Cardiol. 2002;39:1258-1263.

33 Leclercq C, Walker S, Linde C, Clementy J, Marshall AJ, Ritter P, Djiane P, Mabo P, Levy T, Gadler F, Bailleul C, Daubert JC. Comparative effects of permanent biventricular and right-univentricular pacing in heart failure patients with chronic atrial fibrillation. Eur Heart J. 2002;23:1780-1787.

34 Yu CM, Bax JJ, Monaghan M, Nihoyannopoulos P. Echocardiographic evaluation of cardiac dyssynchrony for predicting a favourable response to cardiac resynchronisation therapy. Heart. 2004;90 Suppl 6:vi17-22.

35 Bax JJ, Bleeker GB, Marwick TH, Molhoek SG, Boersma E, Steendijk P, van der Wall EE, Schalij MJ. Left ventricular dyssynchrony predicts response and prognosis after cardiac resynchronization therapy. J Am Coll Cardiol. 2004;44:1834-1840.

36 Bax JJ, Marwick TH, Molhoek SG, Bleeker GB, van Erven L, Boersma E, Steendijk P, van der Wall EE, Schalij MJ. Left ventricular dyssynchrony predicts benefit of cardiac resyn- 


\section{4 \\ Chapter 3}

chronization therapy in patients with end-stage heart failure before pacemaker implantation. Am J Cardiol. 2003;92:1238-1240.

37 Alonso C, Leclercq C, Victor F, Mansour H, de Place C, Pavin D, Carre F, Mabo P, Daubert JC. Electrocardiographic predictive factors of long-term clinical improvement with multisite biventricular pacing in advanced heart failure. Am J Cardiol. 1999;84:1417-1421.

38 Wyman BT, Hunter WC, Prinzen FW, McVeigh ER. Mapping propagation of mechanical activation in the paced heart with MRI tagging. Am J Physiol. 1999;276:H881-891.

39 Bax JJ, Abraham T, Barold SS, Breithardt OA, Fung JW, Garrigue S, Gorcsan J, 3rd, Hayes DL, Kass DA, Knuuti J, Leclercq C, Linde C, Mark DB, Monaghan MJ, Nihoyannopoulos P, Schalij MJ, Stellbrink C, Yu CM. Cardiac resynchronization therapy: Part 1--issues before device implantation. J Am Coll Cardiol. 2005;46:2153-2167.

40 Bordachar P, Garrigue S, Lafitte S, Reuter S, Jais P, Haissaguerre M, Clementy J. Interventricular and intra-left ventricular electromechanical delays in right ventricular paced patients with heart failure: implications for upgrading to biventricular stimulation. Heart. 2003;89:1401-1405.

41 Kerwin WF, Botvinick EH, O'Connell JW, Merrick SH, DeMarco T, Chatterjee K, Scheibly K, Saxon LA. Ventricular contraction abnormalities in dilated cardiomyopathy: effect of biventricular pacing to correct interventricular dyssynchrony. J Am Coll Cardiol. 2000;35:1221-1227.

42 Verbeek XAAM, Vernooy K, Peschar M, Van Der Nagel T, Van Hunnik A, Prinzen FW. Quantification of interventricular asynchrony during LBBB and ventricular pacing. Am J Physiol Heart Circ Physiol. 2002;283:H1370-1378.

43 Pitzalis MV, Iacoviello M, Romito R, Massari F, Rizzon B, Luzzi G, Guida P, Andriani A, Mastropasqua F, Rizzon P. Cardiac resynchronization therapy tailored by echocardiographic evaluation of ventricular asynchrony. J Am Coll Cardiol. 2002;40:1615-1622.

44 Pitzalis MV, Iacoviello M, Romito R, Guida P, De Tommasi E, Luzzi G, Anaclerio M, Forleo C, Rizzon P. Ventricular asynchrony predicts a better outcome in patients with chronic heart failure receiving cardiac resynchronization therapy. J Am Coll Cardiol. 2005;45:65-69.

45 Marcus GM, Rose E, Viloria EM, Schafer J, De Marco T, Saxon LA, Foster E. Septal to posterior wall motion delay fails to predict reverse remodeling or clinical improvement in patients undergoing cardiac resynchronization therapy. J Am Coll Cardiol. 2005;46:22082214.

46 Bader H, Garrigue S, Lafitte S, Reuter S, Jais P, Haissaguerre M, Bonnet J, Clementy J, Roudaut R. Intra-left ventricular electromechanical asynchrony. A new independent predictor of severe cardiac events in heart failure patients. J Am Coll Cardiol. 2004;43:248-256.

47 Breithardt OA, Stellbrink C, Herbots L, Claus P, Sinha AM, Bijnens B, Hanrath P, Sutherland GR. Cardiac resynchronization therapy can reverse abnormal myocardial strain distribution in patients with heart failure and left bundle branch block. J Am Coll Cardiol. 2003;42:486-494.

48 Bleeker GB, Schalij MJ, Molhoek SG, Verwey HF, Holman ER, Boersma E, Steendijk P, Van Der Wall EE, Bax JJ. Relationship between QRS duration and left ventricular dyssynchrony in patients with end-stage heart failure. J Cardiovasc Electrophysiol. 2004;15:544549.

49 Bleeker GB, Schalij MJ, Molhoek SG, Holman ER, Verwey HF, Steendijk P, van der Wall EE, Bax JJ. Frequency of left ventricular dyssynchrony in patients with heart failure and a narrow QRS complex. Am J Cardiol. 2005;95:140-142.

50 Lindner O, Vogt J, Kammeier A, Wielepp P, Holzinger J, Baller D, Lamp B, Hansky B, Korfer R, Horstkotte D, Burchert W. Effect of cardiac resynchronization therapy on global and regional oxygen consumption and myocardial blood flow in patients with non-ischaemic and ischaemic cardiomyopathy. Eur Heart J. 2005;26:70-76. 
51 Rodriguez LM, Timmermans C, Nabar A, Beatty G, Wellens HJ. Variable patterns of septal activation in patients with left bundle branch block and heart failure. J Cardiovasc Electrophysiol. 2003;14:135-141.

52 Auricchio A, Fantoni C, Regoli F, Carbucicchio C, Goette A, Geller C, Kloss M, Klein H. Characterization of left ventricular activation in patients with heart failure and left bundlebranch block. Circulation. 2004;109:1133-1139.

53 Gasparini M, Mantica M, Galimberti P, Bocciolone M, Genovese L, Mangiavacchi M, Marchesina UL, Faletra F, Klersy C, Coates R, Gronda E. Is the left ventricular lateral wall the best lead implantation site for cardiac resynchronization therapy? Pacing Clin Electrophysiol. 2003;26:162-168.

54 Butter C, Auricchio A, Stellbrink C, Fleck E, Ding J, Yu Y, Huvelle E, Spinelli J. Effect of resynchronization therapy stimulation site on the systolic function of heart failure patients. Circulation. 2001;104:3026-3029.

55 Puglisi A, Lunati M, Marullo AG, Bianchi S, Feccia M, Sgreccia F, Vicini I, Valsecchi S, Musumeci F, Vitali E. Limited thoracotomy as a second choice alternative to transvenous implant for cardiac resynchronisation therapy delivery. Eur Heart J. 2004;25:1063-1069.

56 Koos R, Sinha AM, Markus K, Breithardt OA, Mischke K, Zarse M, Schmid M, Autschbach R, Hanrath P, Stellbrink C. Comparison of left ventricular lead placement via the coronary venous approach versus lateral thoracotomy in patients receiving cardiac resynchronization therapy. Am J Cardiol. 2004;94:59-63.

57 Blanc JJ, Etienne Y, Gilard M, Mansourati J, Munier S, Boschat J, Benditt DG, Lurie KG. Evaluation of different ventricular pacing sites in patients with severe heart failure: results of an acute hemodynamic study. Circulation. 1997;96:3273-3277.

58 Touiza A, Etienne Y, Gilard M, Fatemi M, Mansourati J, Blanc JJ. Long-term left ventricular pacing: assessment and comparison with biventricular pacing in patients with severe congestive heart failure. J Am Coll Cardiol. 2001;38:1966-1970.

59 Verbeek XAAM, Vernooy K, Peschar M, Cornelussen RNM, Prinzen FW. Intra-ventricular resynchronization for optimal left ventricular function during pacing in experimental left bundle branch block. J Am Coll Cardiol. 2003;42:558-567.

60 Verbeek XA, Auricchio A, Yu Y, Ding J, Pochet T, Vernooy K, Kramer A, Spinelli J, Prinzen FW. Tailoring cardiac resynchronization therapy using interventricular asynchrony. Validation of a simple concept. Am J Physiol Heart Circ Physiol. 2006;290:H968-977.

61 Bleasdale RA, Turner MS, Mumford CE, Steendijk P, Paul V, Tyberg JV, Morris-Thurgood JA, Frenneaux MP. Left ventricular pacing minimizes diastolic ventricular interaction, allowing improved preload-dependent systolic performance. Circulation. 2004;110:2395-2400.

62 Van Gelder BM, Bracke FA, Meijer A, Pijls NH. The Hemodynamic Effect of Intrinsic Conduction During Left Ventricular Pacing as Compared to Biventricular Pacing. J Am Coll Cardiol. 2005;46:2305-2310.

63 Etienne Y, Mansourati J, Gilard M, Valls-Bertault V, Boschat J, Benditt DG, Lurie KG, Blanc JJ. Evaluation of left ventricular based pacing in patients with congestive heart failure and atrial fibrillation. Am J Cardiol. 1999;83:1138-1140, A1139.

64 Sogaard P, Egeblad H, Pedersen AK, Kim WY, Kristensen BO, Hansen PS, Mortensen PT. Sequential versus simultaneous biventricular resynchronization for severe heart failure: evaluation by tissue Doppler imaging. Circulation. 2002;106:2078-2084.

65 Perego GB, Chianca R, Facchini M, Frattola A, Balla E, Zucchi S, Cavaglia S, Vicini I, Negretto M, Osculati G. Simultaneous vs. sequential biventricular pacing in dilated cardiomyopathy: an acute hemodynamic study. Eur J Heart Fail. 2003;5:305-313.

66 Penicka M, Bartunek J, De Bruyne B, Vanderheyden M, Goethals M, De Zutter M, Brugada $\mathrm{P}$, Geelen P. Improvement of left ventricular function after cardiac resynchronization therapy is predicted by tissue Doppler imaging echocardiography. Circulation. 2004;109:978-983. 


\section{$46 \mid$ Chapter 3}

67 Ansalone G, Giannantoni P, Ricci R, Trambaiolo P, Laurenti A, Fedele F, Santini M. Doppler myocardial imaging in patients with heart failure receiving biventricular pacing treatment. Am Heart J. 2001;142:881-896.

68 Garrigue S, Jais P, Espil G, Labeque JN, Hocini M, Shah DC, Haissaguerre M, Clementy J. Comparison of chronic biventricular pacing between epicardial and endocardial left ventricular stimulation using Doppler tissue imaging in patients with heart failure. Am J Cardiol. 2001;88:858-862.

69 Bordachar P, Lafitte S, Reuter S, Sanders P, Jais P, Haissaguerre M, Roudaut R, Garrigue S, Clementy J. Echocardiographic parameters of ventricular dyssynchrony validation in patients with heart failure using sequential biventricular pacing. J Am Coll Cardiol. 2004;44:21572165.

70 Yu CM, Fung JW, Zhang Q, Chan CK, Chan YS, Lin H, Kum LC, Kong SL, Zhang Y, Sanderson JE. Tissue Doppler imaging is superior to strain rate imaging and postsystolic shortening on the prediction of reverse remodeling in both ischemic and nonischemic heart failure after cardiac resynchronization therapy. Circulation. 2004;110:66-73.

71 Yu CM, Zhang Q, Fung JW, Chan HC, Chan YS, Yip GW, Kong SL, Lin H, Zhang Y, Sanderson JE. A novel tool to assess systolic asynchrony and identify responders of cardiac resynchronization therapy by tissue synchronization imaging. J Am Coll Cardiol. 2005;45:677684.

72 Zhang Q, Yu CM, Fung JW, Zhang Y, Chan YS, Chan HC, Yip GW, Sanderson JE. Assessment of the effect of cardiac resynchronization therapy on intraventricular mechanical synchronicity by regional volumetric changes. Am J Cardiol. 2005;95:126-129.

73 Kass DA. Ventricular resynchronization: pathophysiology and identification of responders. Rev Cardiovasc Med. 2003;4 Suppl 2:S3-S13. 


\section{Chapter 4}

\section{Left Bundle Branch Block Induces Ventricular Remodeling and Functional Septal Hypoperfusion}

Kevin Vernooy, MD, ${ }^{\mathrm{a}, \mathrm{c}, *}$ Xander A.A.M. Verbeek, $\mathrm{PhD},{ }^{\mathrm{a}}$ Maaike Peschar, PhD, ${ }^{\mathrm{a}}$ Harry J.G.M. Crijns, MD, PhD,${ }^{\mathrm{c}}$ Theo Arts, PhD, Richard N.M. Cornelussen, PhD, ${ }^{a}$ Frits W. Prinzen, $\mathrm{PhD}^{\mathrm{a}}$

Departments of Physiology, Biophysics, ${ }^{\mathrm{b}}$ and Cardiology, Cardiovascular Research Institute Maastricht, Maastricht, the Netherlands

European Heart Journal 2005 Jan;26(1):91-8 
$48 \mid$ Chapter 4

\section{Abstract}

Aims. Left ventricular (LV) dilatation, hypertrophy, and septal perfusion defects are frequently observed in patients with left bundle branch block (LBBB). We investigated whether isolated LBBB causes these abnormalities.

Methods and results. In eight dogs, $L B B B$ was induced by radio frequency ablation. Two-dimensional echocardiography showed that 16 weeks of LBBB decreased LV ejection fraction (by $23 \pm 14 \%$ ) and increased LV cavity volume (by $25 \pm 19 \%$ ) and wall mass (by $17 \pm 16 \%$ ). The LV septal-to-lateral wall mass ratio decreased by $6 \pm 9 \%$, indicating asymmetric hypertrophy. After onset of LBBB, myocardial blood flow (MBF, fluorescent microspheres) and systolic circumferential shortening (CSsys, magnetic resonance (MR) tagging) decreased in the septum to $83 \pm 16 \%$ and $-11 \pm 20 \%$ of baseline, respectively, and increased in LV lateral wall to $118 \pm 12 \%$ and $180 \pm 90 \%$ of baseline, respectively. MBF and CSsys values did not change over 16 weeks of LBBB. Changes in external mechanical work paralleled those in CSsys. Glycogen content was not significantly different between septum and LV lateral wall of LBBB hearts (16 weeks) and control samples, indicating absence of hibernation.

Conclusions. The asynchronous ventricular activation during LBBB leads to redistribution of circumferential shortening and myocardial blood flow and, in the long run, LV remodelling. Septal hypoperfusion during LBBB appears to be primarily determined by reduced septal workload. 


\section{INTRODUCTION}

Epidemiological studies have identified left bundle branch block (LBBB) as an independent risk factor for cardiac mortality. ${ }^{1-3}$ While in the general population LBBB has an incidence of $1-3 \%$ at age 65 , this incidence is $\sim 30 \%$ in patients with heart failure. ${ }^{2}$ Little is known of the etiology during the early phase of LBBB, because it usually has a silent onset. Understanding LBBB is further complicated by its frequent coincidence with other cardiovascular derangements. $^{4,5}$

In patients, LBBB is often accompanied by left ventricular (LV) dilatation, reduced LV ejection fraction (EF), ${ }^{4-6}$ and septal perfusion defects, ${ }^{7,8}$ even in the absence of coronary artery disease. It is not known whether these abnormalities are the cause of the abnormal conduction or whether the conduction disturbance is a marker of a more progressive disease state. ${ }^{9}$

Structural adaptation of the LV could be expected with LBBB, because in canine hearts chronic pacing at the LV lateral wall, also leading to asynchronous electrical activation, has been shown to lead to asymmetric hypertrophy and ventricular dilatation. ${ }^{10}$ However, during LV pacing the activation sequence is opposite to that of LBBB and the ectopic stimulus is generated outside the Purkinje system.

Moreover, in these LV pacing experiments it was observed that the nonuniform distribution of blood flow disappeared over time,${ }^{11}$ which seems in conflict with the septal underperfusion in patients with LBBB. Also, it is still controversial whether the redistribution of perfusion during asynchronous activation is a functional adaptation to altered mechanical work, and so demand, or signifies hampered perfusion due to the abnormal contraction. ${ }^{11,12}$ In the latter case structural and functional abnormalities in underperfused regions would be anticipated.

The aim of the present study was to investigate to what extent isolated LBBB causes ventricular remodeling and loss of LV pump function and whether abnormal septal perfusion contributes to these changes. To this purpose LBBB was induced in normal canine hearts. LV endocardial electrical activation (endocardial mapping), myocardial circumferential shortening (MR tagging) and myocardial blood flow (MBF, fluorescent microspheres) were mapped before, shortly and chronically (16 weeks) after onset of LBBB. Ventricular remodeling was assessed by serial 2D-echocardiography. Tissue glycogen contents were used to detect potential hibernation, a sign of longer lasting restriction of perfusion. 
$50 \mid$ Chapter 4

\section{METHODS}

Animal handling was performed according to the Dutch Law on Animal Experimentation and the European Directive for the Protection of Vertebrate Animals Used for Experimental and Other Scientific Purposes (86/609/EU). The Animal Experimental Committee of the Maastricht University approved the protocol.

\section{Experimental protocol}

The experiments were performed on 8 adult mongrel dogs of both sex and unknown age, with a weight of $28.0 \pm 0.5 \mathrm{~kg}$. After pentothal induction, anesthesia was maintained by ventilation with $\mathrm{O}_{2}$ and $\mathrm{N}_{2} \mathrm{O}(1: 2)$ in combination with infusion of midazolam $(0.1 \mathrm{mg} / \mathrm{kg} / \mathrm{hr}$ i.v. $)$ and sufentanyl $(3 \mu \mathrm{g} / \mathrm{kg} / \mathrm{hr}$ i.v. $){ }^{13}$ During sterile surgery, LBBB was induced by radio frequency ablation. ${ }^{14}$ Two catheter tip manometers (CD-Leycom, Zoetermeer, the Netherlands) were used to measure LV and right ventricular (RV) pressures. Cardiac output was measured by thermodilution. A basket catheter (EPT Constellation, Boston Scientific, San Jose, CA) was unfolded in the LV to obtain LV endocardial activation times. ${ }^{14}$ For MBF measurements, using the fluorescent microsphere technique, ${ }^{11}$ a catheter was placed in the LV for microspheres injection. For each MBF measurement $5 \times 10^{6}$ fluorescent microspheres $(15.5 \mu \mathrm{m} \pm 2 \%$, Molecular Probes, Eugene, OR) were injected.

Hemodynamic, ECG and LV endocardial electrical potential measurements and microspheres injections were performed before (baseline) and shortly after ( $\sim 30 \mathrm{~min}$ ) creation of LBBB (acute LBBB). Endocardial mapping was performed directly after hemodynamic measurements to prevent interference of the basket electrode with LV function measurements.

Two-dimensional echocardiographic images of the LV were made before (baseline) and every two weeks after onset of LBBB up to 16 weeks (chronic LBBB). The animals were premedicated with acepromazine $(0.6 \mathrm{mg} / \mathrm{kg}$ i.m. $){ }^{13}$

MR tagging measurements were performed one week before (baseline), $3 \pm 1$ weeks after (acute LBBB) as well as $15 \pm 1$ (chronic LBBB) weeks after creation of LBBB under the same anesthetic conditions as mentioned above using manual ventilation.

After 16 weeks of LBBB the animals were anesthetized again, repeating the measurements of hemodynamics, ECG and LV endocardial mapping and MBF by microspheres injections. To investigate whether the remodeling process has caused impaired septal perfusion, in three experiments microspheres were injected within 15 min after starting simultaneous RV apex and LV lateral wall stimulation (biventricular pacing). 
Finally, the heart was removed and transmural tissue samples for glycogen analysis were taken from the septum and LV lateral wall and quickly immersed in liquid nitrogen and stored at $-80^{\circ} \mathrm{C}$. Control values for myocardial glycogen content were obtained from 10 samples from sham operated control dogs, ${ }^{10}$ which were virtually equal to 69 historic control values. ${ }^{15}$ For microspheres analysis the $\mathrm{LV}$ was stored at $-20^{\circ} \mathrm{C}$ together with the reference blood samples.

\section{Magnetic Resonance Imaging}

Cine images were acquired on a Philips Gyroscan 1.5 T (NT, Philips Medical Systems, Best, the Netherlands). The RF receiver coil was a standard synergy body coil for thorax examinations. Breath hold $(\sim 12 \mathrm{sec})$ was accomplished by discontinuing manual ventilation and followed by a recovery period of $\sim 45-60$ sec. Images of 7 short axis cross-sections, slice thickness $8 \mathrm{~mm}$ with inter-slice distance $0 \mathrm{~mm}$, were obtained to capture the whole heart. Cine-images were acquired using non-tagged steady state gradient echo sequences, starting $28 \mathrm{~ms}$ after the R-wave on the vectorcardiogram (field of view $400 \mathrm{~mm}$, image size $256 \times 256$ pixels). Thereafter, a series of grid-tagged images from the same slices were obtained with time intervals of $15 \mathrm{~ms}$, using balanced-FFE scanning.

\section{Data Analysis}

Hemodynamic data analysis was performed as described previously. ${ }^{14}$ Interventricular asynchrony was calculated as the timing difference between the upslope of simultaneously recorded LV and RV pressure curves. ${ }^{14} \mathrm{LV}$ endocardial activation times, derived from endocardial activation maps, were used as measure for intraventricular asynchrony. ${ }^{16}$

The echocardiograms were digitized and short axis images were analyzed by use of software developed in our own laboratory by an experienced echocardiographer who was blinded for the time interval the echocardiogram was performed. ${ }^{14}$ Regional geometry was determined from end-diastolic short axis LV images after division in 4 sectors: anterior, septal, posterior and lateral wall. LV EF was calculated from the LV end-diastolic and end-systolic volume (EDV and ESV, respectively).

MR tagging image analysis was performed off-line using home-made software for MATLAB 5.3.1 (MathWorks; Natick, MA), as previously described in more detail. ${ }^{17}$ Within the region of interest, systolic circumferential shortening $\left(\mathrm{CS}_{\text {sys }}\right)$ was calculated as the change in segment length with respect to begin ejection $\left.\left(\mathrm{L}_{\mathrm{t}}-\mathrm{L}_{0}\right) / \mathrm{L}_{0}\right)$. Begin and end of the ejection phase were determined from the change in LV cavity area, assessed from the endocardial contours during the cardiac cycle. External mechanical work was calculated by combining $\mathrm{CS}_{\text {sys }}$ data, obtained during the MRI scan, with the LV pressure and volume data, ob- 


\section{2 \\ Chapter 4}

tained during the hemodynamic measurements immediately preceding the MRI scan. ${ }^{18}$ Timing of the strain, pressure and volume curves was matched by superimposing the LV volume signal obtained from the MRI scan with that from the hemodynamic measurements. ${ }^{19}$

For MBF measurements the LV was divided in three short axis slices and then divided into twelve transmural sections. Microspheres were isolated from the tissue by digestion (ethanolic $\mathrm{KOH}$ ). Fluorescence was extracted from the beads by 2-ethoxyethylacetate and determined using spectrofluorometry. ${ }^{11}$

To analyze regional glycogen storage, aliquots of ventricular tissues were freeze-dried. After adding $1 \mathrm{M} \mathrm{HCl}$ to the freeze-dried material, glycogen was hydrolyzed at $100^{\circ} \mathrm{C}$ for 3 hours. After neutralization with TRIS/KOH saturated with $\mathrm{KCl}$, the glucose residues were measured fluorometrically. ${ }^{20}$

\section{Statistical Analysis}

The sample size in the present study was based on previous experience in our laboratory. ${ }^{10,11,13,21,22}$ All values are described as mean values with their corresponding standard deviations. Changes over time of electrocardiographic, hemodynamic and echocardiographic variables as well as myocardial blood flow and circumferential shortening were evaluated using repeated measures ANOVA. If ANOVA indicated a significant difference between time points, a Bonferroni post-hoc test was performed to compare selected pairs of time points. Differences in myocardial shortening, work and blood flow and glycogen content between the septum and LV lateral wall were evaluated using a paired $t$-test. In all tests a $\mathrm{p}$ value of 0.05 or less (two-sided) was considered statistically significant.

\section{RESULTS}

\section{Electrophysiologic and hemodynamic changes}

Creation of LBBB did not affect heart rate or PQ interval but increased QRS duration (figure 1, upper row). Intra-LV activation time (figure 1, second row) was prolonged leading to increased intraventricular asynchrony (table 1). None of these variables changed significantly between acute and chronic LBBB. Interventricular asynchrony increased significantly after LBBB was established and remained stable during chronic LBBB (table 1). LBBB immediately decreased cardiac output and LVdP/dt/min without change in LV end-diastolic pressure (table 1). Hemodynamic parameters did not change significantly between acute and chronic LBBB, but during chronic LBBB cardiac output was no longer different from baseline. 


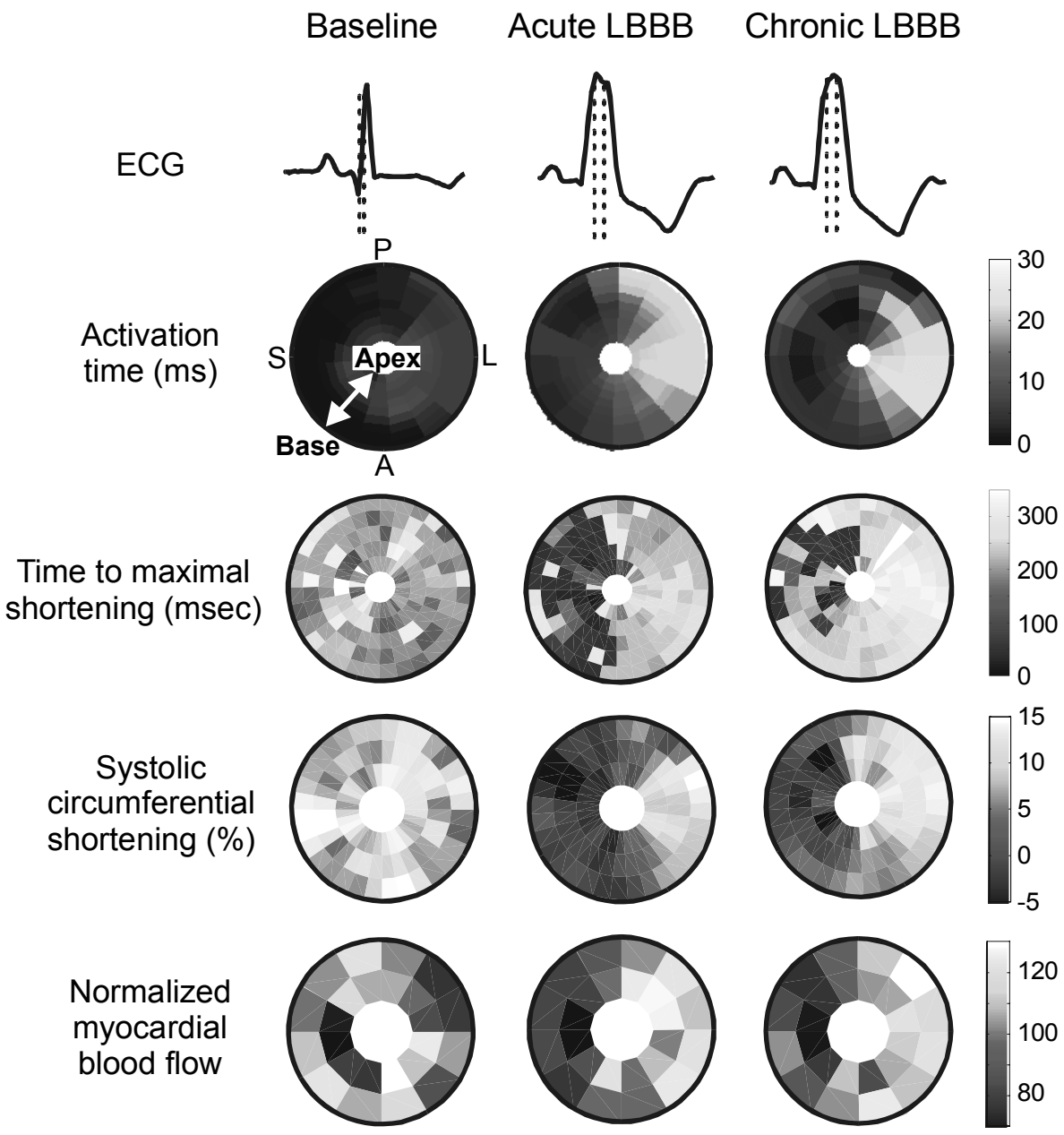

Figure 1. Examples of ECG II tracings (first row), LV endocardial activation maps (second row), LV time to maximal shortening maps (third row), LV systolic circumferential shortening (fourth row) and normalized myocardial blood flow (fifth row) during baseline, acute and chronic LBBB. In the ECG tracings the earliest and latest LV endocardial activation are indicated by dotted lines. Data are presented as bulls-eye plots; S, $\mathrm{P}, \mathrm{L}$ and $\mathrm{A}$ indicate septum, posterior, lateral and anterior LV wall, respectively. The outer ring represents the basal level and the inner ring the apex. The number of rings is smaller for blood flow, because of the smaller number of slices analyzed. Note that during LBBB light colors longest activation time and highest values of circumferential shortening and blood flow, coincide in the LV lateral wall. 


\section{Redistribution of systolic shortening}

Figure 2 presents myocardial circumferential shortening as function of time in eight regions along the circumference in a midbasal short-axis LV slice. During baseline, time course and amplitude of myocardial shortening were similar in the various regions. During LBBB, the early-activated septum showed presystolic myocardial shortening followed by some paradoxical motion, whereas the late-activated LV lateral wall showed pronounced myocardial shortening.

During baseline, $\mathrm{CS}_{\mathrm{sys}}$ was not significantly different between septum and LV lateral wall $(5.9 \pm 2.4 \%$ and $6.5 \pm 2.6 \%$, respectively). LBBB induced asynchrony of contraction, as measured by significant differences in timing of maximal shortening between septum and LV lateral wall (figure 1, third row). Acute LBBB decreased septal $\mathrm{CS}_{\text {sys }}$ to $-0.5 \pm 1.3 \%(-11 \pm 20 \%$ of baseline, indicating some systolic stretching) and increased $\mathrm{CS}_{\text {sys }}$ in the LV lateral wall to $10.1 \pm 3.0 \%$ ( $180 \pm 90 \%$ of baseline, figure $3 \mathrm{a})$. During chronic LBBB no significant changes in $\mathrm{CS}_{\mathrm{sys}}$ were observed as compared to acute LBBB. Changes in external mechanical work paralleled those in $\mathrm{CS}_{\text {sys }}$ (figure $3 \mathrm{~b}$ ).

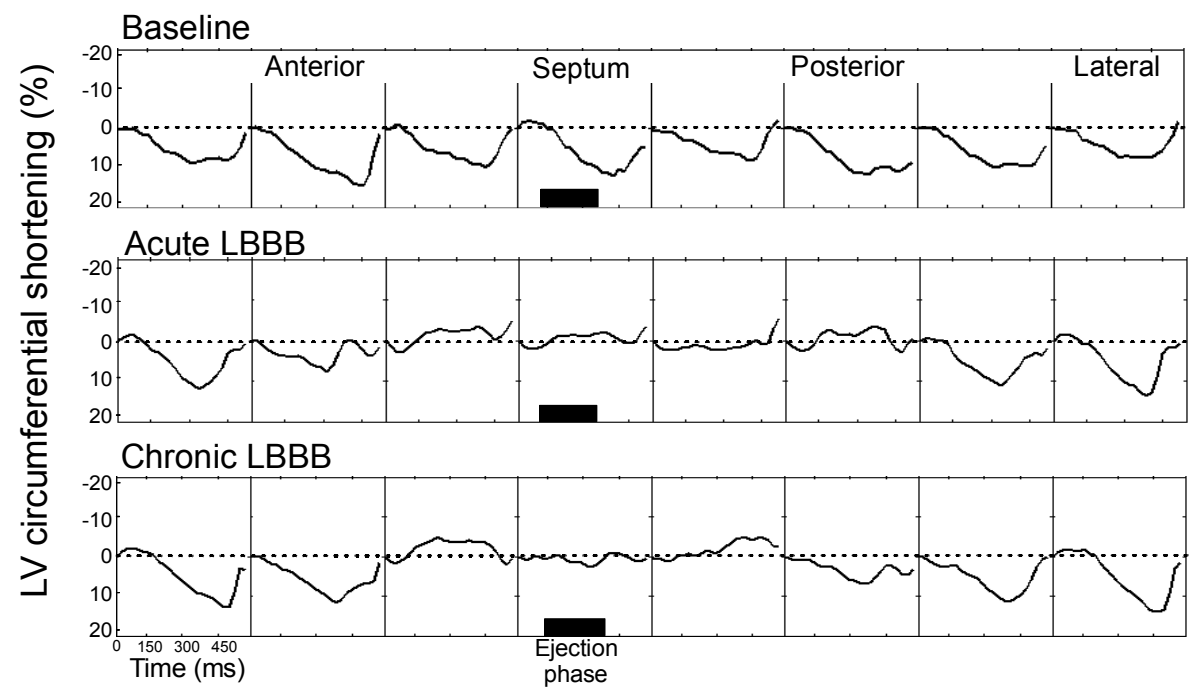

Figure 2. Typical examples of circumferential shortening tracings in eight regions around the LV circumference of midbasal short-axis slides during baseline, acute and chronic LBBB. 


\section{Myocardial blood flow}

During baseline, MBF showed a well known heterogeneous distribution, ${ }^{23}$ but without significant differences between septum and LV lateral wall $(0.78 \pm 0.34$ and $0.76 \pm 0.36 \mathrm{ml} / \mathrm{min} / \mathrm{g}$, respectively). During acute and chronic LBBB MBF was consistently lower in the septum than in the LV lateral wall (figure 1, fifth row). Relative to baseline, MBF decreased by $17 \pm 16 \%$ in the septum but increased by $18 \pm 12 \%$ in the LV lateral wall during acute LBBB (figure $3 \mathrm{c}$ ). These changes resulted in a decrease of the LV septal-to-lateral MBF ratio from $1.28 \pm 0.34$ during baseline to $0.88 \pm 0.16$ and $0.66 \pm 0.20$ during acute and chronic LBBB, respectively. Regional MBF during chronic LBBB was not significantly different from acute LBBB. Immediately after starting biventricular pacing, after 16 weeks of LBBB, MBF distribution normalized as evidenced by a LV septal-to-lateral MBF ratio of $0.96 \pm 0.26$.

\section{Structural remodeling}

During 16 weeks of LBBB, LV EDV and wall mass gradually increased, indicating development of eccentric hypertrophy (table 2 and figure 4). Although both septal and LV lateral wall mass increased significantly during chronic LBBB (table 2), the septal-to-lateral wall mass ratio decreased by $6 \pm 9 \%$ (figure $4 b$ ), indicating asymmetry of hypertrophy. LV EF was reduced significantly within two weeks of LBBB, and tended to decrease further until 16 weeks of LBBB (table 2). The time courses of the relative changes in LV EDV, LV wall mass and LV EF are shown in figure 4. The time courses of LV EDV and LV $\mathrm{EF}$ of two individual dogs in figure $4 \mathrm{a}$ and $4 \mathrm{c}$ illustrate that the degree to which LBBB affected these variables differs between dogs.

Figure 5 shows that the tissue glycogen content, a measure for myocardial hibernation, was not significantly different between the septum and LV lateral wall (133 \pm 30 and $150 \pm 34 \mu \mathrm{mol} / \mathrm{g}$ dry weight, respectively) and not different from control myocardium ( $160 \pm 15 \mu \mathrm{mol} / \mathrm{g}$ dry weight).

\section{DISCUSSION}

The findings in the present study demonstrate that, in otherwise normal hearts, LBBB immediately and persistently induces mechanical asynchrony. As a consequence LBBB leads to reduction of LV ejection fraction and to redistribution of myocardial shortening and blood flow from the septum to the LV lateral wall. Because the patterns of redistribution of myocardial blood flow and external work are similar and remain constant over time and because there is no sign 

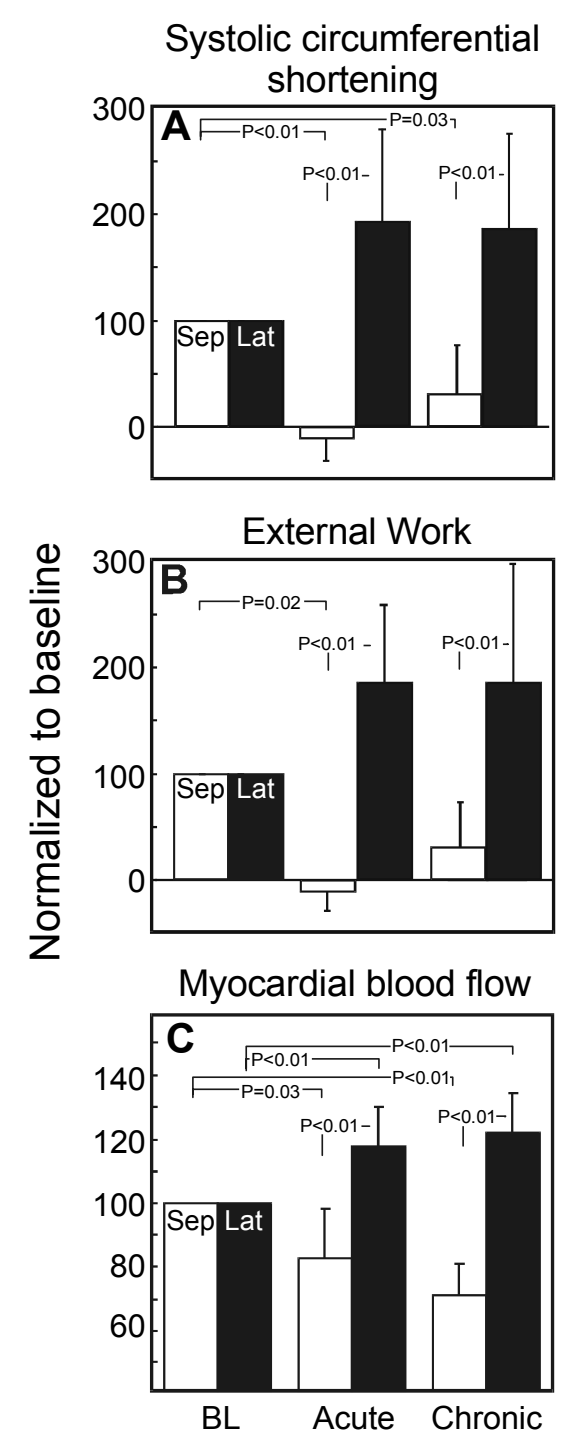

Figure 3. A) Regional LV systolic circumferential shortening, B) external work, and C) myocardial blood flow during baseline, acute and chronic LBBB in the septum (Sep, white bars) and the LV lateral wall (Lat, black bars). Data is normalized to regional baseline values. of hibernation in the septum, the septal underperfusion in LBBB hearts is most likely a functional adaptation to the reduced septal workload. On the long run, LBBB leads to LV dilatation and asymmetric hypertrophy. Therefore, during LBBB loss of pump function and hypertrophy appear to be a greater threat to long-term prognosis than the reduced septal blood flow.

\section{Structural remodeling}

The main part of the $20-30 \%$ dilatation and hypertrophy and the similar relative reduction in $\mathrm{LV}$ ejection fraction occurs within a few weeks of LBBB, but for all three variables a further progression over time is noticed. Comparative studies in patients with LBBB showed a more pronounced LV dilatation $(\sim 75 \%)$ and hypertrophy $(\sim 40 \%)$ and more reduced LV EF $(\sim 25 \%)$ relative to a control group. ${ }^{4,5}$ This more extensive LV remodeling in patients with $\mathrm{LBBB}$ may be due to longer existence of LBBB and presence of other concomitant diseases, i.e. valvular insufficiencies and myocardial infarction. ${ }^{4,5}$ While these patient studies can not distinguish between LBBB as cause or consequence of ventricular remodeling, our data demonstrates that LBBB solely can initiate remodeling in a normal heart. Also, asynchronous ventricular activation induced by pacing the LV free wall caused ven- 
tricular dilatation and asymmetric hypertrophy. ${ }^{10}$

Ventricular hypertrophy and dilatation are known to contribute to the development of heart failure, but the extent and duration of hypertrophy associated with onset of heart failure vary per animal model and disease. In dogs for example, pressure and volume overload hypertrophy require at least $50 \%$ hypertrophy before heart failure develops ${ }^{24}$ whereas hardly any hypertrophy is present in the rapid pacing model of heart failure. ${ }^{25}$ The $\sim 20 \%$ hypertrophy in our LBBB model is similar to the degree of hypertrophy induced by coronary occlusion in canine hearts leading to a $20 \%$ infarct size, but infarcted hearts dilated more pronouncedly. ${ }^{26}$ The $\sim 30 \%$ ventricular dilatation, observed in our canine LBBB hearts, is slightly more pronounced than the dilatation observed in patients with sinus node dysfunction treated with RV pacing, ${ }^{27}$ which results in a similar activation pattern as LBBB. These patients developed over a mean follow-up time of 5.5 years significantly more heart failure than patients treated with atrial pacing. ${ }^{27}$ Similarly, in patients with indications for implantable cardioverter defibrillator therapy, but no pacing indications, ventricular pacing increased the incidence of heart failure compared to ventricular back-up pacing. ${ }^{28}$ Therefore, the reduction in LV pump function and ventricular remodeling induced by long-term asynchronous ventricular activation, might play a role in the high incidence of heart failure in patients with LBBB. ${ }^{1-3}$

The observation that even in our study the degree of ventricular remodeling differed between dogs (figure 4) suggests that individual hearts may have different sensitivity to abnormal conduction. After all, we created LBBB in a controlled way and interindividual variation in QRS duration, as well as inter- and intraventricular asynchrony was small.

The small but significant asymmetrical hypertrophy after 16 weeks of LBBB is most likely due to the redistribution of workload, as evidenced by the regional differences in systolic circumferential shortening and external work (figure 3). ${ }^{10}$ A similar degree of asymmetry of hypertrophy was observed in patients with $\mathrm{LBBB}^{5}$ and in dogs with RV pacing. ${ }^{21}$ Regional differences in macroscopic hypertrophy were related to regional differences in myocyte diameter without differences in regional collagen content, ${ }^{10,22}$ indicating that the hypertrophy is due to a proportional increase of myocyte and collagen volume.

\section{Septal perfusion}

Using the gold-standard for regional myocardial blood flow measurements (microspheres), ${ }^{29}$ the present study demonstrates considerable and consistent redistribution of myocardial blood flow due to LBBB. A similar myocardial blood flow redistribution has been observed during ventricular pacing, 
$58 \mid$ Chapter 4

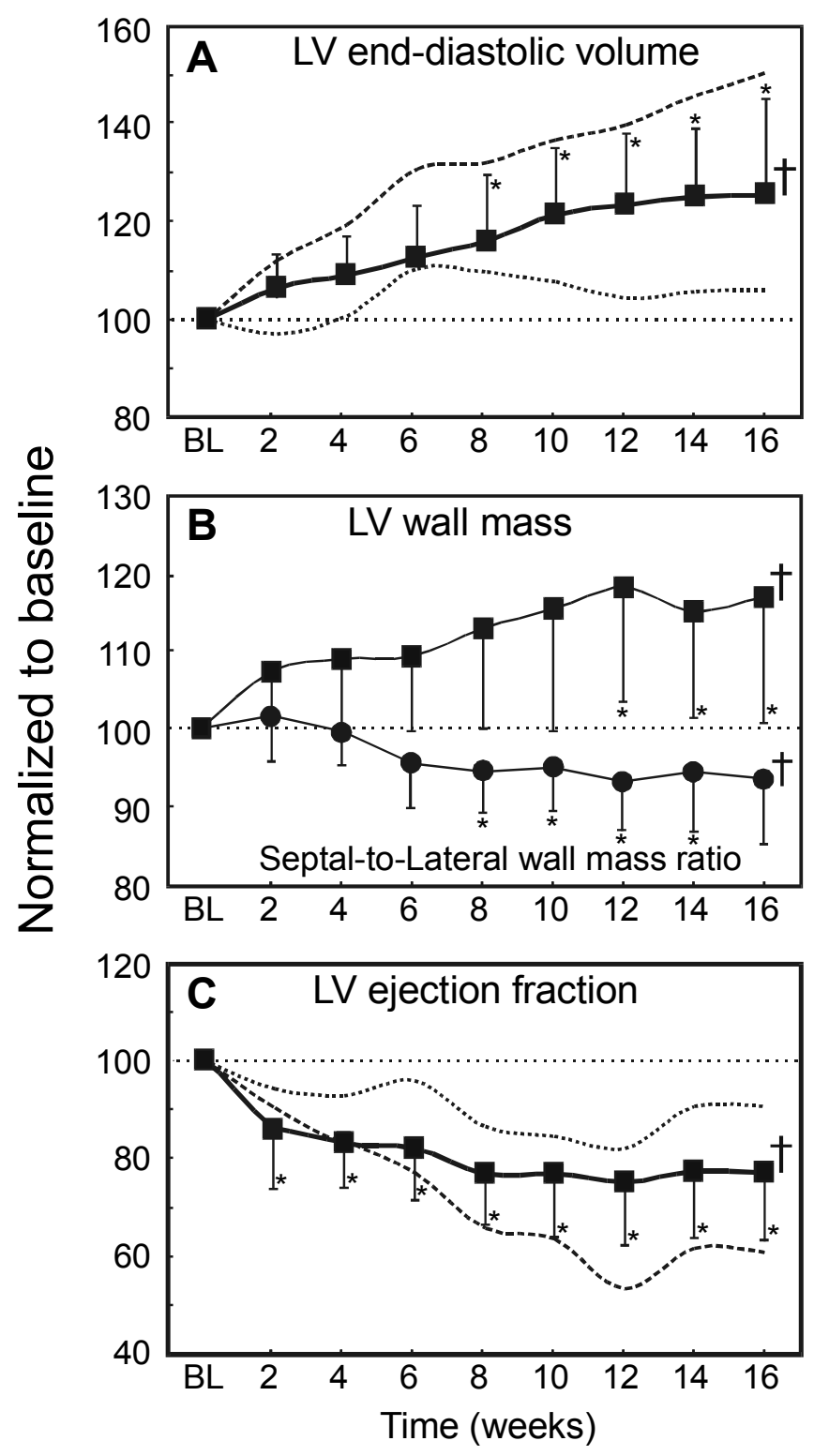

Figure 4. Changes in A) LV end-diastolic volume, in B) LV wall mass (-) and LV septal-to-lateral wall mass ratio $(\bullet)$ and in $\mathbf{C}) \mathrm{LV}$ ejection fraction during 16 weeks of LBBB. The dotted and striped lines in $\mathbf{A}$ and $\mathbf{C}$ indicate the time courses of two individual dogs, who were least and most sensitive to LBBB. $\uparrow$ Significant change over time by ANOVA; * $\mathrm{P}<0.05$ compared to baseline. 
indicating the role of the asynchrony of activation. ${ }^{7,11,12,30,31}$ Both situations reveal reduced blood flow in early-activated regions and increased blood flow in late-activated regions. In contrast to long-term pacing at the LV lateral wall, ${ }^{11}$ the distribution of blood flow in the present study did not normalize during chronic LBBB. This may be related to the more pronounced asymmetry of hypertrophy during long-term LV pacing. This large asymmetry $(\sim 40 \%)$ matched the regional differences in initial blood flow reduction and mechanical load. ${ }^{11}$ Therefore, the small degree of asymmetry of hypertrophy during

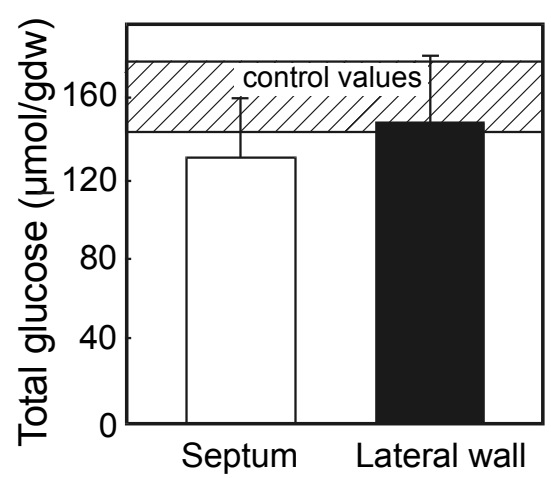

Figure 5. Glycogen content ( $\mu \mathrm{mol}$ glucose per gram dry weight) in the septum and LV lateral wall after 16 weeks of LBBB and in normal untreated control dog hearts (indicated by hatched area).

LBBB explains why septal perfusion remains reduced over time. It

is not well understood why asymmetry of hypertrophy differs between chronic LBBB and LV pacing, because the degree of mechanical differences as well as acute blood flow changes appear similar.

The reduced septal blood flow in LBBB patients has been frequently described, ${ }^{7,8,32,33}$ although the degree of reduction of septal perfusion varies between studies. ${ }^{13} \mathrm{~N}$-ammonia PET perfusion studies showed virtually normal septal perfusion, ${ }^{34,35}$ whereas in nuclear (thallium, SPECT) perfusion studies the reduction was similar to that observed in the present study. ${ }^{4,836}$ Methodological factors, like the kind of tracer and image analysis employed and the use of exercise or a vasodilating agent may underlie these differences. In the present study measurements were made in rest and without a vasoactive agent.

The functional implication of reduced septal perfusion in LBBB hearts is under debate. Some investigators suggest that reduced perfusion in early activated regions is due to restriction of blood flow by the abnormal contraction pattern. ${ }^{7,812,32}$ To some extent such restriction might play a role, since underperfusion is more pronounced at higher heart rates, ${ }^{32}$ probably because at high heart rates the asynchronous contraction leaves less diastolic time for perfusion. However, considerable and/or frequent restriction of septal perfusion would have lead to stunning or hibernation. The present study shows that stunning is unlikely to occur, because systolic shortening does not deteriorate during longer lasting LBBB. There are also no biochemical signs of hibernation. Hibernation, 


\section{0 \\ Chapter 4}

characterized by myocyte dedifferentiation due to longer lasting mild to moderate underperfusion, can increase myocardial glycogen three-fold. ${ }^{37}$ No signs of glycogen accumulation were observed in this study, where measurement error was $<10 \%$ of normal glycogen values. The lack of hibernation is in agreement with a good balance between oxygen supply and demand in asynchronously activated ventricles has been found previously during acute ventricular pacing. Throughout paced ventricles regional systolic shortening, mechanical work and oxygen uptake are mutually related to each other. Moreover, under these conditions no lactate release occurs ${ }^{38}$ and complete vasodilation attenuates the abnormal blood flow distribution, ${ }^{39}$ suggesting that the coronary autoregulation is responsible for the effects. This is further supported by the immediate normalization of blood flow distribution upon resynchronization the activation in chronic LBBB hearts.

Therefore, the reduced septal contractility in the presence of reduced contractile performance, as frequently reported in patients, does not exclude adequate septal perfusion. Rather, the reduced septal perfusion during LBBB appears to be the result of autoregulation following a reduction in local oxygen demand in early activated myocardium.

Table 1. Electrophysiologic and hemodynamic parameters

\begin{tabular}{lccc}
\hline & baseline & acute LBBB & chronic LBBB \\
\cline { 2 - 4 } Heart rate (bpm) & $101 \pm 17$ & $121 \pm 47$ & $88 \pm 30$ \\
QRS duration (ms) & $65 \pm 10$ & $117 \pm 13^{*}$ & $120 \pm 11^{*}$ \\
PQ interval (ms) & $108 \pm 23$ & $101 \pm 15$ & $102 \pm 11$ \\
Intraventricular asynchrony (ms) & $12 \pm 2$ & $26 \pm 6^{*}$ & $25 \pm 1^{*}$ \\
Cardiac Output (L/min) & $3.3 \pm 1.1$ & $2.0 \pm 0.9^{*}$ & $3.2 \pm 1.3$ \\
LV SP (mmHg) & $101 \pm 17$ & $121 \pm 47$ & $88 \pm 30$ \\
LV EDP (mmHg) & $8 \pm 6$ & $6 \pm 7$ & $8 \pm 5$ \\
LVdP/dt|max (mmHg/s) & $1803 \pm 909$ & $1313 \pm 446$ & $1552 \pm 580$ \\
LVdP/dt|min (mmHg/s) & $-1975 \pm 624$ & $-1423 \pm 602^{*}$ & $-1516 \pm 379 *$ \\
Interventricular asynchrony (ms) & $-6 \pm 9$ & $-28 \pm 9 *$ & $-22 \pm 8^{*}$ \\
\hline
\end{tabular}

$\mathrm{LV} \mathrm{SP}=\mathrm{LV}$ systolic pressure $\mathrm{LV}$ EDP $=\mathrm{LV}$ end-diastolic pressure, $\mathrm{LVdP} / \mathrm{dt} \mid \max =\operatorname{maximal}$ rate of $\mathrm{LV}$ pressure rise, $\mathrm{LVdP} / \mathrm{dt} \mid \mathrm{min}=$ maximal rate of $\mathrm{LV}$ pressure decline. ${ }^{*} \mathrm{p}<0.05$ compared to baseline 


\section{Limitations}

The present study shows that in normal dog hearts LBBB can reduce septal perfusion and can cause ventricular remodeling. However, these findings do not exclude the possibility that ventricular remodeling, induced by other disease processes, can cause LBBB or that septal underperfusion can cause LBBB, but clearly indicate that LBBB should be considered as a mechanism of these changes.

In this animal model, LBBB is generated by ablation of the proximal left bundle branch. The LV endocardial activation and the myocardial shortening maps indicate that this ablation was sufficient to force the electrical impulse to be conducted through the LV wall by predominantly slow myocardial conduction as opposed to the rapid conduction through the Purkinje system. In patients, however, variable patterns of LBBB are present. ${ }^{40}$ Differences in the sequence of activation of the ventricles are likely to affect the distribution of myocardial shortening and blood flow, but to what extent this would also affect ventricular performance or remodeling is not clear.

Although no untreated control group was used, it is known from previous animal experiments in our laboratory that myocardial blood flow and LV geometry remain constant over time. ${ }^{10,11}$

Table 2: Echocardiographic parameters

\begin{tabular}{lccc}
\hline & baseline & 2 wks LBBB & Chronic LBBB \\
\cline { 2 - 4 } LV EDV $(\mathrm{mL})$ & $104 \pm 31$ & $110 \pm 36$ & $135 \pm 53^{*}$ \\
LV wall mass (gram) & $126 \pm 31$ & $135 \pm 37$ & $145 \pm 30^{*}$ \\
LV EF $(\%)$ & $43 \pm 4$ & $37 \pm 8^{*}$ & $33 \pm 6^{*}$ \\
\hline
\end{tabular}

$\mathrm{LV} E D V=$ left ventricular end diastolic volume; $\mathrm{EF}=$ ejection fraction. ${ }^{*} \mathrm{p}<0.05$ compared to baseline

\section{CONCLUSions}

LBBB induces immediate and persistent LV asynchronous electrical activation, reduced LV pump function and redistribution in LV myocardial blood flow, systolic circumferential shortening and external work. The parallel decrease in septal blood flow and myocardial work, their constancy over time and the absence of hibernation in the septum indicates that the reduced septal work appears the major determinant of septal hypoperfusion during LBBB. Therefore, 


\section{2 \\ Chapter 4}

the contractile dyscoordination during LBBB appears to play an important role in the development of LV dilatation and hypertrophy.

\section{ACKNOWLEDGEMENTS}

The authors are indebted to Arne van Hunnik and Theo van der Nagel for their technical assistance during the experiments and to Benjamin Burgers for his biochemical assistance. Also, the contribution of Anneke van Susteren to the MR tagging data analysis is appreciated.

The study was financially supported by grants from the Netherlands Heart Foundation (2000.189 and 2000.227) and The Netherlands Organization for Health Research and Development (KV).

\section{REFERENCES}

1 Casiglia E, Spolaore P, Ginocchio G, Marchioro M, Mazza A, di Menza G, Maniati G, Daskalakis C, Colangeli G, Ambrosio GB. Mortality in relation to Minnesota code items in elderly subjects. Sex-related differences in a cardiovascular study in the elderly. Jpn Heart J. 1993;34:567-577.

2 Baldasseroni S, Opasich C, Gorini M, Lucci D, Marchionni N, Marini M, Campana C, Perini G, Deorsola A, Masotti G, Tavazzi L, Maggioni AP. Left bundle-branch block is associated with increased 1-year sudden and total mortality rate in 5517 outpatients with congestive heart failure: a report from the Italian network on congestive heart failure. Am Heart J. 2002;143:398-405.

3 Schneider JF, Thomas HE, Jr., Kreger BE, McNamara PM, Kannel WB. Newly acquired left bundle-branch block: the Framingham study. Ann Intern Med. 1979;90:303-310.

4 Bavelaar-Croon CD, Wahba FF, Van Hecke MV, Atsma DE, Stokkel MP, Pauwels EK, Van der Wall EE. Perfusion and functional abnormalities outside the septal region in patients with left bundle branch block assessed with gated SPECT. Q J Nucl Med. 2001;45:108-114.

5 Prinzen FW, Cheriex EC, Delhaas T, van Oosterhout MF, Arts T, Wellens HJ, Reneman RS. Asymmetric thickness of the left ventricular wall resulting from asynchronous electric activation: a study in dogs with ventricular pacing and in patients with left bundle branch block. Am Heart J. 1995;130:1045-1053.

6 Hamby RI, Weissman RH, Prakash MN, Hoffman I. Left bundle branch block: a predictor of poor left ventricular function in coronary artery disease. Am Heart J. 1983;106:471-477.

7 Hirzel HO, Senn M, Nuesch K, Buettner C, Pfeiffer A, Hess OM, Krayenbuehl HP. Thallium-201 scintigraphy in complete left bundle branch block. Am J Cardiol. 1984;53:764-769.

8 Hasegawa S, Sakata Y, Ishikura F, Hirayama A, Kusuoka H, Nishimura T, Kodama K. Mechanism for abnormal thallium-201 myocardial scintigraphy in patients with left bundle branch block in the absence of angiographic coronary artery disease. Ann Nucl Med. 1999;13:253-259.

9 Littmann L, Symanski JD. Hemodynamic implications of left bundle branch block. J Electrocardiol. 2000;33:115-121. 
10 van Oosterhout MF, Prinzen FW, Arts T, Schreuder JJ, Vanagt WY, Cleutjens JP, Reneman RS. Asynchronous electrical activation induces asymmetrical hypertrophy of the left ventricular wall. Circulation. 1998;98:588-595.

11 van Oosterhout MF, Arts T, Bassingthwaighte JB, Reneman RS, Prinzen FW. Relation between local myocardial growth and blood flow during chronic ventricular pacing. Cardiovase Res. 2002;53:831-840.

12 Ono S, Nohara R, Kambara H, Okuda K, Kawai C. Regional myocardial perfusion and glucose metabolism in experimental left bundle branch block. Circulation. 1992;85:1125-1131.

13 Peschar M, Vernooy K, Vanagt WY, Reneman RS, Vos MA, Prinzen FW. Absence of reverse electrical remodeling during regression of volume overload hypertrophy in canine ventricles. Cardiovasc Res. 2003;58:510-517.

14 Verbeek XAAM, Vernooy K, Peschar M, Van Der Nagel T, Van Hunnik A, Prinzen FW. Quantification of interventricular asynchrony during LBBB and ventricular pacing. Am J Physiol Heart Circ Physiol. 2002;283:H1370-1378.

15 Prinzen FW, Van der Vusse GJ, Arts T, Roemen TH, Coumans WA, Reneman RS. Accumulation of nonesterified fatty acids in ischemic canine myocardium. Am J Physiol. 1984;247:H264-272.

16 Verbeek XAAM, Vernooy K, Peschar M, Cornelussen RNM, Prinzen FW. Intra-ventricular resynchronization for optimal left ventricular function during pacing in experimental left bundle branch block. J Am Coll Cardiol. 2003;42:558-567.

17 Van Der Toorn A, Barenbrug P, Snoep G, Van Der Veen FH, Delhaas T, Prinzen FW, Maessen J, Arts T. Transmural gradients of cardiac myofiber shortening in aortic valve stenosis patients using MRI tagging. Am J Physiol Heart Circ Physiol. 2002;283:H1609-1615.

18 Breithardt OA, Stellbrink C, Herbots L, Claus P, Sinha AM, Bijnens B, Hanrath P, Sutherland GR. Cardiac resynchronization therapy can reverse abnormal myocardial strain distribution in patients with heart failure and left bundle branch block. J Am Coll Cardiol. 2003;42:486-494.

19 Prinzen FW, Hunter WC, Wyman BT, McVeigh ER. Mapping of regional myocardial strain and work during ventricular pacing: experimental study using magnetic resonance imaging tagging. J Am Coll Cardiol. 1999;33:1735-1742.

20 Jansson E. Acid soluble and insoluble glycogen in human skeletal muscle. Acta Physiol Scand. 1981;113:337-340.

21 van Oosterhout MF, Arts T, Muijtjens AM, Reneman RS, Prinzen FW. Remodeling by ventricular pacing in hypertrophying dog hearts. Cardiovasc Res. 2001;49:771-778.

22 Peschar M, van Oosterhout MF, Willems J, Roussea AMJ, Glatz JFC, Reneman RS, Prinzen FW. Metabolic remodeling in global and regional hypertrophy of the canine heart. 2003 (thesis).

23 Bassingthwaighte JB, Beard DA, Li Z. The mechanical and metabolic basis of myocardial blood flow heterogeneity. Basic Res Cardiol. 2001;96:582-594.

24 Tagawa H, Koide M, Sato H, Zile MR, Carabello BA, Cooper Gt. Cytoskeletal role in the transition from compensated to decompensated hypertrophy during adult canine left ventricular pressure overloading. Circ Res. 1998;82:751-761.

25 Howard RJ, Moe GW, Armstrong PW. Sequential echocardiographic-Doppler assessment of left ventricular remodelling and mitral regurgitation during evolving experimental heart failure. Cardiovasc Res. 1991;25:468-474.

26 Jugdutt BI, Tang SB, Khan MI, Basualdo CA. Functional impact of remodeling during healing after non-Q wave versus $Q$ wave anterior myocardial infarction in the dog. J Am Coll Cardiol. 1992;20:722-731.

27 Nielsen JC, Andersen HR, Thomsen PE, Thuesen L, Mortensen PT, Vesterlund T, Pedersen AK. Heart failure and echocardiographic changes during long-term follow-up of patients 


\section{4 \\ Chapter 4}

with sick sinus syndrome randomized to single-chamber atrial or ventricular pacing. Circulation. 1998;97:987-995.

28 Wilkoff BL, Cook JR, Epstein AE, Greene HL, Hallstrom AP, Hsia H, Kutalek SP, Sharma A. Dual-chamber pacing or ventricular backup pacing in patients with an implantable defibrillator: the Dual Chamber and VVI Implantable Defibrillator (DAVID) Trial. Jama. 2002;288:3115-3123.

29 Prinzen FW, Bassingthwaighte JB. Blood flow distributions by microsphere deposition methods. Cardiovasc Res. 2000;45:13-21.

30 Delhaas T, Arts T, Prinzen FW, Reneman RS. Regional fibre stress-fibre strain area as an estimate of regional blood flow and oxygen demand in the canine heart. J Physiol. 1994;477 ( Pt 3):481-496.

31 Prinzen FW, Augustijn CH, Arts T, Allessie MA, Reneman RS. Redistribution of myocardial fiber strain and blood flow by asynchronous activation. Am J Physiol. 1990;259:H300-308.

32 Skalidis EI, Kochiadakis GE, Koukouraki SI, Parthenakis FI, Karkavitsas NS, Vardas PE. Phasic coronary flow pattern and flow reserve in patients with left bundle branch block and normal coronary arteries. J Am Coll Cardiol. 1999;33:1338-1346.

33 Inanir S, Caymaz O, Okay T, Dede F, Oktay A, Deger M, Turgut Turoglu H. Tc-99m sestamibi gated SPECT in patients with left bundle branch block. Clin Nucl Med. 2001;26:840-846.

34 Zanco P, Desideri A, Mobilia G, Cargnel S, Milan E, Celegon L, Buchberger R, Ferlin G. Effects of left bundle branch block on myocardial FDG PET in patients without significant coronary artery stenoses. J Nucl Med. 2000;41:973-977.

35 Neri G, Zanco P, Zanon F, Buchberger R. Effect of biventricular pacing on metabolism and perfusion in patients affected by dilated cardiomyopathy and left bundle branch block: evaluation by positron emission tomography. Europace. 2003;5:111-115.

36 Nowak B, Sinha AM, Schaefer WM, Koch KC, Kaiser HJ, Hanrath P, Buell U, Stellbrink C. Cardiac resynchronization therapy homogenizes myocardial glucose metabolism and perfusion in dilated cardiomyopathy and left bundle branch block. J Am Coll Cardiol. 2003;41:1523-1528.

37 Heusch G. Hibernating myocardium. Physiol Rev. 1999;13:253-259.

38 Delhaas T, Arts T, Prinzen FW, Reneman RS. Phasic coronary flow and flow reserve in the canine heart. J Physiol. 1999;33:481-496.

39 Amitzur G, Manor D, Pressman A, Adam D, Hammerman H, Shofti R, Beyar R, Sideman S. Modulation of the arterial coronary blood flow by asynchronous activation with ventricular pacing. Pacing Clin Electrophysiol. 1995;18:697-710.

40 Rodriguez LM, Timmermans C, Nabar A, Beatty G, Wellens HJ. Variable patterns of septal activation in patients with left bundle branch block and heart failure. J Cardiovasc Electrophysiol. 2003;14:135-141. 


\section{Chapter 5}

\section{Intraventricular resynchronization for optimal left ventricular function during pacing in experimental left bundle branch block}

Xander A.A.M. Verbeek, PhD, Kevin Vernooy, MD, Maaike Peschar, $\mathrm{PhD}$, Richard N.M. Cornelussen, PhD, and Frits W. Prinzen, PhD

Department of Physiology, Cardiovascular Research Institute Maastricht, Maastricht, the Netherlands

Journal of the American College of Cardiology 2003 Aug 6;42(3):55867. 
$66 \mid$ Chapter 5

\section{Abstract}

Objective. To investigate to what extent intraventricular (intraVA) and interventricular asynchrony (interVA) determine LV function in canine hearts with left bundle branch block (LBBB) during ventricular pacing.

Background. Pacing therapy improves left ventricular (LV) pump function in patients with heart failure and abnormal ventricular conduction, supposedly due to resynchronization. However, the relation between LV pump function and measures of asynchrony is not well established.

Methods. In 15 experiments LV (various sites) and BiV pacing was performed at AV-delays of $20-140 \mathrm{~ms}$. Measured were $\mathrm{LVdP} /\left.\mathrm{dt}\right|_{\max }$ and stroke work (SW, conductance catheter), interVA (time delay between the upslope of LV and RV pressures) and intraVA (from endocardial electrical activation maps).

Results. Induction of LBBB increased interVA $(-6.4 \pm 8.6$ to $-28.4 \pm 8.5 \mathrm{~ms}$ (RV earlier)) and intraVA (4.9 \pm 2.4 to $18.0 \pm 3.3 \mathrm{~ms})$ while $\mathrm{LVdP} /\left.\mathrm{dt}\right|_{\max }$ and $\mathrm{SW}$ decreased $(-13 \pm 18 \%$ and $-39 \pm 24 \%$, respectively). During LBBB, LV and BiV pacing increased $\mathrm{LVdP} /\left.\mathrm{dt}\right|_{\max }$ and $\mathrm{SW}$ (mean increases $14-21 \%$ and $11-15 \%$, respectively) without changing preload. Optimal improvement in LV function was obtained consistently when intraVA returned to pre-LBBB values while interVA remained elevated. Normalization of intraVA required AV-delays shorter than baseline PQ-time during LV apex and BiV pacing thus excluding endogenous LV activation, but AV-delays virtually equal to baseline PQ-time (difference $4 \pm 9 \mathrm{~ms}$, N.S.) during pacing at (mid)lateral LV sites in order to obtain fusion between pacing induced and endogenous activation.

Conclusions. In LBBB hearts optimal restoration of LV systolic function by pacing requires intraventricular resynchronization. The optimal AV-delay to achieve this depends on the site of pacing and on baseline PQ-time. 


\section{INTRODUCTION}

Recent clinical studies show that left ventricular (LV) and biventricular pacing (BiV) improve LV pump function in patients with heart failure in combination with conduction defects. ${ }^{1-5}$ The majority of the patients responding to this pacing therapy have left bundle branch block (LBBB). Also experiments in dogs with isolated LBBB show that $\mathrm{LV}$ and BiV pacing can improve LV function, indicating that proper modes of pacing can restore part of the LBBB induced impairment in LV pump function. ${ }^{6,7}$

The positive impact of pacing therapy on LV pump function has been attributed to "resynchronization" of ventricular activation. In order to optimize pacing therapy, some studies focused on minimization of the QRS-duration which is considered as a measure for total ventricular asynchrony. Although improved LV pump function has been associated reduced QRS-duration with improved LV function ${ }^{8,9}$ others revealed that optimal improvement of LV function occurs at unchanged or even increased QRS-duration. ${ }^{3,10}$ Alternatively, intraventricular and interventricular asynchrony have been proposed as determinants of pump function, but also here conflicting results are reported as to which of these parameters requires resynchronization. ${ }^{10-15}$ Furthermore, simultaneous $\mathrm{BiV}$ pacing has been applied in order to resynchronize activation of the ventricles but some studies show that LV pacing alone results in similar hemodynamic benefit. ${ }^{1,2}$ Thus, it is still unknown what property of ventricular activation should be normalized. As a consequence it is also not clear what the best strategy of pacing is in failing hearts with LBBB.

The aim of the present study was to explore the mechanism of improvement in LV pump function during LV-based pacing of hearts with LBBB and the role of total (QRS duration), inter or intraventricular resynchronization. Moreover, we investigated how the mechanism of hemodynamic improvement determines the pacing strategy (pacing site(s) and AV-delay). To this purpose pacing was performed in canine hearts with experimental $\mathrm{LBBB}^{7}$ at four LV sites, the RV apex and simultaneously at the RV and LV apex (BiV pacing) using a large number of AV-delays. Changes in LV systolic function parameters (pressurevolume relations) were correlated to direct, accurate measures of inter and intraventricular asynchrony.

\section{METHODS}

Animal handling was performed according to the Dutch Law on Animal Experimentation (WOD) and the European Directive for the Protection of Verte- 


\section{8 \\ Chapter 5}

brate Animals used for Experimental and other Scientific Purposes (86/609/EU). The protocol was approved by the Experimental Animal Committee of the Maastricht University.

\section{Preparation}

Fifteen dogs were premedicated and anesthetized as described previously. ${ }^{7}$ ECG was recorded from the limb leads. LV pressure and volume were measured using a 7F combined cathetertip manometer and conductance catheter and RV pressure with a 7F cathetertip manometer (Sentron). For assessment of LV endocardial activation maps, a basket catheter (EPT Constellation TM) consisting of eight flexible splines with 8 electrodes each (inter electrode distance $=7 \mathrm{~mm}$ ) was unfolded in the LV. After opening the chest temporary pacing leads (Medtronic, type 6500) were attached to the right atrium and the epicardium of the LV apex, anterior, lateral and posterior wall while another lead was positioned transvenously into the RV apex. Pacing was performed with an external pacemaker (Medtronic AV pacing System Analyzer Model 5311B) connected to the $\mathrm{RV}$ apex electrode and to a four channel external pulse stimulator (Medtronic, model 2883). The four LV electrodes were connected to the external pulse stimulator. The external pacemaker was programmed in the VDD mode so that atrial sensing was used to govern the rate of ventricular pacing. The pacing electrodes served as cathode and an indifferent electrode as anode.

\section{Protocol}

After completion of the preparation and after a stabilization period measurements of hemodynamics and ECG and endocardial activation mapping were performed. Subsequently, LBBB was induced with use of RF ablation. To this purpose a Medtronic MarinR ablation catheter was introduced into the carotid artery and, under fluoroscopic control, advanced through the aortic valve until its tip was positioned against the basal septum. Guided by the electrogram, derived from the tip, the left bundle branch was located (evidenced by a sharp spike preceding the Q-wave) and subsequently ablated using a Medtronic AtakR ablation unit. After a 15-30 min stabilization period measurements were performed during VDD pacing at the five ventricular sites alone and during simultaneous biventricular (RV apex $+\mathrm{LV}$ apex, $\mathrm{BiV}$ ) pacing at $\mathrm{AV}$-delays ranging from $20 \mathrm{~ms}$ to $140 \mathrm{~ms}$, alternated with baseline LBBB measurements.

Successful pre and post LBBB measurements were acquired in 11 dogs and successful pacing measurements in 12 dogs. Endocardial mapping was performed directly after hemodynamic measurements in order to exclude interference of the basket catheter with LV function measurements. Because of contact problems good endocardial maps before and after creation of LBBB were ac- 
quired in 7 dogs and during pacing with a sufficient range of AV-delays in 5 animals.

\section{Data analysis}

Pressures and ECG signals were digitized at $200 \mathrm{~Hz}$ and stored on disk for offline analysis. Measurements were performed on all heartbeats within one ventilation cycle. The conductance catheter was connected with a Leycom Sigma 5DF signal conditioner processor (CardioDynamics) ${ }^{16}$ Calibration of absolute LV volume was performed by correcting for parallel conductance (using hypertonic saline injection) and calibrating stroke volume using thermodilution cardiac output. Data were analyzed using the CIRCLAB software package, developed by Dr. P. Steendijk, Leiden University Medical Center.

In addition to paced AV-delays, true AV-delays were calculated as the timing difference between the onset of the P-wave and the pacing stimulus in the ECG in order to account for differences in location of the atrial sensing lead between experiments. ${ }^{7}$

Excitation time difference (TVV) between the RV and LV during LV pacing was calculated as the difference between baseline LBBB PQ-time and true AV-delay (onset LV excitation). ${ }^{7}$ During BiV pacing TVV was assumed to be zero, except for the long AV-delays when endogenous activation (Q-wave) preceded the pacing stimulus.

InterVA was calculated as the timing difference between the upslopes of simultaneously recorded LV and RV pressure curves, estimated by cross correlation. ${ }^{7}$ Positive timing differences indicate an earlier LV than RV pressure rise.

Endocardial electrical activation maps were determined from unipolar endocardial electrograms recorded from the basket electrodes. Because of contact problems the basal three electrodes on each spline were discarded, thus providing activation maps of 2/3th of the LV long axis. From these maps the 2D Activation Delay Vector (ADV) was determined as a measure of intraVA in circumferential direction. ${ }^{17}$ The ADV amplitude was used as measure for intraVA and the ADV angle expresses the main direction of conduction.

Trans-septal conduction delay was calculated during LBBB as the timing difference between the Q-wave (onset RV activation during LBBB) and the first LV endocardial activation which was always on the septum, as has been used by Vassalo et al in human LBBB hearts. ${ }^{18}$ Transmural LV conduction delay was calculated as the first endocardial activation during epicardial LV pacing. 
$70 \mid$ Chapter 5

\section{Statistical analysis}

Statistical significance of the effect of induction of LBBB and of pacing in LBBB was evaluated using one way ANOVA for repeated measurements, followed by Tukey post-hoc testing for comparison between pacing sites. $\mathrm{P}<0.05$ was considered significant. Data are presented as mean \pm SD.

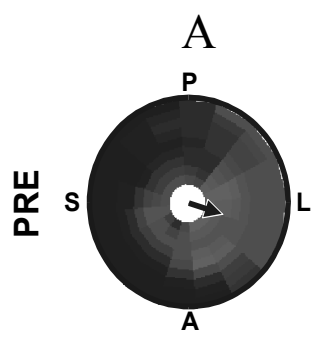

$\mathrm{B}$
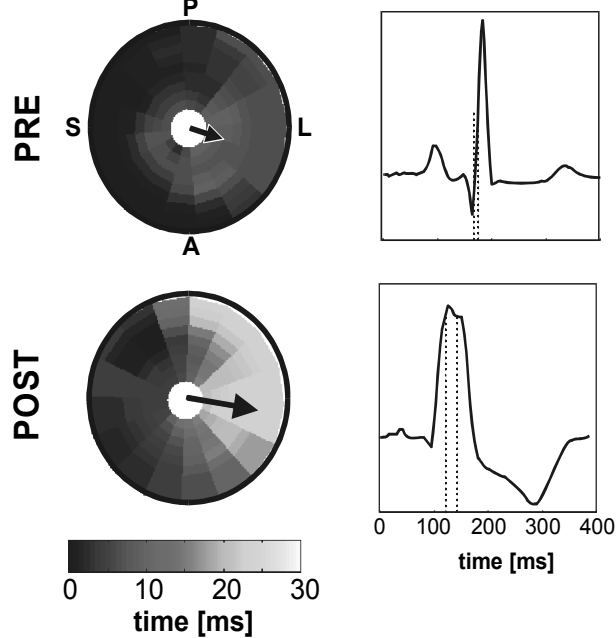

$\mathrm{C}$
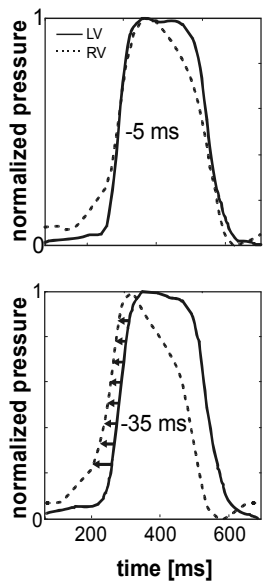

$\mathrm{D}$
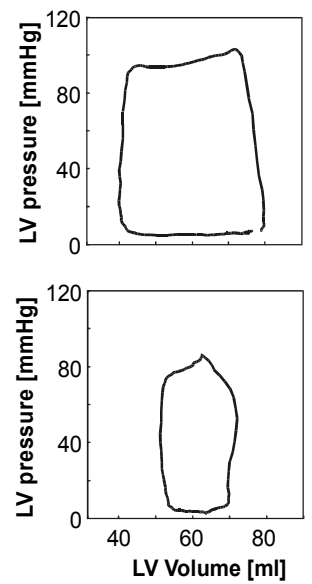

Figure 1. Examples of (A) LV endocardial activation maps with the ADV (B) ECG tracings, (C) RV and LV pressure signals and (D) pressure volume loops, before and after creation of LBBB. In (B) the earliest and latest LV endocardial activation are indicated by the dotted lines. In (C) RV and LV pressures are normalized in order to reveal timing differences. LV endocardial activation maps are presented as bulls-eye plots with the inner disc representing the LV apex and the outer circle disc the LV base and S,A.L.P representing septum, anterior, lateral and posterior wall, respectively.

\section{RESULTS}

\section{Creation of LBBB.}

Induction of LBBB increased QRS-duration as well as interVA and intraVA (figure 1, table 1). During LBBB, LV endocardial activation started at the septum and moved towards the lateral wall. The increased asynchrony consistently 
reduced stroke volume and stroke work as well as $\mathrm{LVdP} /\left.\mathrm{dt}\right|_{\max }$ but did not significantly affect LV and RV end systolic and end diastolic pressures nor LV end-diastolic volume (figure 1, table 1).

\section{Inter and intraventricular resynchronization during pacing}

Figure 2 shows interVA as a function of the AV-delay and TVV during LV apex, lateral wall and $\mathrm{BiV}$ pacing in one experiment. Results for $\mathrm{LV}$ anterior and posterior wall pacing were similar to those of LV lateral wall pacing. During $\mathrm{LV}$ pacing with decreasing AV-delay interVA increased linearly to positive values ( $\mathrm{LV}$ earlier than $\mathrm{RV})(\mathrm{r}=0.95 \pm 0.04$ for all experiments and $\mathrm{LV}$ sites). Interventricular resynchronization (interVA $=0$ ) was possible during pacing at all LV sites. Pacing the LV simultaneously with endogenous RV excitation $(\mathrm{TVV}=0)$ resulted in negative interVA values (figure $2 b$ ). Similarly, BiV pacing resulted in a fixed negative interVA per experiment, which was reached at AVdelays shorter than the baseline PQ-time, guaranteeing simultaneous LV and $\mathrm{RV}$ activation prior to endogenous activation (dotted line, figure 2a).

Endocardial activation maps showed that during pacing at short $\mathrm{AV}$-delays $(\mathrm{TVV}<<0)$ the electrical impulse propagated away from the pacing site (figure 3 , left panels). For LV anterior, lateral and posterior wall pacing this caused a large intraVA. Intraventricular resynchronization (intraVA=0) occurred when the endogenous activation wave merged with the pacing induced activation wave (TVV=0) (figure 3, middle panels). The fact that this occurred at TVV 0 during epicardial pacing could be explained by nearly identical transseptal and transmural conduction delays ( $34 \pm 7 \mathrm{~ms}$ and $37 \pm 7 \mathrm{~ms}$, respectively). During LV apex and $\mathrm{BiV}$ pacing intraventricular resynchronization was obtained at short $\mathrm{AV}$-delays while intraVA increased with increasing AV-delay (figure 3, upper and lower rows). For all pacing conditions, asynchrony in longitudinal direction (radial direction on polar plots) was small compared to that in circumferential direction.

For all pacing sites intraVA correlated linearly to interVA $(\mathrm{r}=0.94 \pm 0.05)$ with a significant intercept of $-19 \pm 10 \mathrm{~ms}$ indicating that intraventricular resynchronization did not coincide with interventricular resynchronization. 
$72 \mid$ Chapter 5
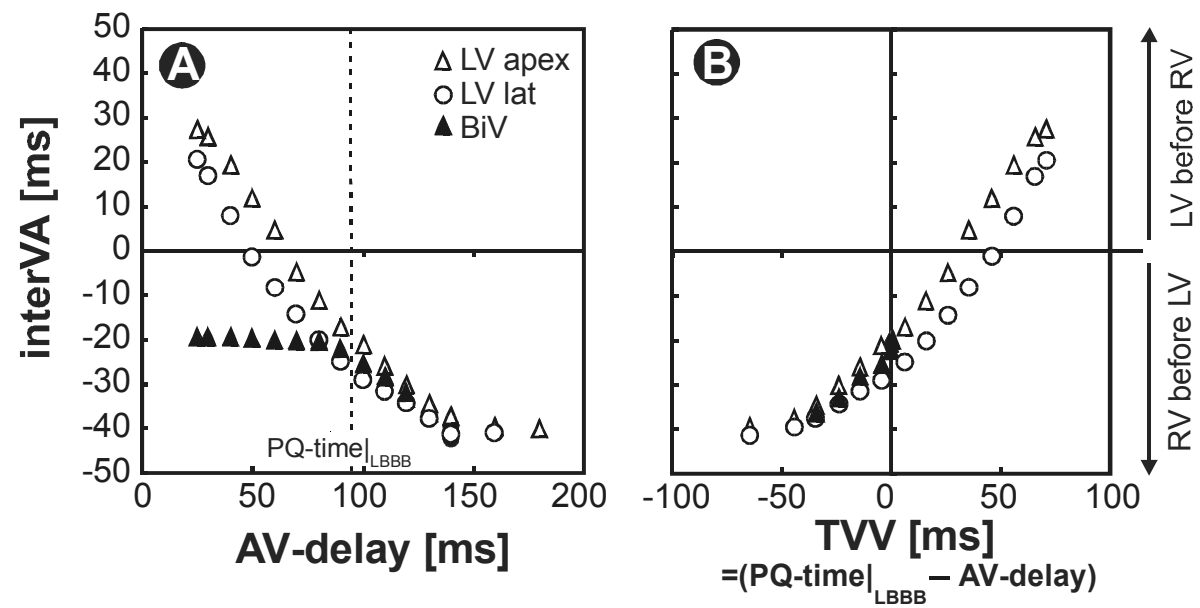

Figure 2. Interventricular asynchrony as function of (A) the paced AV-delay and (B) LV-RV excitation time difference (TVV) during LV apex, BiV and LV lateral wall pacing. Results for anterior and posterior wall pacing were comparable to those of lateral wall pacing.

\section{Hemodynamic changes during pacing and as a function of the AV-delay}

Typical examples of pressure-volume loops during LV pacing in LBBB hearts illustrate that pacing from various sites increased stroke work at essentially unchanged end-diastolic volume (figure 4). This figure illustrates that the optimal AV-delay varied between pacing sites.

Figure 5 shows the changes in $\mathrm{LVdP} /\left.\mathrm{dt}\right|_{\max }$ as a function of the paced AV-delay (left panels) and TVV (right panels) during LV apex pacing and LV lateral wall pacing for two experiments. Largest hemodynamic improvement occurred at short paced AV-delays during LV apex pacing, but at intermediate paced AV-delays during LV lateral wall pacing. During LV lateral wall pacing large differences in optimal paced AV-delay were observed between the two experiments, but this was due to differences in PQ-time, because optimal $\mathrm{LVdP} /\left.\mathrm{dt}\right|_{\max }$ was found consistently at $\mathrm{TVV}=0$ (figure 5 , right panels).

For the whole group of experiments $\mathrm{LVdP} /\left.\mathrm{dt}\right|_{\max }$ and stroke work increased significantly by $\mathrm{LV}$ and $\mathrm{BiV}$ pacing (mean increases ranging from 14 to $21 \%$ and 11 to $15 \%$ for $\mathrm{LVdP} /\left.\mathrm{dt}\right|_{\max }$ and $\mathrm{SW}$, respectively) with no significant differences between pacing sites except for a significantly larger $\mathrm{LVdP} /\left.\mathrm{dt}\right|_{\max }$ during LV apex pacing (table 2). RV apex pacing did not significantly increase $\mathrm{LVdP} /\left.\mathrm{dt}\right|_{\max }$ and SW. Pacing introduced no significant changes in LV systolic or 
end-diastolic pressure, end-diastolic volume or heart rate. During LV apex pacing optimal hemodynamic improvement occurred at TVV $>0$, while for all other LV pacing sites optimal hemodynamic improvement occurred at TVV not significantly different from zero.

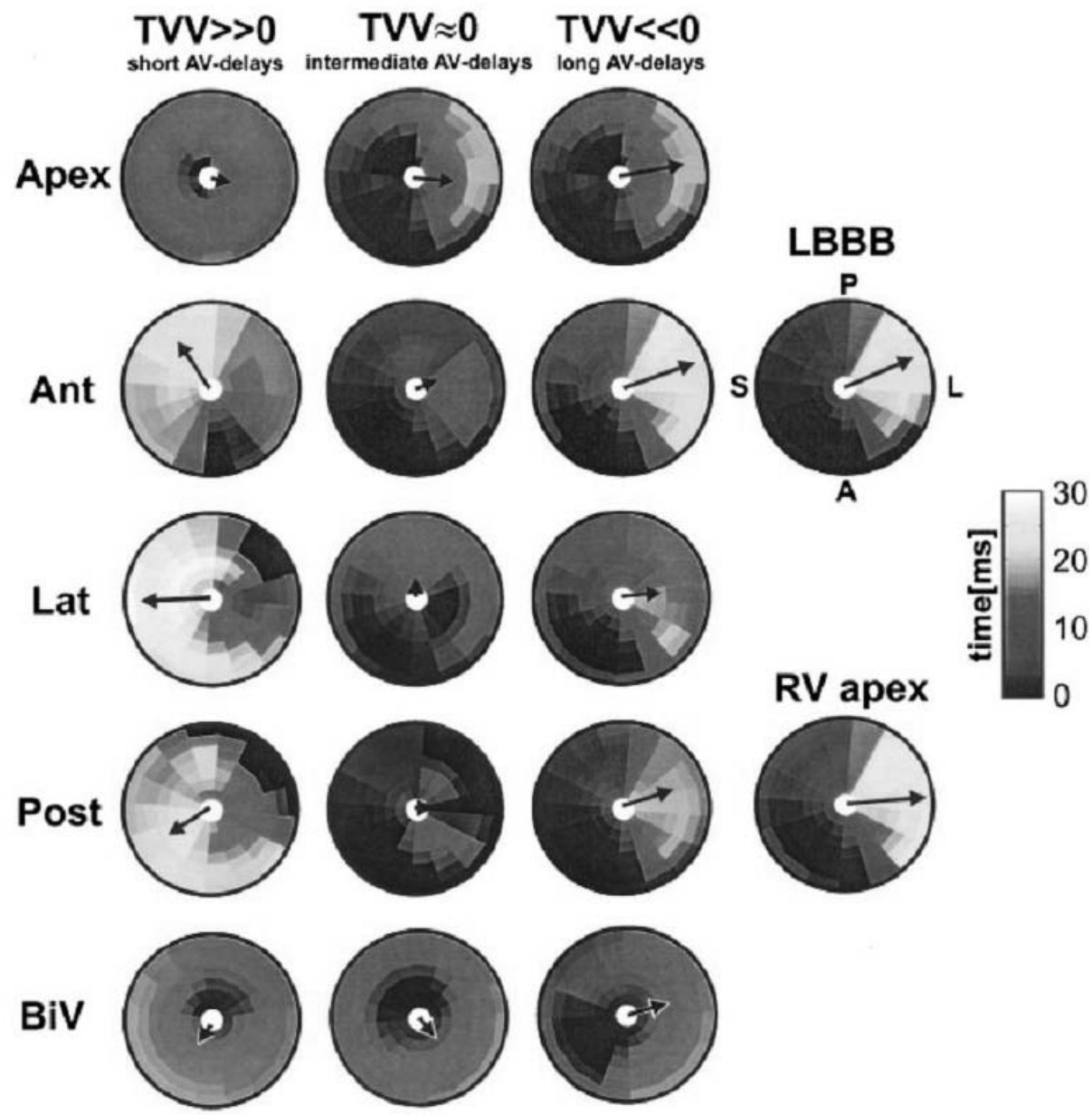

Figure 3. Examples of LV endocardial activation maps during LBBB and pacing at various LV sites and TVVs smaller, equal and larger than zero. Also presented is an example of LV endocardial activation during RV pacing at a short AV-delay. The black arrows denote the activation delay vectors, which amplitude reflects the degree of intraVA. 


\section{4 \\ Chapter 5}

\section{Relation between hemodynamic changes and asynchrony values}

Figure 6 shows changes in $\mathrm{LVdP} /\left.\mathrm{dt}\right|_{\max }$ versus interVA (figure 6a) and intraVA (figure $6 \mathrm{~b}$ ) measured at the different $\mathrm{AV}$-delays during $\mathrm{LV}$ apex, lateral wall and $\mathrm{BiV}$ pacing in one experiment. During $\mathrm{LV}$ apex pacing, $\mathrm{LVdP} /\left.\mathrm{dt}\right|_{\max }$ reached a plateau around interVA $=0 \mathrm{~ms}$, which extended to the most positive interVA values ( short $\mathrm{AV}$-delays), whereas during $\mathrm{BiV}$ pacing the highest $\mathrm{LVdP} /\left.\mathrm{dt}\right|_{\max }$ values were found at the fixed interVA values and during pacing the LV lateral wall a relatively sharp $\mathrm{LVdP} /\left.\mathrm{dt}\right|_{\max }$ peak occurred at negative interVA values (figure 6a). For all pacing sites, interVA at peak $\mathrm{LVdP} /\left.\mathrm{dt}\right|_{\max }$ varied between experiments but was always negative but the highest $\mathrm{LVdP} /\left.\mathrm{dt}\right|_{\max }$ values were observed at intraVA values close to zero (figure 6b).

For the whole group of experiments and all pacing sites except the RV apex, maximum hemodynamic improvement was obtained at intraVA values not significantly different from pre-LBBB values, while interVA was incompletely restored (range from -2 to $-32 \mathrm{~ms}$ ) and QRS-duration did not change significantly from LBBB values (figure 7). Results for anterior and posterior wall pacing (not shown) were similar to those for lateral wall pacing.

Table 1. Hemodynamic, inter- and intraventricular asynchrony values (mean $\pm \mathrm{SD}$ ) before and after induction of LBBB

\begin{tabular}{lcc}
\hline & Pre LBBB $(\mathrm{n}=11)$ & Post LBBB $(\mathrm{n}=11)$ \\
\cline { 2 - 3 } QRS (ms) & $66 \pm 8.4$ & $113 \pm 12.8^{*}$ \\
PQ-interval (ms) & $106 \pm 10$ & $103 \pm 19$ \\
interVA (ms) & $-6.4 \pm 8.6$ & $-28.4 \pm 8.5^{*}$ \\
intraVA (ms, n=7) & $4.6 \pm 2.2$ & $18.2 \pm 3.2 \dagger$ \\
HR (bpm) & $112 \pm 18$ & $131 \pm 33$ \\
LV SP (mmHg) & $99 \pm 17$ & $99 \pm 25$ \\
LV EDP (mmHg) & $7.7 \pm 5.4$ & $5.3 \pm 4.7$ \\
LVdP/dt|max (mmHg/s) & $1627 \pm 644$ & $1345 \pm 413^{*}$ \\
LV EDV (ml) & $94 \pm 49$ & $78 \pm 29$ \\
SV (ml) & $36.0 \pm 9.2$ & $22.0 \pm 5.2^{*}$ \\
SW (mmHg*ml) & $3480 \pm 1062$ & $1972 \pm 635^{*}$ \\
\hline
\end{tabular}

* paired t-test, $\uparrow$ unpaired t-test, $\mathrm{P}<0.05$ 

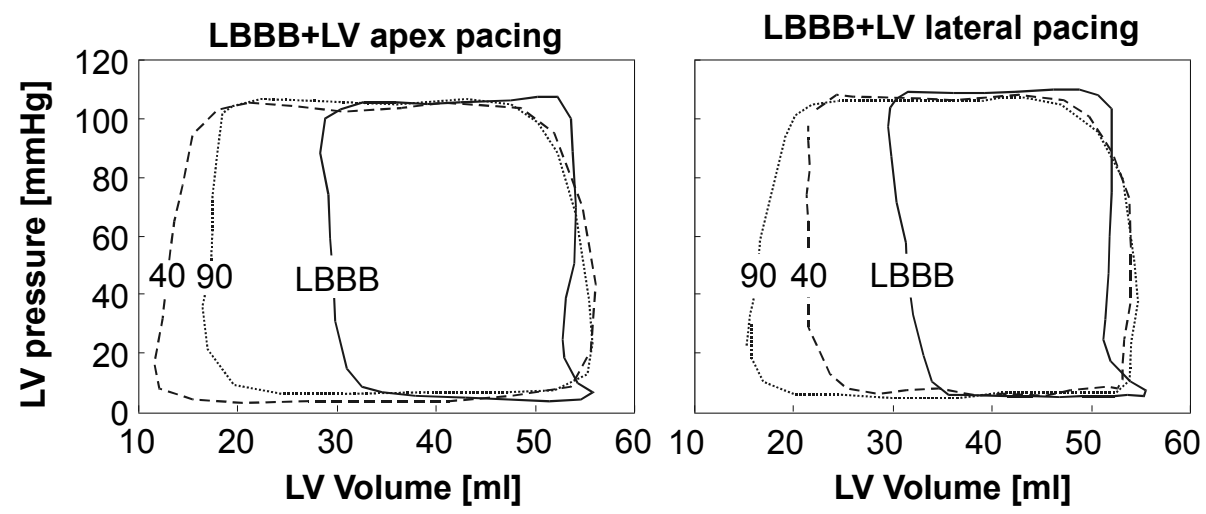

Figure 4. Pressure-volume loops measured with the conductance catheter, showing the acute effect of pacing during LBBB for LV apex (left panel) and LV lateral pacing (right panel) at paced AV-delays of 40 and $90 \mathrm{~ms}$. Results for anterior and posterior wall pacing were comparable to those of lateral wall pacing.

\section{DisCUSSION}

The findings of the present study indicate that in canine hearts with experimental LBBB, LV based pacing can recover LV function in terms of $\mathrm{LVdP} /\left.\mathrm{dt}\right|_{\max }$ and stroke work. Relative improvements in $\mathrm{LVdP} /\left.\mathrm{dt}\right|_{\max }(20-23 \%)$ were in the same range as those observed in patients ${ }^{1,3}$ and occurred in the absence of changes in diastolic function parameters. Maximum improvement of LV function is consistently obtained at intraventricular resynchronization of activation. This requires pacing with AV-delays equal to baseline PQ-time for all LV sites, except for LV apex and BiV pacing, which require AV-delays shorter than PQtime during baseline LBBB.

\section{Hemodynamic effects of pacing during LBBB}

The present study extends the insights in effects of resynchronization therapy by providing data on the improvement of $\mathrm{LVdP} /\left.\mathrm{dt}\right|_{\max }$ and stroke work in LBBB hearts during pacing at different sites and at a large range of AV-delays. Improvements in $\mathrm{LVdP} /\left.\mathrm{dt}\right|_{\max }$ and SW were obtained at unchanged diastolic function, indicating increased ventricular contractility. 
$76 \mid$ Chapter 5
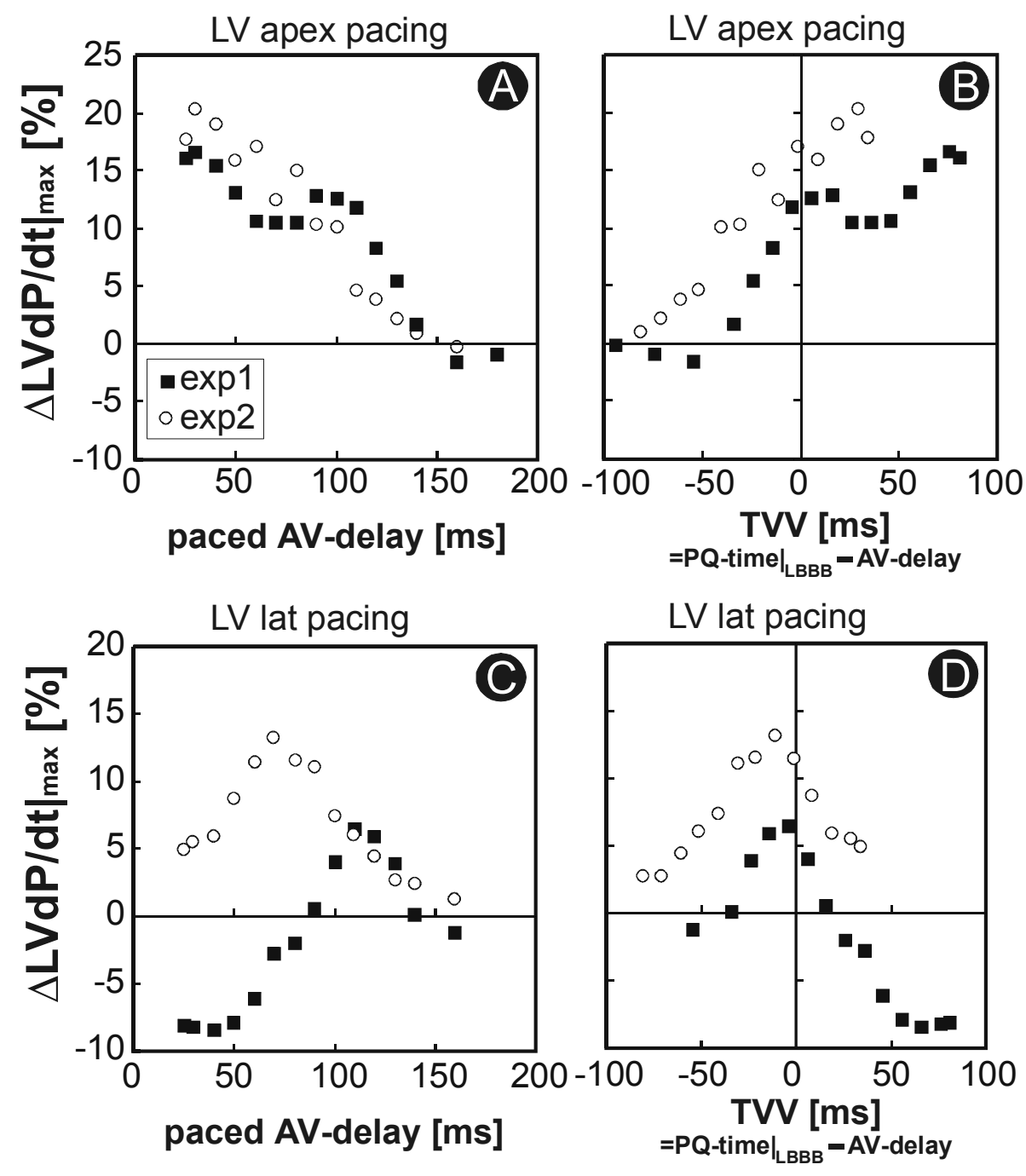

Figure 5. Changes in $\mathrm{LVdP} /\left.\mathrm{dt}\right|_{\max }$ relative to baseline $\mathrm{LBBB}$ as a function of the (A and C) paced AV-delay and (B and D) TVV for two experiments during LV apex and LV lateral wall pacing. Results for anterior and posterior wall pacing were comparable to those of lateral wall pacing. 
Because asynchronous electrical activation induces opposing contraction patterns within the LV wall, ${ }^{19,20}$ it is most likely that electrical resynchronization increases contractility by improving coherence of contraction of the various myocardial regions. This idea is supported by more uniform strain patterns observed during $\mathrm{BiV}$ pacing than during $\mathrm{RV}$ pacing in canine hearts without conduction abnormalities. ${ }^{17}$ The important role of better coherence of LV contraction is further emphasized by the lack of mitral regurgitation in our experimental LBBB model, as determined using both color Doppler imaging and left atrial pressure measurements. As a consequence, reduction of mitral regurgitation, mentioned to contribute to the beneficial effect of resynchronization therapy in patients, does not contribute to the improvement of LV function in experimental LBBB.

\section{Intra-ventricular resynchronization.}

The importance of intraVA for LV function is emphasized by the finding that for different degrees of interVA the same optimal LV function is obtained as long as intraVA is close to zero. This result is independent from the pacing site and strategy required to achieve intra-ventricular resynchronization (exclusion of endogenous activation ( $\mathrm{LV}$ apex and BiV pacing) or fusion of endogenous and pacing induced activation (LV anterior, lateral, and posterior wall pacing). Asynchrony around the LV circumference appears especially relevant, probably because it is considerably larger than asynchrony in the longitudinal direction, an observation in agreement with MRI tagging studies during ventricular pacing. ${ }^{17}$

Observations on LV wall motion and velocity using echocardiography and Tissue Doppler imaging in patients suggest improved LV synchrony during biventricular pacing ${ }^{12,15,21}$. The requirement of intra-ventricular resynchronization for optimal LV function is supported by MRI tagging measurements of mechanical asynchrony in canine hearts with pacing induced heart failure and experimental LBBB. ${ }^{22}$ These investigators concluded, however, that during optimal LV pacing electrical asynchrony persists, but this is based mainly on extrapolation of electrical activation measured during LV pacing with short AVdelay. Endocardial mapping data from the present study, with similar PQ time $(\sim 100 \mathrm{~ms})$ and optimal paced AV-delay $(\sim 70 \mathrm{~ms})$, demonstrate that electrical asynchrony differs significantly between short and intermediate AV-delays (figure 3). Therefore, their conclusion that fusion is absent during pacing at optimal $\mathrm{AV}$-delay, based on electrical activation determined during pacing at short AVdelays, does not seem justified.

The discrepancy between our finding that the QRS duration and interventricular resynchronization are poor predictors of optimal LV function and the value attributed to these parameters in other studies can be explained by the 

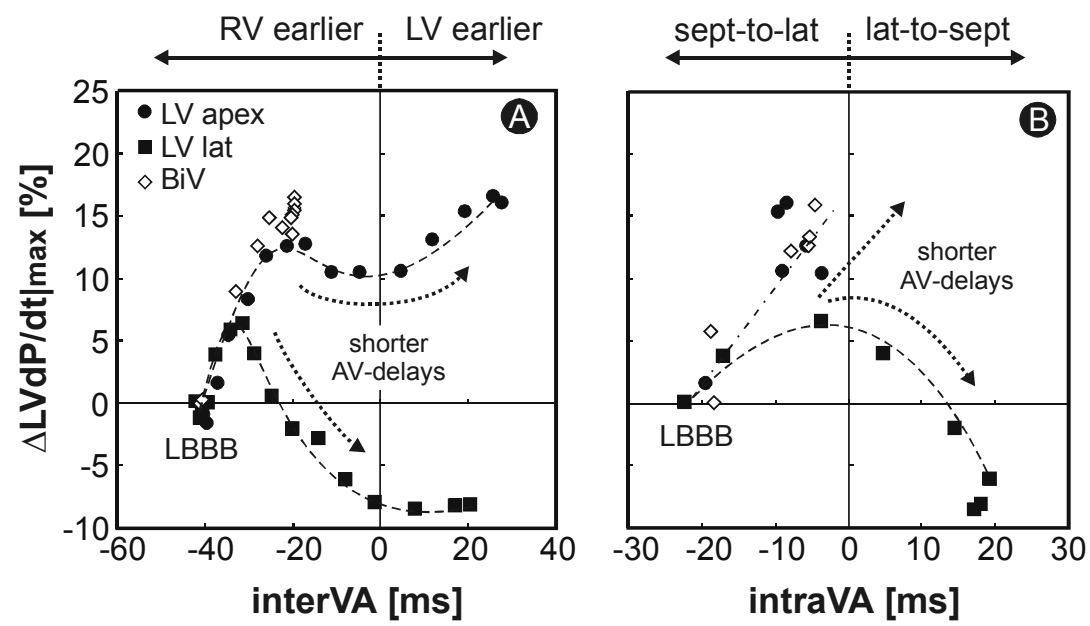

Figure 6. Typical example of the relation between changes in $\mathrm{LVdP} /\left.\mathrm{dt}\right|_{\max }$ and interVA (A) and intraVA (B) during LV apex, LV lateral wall and biventricular pacing with AVdelays ranging from 20 to $200 \mathrm{~ms}$. The dotted arrows indicate shortening of the AV-delay. Data points most remote from baseline LBBB denote the shortest AV-delay ( $20 \mathrm{~ms})$, subsequent points were obtained at $10 \mathrm{~ms}$ increase, except for intraVA. The sign given to intraVA values indicates the direction of the wave front as indicated above the graphs. Results for anterior and posterior wall pacing were comparable to those of lateral wall

use of a small range of AV delays in those studies ${ }^{8,9,13,23}$ and by the fact that hemodynamics improve over a range of interVA and QRS duration. ${ }^{1,3,6,24}$

\section{Optimization of AV-delay}

Our results show that the paced AV-delay modulates interVA and intraVA besides AV timing. In the present study the latter does not seem to be crucial for improving LV systolic function, because none of the diastolic function parameters changed when LV systolic function was optimized. The insensitivity of systolic function to changes in diastolic function has also been observed in patients receiving resynchronization therapy. ${ }^{25}$ Together, these findings suggest that optimizing AV-delay should be based on assessment of systolic rather than diastolic function, as suggested elsewhere. ${ }^{26,27}$ 

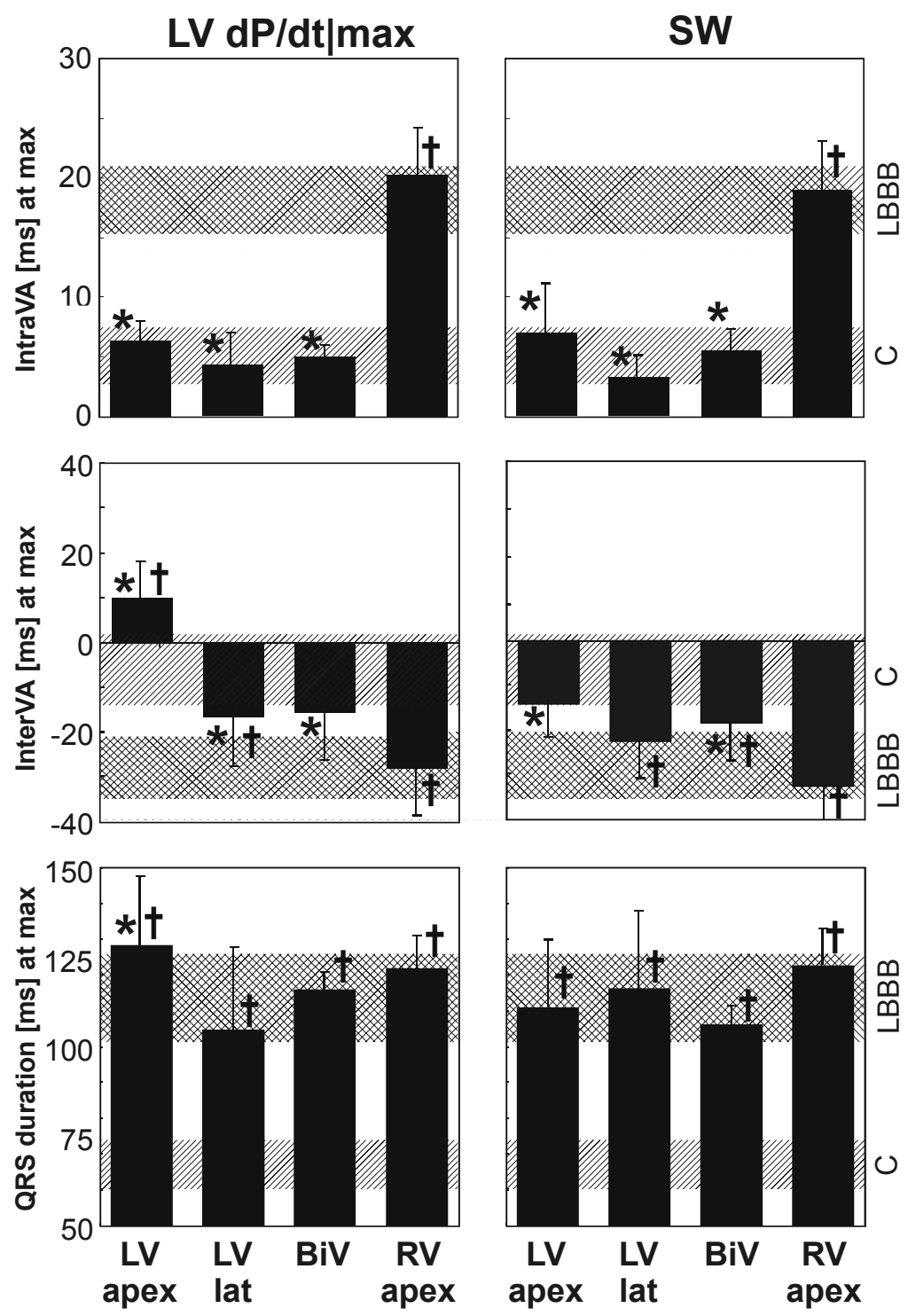

Figure 7. Values of intraVA $(n=5)$, interVA $(n=12)$ and QRS-duration $(n=12)$ at maximum increase of $\mathrm{LVdP} /\left.\mathrm{dt}\right|_{\max }$ (left column) and Stroke Work (right column). The mean \pm sd of preLBBB (C) and post-LBBB (LBBB) values is indicated by the patterned bars. (*, $\uparrow$ : versus LBBB and C, respectively). Results for anterior and posterior wall pacing were comparable to those of lateral wall pacing. 
$80 \mid$ Chapter 5

\section{Possible limitations of the experimental design.}

The present study was meant to unravel the mechanism of pacing therapy. The animal model allowed detailed measurements of electrical activation and LV function during a large number of pacing strategies. Before extrapolating the data from this animal study to patients with heart failure, several aspects have to be kept in mind.

First of all, in the present study only short-term hemodynamic changes are studied. In patients receiving resynchronization therapy, short-term hemodynamic improvements were associated with long-term clinical benefit, ${ }^{28}$ but it is not clear if the degree of short-term improvement predicts the degree of clinical improvement on an individual basis. Furthermore, patient hearts are often pathologically enlarged as a result of which endocardial activation takes longer $\left(\sim 60 \mathrm{~ms}^{18}\right)$ than in our healthy dog hearts $(\sim 30 \mathrm{~ms})$. Moreover, due to the potential presence of fibrotic and thus poorly conducting regions, the pacing site is a more determinative factor, which may explain why some studies in patients show that hemodynamic effects of pacing depend on the pacing site. ${ }^{21,24}$ Also, failing hearts may differ from healthy dog hearts with respect to filling pressure, electromechanical delay (see preceding text), and other potential adaptational changes.

We created proximal LBBB using radiofrequency ablation resulting in a more localized lesion than the diffuse fibrosis observed in patients. ${ }^{29}$ However, even in our animal model, electrical and mechanical activation maps ${ }^{17}$ indicate that impulse conduction in the LV wall occurs mainly through muscle conduction without signs of retrograde entry into the Purkinje system. The observation that the relative difference in the QRS duration and interVA between normal and LBBB individuals is similar in our dogs and in patients suggests that sequelae of experimental LBBB are at least comparable to those in patients. Also the hemodynamic effect of resynchronization appears to be quantitatively comparable. Therefore, it appears worthwhile to investigate whether the main findings of the present study also apply to patients with dilated and dysfunctional ventricles.

\section{CONClusions}

Intra-ventricular asynchrony around the LV circumference is an important determinant of LV pump function during LBBB and ventricular pacing. Pacing strategy for intra-ventricular resynchronization depends on the site of pacing and on the baseline LBBB PQ time. 


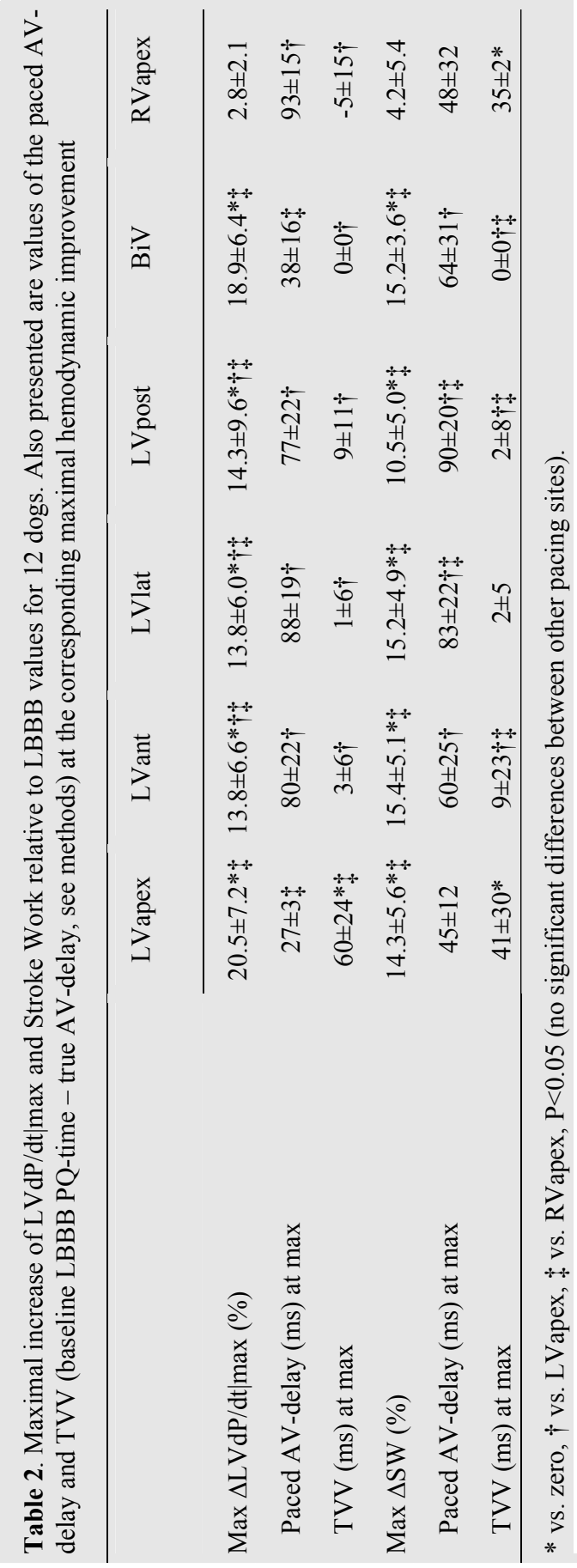




\section{2 \\ Chapter 5}

\section{ACKNOWLEDGEMENTS}

The authors are indebted to Sabine Eysbouts for her help with the electrical mapping system and Arne van Hunnik for his assistance with the animal experiments. This study was supported by grants from the Netherlands Heart Foundation (2000.189 and 2000.227).

\section{REFERENCES}

1 Auricchio A, Stellbrink C, Block M, Sack S, Vogt J, Bakker P, Klein H, Kramer A, Ding J, Salo R, Tockman B, Pochet T, Spinelli J. Effect of pacing chamber and atrioventricular delay on acute systolic function of paced patients with congestive heart failure. The Pacing Therapies for Congestive Heart Failure Study Group. The Guidant Congestive Heart Failure Research Group. Circulation. 1999;99:2993-3001.

2 Blanc JJ, Etienne Y, Gilard M, Mansourati J, Munier S, Boschat J, Benditt DG, Lurie KG. Evaluation of different ventricular pacing sites in patients with severe heart failure: results of an acute hemodynamic study. Circulation. 1997;96:3273-3277.

3 Kass DA, Chen CH, Curry C, Talbot M, Berger R, Fetics B, Nevo E. Improved left ventricular mechanics from acute VDD pacing in patients with dilated cardiomyopathy and ventricular conduction delay. Circulation. 1999;99:1567-1573.

4 Nelson GS, Berger RD, Fetics BJ, Talbot M, Spinelli JC, Hare JM, Kass DA. Left ventricular or biventricular pacing improves cardiac function at diminished energy cost in patients with dilated cardiomyopathy and left bundle-branch block. Circulation. 2000;102:30533059 .

5 Saxon LA, Kerwin WF, Cahalan MK, Kalman JM, Olgin JE, Foster E, Schiller NB, Shinbane JS, Lesh MD, Merrick SH. Acute effects of intraoperative multisite ventricular pacing on left ventricular function and activation/contraction sequence in patients with depressed ventricular function. J Cardiovasc Electrophysiol. 1998;9:13-21.

6 Liu L, Tockman B, Girouard S, Pastore J, Walcott G, KenKnight B, Spinelli J. Left ventricular resynchronization therapy in a canine model of left bundle branch block. Am J Physiol Heart Circ Physiol. 2002;282:H2238-2244.

7 Verbeek XAAM, Vernooy K, Peschar M, Van Der Nagel T, Van Hunnik A, Prinzen FW. Quantification of interventricular asynchrony during LBBB and ventricular pacing. Am J Physiol Heart Circ Physiol. 2002;283:H1370-1378.

8 Alonso C, Leclercq C, Victor F, Mansour H, de Place C, Pavin D, Carre F, Mabo P, Daubert JC. Electrocardiographic predictive factors of long-term clinical improvement with multisite biventricular pacing in advanced heart failure. Am J Cardiol. 1999;84:1417-1421.

9 Janousek J, Vojtovic P, Hucin B, Tlaskal T, Gebauer RA, Gebauer R, Matejka T, Marek J, Reich O. Resynchronization pacing is a useful adjunct to the management of acute heart failure after surgery for congenital heart defects. Am J Cardiol. 2001;88:145-152.

10 Nelson GS, Curry CW, Wyman BT, Kramer A, Declerck J, Talbot M, Douglas MR, Berger RD, McVeigh ER, Kass DA. Predictors of systolic augmentation from left ventricular preexcitation in patients with dilated cardiomyopathy and intraventricular conduction delay. Circulation. 2000;101:2703-2709.

11 Garrigue S, Jais P, Espil G, Labeque JN, Hocini M, Shah DC, Haissaguerre M, Clementy J. Comparison of chronic biventricular pacing between epicardial and endocardial left ventricular stimulation using Doppler tissue imaging in patients with heart failure. Am J Cardiol. 2001;88:858-862. 
12 Yu CM, Chau E, Sanderson JE, Fan K, Tang MO, Fung WH, Lin H, Kong SL, Lam YM, Hill MR, Lau CP. Tissue Doppler echocardiographic evidence of reverse remodeling and improved synchronicity by simultaneously delaying regional contraction after biventricular pacing therapy in heart failure. Circulation. 2002;105:438-445.

13 Kerwin WF, Botvinick EH, O'Connell JW, Merrick SH, DeMarco T, Chatterjee K, Scheibly K, Saxon LA. Ventricular contraction abnormalities in dilated cardiomyopathy: effect of biventricular pacing to correct interventricular dyssynchrony. J Am Coll Cardiol. 2000;35:1221-1227.

14 Toussaint JF, Lavergne T, Kerrou K, de DB, Ponce F, Froissart M, Le HJ, Guize L, Paillard $\mathrm{M}$. Ventricular coupling of electrical and mechanical dyssynchronization in heart failure patients. Pacing Clin Electrophysiol. 2002;25:178-182.

15 Sogaard P, Kim WY, Jensen HK, Mortensen P, Pedersen AK, Kristensen BO, Egeblad H. Impact of acute biventricular pacing on left ventricular performance and volumes in patients with severe heart failure. A tissue doppler and three-dimensional echocardiographic study. Cardiology. 2001;95:173-182.

16 Baan J, van der Velde ET, de Bruin HG, Smeenk GJ, Koops J, van Dijk AD, Temmerman D, Senden J, Buis B. Continuous measurement of left ventricular volume in animals and humans by conductance catheter. Circulation. 1984;70:812-823.

17 Wyman BT, Hunter WC, Prinzen FW, Faris OP, McVeigh ER. Effects of single- and biventricular pacing on temporal and spatial dynamics of ventricular contraction. Am J Physiol Heart Circ Physiol. 2002;282:H372-379.

18 Vassallo JA, Cassidy DM, Marchlinski FE, Buxton AE, Waxman HL, Doherty JU, Josephson ME. Endocardial activation of left bundle branch block. Circulation. 1984;69:914-923.

19 Prinzen FW, Augustijn CH, Arts T, Allessie MA, Reneman RS. Redistribution of myocardial fiber strain and blood flow by asynchronous activation. Am J Physiol. 1990;259:H300-308.

20 Prinzen FW, Hunter WC, Wyman BT, McVeigh ER. Mapping of regional myocardial strain and work during ventricular pacing: experimental study using magnetic resonance imaging tagging. J Am Coll Cardiol. 1999;33:1735-1742.

21 Ansalone G, Giannantoni P, Ricci R, Trambaiolo P, Fedele F, Santini M. Doppler myocardial imaging to evaluate the effectiveness of pacing sites in patients receiving biventricular pacing. J Am Coll Cardiol. 2002;39:489-499.

22 Leclercq C, Faris O, Tunin R, Johnson J, Kato R, Evans F, Spinelli J, Halperin H, McVeigh E, Kass DA. Systolic improvement and mechanical resynchronization does not require electrical synchrony in the dilated failing heart with left bundle-branch block. Circulation. 2002;106:1760-1763.

23 Leclercq C, Cazeau S, Le Breton H, Ritter P, Mabo P, Gras D, Pavin D, Lazarus A, Daubert JC. Acute hemodynamic effects of biventricular DDD pacing in patients with end-stage heart failure. J Am Coll Cardiol. 1998;32:1825-1831.

24 Butter C, Auricchio A, Stellbrink C, Fleck E, Ding J, Yu Y, Huvelle E, Spinelli J. Effect of resynchronization therapy stimulation site on the systolic function of heart failure patients. Circulation. 2001;104:3026-3029.

25 Auricchio A, Ding J, Spinelli JC, Kramer AP, Salo RW, Hoersch W, KenKnight BH, Klein HU. Cardiac resynchronization therapy restores optimal atrioventricular mechanical timing in heart failure patients with ventricular conduction delay. J Am Coll Cardiol. 2002;39:11631169.

26 Kindermann M, Frohlig G, Doerr T, Schieffer H. Optimizing the AV delay in DDD pacemaker patients with high degree AV block: mitral valve Doppler versus impedance cardiography. Pacing Clin Electrophysiol. 1997;20:2453-2462.

27 Cazeau S, Leclercq C, Lavergne T, Walker S, Varma C, Linde C, Garrigue S, Kappenberger L, Haywood GA, Santini M, Bailleul C, Daubert JC. Effects of multisite biventricular pacing 


\section{Chapter 5}

84

in patients with heart failure and intraventricular conduction delay. $\mathrm{N}$ Engl $\mathrm{J}$ Med. 2001;344:873-880.

28 Auricchio A, Stellbrink C, Sack S, Block M, Vogt J, Bakker P, Huth C, Schondube F, Wolfhard U, Bocker D, Krahnefeld O, Kirkels H. Long-term clinical effect of hemodynamically optimized cardiac resynchronization therapy in patients with heart failure and ventricular conduction delay. J Am Coll Cardiol. 2002;39:2026-2033.

29 Demoulin JC, Simar LJ, Kulbertus HE. Quantitative study of left bundle branch fibrosis in left anterior hemiblock: A stereologic approach. Am J Cardiol. 1975;36:751-756. 


\section{Chapter 6}

Calculation of effective VV-interval facilitates optimization of $\mathrm{AV}$-delay and VV-interval in cardiac resynchronization therapy

Kevin Vernooy, MD, ${ }^{\mathrm{a}, \mathrm{b}}$ Xander A.A.M. Verbeek, PhD, ${ }^{\mathrm{a}}$ Richard N.M. Cornelussen, PhD, ${ }^{a}$ Barbara Dijkman, MD, PhD, ${ }^{b}$ Arne van Hunnik, BSc, ${ }^{a}$ Marion Kuiper, BSc, ${ }^{a}$ Harry J.G.M. Crijns, MD, PhD, ${ }^{b}$ Theo Arts, $\mathrm{PhD},{ }^{\mathrm{c}}$ and Frits W. Prinzen, PhD. ${ }^{\mathrm{a}}$

Department of Physiology, ${ }^{\mathrm{a}}$ Cardiology, ${ }^{\mathrm{b}}$ and Biophysics, ${ }^{\mathrm{c}}$ Cardiovascular Research Institute Maastricht, Maastricht, the Netherlands

Heart Rhythm 2006 Dec (in press) 
${ }_{86} \mid$ Chapter 6

\section{Abstract}

Background. In hearts with left bundle branch block (LBBB), both atrioventricular (AV-) delay and inter-ventricular (VV-) interval determine left ventricular (LV) pump function in cardiac resynchronization therapy (CRT). The optimal combination of AV-delay and VV-interval is currently found by extensive hemodynamic testing.

Objective. We investigated whether the effective VV-interval (VVeff) can be used to optimize AV-delay and VV-interval.

Methods. In eight canine hearts with chronic LBBB, LV pacing was performed at various AV-delays as well as biventricular (BiV) pacing at multiple AVdelays and VV-intervals. LV pump function was assessed from LVdP/dt|max and stroke volume (conductance catheter). Inter-ventricular asynchrony was calculated from the timing difference between upslope of LV and RV pressure curves. VVeff was defined as the time delay between the activation of the RV apex and LV lateral wall, irrespective of the source of RV activation (RV pacing or intrinsic conduction). VVeff was determined from pacemaker settings and surface ECGs taken during BiV pacing at various AV-delays (positive values denote LV pre-excitation).

Results. For all animals, the relation between VVeff and LVdP/dt|max as well as LV stroke work was parabolic. Maximal improvement in $\mathrm{LVdP} / \mathrm{dt} \mid \max$ was similar during $\mathrm{LV}$, simultaneous $\mathrm{BiV}$ (BiV0) and sequential BiV (BiVS) pacing, and was obtained at similar values of VVeff. VVeff was strongly correlated with inter-ventricular asynchrony $(\mathrm{R}=0.97 \pm 0.03)$. Optimum $\mathrm{LVdP} / \mathrm{dt} \mid \mathrm{max}$ occurred at VVeff ranging from -24 to 12 (mean $-6 \pm 13 \mathrm{~ms}$ ). For each experiment this optimal VVeff was virtually equal to the value halfway between its minimum (during $\mathrm{LV}$ pacing at short $\mathrm{AV}$-delay) and maximum (during LBBB) value $(\mathrm{R}=0.91)$.

Conclusion. The use of VVeff facilitates finding the best combination of AVdelay and VV-interval during BiV pacing. For each individual heart the VVeff, resulting in optimum LV pump function, can be estimated using surface ECG recordings during $\mathrm{BiV}$ pacing. 


\section{INTRODUCTION}

Cardiac resynchronization therapy (CRT) significantly improves left ventricular (LV) pump function, exercise capacity, clinical status, and survival in patients with heart failure and conduction disturbances, especially left bundle branch block (LBBB). ${ }^{1,2}$ One of the issues to be solved is how to achieve optimal timing of LV and right ventricular (RV) stimulation. Biventricular (BiV) pacemakers have the option to adjust not only timing between atrium and ventricles (AV-delay), but also the time interval between RV and LV stimulation, the inter-ventricular interval (VV-interval). In several studies small, but significant, improvements of hemodynamics were reported for sequential BiV (BiVS) pacing over simultaneous BiV (BiV0) pacing. ${ }^{3-5}$ However, optimization of BIVS pacing requires extensive hemodynamic or echocardiographic analysis of many combinations of AV-delay and VV-interval. Nevertheless, a large randomized trial comparing BiVS versus $\mathrm{BiV0}$ pacing, showed no significant differences in symptoms or quality of life. ${ }^{6}$

The aim of the present study was to investigate the effects of AV-delay and VV-interval on LV pump function and to derive a simpler approach to optimize timing of LV and RV stimulation in CRT. We reasoned that the programmed AV-delay influences the contribution of intrinsic conduction to total ventricular activation by fusion of intrinsic activation wave with the activation wave originating from the pacing sites. ${ }^{7}$ Similarly the VV-interval is expected to influence the contribution of the LV and RV stimulation to LV activation. Therefore, both $\mathrm{AV}$-delay and VV-interval may determine the degree of intra-ventricular asynchrony.

In a previous study, we found that during $\mathrm{LV}$ and simultaneous $\mathrm{BiV}$ pacing in LBBB hearts, LV pump function is directly related to intra-ventricular asynchrony, irrespective of the source of RV activation (RV pacing or intrinsic conduction through the right bundle).$^{8}$ For the purposes of the present study, we assume that the same holds true for BiV pacing at any AV-delay and any VVinterval. Accordingly, we tested the hypothesis that LV pump function is related to a single parameter: the effective VV-interval (VVeff), VVeff being defined as the actual time delay between the onset of activation of the RV apex and LV lateral wall.

In the present study, we investigate the relation between VVeff and LV pump function, how VVeff may be derived from electrocardiographic signals, and to what extent VVeff can be used to optimize LV pump function. The experiments were performed in canine hearts with chronic LBBB. ${ }^{9}$ 


\section{8 \\ Chapter 6}

\section{METHODS}

\section{Concept of resynchronization}

In hearts without conduction disturbances, activation of both ventricles occurs through intrinsic conduction and the times of activation of RV ( $\left.T_{R V}\right)$ and $L V$ $\left(\mathrm{T}_{\mathrm{LV}}\right.$ ) are very similar (figure 1A). During uncomplicated LBBB (figure $1 \mathrm{~b}$ ), $T_{R V}$ is not affected whereas activation to the $L V$ lateral wall $\left(T_{L V}\right)$ is delayed (indicated by $\mathrm{T}_{\mathrm{RV}-\mathrm{LV}}$ ). During $\mathrm{BiV}$ pacing (figure $1 \mathrm{C}$ ), the $\mathrm{RV}$ and $\mathrm{LV}$ lateral wall can be activated by the pacing stimulus at $\mathrm{T}_{\mathrm{A}-\mathrm{RV} \text { pace }}$ and $\mathrm{T}_{\mathrm{A}-\mathrm{LV} \text { pace }}$, respectively, but only if stimulation occurs before $\mathrm{T}_{\mathrm{RV}}$ and $\mathrm{T}_{\mathrm{LV}}$, respectively.

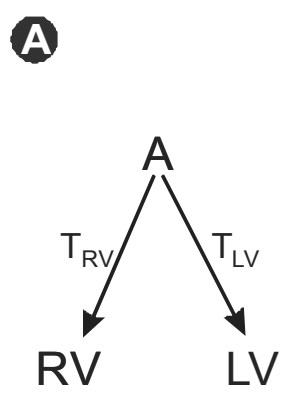

Normal conduction
B

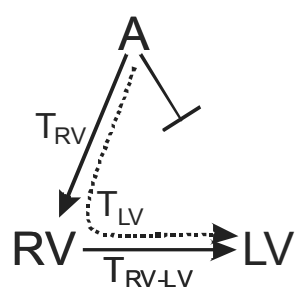

LBBB

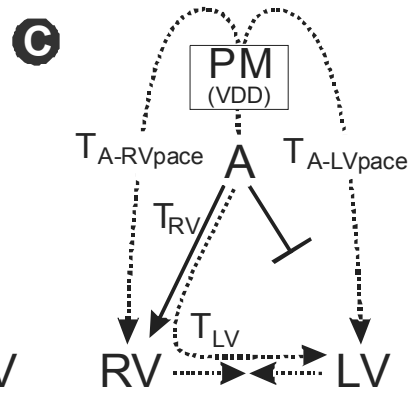

LBBB+
BiV Pacing

Figure 1. Schematic pathways of ventricular activation during normal conduction, LBBB, and LBBB with biventricular (BiV) pacing. (A) During normal conduction activation of both ventricles occurs through intrinsic activation and the time of RV and LV activation $\left(\mathrm{T}_{\mathrm{RV}}\right.$ and $\mathrm{T}_{\mathrm{LV}}$, respectively) is similar. (B) During LBBB, the RV remains activated by intrinsic conduction, whereas activation to the LV lateral wall (TLV) is delayed because of slow myocardial conduction $\left(\mathrm{T}_{\mathrm{RV}-\mathrm{LV}}\right.$, figure $\left.1 \mathrm{~B}\right)$. (C) During BiV pacing, the RV and LV lateral wall can be activated by the pacing stimulus ( $\mathrm{T}_{\mathrm{A}-\mathrm{RVpace}}$ and $\mathrm{T}_{\mathrm{A}-\mathrm{LV} \text { pace, }}$, respectively) if stimulation occurs before $\mathrm{T}_{\mathrm{RV}}$ and $\mathrm{T}_{\mathrm{LV}}$, respectively.

Following up on this scheme, figure 2 depicts our hypothesis how AV-delay and VV-interval determine the way and degree of resynchronization. At short AV-delays, both ventricles are activated by RV and LV stimulation and the timing of RV and LV activation depends exclusively on differences between $T_{A-}$ RVpace and $\mathrm{T}_{\mathrm{A}-\mathrm{LV} \text { pace }}$ (figure 2, left panel). At longer AV-delays, when $\mathrm{T}_{\mathrm{A}-\mathrm{RV} \text { pace }}$ equals $\mathrm{T}_{\mathrm{RV}}, \mathrm{RV}$ activation occurs by a combination of RV pacing and intrinsic activation (figure 2 , middle panel). When $\mathrm{T}_{\mathrm{A}-\mathrm{RVpace}}$ exceeds $\mathrm{T}_{\mathrm{RV}}$, the $\mathrm{RV}$ is activated by intrinsic conduction. At such long AV-delays, the LV lateral wall can 
still be activated by LV pacing because $\mathrm{T}_{\mathrm{A}-\mathrm{LV} \text { pace }}$ is usually shorter than $\mathrm{T}_{\mathrm{LV}}$ (figure 2 , right panel).

In order to estimate the contribution of RV and LV stimulation as well as intrinsic conduction to ventricular activation in a simple term, we propose the effective VV-interval (VVeff). VVeff is defined as the time difference between the activation of the LV lateral wall $\left(\mathrm{T}_{\mathrm{LV}}\right)$ and $\mathrm{RV}$, irrespective of whether this occurs by $R V$ pacing $\left(\mathrm{T}_{\mathrm{A}-\mathrm{RV} \text { pace }}\right)$ or by intrinsic conduction $\left(\mathrm{T}_{\mathrm{RV}}\right)$, whichever occurs first.

\section{Experimental Protocol}

Experiments were performed in 8 canine hearts with chronic LBBB.9 Animal handling was performed according to the Dutch Law on Animal Experimentation and the European Directive for the Protection of Vertebrate Animals used for Experimental and other Scientific Purposes (86/609/EU). The protocol was approved by the Maastricht University Experimental Animal Committee.

LBBB was created by radio-frequency ablation, as previously described in detail. ${ }^{9,10}$ After 8 weeks of LBBB, the dogs were premedicated and anesthetized with midazolam and sufentanil, and ECG and LV and RV pressures were recorded. ${ }^{8}$ The chest was laterally opened and a LV epicardial screw-in pacing lead (Medtronic model 6917A, Minneapolis, MN, USA) was positioned on the LV lateral wall. Right atrial and RV apex pacing leads (Medtronic model 5568 and 5068, respectively) were positioned transvenously through the left jugular vein. After closing the thorax, hemodynamic measurements were performed during an extensive pacing protocol (see below). The electrocardiogram (ECG) was recorded from limb leads. LV pressure and volume were determined with a $7 \mathrm{~F}$ combined catheter-tip manometer and conductance catheter, and RV pressure was determined with a $7 \mathrm{~F}$ catheter-tip manometer (CD-Leycom, Zoetermeer, the Netherlands). Pressures and ECG signals were digitized at $200 \mathrm{~Hz}$ and stored for off-line analysis. Measurements were performed on all heartbeats within one ventilation cycle. The conductance catheter was connected with a Leycom Sigma 5DF signal conditioner processor (CD-Leycom). Absolute LV volume was calculated by correcting for parallel conductance (using hypertonic saline injection) and by calibrating stroke volume using thermodilution cardiac output. Data were analyzed using the CIRCLAB software package. ${ }^{11}$

Inter-ventricular asynchrony was defined as the timing difference between the upslope of the simultaneously recorded LV and RV pressure curves, calculated by cross-correlation. ${ }^{10}$ 


\section{$90 \mid$ Chapter 6}

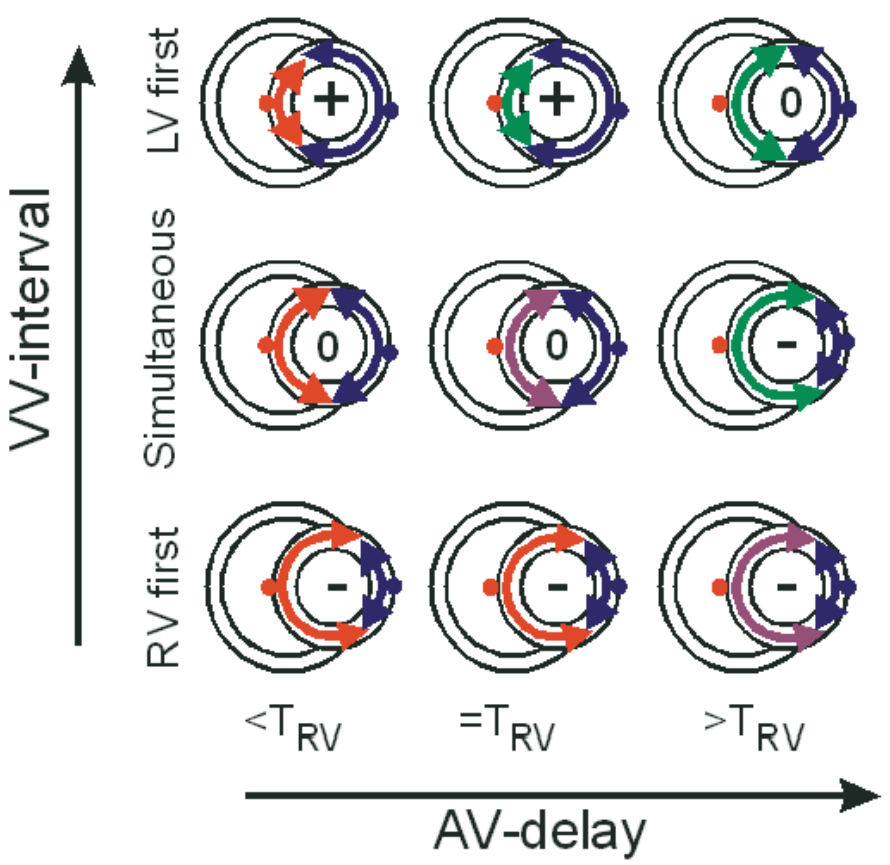

\section{- RV pacing activation LV pacing activation \\ - Intrinsic activation \\ - RV pacing/intrinsic activation}

Figure 2. Schematic representation of LV electrical activation at various AV-delays and $\mathrm{VV}$-intervals. At short AV-delays, before onset of intrinsic activation $\left(<\mathrm{T}_{\mathrm{RV}}\right.$, left column), both ventricles are completely activated by RV (red arrow) and LV pacing (blue arrow) and the timing of RV and LV activation is completely dependent on timing differences between the RV and LV pacing. When the AV-delay is prolonged to the onset of intrinsic activation $\left(=\mathrm{T}_{\mathrm{RV}}\right.$, middle column $), \mathrm{RV}$ pacing occurs simultaneously with intrinsic conduction resulting in a combination of RV pacing and intrinsic conduction (purple arrow). When RV pacing occurs later than intrinsic conduction $\left(>\mathrm{T}_{\mathrm{RV}}\right.$, right column), the $\mathrm{RV}$ is activated by intrinsic conduction through the right bundle (green arrow). At longer AVdelays the LV lateral wall can still be activated by LV pacing because activation of the LV lateral wall is delayed because of slow myocardial conduction.

The effective VV-interval represents the actual time difference between the activation of the RV and LV lateral wall, either by ventricular pacing or by intrinsic activation. Positive values ("+") indicate an earlier onset of LV than RV electrical activation, whereas negative values ("-") indicate earlier RV activation. 


\section{Pacing protocol}

Pacing was performed in VDD-mode at various AV-delays and VV-intervals using an external pacemaker (Medtronic AV pacing System Analyzer Model 5311B), connected to an external pulse stimulator (Medtronic, model 2883). Three different pacing modes were used: LV pacing, BiV0, and BiVS pacing. During LV and BiV0 pacing, AV-delays were varied in $10 \mathrm{~ms}$ steps from $30 \mathrm{~ms}$ to $200 \mathrm{~ms}$. BiVS pacing was performed at three AV-delays: $50 \mathrm{~ms}$ shorter than, equal to, and $50 \mathrm{~ms}$ longer than the PQ-time derived from the surface ECG. At each AV-delay the VV-interval was varied from $-50 \mathrm{~ms}$ to $50 \mathrm{~ms}$ in $10 \mathrm{~ms}$ steps. Each hemodynamic measurements during ventricular pacing was followed by a baseline LBBB measurement in order to correct for baseline shift and bias of the previous pacing configuration.

\section{Calculation of VVeff}

VVeff was defined as the actual time difference in onset activation between the $R V$ and LV lateral wall. $T_{R V}$ and $T_{L V}$ were determined from a series of recordings of surface ECGs made during simultaneous BiV (BiV0) pacing with $\mathrm{AV}$-delay ranging from 30 to $200 \mathrm{~ms}$, increasing the AV-delay in steps of 10 ms. $T_{R V}$ was determined as the AV-delay at which the QRS complex indicates a contribution of intrinsic activation and $\mathrm{T}_{\mathrm{LV}}$ as the shortest $\mathrm{AV}$-delay at which the QRS morphology was equal to that during baseline LBBB (figure 3). Onset of activation of the RV and LV was assumed to occur at the time of the pacing stimulus $\left(\mathrm{T}_{\mathrm{A}-\mathrm{RVpace}}\right.$ and $\mathrm{T}_{\mathrm{A}-\mathrm{LVpace}}$, respectively), if these intervals were shorter than $T_{R V}$ and $T_{L V}$, respectively. Positive VVeff values indicate an earlier activation of the LV lateral wall than the RV, as occurs during LV pacing at short AV-delays, and during BiV pacing with a VV-interval resulting in LV first pacing (figure 2, upper left panel). Negative VVeff values indicate earlier RV activation, which may occur during $\mathrm{LV}$ and $\mathrm{BiV}$ pacing at $\mathrm{AV}$-delays longer than $\mathrm{T}_{\mathrm{RV}}$ or during $\mathrm{BiV}$ pacing at short $\mathrm{AV}$-delays with a $\mathrm{VV}$-interval resulting in $\mathrm{RV}$ first pacing (figure 2).

Minimal VVeff is defined as the time difference between $T_{L V}$ and $T_{R V}$ and can be determined by BiV0 pacing, increasing the AV-delay until the QRS morphology has returned to baseline LBBB (figure 3). Maximal VVeff is determined by single LV pacing, decreasing the AV-delay until the QRS shows complete LV pre-excitation. The time difference between this programmed AVdelay and $\mathrm{T}_{\mathrm{RV}}$ is maximal VVeff. 


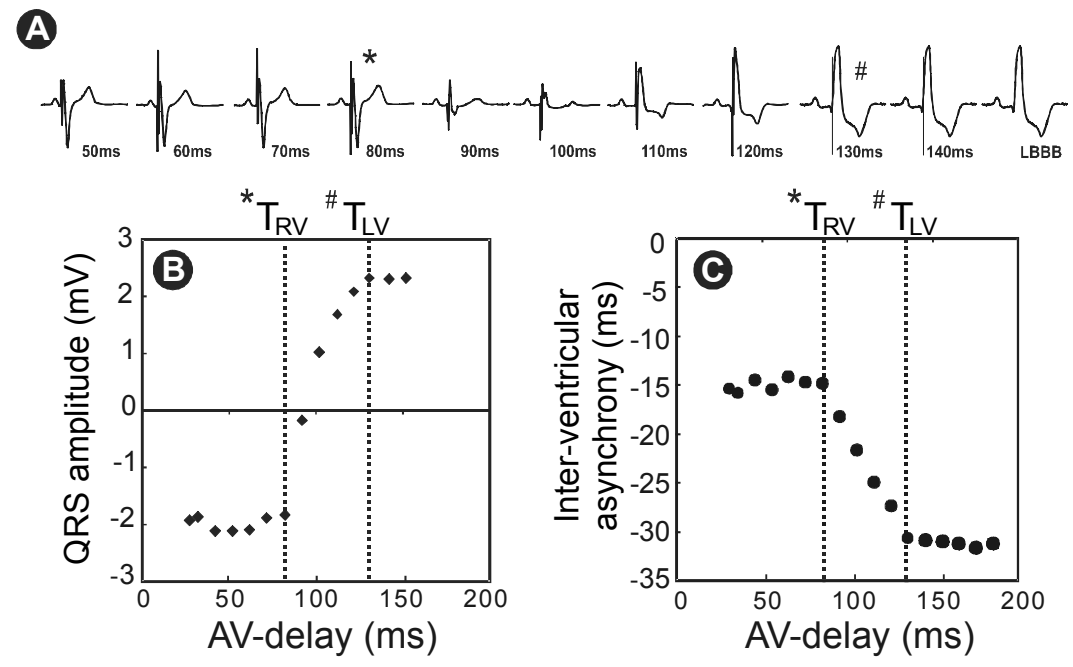

Figure 3. Determination of onset of intrinsic $R V\left(T_{R V}\right)$ and $L V\left(T_{L V}\right)$ activation. $T_{R V}$ is determined during stepwise increase of AV-delay during simultaneous biventricular pacing. Coming from a short AV-delay, the smallest AV-delay at which contribution of intrinsic conduction took place was defined as $T_{R V}$. $T_{L V}$ was determined during BiV0 pacing as the AV-delay at which contribution from pacing was lost. Contribution of intrinsic conduction and loss of contribution by LV pacing was recognized by (A) changing QRS morphology and (B) amplitude, and (C) changing value of inter-ventricular asynchrony.

\section{Statistical analysis}

All values are presented as mean values with their corresponding standard deviations. Statistical significance between LBBB and different optimal pacing configurations for $\mathrm{LV}, \mathrm{BiV0}$ and $\mathrm{BiVS}$ was evaluated using repeated measures of ANOVA. If ANOVA indicated a significant difference, a Bonferroni post hoc test was performed for a comparison between LBBB and the different pacing configurations. Comparison between the predicted VVeff and VVeff resulting in optimal hemodynamic improvement was performed by means of linear regression. In all tests a P-value $<0.05$ or less (two-sided) was considered statistically significant. 

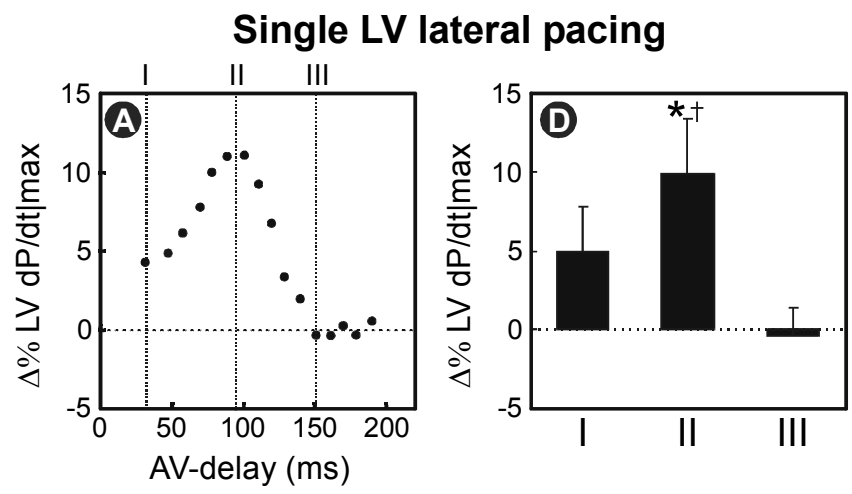

Simultaneous biventricular pacing
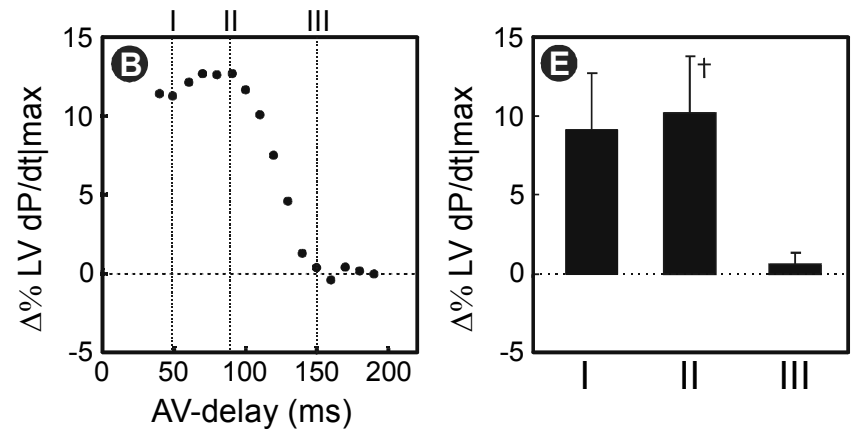

Sequential biventricular pacing at short AV-delay
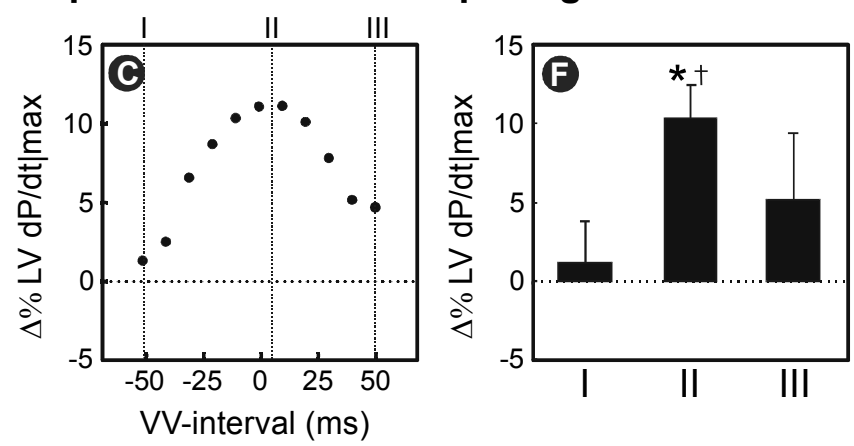

Figure 4. Typical examples of relation between AV-delay and LVdP/dt|max (relative to baseline LBBB values) during A) single LV lateral pacing, and B) simultaneous biventricular pacing. C) Typical example of relation between VV-interval and $\mathrm{LVdP} / \mathrm{dt} / \mathrm{max}$ during biventricular pacing at short AV-delay. Data from panels A, B and C were derived from the same experiment. D,E,F) Group data of $\mathrm{LVdP} / \mathrm{dt} / \mathrm{max}$ at situations I,II and III, indicated in panels A, B and $\mathbf{C}$ ). One way ANOVA followed by Bonferroni post hoc test was performed between situation I,II and III. * $\mathrm{P}<0.05$ versus $\mathrm{I}, \uparrow \mathrm{P}<0.05$ versus III. Data is presented as mean $\pm \mathrm{SD}$. 


\section{4 \\ Chapter 6}

\section{RESULTS}

For all 8 animals $\mathrm{T}_{\mathrm{RV}}$, determined according to the procedure mentioned above and displayed in figure 3 , was $90 \pm 19 \mathrm{~ms}$. $\mathrm{T}_{\mathrm{RV}}$ was strongly related to intrinsic $\mathrm{PQ}$-time $(\mathrm{R}=0.84)$. On average $\mathrm{T}_{\mathrm{RV}}$ was $35 \pm 9 \mathrm{~ms}$ shorter than the intrinsic PQtime $(123 \pm 11 \mathrm{~ms})$. The delayed intrinsic activation of the $\mathrm{LV}$ lateral wall during LBBB, $\mathrm{T}_{\mathrm{LV}}$, was $151 \pm 11 \mathrm{~ms}$.

Table 1. Maximum increase in $\mathrm{LVdP} / \mathrm{dt} \mid \max$, during $\mathrm{LV}$, simultaneous $\mathrm{BiV}$ (BiV0) and sequential BiV (BiVS) pacing.

\begin{tabular}{lccc}
\hline & LV & BiV0 & BiVS \\
\cline { 2 - 4 } $\max \Delta \mathrm{LVdP} / \mathrm{dt} \mid \max (\%)$ & $9.9 \pm 3.4^{*}$ & $10.1 \pm 3.6^{*}$ & $10.4 \pm 2.1^{*}$ \\
$\mathrm{VV}$ eff (ms) at max & $0 \pm 25^{*}$ & $-7 \pm 19^{*}$ & $-6 \pm 13^{*}$ \\
$\Delta \mathrm{LV}$ EDP (mmHg) at max & $-0.7 \pm 1.0$ & $-0.2 \pm 1.2$ & $-0.5 \pm 2.2$ \\
$\Delta \mathrm{LV}$ SP (mmHg) at max & $0.2 \pm 2.3$ & $1.0 \pm 1.1$ & $0.6 \pm 1.3$ \\
inter-ventricular asynchrony (ms) at max & $-15 \pm 9^{*}$ & $-16 \pm 9^{*}$ & $-15 \pm 6^{*}$ \\
\hline
\end{tabular}

Data is presented relative to baseline $\mathrm{LBBB}$ values as mean $\pm \mathrm{SD}$. $\mathrm{LVdP} / \mathrm{dt} \mid \max =$ maximum rate of LV pressure rise; VVeff= effective VV-interval; LV EDP= LV end-diastolic pressure; LV SP= LV systolic pressure. One way ANOVA followed by Bonferroni post hoc test between pacing modes and LBBB baseline. * vs. LBBB, $\mathrm{P}<0.05$. No significant changes between LV, BiV0 and BiVS pacing.

Figure 4 shows the effect of the AV-delay during BiV0 and LV pacing and the effect of the VV-interval during BiVS pacing at short AV-delay on $\mathrm{LVdP} / \mathrm{dt} / \mathrm{max}$. The typical examples show parabolic relations with $\mathrm{LVdP} / \mathrm{dt} \mid \mathrm{max}$ for AV-delay during LV pacing (panel A) and for VV-interval during BiVS pacing (panel C), and a Z-shaped relation between LVdP/dt|max and AV-delay during BiV0 pacing (panel B). During LV and BiV0 pacing, optimal $\mathrm{LVdP} / \mathrm{dt} / \mathrm{max}$ was reached at intermediate AV-delays (situation II). When using shorter AV-delays (situation I), LV function decreased as compared with situation II during LV pacing (panels $\mathrm{A}$ and $\mathrm{D}$ ) but not during BiV0 pacing (panels B and E). Situation III resembles baseline LBBB situation. Compared with the optimal VV-interval during BiVS pacing at short AV-delay (situation II in panels $\mathrm{C}$ and $\mathrm{F}$ ), extreme RV pre-excitation (negative VV-intervals, situation I) and LV pre-excitation (positive VV-intervals, situation III) decreased LVdP/dt|max.

Maximal improvement in $\mathrm{LVdP} / \mathrm{dt} / \max$ was similar during $\mathrm{LV}, \mathrm{BiV0}$ and BiVS pacing (table 1). These maximum $\mathrm{LVdP} / \mathrm{dt} \mid \max$ values occurred at unchanged LV end-diastolic and systolic pressure (LV EDP and LV SP, respectively). Moreover, maximal improvement in $\mathrm{LVdP} / \mathrm{dt} \mid \max$ during $\mathrm{LV}, \mathrm{BiV} 0$ and 
BiVS pacing was obtained at similar values of inter-ventricular asynchrony and VVeff. The absolute values of the hemodynamic parameters during LBBB and maximal improvement in $\mathrm{LVdP} / \mathrm{dt} \mid$ max are presented in table 2.

When plotting the values of inter-ventricular asynchrony as function of VVeff, a linear relation was found (figure 5A). This linear relation was present for all values obtained during pacing in the different configurations (LV, BiV0, and BiVS pacing at various AV-delays and VV-intervals). This linear relation between inter-ventricular asynchrony and VVeff was present in all animals, correlation coefficient being $0.97 \pm 0.03$. These regression lines as well as values of inter-ventricular asynchrony and VVeff differed to some extent between animals (figure 5B).

Within each experiment, VVeff was related to changes in LV pump function. For all pacing configurations, $\mathrm{LVdP} / \mathrm{dt} / \max$ and $\mathrm{LV}$ stroke work fitted to parabolic shaped curves when plotted as function of VVeff (Figure 5C and 6). The $\mathrm{LVdP} / \mathrm{dt} \mid$ max curves for all animals are depicted in figure 5D.

The average optimal VVeff was not significantly different from zero $(-6 \pm 13$ $\mathrm{ms}$, table 2). However, figure $5 \mathrm{~d}$ shows that individual optimal VVeff largely varied, ranging from -24 to $12 \mathrm{~ms}$, even in this model of reproducible LBBB.

Figure $5 \mathrm{~A}$ and $5 \mathrm{~B}$ show that maximal improvement in $\mathrm{LVdP} / \mathrm{dt} \mid$ max coincided with the value of VVeff halfway between its minimal and maximal value (figure 5A and 5C). This relation indicates that, the pacemaker setting resulting in maximal improvement in LV pump function could be predicted using VVeff. Indeed, for all animals, optimal VVeff could accurately be predicted from the value of VVeff halfway between its minimal and maximal values $(\mathrm{R}=0.92$, figure 7A). The optimum $\mathrm{LVdP} / \mathrm{dt} / \max$ was similar to the improvement in $\mathrm{LVdP} / \mathrm{dt} \mid \mathrm{max}$ at the predicted $\mathrm{VVeff}(\mathrm{R}=0.99$, figure $7 \mathrm{~B})$.

As shown above, optimal VVeff can be obtained by LV pacing, BiV0 pacing, as well as BiVS pacing. In the example used in figure 5, optimum $\mathrm{LVdP} / \mathrm{dt} / \mathrm{max}$ occurred at a VVeff of - $24 \mathrm{~ms}$, indicating that the RV should be activated $24 \mathrm{~ms}$ earlier than the LV lateral wall. For LV pacing, optimal VVeff can be accomplished by fusion with the intrinsic activation ( $\mathrm{T}_{\mathrm{A}-\mathrm{LVpace}} 24 \mathrm{~ms}$ later than $\left.\mathrm{T}_{\mathrm{RV}}\right)$. For BiV pacing, optimal VVeff can be achieved by BiVS pacing at AV-delays shorter than $\mathrm{T}_{\mathrm{RV}}$ with a VV-interval of $-24 \mathrm{~ms}\left(\mathrm{~T}_{\mathrm{A}-\mathrm{RVpace}} 24 \mathrm{~ms}\right.$ earlier than $\mathrm{T}_{\mathrm{A} \text { - }}$ LVpace) or by BiV0 pacing at an AV-delay similar to the above mentioned LV pacing ( $24 \mathrm{~ms}$ later than $\mathrm{T}_{\mathrm{RV}}$ ), resulting in fusion with the intrinsic activation and loss of capture of RV pacing. 
$96 \mid$ Chapter 6

Table 2. Absolute values of hemodynamic parameters at baseline LBBB and at settings of optimal LVdP/dt|max.

\begin{tabular}{lcc}
\hline & baseline LBBB & $\begin{array}{c}\text { maximum } \\
\text { LVdP/dt|max }\end{array}$ \\
\cline { 2 - 3 } max LVdP/dt|max $(\mathrm{mmHg} / \mathrm{s})$ & $1761 \pm 481$ & $1902 \pm 542^{*}$ \\
LV stroke work $(\mathrm{mmHg} * \mathrm{ml})$ & $2416 \pm 492$ & $2783 \pm 548^{*}$ \\
LV stroke volume $(\mathrm{ml})$ & $28 \pm 5$ & $35 \pm 6^{*}$ \\
LV EDP(mmHg) & $10 \pm 3$ & $10 \pm 3$ \\
LV SP(mmHg) & $101 \pm 19$ & $102 \pm 20$ \\
LVdP/dt|min (mmHg/s) & $-1779 \pm 327$ & $-1818 \pm 353$ \\
RVdP/dt|max (mmHg/s) & $568 \pm 217$ & $600 \pm 164$ \\
inter-ventricular asynchrony (ms) & $-30 \pm 7$ & $-10 \pm 11^{*}$ \\
VVeff (ms) & $-55 \pm 9$ & $-6 \pm 13^{*}$ \\
\hline
\end{tabular}

$\mathrm{LVdP} / \mathrm{dt} \mid \max =$ maximum rate of $\mathrm{LV}$ pressure rise; $\mathrm{LV} \mathrm{EDP}=\mathrm{LV}$ end-diastolic pressure; $\mathrm{LV} \mathrm{SP}=$ $\mathrm{LV}$ systolic pressure; $\mathrm{LVdP} / \mathrm{dt} \mid \mathrm{min}=$ maximum rate of $\mathrm{LV}$ pressure decline; $\mathrm{RVdP} / \mathrm{dt} \mid \mathrm{max}=$ maximum rate of right ventricular pressure rise; VVeff $=$ effective VV-interval. Paired Student's ttest was performed to compare differences between baseline LBBB and values at optimal ventricular resynchronization. ${ }^{*} \mathrm{P}<0.05$ (paired t-test)

\section{DISCUSSION}

The present study shows that in canine LBBB hearts, LV pump function during CRT depends on both AV-delay and VV-interval. Optimum LV pump function can be found by varying only VVeff, rather than sweeping through many combinations of AV-delay and VV-interval. VVeff is easily determined from the surface ECG and programmed atrial-RV and atrial-LV delays. The pacemaker setting, at which optimum LV pump function occurs, can be estimated from the value of VVeff, which is halfway between its minimum and maximum values. Individual optimization of ventricular resynchronization is warranted because even in the non-failing canine LBBB hearts, considerable individual variation in optimal VVeff was found. 


\section{Validation of the VVeff concept}

The findings in the present study support the validity of the following, basic assumptions in the VVeff concept. (1) LV pump function in the LBBB heart is not influenced by the way the RV activation occurs: by RV pacing or by intrinsic conduction through the right bundle branch. (2) Optimum LV function occurs at minimal intra-LV asynchrony. Previous experimental pacing studies on canine LBBB hearts showed that minimal intra-LV asynchrony coincided with the halfway value of inter-ventricular asynchrony and with optimal LV pump function. ${ }^{7}$ Here we show that the halfway value of inter-ventricular asynchrony coincides with optimal LV pump function also during the various combinations of AV-delay and VV-interval.

In theory, various factors could have disturbed the unique relation between VVeff and pump function in the various pacing modes, such as the role of $\mathrm{AV}$ delay in ventricular filling, position of the LV and RV leads and inhomogeneities in impulse conduction. The AV-delay is known to be important for proper filling in conventional pacemaker therapy, like in patients with complete heart block. ${ }^{12}$ Along the same lines, much attention is paid to AV-delay and optimal filling in CRT. ${ }^{13,14}$ However, various studies, including the present one and our previous study in patients, ${ }^{7}$ shows that hemodynamic improvement occurs at unchanged LVEDP. It is also possible that the AV-delay for optimal filling falls within the range of that needed for optimal resynchronization.

In our concept, the sites of earliest RV and LV activation are opposite to each other. The observation that LV pump function is equal during LV and BiV pacing if VVeff is the same indicates that a relatively small difference in activation sequence, between LBBB and RV pacing, does not have a major impact on LV function. Also, in patients we have shown that LV and BiV pacing at various AV-delays fit to the same relation inter-ventricular asynchrony - LV function curve. ${ }^{8}$ Moreover, this relation was comparable in patients with and without ischemic cardiomyopathy, ${ }^{8}$ suggesting that inhomogeneities, as induced by infarcted regions, do not strongly influence the sequence of activation. This insensitivity to precise activation pattern may be explained by the broad wave fronts over long distances, underlying the activation of the ventricles.

\section{Estimation of VVeff for optimal LV pump function}

While VVeff is helpful in understanding the interaction between AV-delay and VV-interval for ventricular asynchrony, the present study also shows that optimal timing of RV and LV stimulation can be predicted relatively easily, using measurement of ECG during BiV pacing at various AV-delays and reading the programmed $\mathrm{T}_{\mathrm{A}-\mathrm{RV} \text { pace }}$ and $\mathrm{T}_{\mathrm{A}-\mathrm{LV} \text { pace. }}$. This procedure provides minimal and maximal values of VVeff and inter-ventricular asynchrony, from which the 
$98 \mid$ Chapter 6

value of VVeff and inter-ventricular asynchrony halfway their minimal and maximal value can be calculated. The finding that this halfway
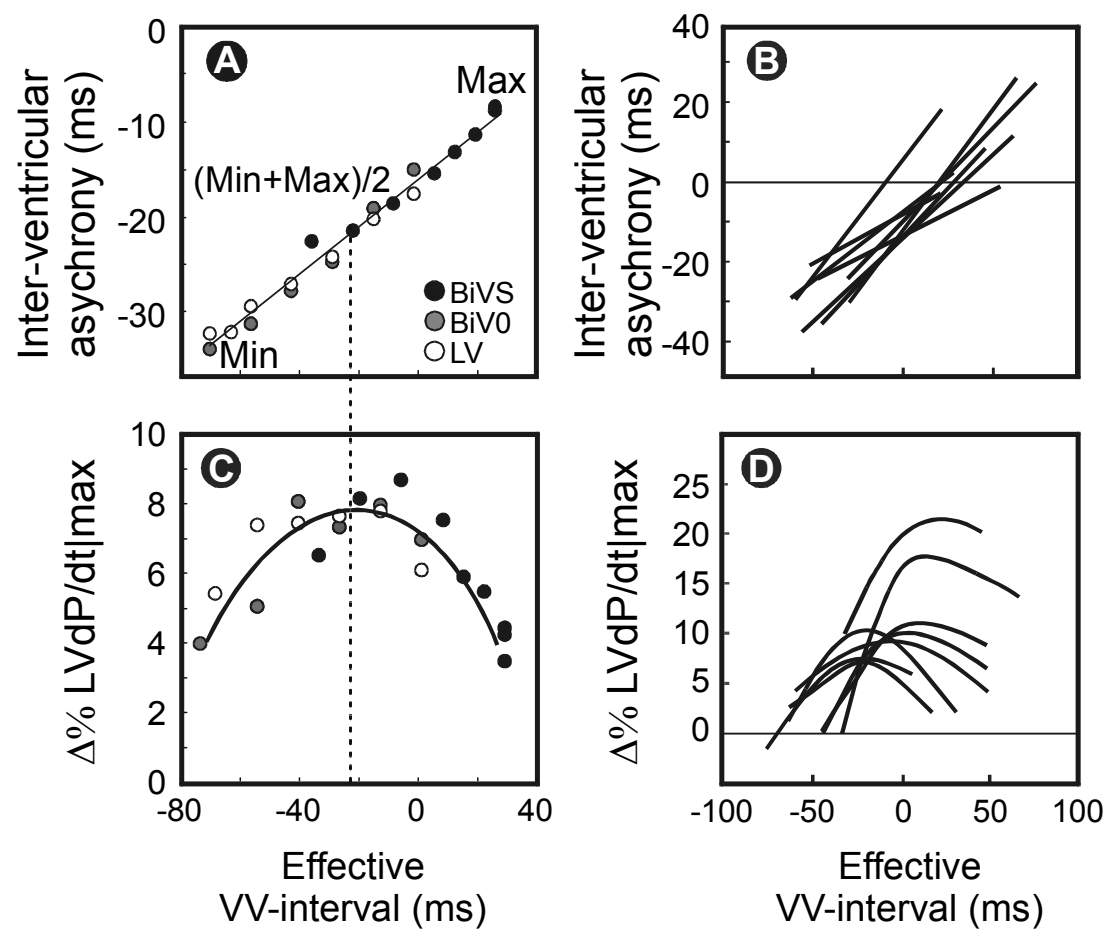

Figure 5. (A) Typical example of the linear relation between inter-ventricular asynchrony and effective VV-interval, derived from data obtained during all pacing configurations (LV, simultaneous BiV (BiV0) and sequential BiV (BIVS) pacing). (C) Typical example of the relation between effective VV-interval and improvement in $\mathrm{LVdP} / \mathrm{dt} / \mathrm{max}$ for all pacing configuration. (B,D) The relation of effective VV-interval with inter-ventricular asynchrony and $\mathrm{LVdP} / \mathrm{dt} / \max$ for all animals.

value provides an accurate estimation of VVeff, and so the optimal combination of AV-delay and VV-interval, extends similar findings in previous studies on $\mathrm{LV}$ and simultaneous BiV pacing. ${ }^{7}$ Because the latter observations were also made in patients, ${ }^{7}$ it is likely that the concept of VVeff is applicable in patients as well.

The average VVeff at optimum $\mathrm{LVdP} / \mathrm{dt} \mid$ max was close to zero in the current study, but ranged from -24 to $12 \mathrm{~ms}$ within this controlled study group of canine LBBB hearts. As these animals have hypertrophy, but otherwise relatively healthy hearts without complicated medical histories, an even larger individual variation in VVeff at optimum LV pump function can be expected in patients. This is supported by the finding that the range of inter-ventricular asyn- 


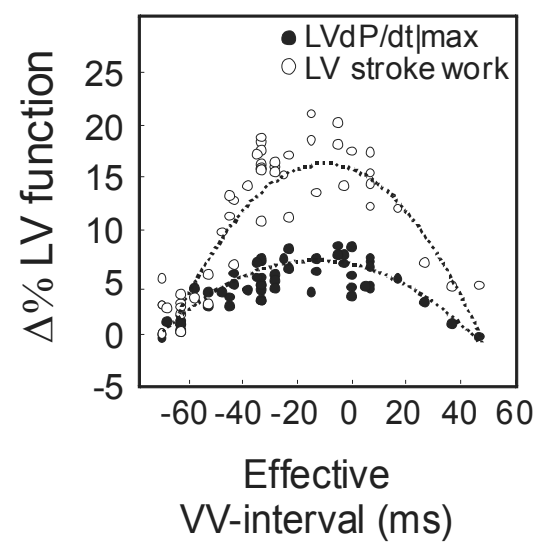

Figure 6. The relation between effective VV-interval and LV pump function was present for both $\mathrm{LVdP} / \mathrm{dt} \mid \max$ and $\mathrm{LV}$ stroke work. chrony at optimum $\mathrm{LVdP} / \mathrm{dt} \mid \max$ in patients with LBBB and heart failure was larger than that observed in the present study (-42 to $31 \mathrm{~ms}$ ). Possible explanations for the variation in VVeff in our canine LBBB model include differences in pacing lead position and differences in $\mathrm{LV}$ remodeling, i.e. differences in LV dilatation and hypertrophy. The variation in VVeff (dogs) and interventricular asynchrony (patients) at optimum LVdP/dt|max signifies the importance of individual optimization of ventricular resynchronization.

The present study shows that each value of VVeff can be achieved using various combinations of pacing configurations. Similarly, opti-

mum LV pump function can be found by more than one combination of AVdelay and VV-interval. Several small studies showed larger hemodynamic benefit from sequential BiV pacing than from simultaneous BiV pacing. ${ }^{3-5,15,16}$ However, a recently published randomized clinical trial did not show benefit for sequential BiV pacing. ${ }^{6}$ From our results, it can be concluded that, in hearts with optimal VVeff equal to zero, BiV0 pacing is as effective as BiVS pacing. In hearts with negative optimal VVeff, this optimum can be reached using BiV0 pacing and an AV-delay allowing some fusion with intrinsic conduction. Only in hearts with a positive optimal VVeff, BiVS would create a benefit, because LV pre-excitation can only be achieved using positive VV-intervals. Only two studies systematically investigated a large range of AV-delays and VVintervals. ${ }^{4,6}$ Interestingly, Whinnett end colleagues ${ }^{13}$ showed similar relation between AV-delay and VV-interval with non-invasively determined arterial blood pressure as we found for $\mathrm{LVdP} / \mathrm{dt} \mid \max$.

\section{Possible clinical application}

So far, finding the optimal combination of AV-delay and VV-interval during $\mathrm{BiV}$ pacing is regarded as too complex a problem for routine clinical practice. Normally, AV-delay is set first to optimize ventricular filling. Subsequently, optimization of the VV-interval is performed. The results from the present study indicate that VVeff may be of potential clinical relevance to optimize ventricular resynchronization, because VVeff can be determined relatively easily from 


\section{$100 \mid$ Chapter 6}

the surface ECG. Only a couple of pacing configurations, resulting in minimal and maximal values of VVeff, are necessary to estimate optimal VVeff. Moreover, the use of RV and LV electrograms, rather than the use of the surface ECG, might facilitate calculation of VVeff in clinical practice.

We propose two potential methods for optimization ventricular resynchronization and LV pump function. The first method is optimization of the VVinterval at relatively short AV-delay. At relatively short AV-delays (shorter than $\mathrm{T}_{\mathrm{RV}}$, for example $50 \%$ of PQ-time minus $30 \mathrm{~ms}^{17}$ ) ventricular filling is not hampered and ventricular intrinsic activation is absent. As a result, the programmed VV-interval equals VVeff. A second method to program the pacemaker with the optimal VVeff is to obtain fusion of LV pacing with intrinsic activation. After determination of $\mathrm{T}_{\mathrm{RV}}$ and minimal and maximal VVeff, AV-delay can be programmed in order to achieve optimal VVeff (in this case RV pacing can be turned off or $\mathrm{T}_{\mathrm{A}-\mathrm{RV} \text { pace }}$ can be programmed longer than $\mathrm{T}_{\mathrm{RV}}$ ). ${ }^{18}$ However, during LV pacing, loss of synchrony can occur when AV conduction changes in due to autonomic discharge, changes in heart rate, and drugs
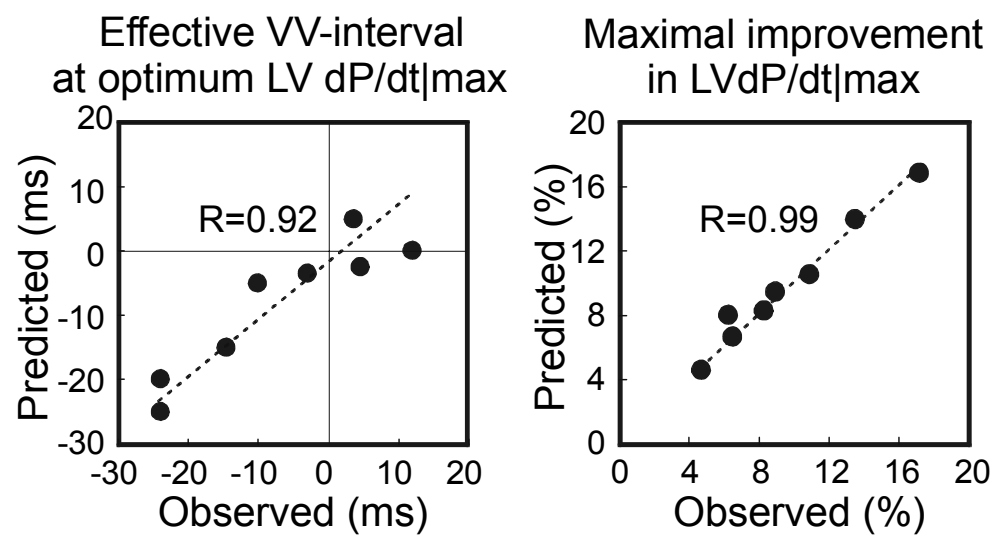

Figure 7. (A) Correlation between the observed effective VV-interval resulting in maximal LV hemodynamic improvement and the effective VV-interval predicted by the "halfway value" of the model ( $\mathrm{y}=0.71 \mathrm{x}-3.2, \mathrm{R}=0.92, \mathrm{P}<0.001)$. (B) Correlation between the observed maximal improvement in LVdP/dt|max (relative to baseline LBBB) and the predicted LV improvement in $\mathrm{LVdP} / \mathrm{dt} \mid \max (\mathrm{y}=0.94 \mathrm{x}+0.6, \mathrm{R}=0.99, \mathrm{P}<0.001)$.

\section{Limitations}

Obviously, the findings from the present animal study require further validation in patients. Although chronic LBBB resulted in significant LV dilatation and 
hypertrophy, ${ }^{9}$ there were no signs of heart failure in our dogs. Nevertheless, various data on which the concept of the present study was based, were also found in patients with LBBB and heart failure. ${ }^{7}$ This includes the similar hemodynamic response curves for inter-ventricular asynchrony during $\mathrm{BiV}$ and $\mathrm{LV}$ pacing, and that optimum $\mathrm{LVdP} / \mathrm{dt} /$ max was found halfway between the minimum and maximum values of inter-ventricular asynchrony. ${ }^{7}$

We investigated the use of VVeff in a setting where the LV lead position was presumably close to the optimal position, the LV lateral wall. A Clinically relevant question is, whether sequential $\mathrm{BiV}$ pacing can salvage suboptimal LV lead position. We did not investigate this question in the present study. However, using our concept of resynchronization of the present study, a less optimal (= not completely opposite) lead position would lead to a longer conduction pathway, and consequently to less optimal resynchronization. Because the length of the conduction pathway is not influenced by any VV-interval, it is not likely that sequential BiV pacing would correct for suboptimal LV lead placement. This, however, need to be confirmed in other studies.

In the present study, values of inter-ventricular asynchrony were determined invasively, as the time difference between the upslope of simultaneously recorded LV and RV pressure curves. Inter-ventricular asynchrony can also be determined non-invasively by using echocardiography to measure the time difference between pulmonary and aortic valve opening. We used the invasive method because it allows multiple measurements on a beat-to-beat basis, which is important if dozens of different pacemaker settings are to be studied. This invasive measurement does not influence the clinical relevance of our findings, because inter-ventricular asynchrony only served to validate that the VVeff closely matches mechanical inter-ventricular asynchrony.

\section{Conclusions}

The present study shows that the effective VV-interval, determined from the surface ECG, could greatly facilitate finding the biventricular pacing settings that result in optimum LV pump function. The value of the effective VVinterval halfway between its minimal and maximal values predicts optimum LV pump function in each canine LBBB heart.

\section{ACKNOWLEDGEMENTS}

The present study was financially supported by grants from the Netherlands Heart Foundation (2000.189 and 2000.227), the Netherlands Organization for 


\section{$102 \mid$ Chapter 6}

Health, Research and Development, and Bakken Research Center Medtronic, The Netherlands.

\section{REFERENCES}

1 St John Sutton MG, Plappert T, Abraham WT, Smith AL, DeLurgio DB, Leon AR, Loh E, Kocovic DZ, Fisher WG, Ellestad M, Messenger J, Kruger K, Hilpisch KE, Hill MR. Effect of cardiac resynchronization therapy on left ventricular size and function in chronic heart failure. Circulation. 2003;107:1985-1990.

2 Cleland JG, Daubert JC, Erdmann E, Freemantle N, Gras D, Kappenberger L, Tavazzi L. The effect of cardiac resynchronization on morbidity and mortality in heart failure. N Engl $\mathrm{J}$ Med. 2005;352:1539-1549.

3 Sogaard P, Egeblad H, Pedersen AK, Kim WY, Kristensen BO, Hansen PS, Mortensen PT. Sequential versus simultaneous biventricular resynchronization for severe heart failure: evaluation by tissue Doppler imaging. Circulation. 2002;106:2078-2084.

4 Perego GB, Chianca R, Facchini M, Frattola A, Balla E, Zucchi S, Cavaglia S, Vicini I, Negretto M, Osculati G. Simultaneous vs. sequential biventricular pacing in dilated cardiomyopathy: an acute hemodynamic study. Eur J Heart Fail. 2003;5:305-313.

5 Van Gelder BM, Bracke FA, Meijer A, Lakerveld LJ, Pijls NH. Effect of optimizing the VV interval on left ventricular contractility in cardiac resynchronization therapy. Am J Cardiol. 2004;93:1500-1503.

6 Boriani G, Muller CP, Seidl KH, Grove R, Vogt J, Danschel W, Schuchert A, Djiane P, Biffi M, Becker T, Bailleul C, Trappe HJ. Randomized comparison of simultaneous biventricular stimulation versus optimized interventricular delay in cardiac resynchronization therapy. The Resynchronization for the HemodYnamic Treatment for Heart Failure Management II implantable cardioverter defibrillator (RHYTHM II ICD) study. Am Heart J. 2006;151:10501058.

7 Verbeek XA, Auricchio A, Yu Y, Ding J, Pochet T, Vernooy K, Kramer A, Spinelli J, Prinzen FW. Tailoring cardiac resynchronization therapy using interventricular asynchrony. Validation of a simple model. Am J Physiol Heart Circ Physiol. 2006;290:H968-977.

8 Verbeek XA, Vernooy K, Peschar M, Cornelussen RN, Prinzen FW. Intra-ventricular resynchronization for optimal left ventricular function during pacing in experimental left bundle branch block. J Am Coll Cardiol. 2003;42:558-567.

9 Vernooy K, Verbeek XA, Peschar M, Crijns HJ, Arts T, Cornelussen RN, Prinzen FW. Left bundle branch block induces ventricular remodelling and functional septal hypoperfusion. Eur Heart J. 2005;26:91-98.

10 Verbeek XAAM, Vernooy K, Peschar M, Van Der Nagel T, Van Hunnik A, Prinzen FW. Quantification of interventricular asynchrony during LBBB and ventricular pacing. Am J Physiol Heart Circ Physiol. 2002;283:H1370-1378.

11 Peschar M, Vernooy K, Vanagt WY, Reneman RS, Vos MA, Prinzen FW. Absence of reverse electrical remodeling during regression of volume overload hypertrophy in canine ventricles. Cardiovasc Res. 2003;58:510-517.

12 Ritter P, Padeletti L, Gillio-Meina L, Gaggini G. Determination of the optimal atrioventricular delay in DDD pacing. Comparison between echo and peak endocardial acceleration measurements. Europace. 1999;1:126-130.

13 Whinnett ZI, Davies JE, Willson K, Manisty CH, Chow AW, Foale RA, Davies DW, Hughes AD, Mayet J, Francis DP. Haemodynamic effects of changes in AV and VV delay in cardiac resynchronisation therapy show a consistent pattern: analysis of shape, magnitude and relative importance of AV and VV delay. Heart. 2006, published ahead of print. 
14 Morales MA, Startari U, Panchetti L, Rossi A, Piacenti M. Atrioventricular delay optimization by doppler-derived left ventricular $\mathrm{dP} / \mathrm{dt}$ improves 6-month outcome of resynchronized patients. Pacing Clin Electrophysiol. 2006;29:564-568.

15 Vanderheyden M, De Backer T, Rivero-Ayerza M, Geelen P, Bartunek J, Verstreken S, De Zutter M, Goethals M. Tailored echocardiographic interventricular delay programming further optimizes left ventricular performance after cardiac resynchronization therapy. Heart Rhythm. 2005;2:1066-1072.

16 Bordachar P, Lafitte S, Reuter S, Sanders P, Jais P, Haissaguerre M, Roudaut R, Garrigue S, Clementy J. Echocardiographic parameters of ventricular dyssynchrony validation in patients with heart failure using sequential biventricular pacing. J Am Coll Cardiol. 2004;44:21572165.

17 Auricchio A, Stellbrink C, Block M, Sack S, Vogt J, Bakker P, Klein H, Kramer A, Ding J, Salo R, Tockman B, Pochet T, Spinelli J. Effect of pacing chamber and atrioventricular delay on acute systolic function of paced patients with congestive heart failure. The Pacing Therapies for Congestive Heart Failure Study Group. The Guidant Congestive Heart Failure Research Group. Circulation. 1999;99:2993-3001.

18 Van Gelder BM, Bracke FA, Meijer A, Pijls NH. The Hemodynamic Effect of Intrinsic Conduction During Left Ventricular Pacing as Compared to Biventricular Pacing. J Am Coll Cardiol. 2005;46:2305-2310. 


\section{Chapter 7}

\section{Cardiac resynchronization therapy cures dyssynchronopathy in canine LBBB hearts}

Kevin Vernooy, MD ${ }^{\mathrm{a}, \mathrm{c}}$ Richard N.M. Cornelussen, PhD, ${ }^{\mathrm{a}}$ Xander A.A.M. Verbeek, PhD, ${ }^{\mathrm{a}}$ Ward Y.R. Vanagt, $\mathrm{MD},{ }^{\mathrm{a}}$ Arne van Hunnik, BSc, ${ }^{a}$ Marion Kuiper, BSc, ${ }^{\text {a }}$ Theo Arts, PhD, ${ }^{\mathrm{b}}$ Harry J.G.M. Crijns, MD, $\mathrm{PhD},{ }^{\mathrm{c}}$ Frits W. Prinzen, $\mathrm{PhD}^{\mathrm{a}}$

Departments of Physiology, ${ }^{\mathrm{a}}$ Biophysics, ${ }^{\mathrm{b}}$ and Cardiology, ${ }^{\mathrm{c}}$ Cardiovascular Research Institute Maastricht, Maastricht, the Netherlands 
$106 \mid$ Chapter 7

\section{Abstract}

Aim. We investigated to what extent biventricular pacing (BVP) can normalize LV function and remodeling, induced by isolated left bundle branch block (LBBB).

Methods and results. In 16 dogs $\mathrm{LBBB}$ was induced. Eight animals were followed for 16 weeks and in 8 animals BVP was started after 8 weeks. LV pressure, LV geometry (2D-echocardiography), systolic circumferential shortening (CSsys, MRI tagging) and myocardial blood flow (MBF, microspheres) was measured. ${ }^{*}$ and ${ }^{*}$ indicate $\mathrm{p}<0.05$ compared to pre-LBBB and 8 weeks of LBBB, respectively. Data is presented relative to pre-LBBB values (mean $\pm \mathrm{SEM}$ ). BVP increased LVdP/dt|max from $78 \pm 5 \% *$ to $86 \pm 5 \% *^{* \#}$ (immediately) and $89 \pm 6 \%{ }^{\#}$ (after 8 weeks) and normalized regional differences in CSsys and MBF. After 8 weeks of BVP, LV end-diastolic volume (EDV) was reduced from $123 \pm 3 \% *$ to $109 \pm 6 \%{ }^{*}$ and LV lateral wall mass was reduced from $128 \pm 5 \% *$ to $113 \pm 3 \% \%^{* \#}$. The acute increase in $\mathrm{LVdP} / \mathrm{dt} \mid \max$ upon BVP correlated with LV EDV and LV wall mass after 8 weeks of BVP.

Conclusions. In canine hearts with long-term isolated LBBB, BVP largely reverses global and regional functional and structural abnormalities induced by LBBB. 


\section{INTRODUCTION}

Over a decade ago cardiac resynchronization therapy (CRT) has been introduced as an adjunctive therapy for patients with chronic heart failure and ventricular conduction disturbances, especially left bundle branch block (LBBB). In these patients CRT improves left ventricular (LV) pump function, ${ }^{1,2}$ which has been attributed to resynchronization of activation and contraction. ${ }^{1,3,4}$ CRT improves clinical status, exercise capacity and survival in patients with NYHA functional class III and IV ${ }^{5,6}$ Furthermore, CRT causes significant regression of LV dimensions, referred to as reverse remodeling. ${ }^{3,7}$ A recent study indicates that reverse remodeling predicts survival.8 It would therefore be important to know to what extent CRT can reverse remodeling in LBBB hearts.

Reversal of ventricular dilatation by CRT in LBBB hearts implies a causal relation between dyssynchrony and dilatation. In patients such a relationship is hard to establish due to the silent onset of LBBB and the considerable comorbidity in patients with LBBB. ${ }^{9}$ Animal studies provided evidence that dyssynchrony not only induces ventricular dilatation, but also asymmetric hypertrophy. Data from various studies suggests that dilatation and asymmetric hypertrophy is due to a combination of reduction in global pump function and regional differences in myocardial workload. ${ }^{10,11,12,14}$ In LBBB hearts workload is lowest in the septum and highest in the LV lateral wall. As a consequence, hypertrophy and molecular alterations are most pronounced in the lateral wall. ${ }^{10,13,14}$ We regard this combination of abnormalities specific for dyssynchronously activated hearts and define it as "dyssynchronopathy".

The aim of the present study was to investigate the effect of CRT on hearts with long-term isolated LBBB. Based on the above mentioned experimental findings that LBBB results in dyssynchronopathy, we hypothesize that CRT can cure dyssynchronopathy. This would imply acute restoration of LV pump function and the abnormal distribution of regional LV blood flow and mechanical work, followed by reversal of the LBBB-induced LV dilatation and asymmetric hypertrophy back to values before induction of LBBB. These hypotheses were investigated in canine hearts. After induction of LBBB by RF ablation, the animals were treated with biventricular pacing (BVP) after 8 weeks (LBBB+BVP group), using a previously studied group of animals with 16 weeks of LBBB as control (LBBB group). ${ }^{10,11}$ 
$108 \mid$ Chapter 7

\section{METHODS}

Animal handling was performed according to the Dutch Law on Animal Experimentation (WOD) and the European Directive for the Protection of Vertebrate Animals Used for Experimental and Other Scientific Purposes $(86 / 609 / \mathrm{EU})$. The protocol was approved by the Experimental Committee of the Maastricht University.

\section{Experimental protocol}

LBBB was induced by RF ablation in sixteen adult mongrel dogs of both sex and unknown age. Anesthesia during this procedure was induced with pentothal and maintained by ventilation with $\mathrm{O} 2$ and $\mathrm{N} 2 \mathrm{O}(1: 2)$ in combination with an infusion of midazolam and sufentanyl.4,10 A catheter tip manometer was used to measure LV pressure.4,10 For myocardial blood flow (MBF) measurements, using the fluorescent microspheres technique, a catheter was placed in the LV for microspheres injection. ${ }^{4,10}$

Subsequently, eight dogs (LBBB+BVP group) underwent a biventricular pacemaker implantation 8 weeks after induction of LBBB using the same anesthesia as used in the previous procedure. The implantation procedure is described in more detail below. A previously studied group of 8 animals with 16 weeks of LBBB served as control group (LBBB group). ${ }^{10,11}$ All dogs were anesthetized again 16 weeks after induction of LBBB and sacrificed. Finally the heart was removed and stored at $-20^{\circ} \mathrm{C}$ together with the reference blood samples for microspheres analysis. ${ }^{15}$

LV pressure and ECG measurements as well as fluorescent microspheres injections were performed before and shortly after $(30-60 \mathrm{~min})$ induction of LBBB (at week 0), before and acutely after onset of BVP (week 8 , in the LBBB+BVP group only) and at week 16 . At week 16 measurements were performed during LBBB (which was reverted in the LBBB+BVP group by turning off the pacemaker) and during BVP.

2D-Echocardiographic images were made before and every two weeks after onset of LBBB and BVP.

MR tagging measurements were performed 1 week before, 6-8 weeks after induction of LBBB as well as after 8 weeks of BVP under the same anesthetic conditions as mentioned above using manual ventilation with room air. Multislice short axis cine and MR tagging images were acquired during breath hold at a frame rate of $15 \mathrm{~ms}$, as previously described.10 In order to prevent disturbances of pacemaker action due to the magnetic field of the MR scanner the implanted pacemaker was removed. The pacemaker leads were exteriorized and connected to an external pacemaker. BVP was performed in D00 mode with a lower heart rate just above sinus rhythm. 


\section{Pre-LBBB}
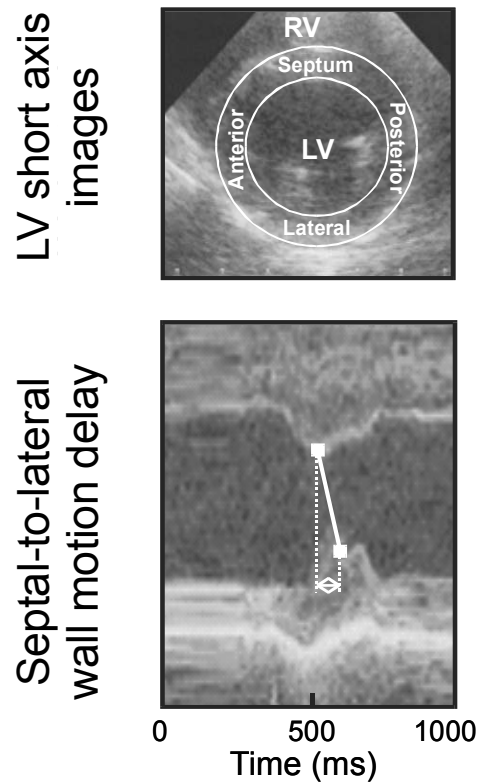

LBBB
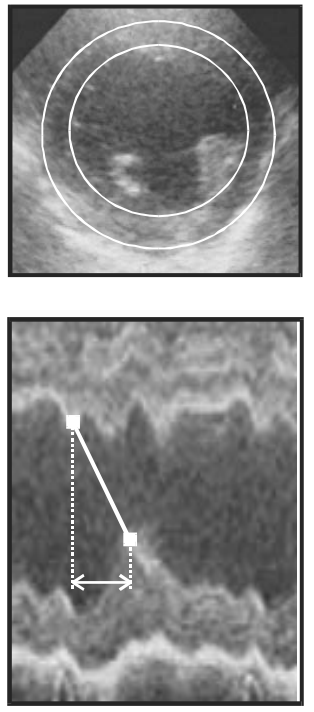

LBBB+BVP
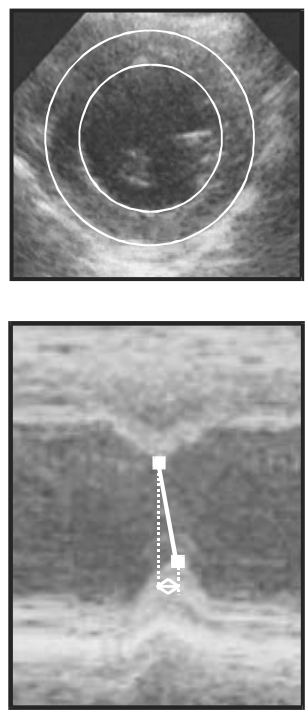

Figure 1. LV short-axis echocardiographic images (upper row) and short-axis M-mode echocardiographic images (lower panel) recorded from a dog before induction of LBBB (pre-LBBB), after 8 weeks of LBBB (LBBB) and after 8 weeks of biventricular pacing (LBBB+BVP). Note the LV dilatation and asymmetric hypertrophy after 8 weeks of LBBB and reversal of LV dilatation and asymmetric hypertrophy after 8 weeks of BVP. Short axis M-mode echocardiographic images illustrating the time delay between the inward movement of the septum and the LV lateral wall. Note the large time delay during LBBB and its restoration during BVP.

\section{Pacemaker implantation procedure}

During a minimally invasive procedure a LV epicardial screw-in pacing lead (Medtronic model 6917A, Minneapolis, MN, USA) was placed on the LV lateral wall. The lead was tunneled to the neck and the thorax was subsequently closed. Cut down of the left jugular vein in the neck provided access to the venous system to position the right atrial (Medtronic model 5568) and right ventricular (RV) lead (Medtronic model 5068).

An extensive pacing protocol was performed in VDD mode at various atrioventricular (AV-) delays and interventricular (VV-) intervals using an external 


\section{$110 \mid$ Chapter 7}

pacemaker (Medtronic AV pacing System Analyzer Model 5311B) to identify pacing configuration with optimal LVdP/dt|max. Optimal LVdP/dt|max could be achieved at a relatively short AV delay $(62 \pm 3 \mathrm{~ms})$ and VV delay of zero. Finally, the permanent internal pacemaker was implanted (Medtronic, InSyncIII). After the dogs had been allowed to recover from surgery ventricular pacing was started using the AV-delay and $\mathrm{VV}$-interval that resulted in best $\mathrm{LVdP} / \mathrm{dt} / \max$.

\section{Data Analysis}

Data analysis was performed as described previously. ${ }^{10} \mathrm{LV}$ end-diastolic volume (EDV) and total and regional LV wall mass were determined from short axis 2D- echocardiographic images (figure 1). ${ }^{13}$ Values were normalized to preLBBB values. Regional geometry was determined within $4 \mathrm{LV}$ wall regions: septum, posterior, lateral and anterior wall. On short-axis M-mode echocardiographic images the time delay between the earliest inward movement of the septum and opposite LV lateral wall, (septal-to-lateral wall motion delay, figure 1), was calculated as a measure of intraventricular mechanical asynchrony. ${ }^{16}$

MR tagging image analysis was performed off-line using home-made software for MATLAB 5.3.1 (MathWorks, Natick, MA, USA), as previously described in more detail. ${ }^{10}$ Myocardial shortening was determined in 32 midwall regions of 5-7 short-axis sections of the LV. From this, systolic circumferential shortening (CSsys) was calculated as the change in segment length during the ejection phase. Begin and end ejection were determined from the radial displacement of the LV wall during the cardiac cycle. Values of regional CSsys were normalized to the mean LV CSsys. Furthermore, the time delay of maximal systolic shortening between the septum and LV lateral wall was obtained with MR Tagging (Sep-Lat shortening delay).

For MBF measurements tissue samples were taken from two cross-sectional slices, each slice being divided into transmural sections of the septum, anterior, lateral and posterior wall. Microspheres were isolated from the tissue by digestion (ethanolic $\mathrm{KOH}$ ). Fluorescence was extracted from the beads by 2ethoxyethylacetate and determined using spectro-fluorometry. Values of regional MBF were normalized to the mean MBF in the entire LV wall. ${ }^{17}$

\section{Statistical Analysis}

The sample size in the present study was based on previous experience in our laboratory. ${ }^{10}$ Significant differences in echocardiographic variables, as well as myocardial blood flow and circumferential shortening between the LBBB group and LBBB+BVP group were analyzed at 16 weeks by unpaired t-test. Within both groups, significant differences in echocardiographic variables, as well as myocardial blood flow and circumferential shortening were analyzed between 8 
weeks and 16 weeks by paired t-test. Changes over time of electrocardiographic and hemodynamic variables presented in table 1 were evaluated using ANOVA for repeated measures. If ANOVA indicated a significant difference between time points, a Bonferroni post hoc test was performed to compare selected pairs of time points. Comparison between the acute hemodynamic improvement and remodeling after 8 weeks of BVP was made by linear regression analysis. All measured values are described as mean $\pm \mathrm{SD}$. For all analyses a $\mathrm{P}$ value $<0.05$, two sided, was considered statistically significant.

\section{RESULTS}

\section{Hemodynamics, electrocardiography and M-mode Echocardiography}

LBBB doubled QRS duration and increased the septal-to-lateral wall motion delay and the Sep-Lat shortening delay. LBBB acutely decreased LVdP/dt|max to $78 \pm 5 \%$ of pre-LBBB values (table 1 ). The values obtained immediately after induction of LBBB were not significantly different from those after 8 weeks (LBBB+BVP group) and 16 weeks of LBBB (LBBB group, data previously shown 4,10). BVP immediately reduced QRS duration and restored the septalto-lateral wall motion delay as well as the Sep-Lat shortening delay. BVP increased $\mathrm{LVdP} / \mathrm{dt} \mid \max$ to $86 \pm 5 \%$ of pre-LBBB values, without affecting $\mathrm{LV}$ systolic or end diastolic pressure. After 8 weeks of BVP LVdP/dt|max was $89 \pm 5 \%$ of pre-LBBB values (table 1).

\section{Differences in septum versus $L V$ lateral wall}

Figure 2 presents myocardial circumferential shortening tracings in eight regions along the circumference in a mid-basal short-axis LV slice. Before LBBB, the time course and amplitude of myocardial shortening were similar in the various LV regions. During LBBB, the early-activated septum showed earlysystolic myocardial shortening followed by paradoxical motion. In the lateactivated LV lateral wall early systolic pre-stretch was followed by pronounced systolic shortening. BVP largely restored the abnormal contraction pattern induced by LBBB.

Induction of LBBB decreased CSsys in the septum to almost zero and approximately doubled CSsys in the LV lateral wall (figure 3). This redistribution of CSsys remained unchanged over 16 weeks of LBBB (LBBB group). However, BVP virtually normalized the redistribution of regional CSsys (figure 3).

Along with CSsys, induction of LBBB resulted in an immediate and persistent redistribution of regional MBF (figure 4). LBBB decreased MBF in the septum and increased MBF in the LV lateral wall to $88 \pm 4 \%$ and $114 \pm 4 \%$, re- 


\section{2 \\ Chapter 7}

spectively. BVP immediately returned MBF distribution close to the pre-LBBB state (septal MBF $100 \pm 5 \%$; LV lateral wall MBF $97 \pm 3 \%$, figure 4). During 8 weeks of BVP MBF distribution remained uniform. Turning off BVP after 8 weeks in the $\mathrm{LBBB}+\mathrm{BVP}$ group resulted again in an immediate redistribution of MBF to values similar to those seen after induction of LBBB.

Table 1. Electrocardiographic and hemodynamic data in LBBB+BVP group.

\begin{tabular}{lccccc}
\hline & Pre-LBBB & Acute LBBB & $\begin{array}{c}8 \text { weeks } \\
\text { LBBB }\end{array}$ & $\begin{array}{c}\text { Acute } \\
\text { BVP }\end{array}$ & 8 weeks BVP \\
\cline { 2 - 6 } Heart rate (bpm) & $89 \pm 3$ & $95 \pm 3$ & $82 \pm 4$ & $90 \pm 4$ & $92 \pm 3$ \\
QRS duration (ms) & $69 \pm 3$ & $119 \pm 3^{*}$ & $123 \pm 4^{*}$ & $108 \pm 3^{* \dagger}$ & $102 \pm 3^{* \dagger}$ \\
$\begin{array}{l}\text { PQ time (ms) } \\
\text { LVdP/dt|max } \\
\text { (mmHg/s) }\end{array}$ & $127 \pm 9$ & $117 \pm 5$ & $129 \pm 8$ & $74 \pm 3^{* \dagger}$ & $74 \pm 9 * \dagger$ \\
$\begin{array}{l}\text { LV SP (mmHg) } \\
\text { LV EDP (mmHg) }\end{array}$ & $105 \pm 4$ & $100 \pm 5$ & $111 \pm 4$ & $116 \pm 3$ & $101 \pm 4$ \\
$\begin{array}{l}\text { Septum-to-lateral } \\
\text { wall motion delay } \\
\text { (ms) }\end{array}$ & $64 \pm 1$ & $6 \pm 1$ & $7 \pm 1$ & $8 \pm 2$ & $6 \pm 1$ \\
$\begin{array}{l}\text { Sep-Lat shortening } \\
\text { delay (ms) }\end{array}$ & $-27 \pm 15$ & N.A. & $222 \pm 13^{*}$ & N.A. & $66 \pm 8 \dagger$ \\
\hline
\end{tabular}

LVdP/dt|max: maximal rate of increase in left ventricular (LV) pressure; LV SP: LV systolic pressure; LV EDP: LV end-diastolic pressure; Septal-to-lateral wall motion delay: time delay from inward movement of septum to LV lateral wall; Sep-Lat shortening delay: time delay from first peak shortening of septum to LV lateral wall; N.A.: data not available. Symbols * and $\dagger$ indicate $\mathrm{p}<0.05$ as compared with pre-LBBB and 8 weeks LBBB, respectively. Values are presented as mean \pm SEM..

\section{LV (reverse) remodeling}

Eight weeks of LBBB resulted in an increase of both LV EDV and LV wall mass. At the regional level, wall mass was increased in the LV lateral wall but not in the septum, indicating asymmetrical hypertrophy (figure 1 and 5). In the LBBB group LV EDV and LV wall mass leveled off between 8 and 16 weeks of LBBB.

Figure 5 shows that within 8 weeks of BVP LV EDV returned to pre-LBBB values (from $123 \pm 3$ to $109 \pm 7 \%$ of pre-LBBB values), indicating reversal of LV dilatation. BVP did not significantly affect total LV mass (from $117 \pm 5$ to $110 \pm 2 \%)$. However, at the regional level a significant decrease was observed in LV lateral wall mass (from $128 \pm 5 \%$ to $113 \pm 3 \%$ ), whereas septal wall mass did 
not change during BVP (figure 5 lower panel). Consequently, the LV septal-tolateral wall mass ratio decreased to $84 \pm 2 \%$ of the pre-LBBB values after 8 weeks of LBBB and increased to $98 \pm 3 \%$ after a subsequent 8 weeks of BVP, indicating reversal of asymmetrical LV hypertrophy.

The relative improvement in LVdP/dt|max acutely after onset of BVP proved to be related to the relative decrease in LV EDV and LV wall mass during 8 weeks of BVP (figure 6). When plotting the changes in LV dimensions as a function of the changes in $\mathrm{LVdP} / \mathrm{dt} \mid \max$ for all dogs in the study, significant correlations were found between $\Delta \% \mathrm{LVdP} / \mathrm{dt} \mid \max$ and $\Delta \% \mathrm{LV}$ EDV $(\mathrm{r}=-0.69$, $\mathrm{p}<0.05)$ and $\Delta \% \mathrm{LV}$ wall mass $(\mathrm{r}=-0.73, \mathrm{P}<0.05)$.

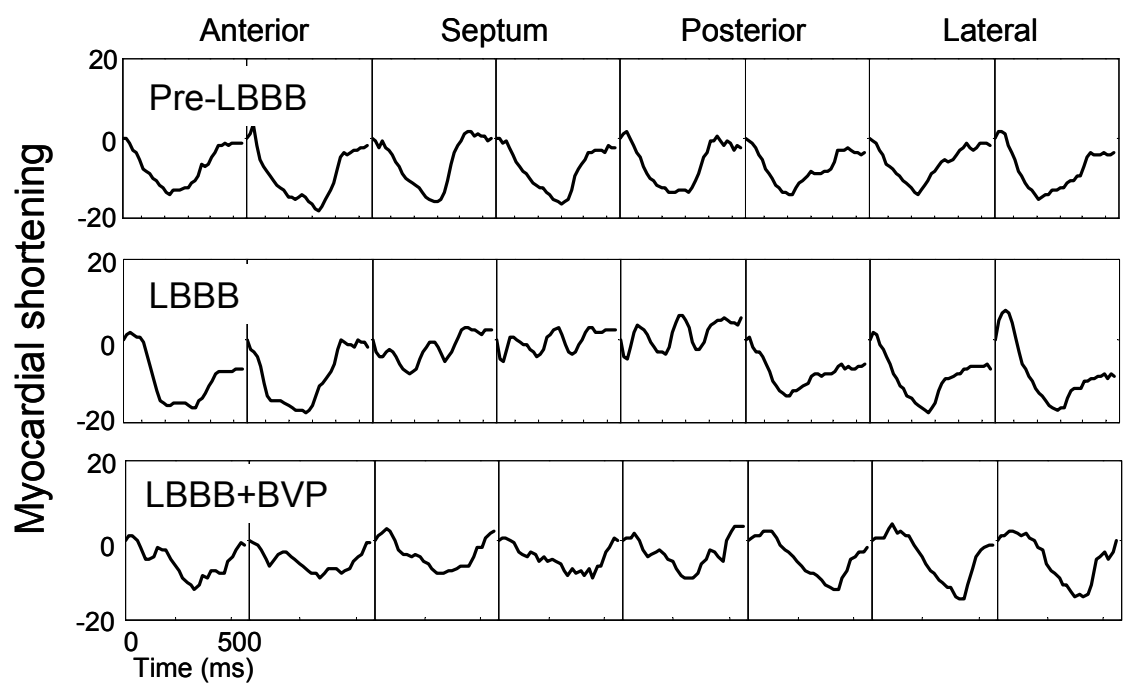

Figure 2. Typical example of myocardial circumferential shortening tracings in eight regions along the circumference in a mid-basal short-axis LV slice. Please note the abnormal shortening patterns during $\mathrm{LBBB}$ and the normalization during BVP (LBBB+BVP). For details, see text 


\section{4 \\ Chapter 7}

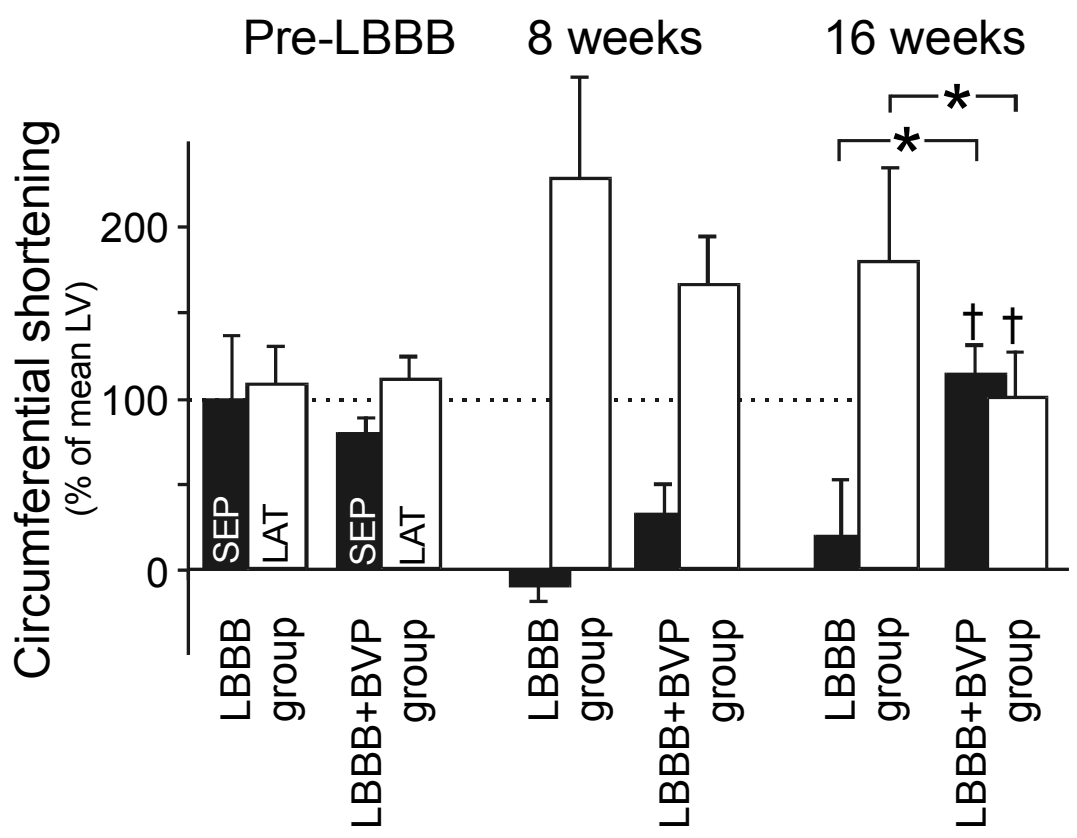

Figure 3. Bars represent LV systolic circumferential shortening in the septum (SEP) and LV lateral wall (LAT) in the LBBB group and LBBB+BVP group at baseline, after 6-8 weeks of LBBB, and after 16 weeks of LBBB (LBBB group) and 8 weeks LBBB + 8 weeks $\mathrm{BVP}$ (LBBB+BVP group). ${ }^{*} \mathrm{P}<0.05$ (unpaired t-test) LBBB group versus LBBB+BVP group at 16 weeks. $\dagger \mathrm{P}<0.05$ (paired t-test) 16 weeks versus 8 weeks within each group. Values are presented as mean $\pm \mathrm{SD}$

\section{DISCUSSION}

The present study demonstrates that in LBBB hearts ventricular resynchronization by BVP largely restores LV pump function. Moreover, as indicated by the uniform distribution of myocardial shortening and blood flow, BVP normalizes myocardial workload distribution. On the long run BVP reduces LV dilatation more than total LV wall mass. However, wall mass is specifically reduced in the late activated, most hypertrophied LV lateral wall. Altogether, the data indicate that BVP almost completely cures hearts with LBBB from dyssynchronopathy. 


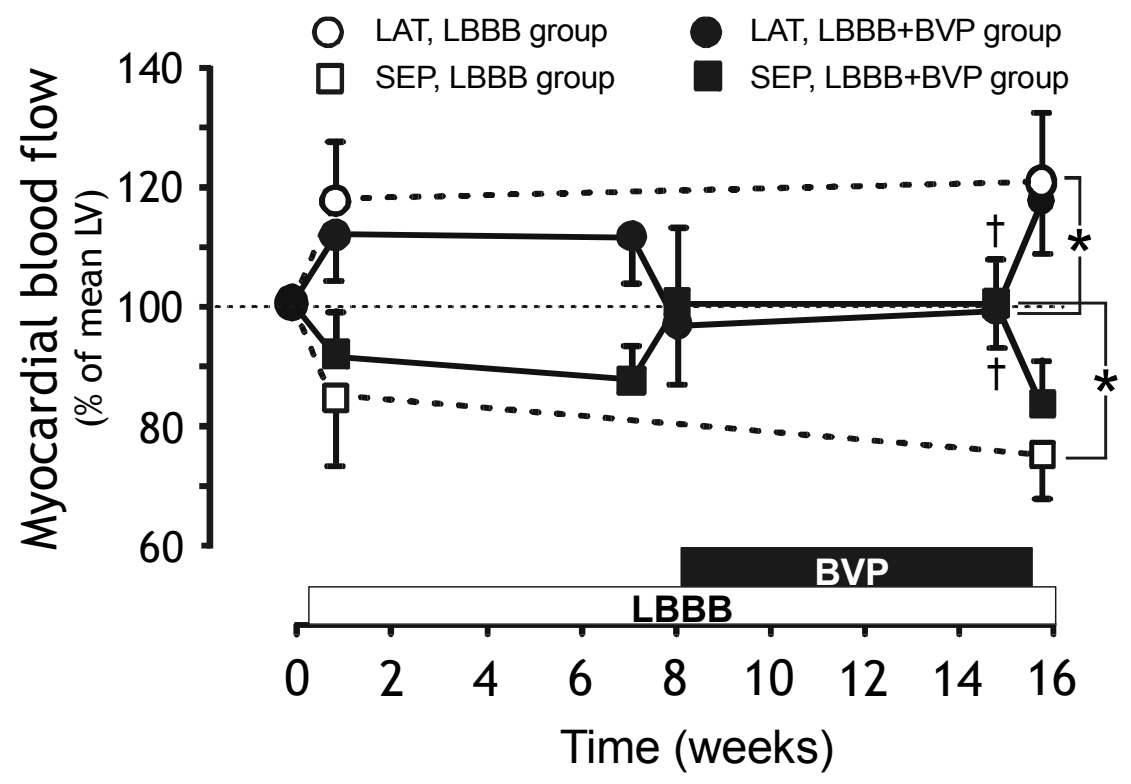

Figure 4. Time course of LV myocardial blood flow in the septum (SEP) and LV lateral wall (LAT) in the LBBB and LBBB+BVP group. ${ }^{*} \mathrm{P}<0.05$ (unpaired t-test) LBBB group versus $\mathrm{LBBB}+\mathrm{BVP}$ group at 16 weeks. $\uparrow \mathrm{P}<0.05$ (paired t-test) 16 weeks versus 8 weeks within each group. Values are presented as mean \pm SD

\section{Reverse remodeling}

The main finding of the present study is that BVP can reverse LV EDV and LV wall mass almost to the level present before induction of LBBB. This is in keeping with the almost complete normalization of LV pump function upon starting BVP. Even clearer is the restoration of uniform distribution of myocardial strains and blood flow, presumably leading to a uniform distribution of wall mass. Together, these data show that BVP "cures" the heart from LBBB. The proof of this idea can only be obtained in animal studies, because in patients data before onset of LBBB are scarce and not systematically present.

The improvement by BVP occurred in an animal model of isolated LBBB. In these animals LV pump function was reduced, as evidenced by a reduction in $\mathrm{LVdP} / \mathrm{dt} \mid \mathrm{max}$, stroke work and ejection fraction without overt heart failure., ${ }^{4,10}$ Therefore, the data from the present study indicate that BVP can improve LV pump function and structure even in the absence of overt heart failure. In previous studies in dogs with normal ventricular impulse conduction BVP did not improve LV function and induced moderate electrical and mechanical asyn- 


\section{6 \\ Chapter 7}

chrony, ${ }^{11,18}$ indicating that BVP is only effective in asynchronously activated hearts. This observation is supported by the findings from clinical studies showing that BVP does not improve in patients without asynchrony at baseline. ${ }^{19,20} \mathrm{~A}$ recent study even indicates that BVP in "non-responders" leads to an increase in LV EDV and LV wall mass. ${ }^{21}$

The majority of the functional improvement was found almost immediately after onset of BVP and only a minor, not significant improvement on the longer run. In a clinical study $\mathrm{Yu}$ et al showed a slow continuing increase in, indirectly measured, $\mathrm{LVdP} / \mathrm{dt} \mid \max$ in patients over the first 3 months after onset of CRT. ${ }^{3}$

The relative decrease of LV EDV during BVP in the present study $(\sim 20 \%)$ is in the same range as observed in clinical studies. ${ }^{3,7,22}$ Also, the time to achieve reverse remodeling is similar in the present study and in patients: within a few months. ${ }^{3}$ This indicates that in case patients do not show reverse remodeling within 3-6 months after starting CRT, remodeling has either become irreversible, there is no ventricular dyssynchrony, or CRT is not applied appropriately. Such observation might be a reason to seek for improving the resynchronization therapy, for example by checking proper pacing lead position or timing of stimulation.

Few clinical studies report on changes in (regional) LV hypertrophy. $\mathrm{Yu}$ and colleagues ${ }^{3}$ did not find significant changes in LV mass during CRT, not even in patients with regression of LV dilatation. This observation is not in conflict with our observations on total LV mass. The present study shows that values on total LV mass conceal changes at the regional level, especially in the most hypertrophied latest activated regions. Asymmetric hypertrophy has been observed in patients during RV apex pacing ${ }^{23}$ and in patients with LBBB. ${ }^{9}$ Zhang and colleagues ${ }^{21}$ did not find asymmetric hypertrophy in their study and no regional difference in the change of local wall mass. This lack of regional change in wall mass could be explained by the small size of the study and/or the measuring technique: measuring the thickness at a certain point. We employed integration over entire wall sectors rather than measuring local thickness; the latter can be expected to be relatively inaccurate due to the irregular endocardial wall. The present study and also an earlier echocardiographic study on LBBB patients ${ }^{9}$ indicates that the ratio of septum to LV lateral wall thickness may be a parameter to assess (reversal of) asymmetric hypertrophy. Also, because presumably asymmetric hypertrophy is an expression of longer lasting and significant redistribution of workload due to asynchronous activation, asymmetric hypertrophy could be an additional diagnostic indication of the success of CRT.

Regression of hypertrophy in the most hypertrophied part of the LV wall may be functionally relevant. Asynchronous ventricular activation in failing hearts, induced by rapid RV pacing, resulted in myocardial protein dysregulation selectively in the late-activated LV lateral wall, such as down regulation of SR Ca-ATPase, phospholamban and connexin $43 .{ }^{14}$ 


\section{Relation between pump function and reverse remodeling}

Ventricular remodeling in asynchronously activated hearts is characterized by global enlargement (LV EDV and LV mass) and an asymmetric distribution of LV mass. ${ }^{9,10,13}$ We have previously proposed that overall LV enlargement is related to the reduction in pump function. ${ }^{12}$ Consequences of reduced pump function, such as a right-ward shift in the LV pressure-volume relation ${ }^{13}$ and neurohumoral activation, ${ }^{24}$ are established triggers for hypertrophy. The finding in the present study, that the acute improvement of LV pump function by BVP predicts the degree of LV reverse remodeling, supports the abovementioned relation between pump function and global LV enlargement.

The finding that the acute improvement of LV pump function by BVP predicts LV reverse remodeling should, however, be extrapolated to the clinical situation with care. Evidence available so far indicates that the relation between hemodynamic improvement and reverse remodeling is less clear in patients. ${ }^{25}$ The number of observations in the present animal study too low to be used for prediction in a large population. Moreover, reversibility of remodeling may be less in patients with longstanding remodeling than in healthy dogs with 2 months of LBBB.

Lower reversibility of reverse remodeling and the observation that CRT can already reverse remodeling in LBBB hearts without overt heart failure could plea for starting CRT in less advanced heart failure. This idea is supported by previous studies. Stellbrink and colleagues ${ }^{25}$ observed that "volume responders" had smaller baseline LV EDV and ESV than non-responders. Secondly, Bleeker and colleagues showed larger relative reduction in NYHA II than in NYHA class III patients. ${ }^{26}$ The regionally different contraction patterns in the asynchronous heart cause significant regional differences in stretch and subsequently workload, being the most likely explanation for the asymmetry of hypertrophy. ${ }^{4,10,13}$ Similarly, the normalization of the contraction patterns by BVP, thereby normalizing regional differences in workload, explain the disappearance of the asymmetry of hypertrophy during BVP.

The immediate change in myocardial blood flow distribution in the present study indicates that this change can predominantly be attributed to the distribution of regional workload upon changing the sequence of activation. PET studies on myocardial blood flow in CRT patients were performed at least 3 weeks after onset of CRT, leaving open the possibility that the change in blood flow distribution is due to reverse remodeling. ${ }^{27-29}$ The parallel change of 
$118 \mid$ Chapter 7
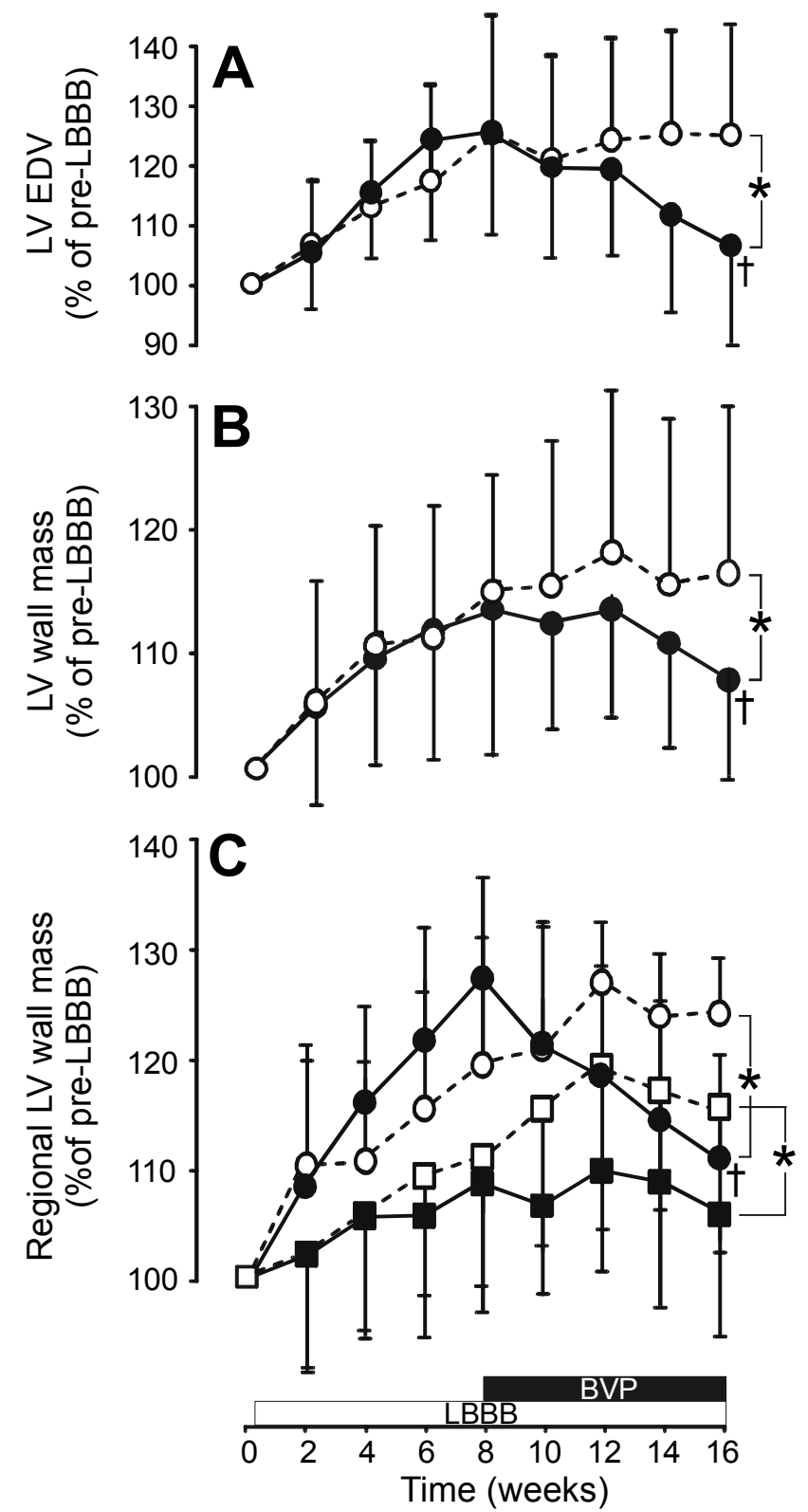

Figure 5. Relative changes in (A) LV end-diastolic volume (LV EDV) and (B) total LV wall mass and (C) septal (squares) and LV lateral wall (circles) mass in the LBBB (open symbols) and LBBB+BVP group (closed symbols). ${ }^{*} \mathrm{p}<0.05$ (unpaired t-test) LBBB group versus $\mathrm{LBBB}+\mathrm{BVP}$ group at 16 weeks. $\uparrow \mathrm{P}<0.05$ (paired t-test) 16 weeks versus 8 weeks within each group. Values are presented as mean \pm SD. 
blood flow and oxygen uptake distribution in CRT patients further supports the redistribution of mechanical work by the change in activation sequence. ${ }^{28-30}$
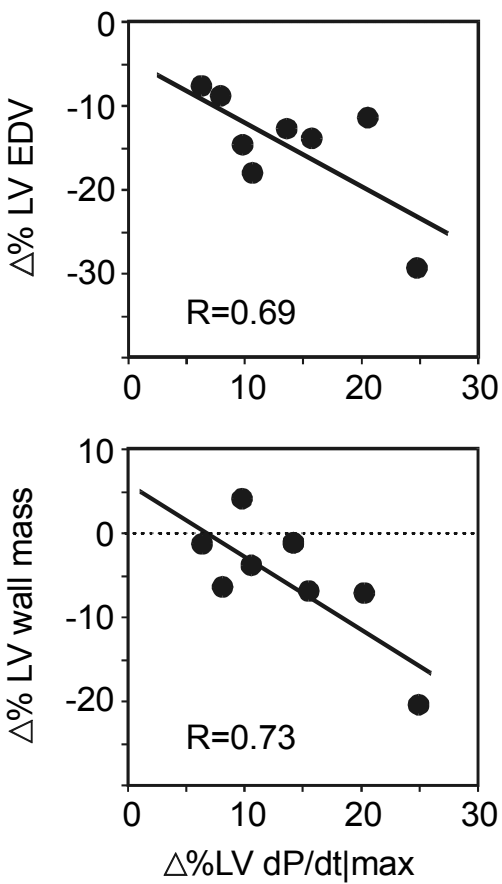

Figure 6. Correlation between the acute hemodynamic improvement during optimal BVP $(\Delta \%$ $\mathrm{LVdP} / \mathrm{dt} / \max )$ and relative reduction of $\mathrm{LV}$ end-diastolic volume $(\Delta \% \mathrm{LV}$ EDV) and $L V$ wall mass $(\Delta \% \mathrm{LV}$ wall mass) after 8 weeks of BVP.

\section{Dog model}

The present study was performed in an animal model of LBBB. There may be various differences between this animal model and patients with conduction disturbances. In the present study LBBB was induced by radio-frequency ablation in the animals, whereas a proximal block of the left bundle may not be present in all patients with LBBB. $^{31,32}$ also, the animals lack any other co-morbidity, which may be of influence in the response to BVP. Nevertheless, the relative increase in QRS duration and septal-to-lateral wall motion delay in the present study was the same as the difference between control and LBBB patients. ${ }^{16}$ Also, the redistribution of blood flow during LBBB and BVP in the present study was similar to that in non-ischemic LBBB patients. ${ }^{28}$

Like patients with LBBB showing lower septal perfusion ${ }^{28}$ and mechanical ventricular asynchrony, ${ }^{16,19}$ all our dogs were "responders" in the sense that BVP improved LV pump function, normalized blood flow redistribution and reduced LV dilation. Moreover, a

previous study showed that the relation between interventricular asynchrony and LV pump function during ventricular pacing was similar in our LBBB animals as compared to CRT candidates. ${ }^{20}$ Thus, despite potential differences between the LBBB animals and patients, our LBBB animal model has many aspects of asynchrony and resynchronization in common with patients with LBBB with and without resynchronization. 


\section{$120 \mid$ Chapter 7}

\section{CONCLUSION}

In canine hearts with isolated LBBB, BVP can reverse most of the LV ventricular remodeling, induced by LBBB. Reverse remodeling consisted of reduction of LV dilatation as well as regression of hypertrophy in the most hypertrophied late activated LV lateral wall. LV reverse remodeling appeared to be related to the more uniform distribution of myocardial workload.

\section{ACKNOWLEDGEMENTS}

The study was financially supported by grants from the Netherlands Heart Foundation (2000.189 and 2000.227), the Netherlands Organization for Health Research and Development (KV) and Bakken Research Center Medtronic, The Netherlands.

\section{REFERENCES}

1 Leclercq C, Faris O, Tunin R, Johnson J, Kato R, Evans F, Spinelli J, Halperin H, McVeigh E, Kass DA. Systolic improvement and mechanical resynchronization does not require electrical synchrony in the dilated failing heart with left bundle-branch block. Circulation. 2002;106:1760-1763.

2 Auricchio A, Stellbrink C, Block M, Sack S, Vogt J, Bakker P, Klein H, Kramer A, Ding J, Salo R, Tockman B, Pochet T, Spinelli J. Effect of pacing chamber and atrioventricular delay on acute systolic function of paced patients with congestive heart failure. The Pacing Therapies for Congestive Heart Failure Study Group. The Guidant Congestive Heart Failure Research Group. Circulation. 1999;99:2993-3001.

3 Yu CM, Chau E, Sanderson JE, Fan K, Tang MO, Fung WH, Lin H, Kong SL, Lam YM, Hill MR, Lau CP. Tissue Doppler echocardiographic evidence of reverse remodeling and improved synchronicity by simultaneously delaying regional contraction after biventricular pacing therapy in heart failure. Circulation. 2002;105:438-445.

4 Verbeek XA, Vernooy K, Peschar M, Cornelussen RN, Prinzen FW. Intra-ventricular resynchronization for optimal left ventricular function during pacing in experimental left bundle branch block. J Am Coll Cardiol. 2003;42:558-567.

5 Bradley DJ, Bradley EA, Baughman KL, Berger RD, Calkins H, Goodman SN, Kass DA, Powe NR. Cardiac resynchronization and death from progressive heart failure: a metaanalysis of randomized controlled trials. JAMA. 2003;289:730-740.

6 Cleland JG, Daubert JC, Erdmann E, Freemantle N, Gras D, Kappenberger L, Tavazzi L. The effect of cardiac resynchronization on morbidity and mortality in heart failure. N Engl $\mathrm{J}$ Med. 2005;352:1539-1549.

7 St John Sutton MG, Plappert T, Abraham WT, Smith AL, DeLurgio DB, Leon AR, Loh E, Kocovic DZ, Fisher WG, Ellestad M, Messenger J, Kruger K, Hilpisch KE, Hill MR. Effect of cardiac resynchronization therapy on left ventricular size and function in chronic heart failure. Circulation. 2003;107:1985-1990. 
8 Yu CM, Bleeker GB, Fung JW, Schalij MJ, Zhang Q, van der Wall EE, Chan YS, Kong SL, Bax JJ. Left Ventricular Reverse Remodeling but Not Clinical Improvement Predicts LongTerm Survival After Cardiac Resynchronization Therapy. Circulation. 2005.

9 Prinzen FW, Cheriex EC, Delhaas T, van Oosterhout MF, Arts T, Wellens HJ, Reneman RS. Asymmetric thickness of the left ventricular wall resulting from asynchronous electric activation: a study in dogs with ventricular pacing and in patients with left bundle branch block. Am Heart J. 1995;130:1045-1053.

10 Vernooy K, Verbeek XA, Peschar M, Crijns HJ, Arts T, Cornelussen RN, Prinzen FW. Left bundle branch block induces ventricular remodelling and functional septal hypoperfusion. Eur Heart J. 2005;26:91-98.

11 Peschar M, de Swart H, Michels KJ, Reneman RS, Prinzen FW. Left ventricular septal and apex pacing for optimal pump function in canine hearts. J Am Coll Cardiol. 2003;41:12181226.

12 Vernooy K, Verbeek XA, Peschar M, Prinzen FW. Relation between abnormal ventricular impulse conduction and heart failure. J Interv Cardiol. 2003;16:557-562.

13 van Oosterhout MF, Prinzen FW, Arts T, Schreuder JJ, Vanagt WY, Cleutjens JP, Reneman RS. Asynchronous electrical activation induces asymmetrical hypertrophy of the left ventricular wall. Circulation. 1998;98:588-595.

14 Spragg DD, Leclercq C, Loghmani M, Faris OP, Tunin RS, DiSilvestre D, McVeigh ER, Tomaselli GF, Kass DA. Regional alterations in protein expression in the dyssynchronous failing heart. Circulation. 2003;108:929-932.

15 van Oosterhout MF, Arts T, Bassingthwaighte JB, Reneman RS, Prinzen FW. Relation between local myocardial growth and blood flow during chronic ventricular pacing. Cardiovasc Res. 2002;53:831-840.

16 Pitzalis MV, Iacoviello M, Romito R, Massari F, Rizzon B, Luzzi G, Guida P, Andriani A, Mastropasqua F, Rizzon P. Cardiac resynchronization therapy tailored by echocardiographic evaluation of ventricular asynchrony. J Am Coll Cardiol. 2002;40:1615-1622.

17 Van Oosterhout MF, Prinzen FW, Sakurada S, Glenny RW, Hales JR. Fluorescent microspheres are superior to radioactive microspheres in chronic blood flow measurements. Am J Physiol. 1998;275:H110-115.

18 Wyman BT, Hunter WC, Prinzen FW, Faris OP, McVeigh ER. Effects of single- and biventricular pacing on temporal and spatial dynamics of ventricular contraction. Am J Physiol Heart Circ Physiol. 2002;282:H372-379.

19 Penicka M, Bartunek J, De Bruyne B, Vanderheyden M, Goethals M, De Zutter M, Brugada $\mathrm{P}$, Geelen P. Improvement of left ventricular function after cardiac resynchronization therapy is predicted by tissue Doppler imaging echocardiography. Circulation. 2004;109:978-983.

20 Verbeek XA, Auricchio A, Yu Y, Ding J, Pochet T, Vernooy K, Kramer A, Spinelli J, Prinzen FW. Tailoring cardiac resynchronization therapy using interventricular asynchrony. Validation of a simple model. Am J Physiol Heart Circ Physiol. 2006;290:H968-977.

21 Zhang Q, Fung JW, Auricchio A, Chan JY, Kum LC, Wu LW, Yu CM. Differential change in left ventricular mass and regional wall thickness after cardiac resynchronization therapy for heart failure. Eur Heart J. 2006;27:1423-1430.

22 Auricchio A, Stellbrink C, Sack S, Block M, Vogt J, Bakker P, Huth C, Schondube F, Wolfhard U, Bocker D, Krahnefeld O, Kirkels H. Long-term clinical effect of hemodynamically optimized cardiac resynchronization therapy in patients with heart failure and ventricular conduction delay. J Am Coll Cardiol. 2002;39:2026-2033.

23 Thambo JB, Bordachar P, Garrigue S, Lafitte S, Sanders P, Reuter S, Girardot R, Crepin D, Reant P, Roudaut R, Jais P, Haissaguerre M, Clementy J, Jimenez M. Detrimental ventricular remodeling in patients with congenital complete heart block and chronic right ventricular apical pacing. Circulation. 2004;110:3766-3772. 


\section{2 \\ Chapter 7}

24 Lee MA, Dae MW, Langberg JJ, Griffin JC, Chin MC, Finkbeiner WE, O'Connell JW, Botvinick E, Scheinman MM, Rosenqvist M. Effects of long-term right ventricular apical pacing on left ventricular perfusion, innervation, function and histology. J Am Coll Cardiol. 1994;24:225-232.

25 Stellbrink C, Breithardt OA, Franke A, Sack S, Bakker P, Auricchio A, Pochet T, Salo R, Kramer A, Spinelli J. Impact of cardiac resynchronization therapy using hemodynamically optimized pacing on left ventricular remodeling in patients with congestive heart failure and ventricular conduction disturbances(1). J Am Coll Cardiol. 2001;38:1957-1965.

26 Bleeker GB, Schalij MJ, Holman ER, Steendijk P, Van der Wal AC, Bax JJ. Cardiac resynchronization therapy in patients with NYHA class II heart failure. HRS 2006 (abstract P699).

27 Nowak B, Sinha AM, Schaefer WM, Koch KC, Kaiser HJ, Hanrath P, Buell U, Stellbrink C. Cardiac resynchronization therapy homogenizes myocardial glucose metabolism and perfusion in dilated cardiomyopathy and left bundle branch block. J Am Coll Cardiol. 2003;41:1523-1528.

28 Lindner O, Vogt J, Kammeier A, Wielepp P, Holzinger J, Baller D, Lamp B, Hansky B, Korfer R, Horstkotte D, Burchert W. Effect of cardiac resynchronization therapy on global and regional oxygen consumption and myocardial blood flow in patients with non-ischaemic and ischaemic cardiomyopathy. Eur Heart J. 2005;26:70-76.

29 Knaapen P, van Campen LM, de Cock CC, Gotte MJ, Visser CA, Lammertsma AA, Visser FC. Effects of cardiac resynchronization therapy on myocardial perfusion reserve. Circulation. 2004;110:646-651.

30 Ukkonen H, Beanlands RS, Burwash IG, de Kemp RA, Nahmias C, Fallen E, Hill MR, Tang AS. Effect of cardiac resynchronization on myocardial efficiency and regional oxidative metabolism. Circulation. 2003;107:28-31.

31 Rodriguez LM, Timmermans C, Nabar A, Beatty G, Wellens HJ. Variable patterns of septal activation in patients with left bundle branch block and heart failure. J Cardiovasc Electrophysiol. 2003; 14:135-141.

32 Auricchio A, Fantoni C, Regoli F, Carbucicchio C, Goette A, Geller C, Kloss M, Klein H. Characterization of left ventricular activation in patients with heart failure and left bundlebranch block. Circulation. 2004;109:1133-1139. 


\section{Chapter 8}

\section{Ventricular Remodeling During Long- term Right Ventricular Pacing Following His Bundle Ablation}

Kevin Vernooy, MD, ${ }^{\mathrm{a}, \mathrm{b}}$ Barbara Dijkman, MD, PhD, ${ }^{\mathrm{a}}$ Emile C. Cheriex, $\mathrm{MD}, \mathrm{PhD},{ }^{\mathrm{a}}$ Frits W. Prinzen, $\mathrm{PhD},{ }^{\mathrm{b}}$ and Harry J.G.M. Crijns, MD, PhD. ${ }^{\mathrm{a}}$

Department of Cardiology, ${ }^{\mathrm{a}}$ and Physiology, ${ }^{\mathrm{b}}$ Cardiovascular Research Institute Maastricht, Maastricht, the Netherlands

American Journal of Cardiology 2006 Apr 15;97(8):1223-7. 
$124 \mid$ Chapter 8

\section{Abstract}

Objective: To investigate ventricular remodeling during long-term right ventricular (RV) pacing after His bundle ablation in patients with atrial arrhythmias.

Methods: Retrospective analysis was performed on echocardiographic data from 45 patients $(57 \pm 11 \mathrm{yrs})$ with atrial arrhythmias who underwent His bundle ablation and pacemaker implantation (HBA-PM) to control ventricular rate. Echocardiography was performed one year before HBA-PM and up to $7 \pm 2$ yrs of follow-up.

Results: An inverse linear relation was found between the relative increase of left ventricular end-diastolic diameter (LVEDD) during long-term RV pacing and LVEDD before HBA-PM $(\mathrm{R}=-0.61, \mathrm{P}<0.001)$. Patients were divided in two groups: patients with LVEDD smaller than the mean LVEDD of 50mm (group I, $46 \pm 2 \mathrm{~mm}, \mathrm{n}=28$ ) and patients with LVEDD larger than $50 \mathrm{~mm}$ (group II, $56 \pm 4 \mathrm{~mm}, \mathrm{n}=17)$. Before HBA-PM, patients in group I had significantly smaller LV weight (167 \pm 44 vs. $238 \pm 56$ gram) and LV end-systolic diameter (LVESD, $30 \pm 2$ vs. $42 \pm 7 \mathrm{~mm})$ and higher LV ejection fraction ( $64 \pm 5$ vs. $49 \pm 12 \%)$ than those in group II. In group I, long-term RV pacing increased LVEDD, LVESD, LV weight, left atrial diameter, and mitral regurgitation and decreased LV ejection fraction and fractional shortening. No significant changes were observed during long-term $\mathrm{RV}$ pacing in group II.

Conclusion: Long-term RV pacing following His bundle ablation adversely affects LV structure and function in patients with initially normal LV dimensions and function. 


\section{INTRODUCTION}

His bundle ablation and pacemaker implantation (HBA-PM) aims to improve symptoms and cardiac function by controlling the ventricular rate in patients with atrial arrhythmias in whom pharmacologic therapy is ineffective or poorly tolerated. ${ }^{1,2}$ Studies on the effects of HBA-PM therapy showed variable results. Some have reported hemodynamic improvement, increased exercise tolerance and quality of life ${ }^{3-5}$ and have even shown patients to recover from tachycardia related heart failure. ${ }^{6,7}$ Others have suggested that HBA-PM therapy decreases left ventricular (LV) ejection fraction. ${ }^{8,9}$

The decreasing ejection fraction after HVA-PM could be due to the induction of a non-physiologic asynchronous ventricular electrical activation by right ventricular (RV) pacing, resulting in an abnormal contraction pattern and impaired cardiac function. ${ }^{10-13}$ In patients with sinus node disease and normal ventricular function, long-term RV pacing increases the incidence of congestive heart failure. ${ }^{14,15}$ Another study showed that the percentage paced ventricular beats is associated with the risk for heart failure (MOST trial). ${ }^{16}$ Nevertheless, in patients with chronic RV pacing and normal LV function the absolute risk for developing heart failure is still small. Animal studies have, however, consistently shown that long-term asynchronous ventricular activation leads to ventricular dilatation and hypertrophy.

The aim of the present study was to investigate changes in LV dimensions and function in patients who experience permanent RV apex pacing. To this purpose, we performed a retrospective echocardiographic analysis in patients during long-term RV pacing following His bundle ablation. We sought to gain insight into the balance between adverse effects of long-term RV pacing and beneficial hemodynamic effects of heart rate regularization by His bundle ablation and try to identify those patients who deteriorate as a consequence RV pacing.

\section{METHODS}

During the last decade sixty patients underwent HBA-PM in our institute. Forty-five patients had undergone an echocardiographic study shortly before as well as after HBA-PM and were included in our analysis. 
$126 \mid$ Chapter 8

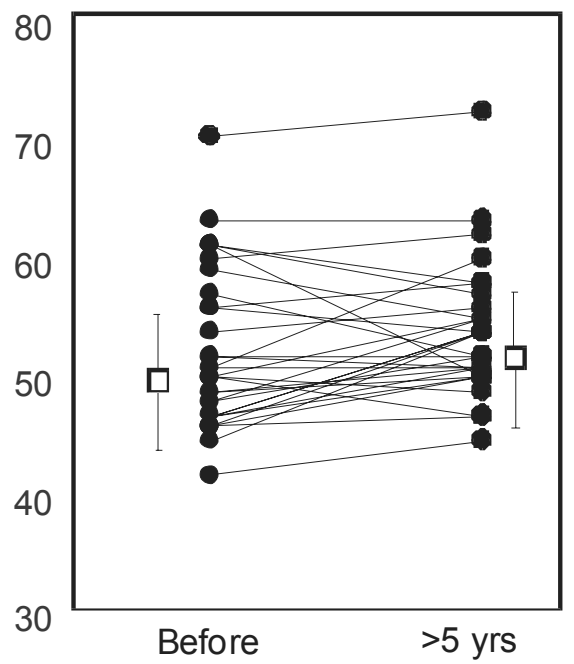

Figure 1. Mean ( $\square$ ) and individual (ロ) left ventricular end-diastolic diameter (LVEDD) of the 45 patients before his bundle ablation and pacemaker implantation, and during long-term ( $>5 \mathrm{yrs})$ right ventricular pacing.

analyzed by Doppler echocardiography.

In order to facilitate combination of the data from all forty-five patients, echocardiographic follow-up was clustered in four periods: before HBA-PM ($0.4 \pm 0.9 \mathrm{yrs}, 45$ patients), within one year after ( $0.6 \pm 0.4 \mathrm{yrs}, 22$ patients), one to five years after ( $2.7 \pm 1.0 \mathrm{yrs}, 26$ patients), and longer than five years after HBAPM (7.7 2.4 yrs, 33 patients).

\section{Statistical analysis}

All values are described as mean values with their corresponding standard deviations. The Wilcoxon test was used to analyze differences between baseline and long-term RV pacing within each group. The Mann-Whitney test was used to analyze differences between the groups. Changes in LVEDD over time were evaluated using repeated measures ANOVA. If ANOVA indicated a significant difference between time points, a Bonferroni post-hoc test was performed to compare selected pairs of time points. In all tests, a p value of 0.05 or less (twosided) was considered statistically significant. 

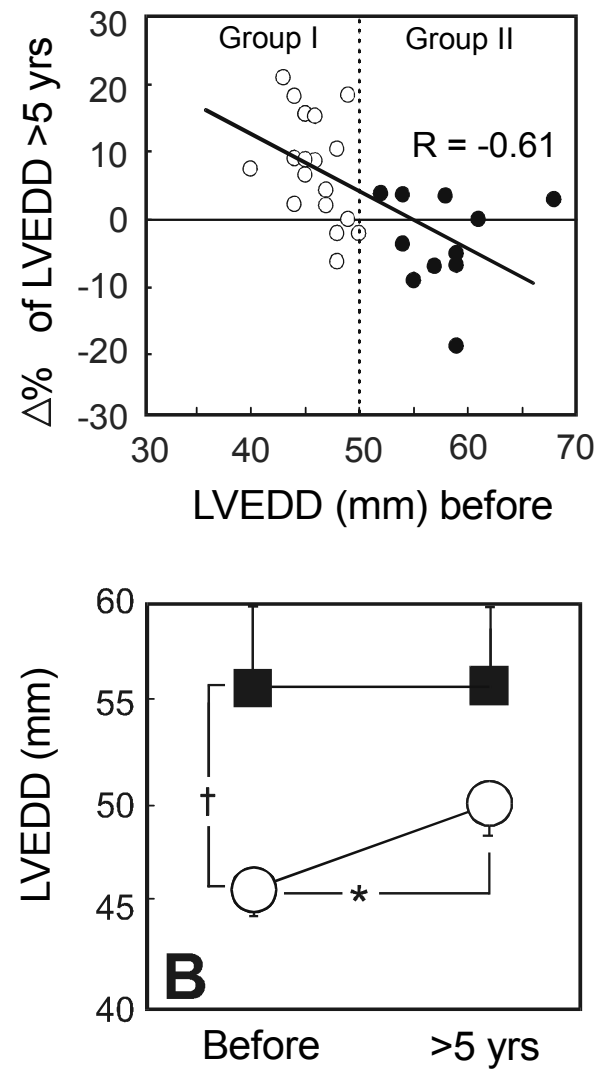

Figure 2. (A) The relative change in left ventricular end-diastolic diameter during long-term ( $>5 \mathrm{yrs})$ right ventricular pacing ( $\Delta \%$ of LVEDD $>5 \mathrm{yrs}$ ) plotted as function of left ventricular end-diastolic diameter (LVEDD) before his bundle ablation and pacemaker implantation (HBA-PM) shows a significant negative correlation $(\mathrm{p}<0.005$, $\mathrm{R}=-0.67$ ). Patients are divided in group $\mathrm{I}$ and II based on average LVEDD (49mm) before onset of pacing (see text). (B) Absolute changes in LVEDD before HBA-PM compared to long-term ( $>5 \mathrm{yrs})$ right ventricular pacing in group I $(\mathrm{O})$ and group II (घ).

\section{RESULTS}

\section{Study population}

His bundle ablation was performed to achieve complete atrioventricular (AV) block, and was followed by implantation of either DDD(R) or VVI(R) pacemaker, for respectively paroxysmal or chronic atrial arrhythmias. The ventricular pacing lead was routinely placed in the RV apex.

\section{Group analysis}

After $>5$ years of $R V$ pacing the average LVEDD in the whole group of 45 patients was not changed as compared to before HBA-PM (from $50 \pm 6$ to $52 \pm 5$ $\mathrm{mm})$. However, as depicted in figure 1, individual patients showed differential responses (figure 1). Plotting the relative change in LVEDD after $>5$ yrs of RV pacing as a function of LVEDD before HBA-PM resulted in a significant inverse linear relation $(\mathrm{r}=-0.61$ $\mathrm{P}=0.005$, figure $2 \mathrm{a}$ ).

In order to investigate the role of the initial LV dimensions on ventricular remodeling, patients were divided in two groups according to the mean LVEDD before HBA-PM: patients with LVEDD $\leq 50 \mathrm{~mm}$ (28 patients, group I) and LVEDD $>50 \mathrm{~mm}$ (17 patients, group II). Age, follow-up duration and pacemaker type was not different between the groups (table 1). Group II consisted of a higher 


\section{8 \\ Chapter 8}

percentage of patients with chronic atrial fibrillation than group I. In group I the majority of patients were female whereas in group II the majority was male.

Table 1. Clinical characteristics before His bundle ablation and pacemaker implantation

\begin{tabular}{lcc}
\hline & Group I & GroupII \\
\cline { 2 - 3 } Number of patients & 28 & 17 \\
Age at pacemaker implantation (yrs) & $57 \pm 9$ & $57 \pm 13$ \\
Gender: Male / Female & $7 / 21$ & $14 / 3$ \\
NYHA fc (1-4) & $1.4 \pm 0.5$ & $1.6 \pm 0.8$ \\
Coronary artery disease & $1(4 \%)$ & $0(0 \%)$ \\
Hypertension & $12(44 \%)$ & $5(29 \%)$ \\
Pacemaker: VVI / DDD & $6 / 16$ & $8 / 9$ \\
Atrial arrhythmias: & & \\
PAFl & $2(7 \%)$ & $0(0 \%)$ \\
PAF & $16(57 \%)$ & $8(47 \%)$ \\
CAF & $6(21 \%)$ & $8(47 \%)$ \\
AT & $4(14 \%)$ & $1(6 \%)$ \\
Cardiac Drugs (on implantation): & & \\
Beta-blocker & $6(21 \%)$ & $6(35 \%)$ \\
Calcium antagonist & $1(4 \%)$ & $2(12 \%)$ \\
ACE inhibition & $8(29 \%)$ & $5(29 \%)$ \\
Nitrates & $3(11 \%)$ & $2(12 \%)$ \\
Antiarrhythmic drugs & $10(36 \%)$ & $7(41 \%)$ \\
Digoxine & $4(14 \%)$ & $5(29 \%)$ \\
Diuretics & $6(21 \%)$ & $6(35 \%)$ \\
Follow-up (yrs) & $7 \pm 1$ & $7 \pm 2$ \\
\hline
\end{tabular}

Characteristics of the patients in group I and II before His bundle ablation and pacemaker implantation (HBA-PM). HT: hypertension; CAD: coronary artery disease; NYHA fc: New York Heart Association functional class Duration: duration of atrial arrhythmia (yrs); PAF: Paroxysmal Atrial fibrillation; CAF: Chronic atrial fibrillation; PAFl: Paroxysmal atrial flutter; AT: Atrial tachycardia.

\section{LV dimensions}

During long-term RV pacing LVEDD increased in group I (figure 2B) with a gradual increase over time, becoming significant after a mean follow-up of $2.6 \pm 1.0$ yrs (figure 3 ). In group II, LVEDD did not change significantly during follow-up. Changes in LVESD during long-term RV pacing in group I and II paralleled those in LVEDD (table 2). 
Echocardiographic analysis did not show any changes in myocardial wall thickness of the septum and LV posterior wall over time in both groups. There was no point in time where the septum and LV posterior wall thickness were significantly different between the groups (table 2).

Due to the increased LVEDD and unchanged septum and LV posterior thickness in group I, estimated LV weight increased, indicating eccentric hypertrophy. LV weight remained unchanged in group II (figure 4A, table 2).

The left atrial diameter increased during long-term RV pacing in group I, without significant changes in group II (figure 4B, table 2).

\section{LV function}

Before HBA-PM, LVEF and LVFS were significantly higher in group I than in group II. During long-term RV pacing both LVEF and LVFS decreased in group I. In group II on the other hand, LVEF and LVFS remained stable over time in group II (figure $4 \mathrm{C}$, table 2). As a result, LVEF and LVFS were not significantly different between both groups after long-term RV pacing.

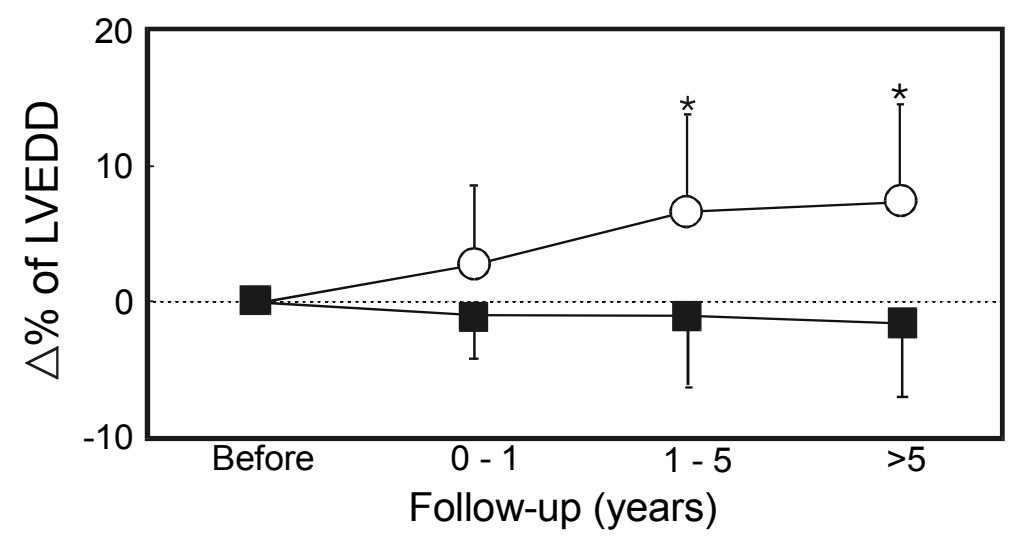

Figure 3. Relative changes in left ventricular end-diastolic diameter ( $\triangle \%$ of LVEDD) over time during right ventricular pacing in group I $(\bigcirc)$ and group II $(\boldsymbol{\bullet}) \cdot * \mathrm{P}<0.05$ as compared to before His bundle ablation and pacemaker implantation. 

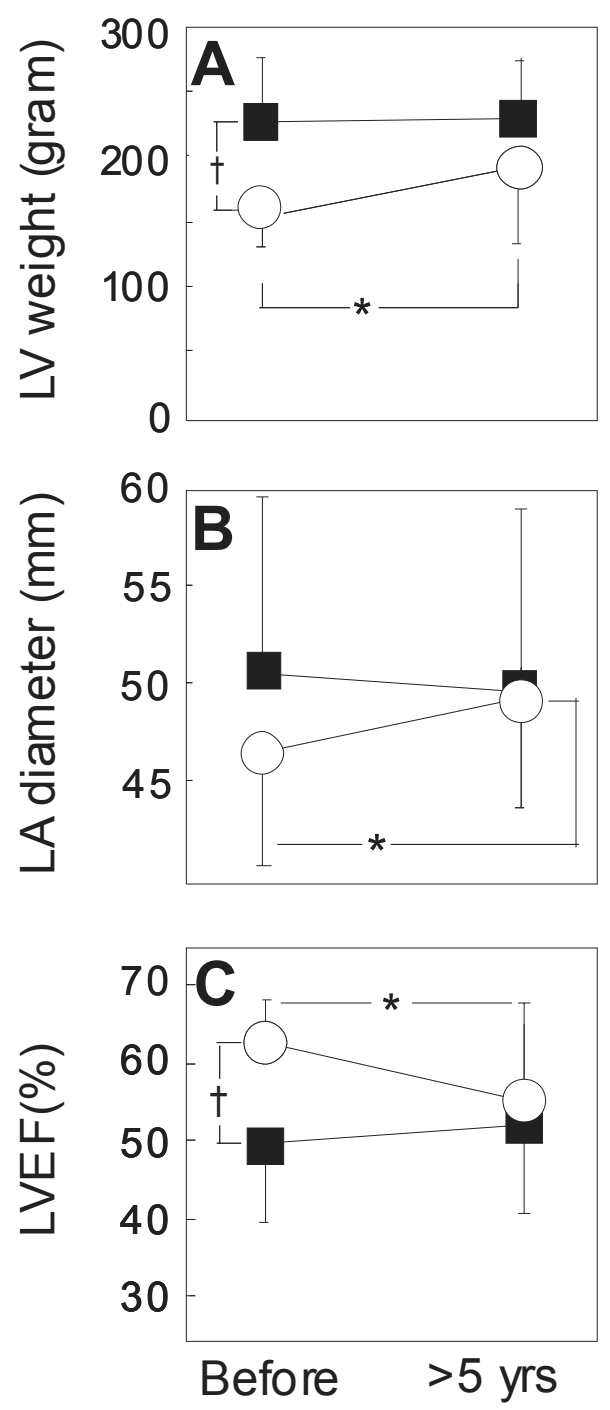

Figure 4. Echocardiographic changes in (A) left ventricular (LV) weight, (B) left atrial (LA) diameter and (C) left ventricular ejection fraction (LVEF) before his bundle ablation and pacemaker implantation, and during long-term ( $>5$ yrs) right ventricular pacing in group $\mathrm{I}(\mathrm{O})$ and group II ( $\mathbf{\square}){ }^{*} \mathrm{p}<0.05$ compared to before within the same group, ${ }^{\dagger} \mathrm{p}<0.05$ group I compared to group II.

\section{Valvular function}

Mitral regurgitation increased slightly during long-term RV pacing in group I. The increased mitral regurgitation during long-term $\mathrm{RV}$ pacing in group I showed no correlation with increased LVEDD ( $\mathrm{r}=$ 0.04 , data not shown). Group II revealed no significant changes in mitral regurgitation during longterm RV pacing (table 2).

\section{Clinical follow-up}

From the sixteen patients in group I and eight patients in group II with paroxysmal atrial fibrillation (PAF) before HBA-PM, respectively six and four patients showed a progression to chronic atrial fibrillation (CAF). During long-term follow-up there were no coronary events in both groups.

\section{DISCUSSION}

The present study indicates that the effects of chronic RV pacing and His bundle ablation on ventricular remodeling in patients with symptomatic, drug-refractory atrial arrhythmias are related to the initial LV dimensions. In patients with normal LV dimensions $(\mathrm{LVEDD}<50 \mathrm{~mm})$ and good LV function $\mathrm{RV}$ pacing induces $\mathrm{LV}$ remodeling and decreases LV pump function whereas in patients with initially somewhat larger LV dimensions RV pacing does not 
affect LV remodeling or function. These data suggest that long-term RV pacing leads to ventricular remodeling and impaired LV function when LV structure and function have not (yet) been affected by the atrial arrhythmias. The beneficial effects of rate control and the negative effects of asynchronous activation appear in balance in patients with already slight LV hypertrophy and dilatation.

Table 2. Echocardiographic parameters

\begin{tabular}{lcccc}
\hline & \multicolumn{2}{c}{ Group I $(\mathrm{n}=21)$} & \multicolumn{2}{c}{ Group II (n=12) } \\
& $\begin{array}{c}\text { Before } \\
\text { HBA-PM }\end{array}$ & $>5$ yrs pacing & $\begin{array}{c}\text { Before } \\
\text { HBA-PM }\end{array}$ & $\begin{array}{c}>5 \text { yrs RV } \\
\text { pacing }\end{array}$ \\
\cline { 2 - 5 } LVEDD (mm) & $46 \pm 2$ & $50 \pm 3^{*}$ & $56 \pm 4 \dagger$ & $56 \pm 6$ \\
LVESD (mm) & $30 \pm 2$ & $34 \pm 4^{*}$ & $42 \pm 7 \dagger$ & $41 \pm 8$ \\
LV weight (gram) & $167 \pm 44$ & $191 \pm 64^{*}$ & $238 \pm 56 \dagger$ & $244 \pm 64$ \\
Left atrial diameter (mm) & $47 \pm 7$ & $49 \pm 7^{*}$ & $51 \pm 9$ & $50 \pm 9$ \\
LVEF (\%) & $64 \pm 5$ & $55 \pm 11^{*}$ & $49 \pm 12 \dagger$ & $51 \pm 11$ \\
LVFS (\%) & $36 \pm 4$ & $32 \pm 5^{*}$ & $26 \pm 7 \dagger$ & $27 \pm 7$ \\
LV posterior wall thickness (mm) & $9 \pm 1$ & $9 \pm 2$ & $9 \pm 1$ & $9 \pm 1$ \\
Septal wall thickness (mm) & $9 \pm 2$ & $9 \pm 2$ & $9 \pm 1$ & $9 \pm 1$ \\
Mitral regurgitation (grade 1-4) & $0.9 \pm 0.8$ & $1.4 \pm 0.9^{*}$ & $1.2 \pm 0.9$ & $1.7 \pm 0.9$ \\
\hline
\end{tabular}

LV: left ventricular, LVEDD: LV end-diastolic diameter, LVEF: LV ejection fraction, LVFS: LV fractional shortening, LVESD: LV end-systolic diameter. Echocardiographic data before His bundle ablation and pacemaker implantation (HBA-PM) as well as during long-term ( $>5 \mathrm{yrs}) \mathrm{RV}$ pacing in group I and II. * $\mathrm{P}<0.05$ compared to before within the same group, $\uparrow \mathrm{P}<0.05$ compared to group I. Data presented as mean $\pm \mathrm{SD}$.

The LV remodeling, observed in patients from group I is in agreement with observations in healthy canine hearts during long-term asynchronous ventricular activation. ${ }^{17-19}$ So far, there are no clinical studies showing ventricular remodeling during asynchronous RV pacing. Nevertheless, there is increasing evidence for a relation between asynchronous ventricular activation and heart failure.

Large clinical trials in patients with sinus node disease showed that RV pacing is associated with an increased incidence of heart failure as compared to right atrial pacing, maintaining normal ventricular activation. ${ }^{14,15}$ However, it took more than five years in these studies to find a significant difference in development of heart failure between atrial and RV paced group. The MOST-trial suggests that the cumulative percent ventricular pacing is a strong predictor for heart failure hospitalization, even when AV synchrony is preserved. ${ }^{16}$ In pa- 


\section{$132 \mid$ Chapter 8}

tients with worse baseline LV function, heart failure and even mortality increased more rapidly after starting pacing. The DAVID trial showed that for patients with standard indications for implantable cardioverter defibrillator therapy and no indications for cardiac pacing, dual-chamber pacing was detrimental as compared to ventricular backup pacing by increasing the combined end points for death or hospitalization for heart failure. ${ }^{20}$

The LV dilatation and hypertrophy may be a link between asynchrony and heart failure in patients with RV pacing, because eccentric hypertrophy is known to be a risk factor for developing heart failure. Moreover, heart failure can be caused by molecular and cellular changes, changes which at least partly have been demonstrated to occur in asynchronously activated animal hearts. ${ }^{21,22}$

The finding that patients from group I show an increase in left atrial diameter during RV pacing (figure 4B) is important, because larger atrial dimensions are known to facilitate development of atrial fibrillation. ${ }^{23}$ This is supported by clinical studies which showed that long-term RV pacing resulted in an increased left atrial diameter ${ }^{24}$ and an increased risk for developing atrial fibrillation. ${ }^{25}$

In group I, LV dilatation became significant after 1-5 years of RV pacing. This time course appears to be slower than that in animals with asynchrony (weeksmonths). This might indicate that rate regulation by RV pacing had some beneficial effects, counteracting the hypertrophy induced by the asynchrony. This appears even more the case in the patients from group II, where HA-RVP did not significantly affect LV dilatation and hypertrophy. The similar percentage of patients with hypertension and minimal other cardiovascular disease in the two groups indicates that the difference in LVEDD might originate from a more severe hemodynamic burden of atrial arrhythmias in group II or a potential difference in susceptibility.

The fact that other studies reported more positively about His bundle ablation can be explained by differences in natural history of the patients. Compared to the other studies, ${ }^{3,48}$ patients in the present study had a higher LV ejection fraction. The present study showed that RV pacing affected LV dilatation especially in patients with normal dimensions and good LV function. The Latter is recently confirmed in a study of Szili-Torok and collegues. ${ }^{9}$ They showed that in patients with permanent atrial fibrillation a good LV function is predictor of deterioration during follow-up.

Another difference between the present study and others is follow-up duration. In the present study a significant LV remodeling was observed after an average follow-up of $\sim 2 \frac{1}{2}$ years while most other studies have clinical followup of less than two years. ${ }^{3,4,8,26}$

Moreover, various studies indicate that His bundle ablation improves quality of life independent of improvement in LV function. ${ }^{9}$ In a prospective ran- 
domized trial in patients with chronic atrial fibrillation and heart failure it was found that His bundle ablation followed by RV pacing was effective and superior to pharmacological treatment in controlling symptoms. However, the clinical benefit did not coincide with improved LV function or smaller LV dimensions. ${ }^{27}$ More support for this idea comes from the OPSITE study which showed that His bundle ablation improved quality of life independent of pacing site (LV, RV or biventricular pacing), despite better LV ejection fraction during LV and biventricular pacing. ${ }^{28}$ These findings indicate that rate control achieved by His bundle ablation and ventricular pacing improves complaints despite a possible deterioration in LV function and dimensions as a result of asynchronous ventricular activation.

The LV remodeling in patients with initially normal LV dimensions and function was associated with a significant increase in mitral regurgitation during long-term RV pacing. No correlation was found between mitral regurgitation and LV dilatation as another possible explanation for the observed LV remodeling. This may indicate that mitral regurgitation and LV remodeling are both consequences of the asynchronous activation and contraction.

\section{Implications}

The results from the present study support the idea that long lasting asynchronous ventricular electrical activation can lead to ventricular remodeling and decreased cardiac function, suggesting that in patients with atrial arrhythmias and structurally normal heart, His bundle ablation and ventricular pacing should only be performed when necessary. This is conform other studies advising to minimize ventricular pacing in the presence of AV conduction, such as in patients with sick sinus syndrome ${ }^{14-16}$ and patients with ICD indications without pacemaker indications. ${ }^{20}$

In patients where His ablation and permanent ventricular pacing can not be avoided, choosing a different pacing site, such as the RV septum, or biventricular pacing may limit the adverse effects of asynchronous ventricular activation. In this regard upgrading an existing RV pacemaker to a biventricular one appears to be an option.

\section{Limitations}

The main limitation of this study is that it is a retrospective evaluation causing various restrictions. One consequence of this approach is that the 45 patients were selected from the total of 60 patients on availability of echocardiograms. This selection should not cause a major bias in the study population because the mean LVEDD of all 60 patients before the ablation procedure and pacemaker 


\section{4 \\ Chapter 8}

implantation was not different from the 45 patients included in the study. Secondly, the moment of the echocardiographic investigations varied between patients. Therefore, follow-up was clustered in four time frames.

No control group was incorporated, as each patient served as its own control because the echocardiographic changes were related to its value before the His bundle ablation and pacemaker implantation.

The medication provided in table 2 is the medication taken just before the His bundle ablation. Most patients have already taken various drugs trying to obtain better ventricular rate control before undergoing His bundle ablation. It is known that these drugs can affect remodeling and might have been given more frequently to the patients with LV dysfunction (group II).

\section{CONClusions}

In conclusion, a retrospective echocardiographic investigation in patients with symptomatic atrial arrhythmias who underwent His bundle ablation and RV pacing was performed. The results show that His bundle ablation and RV pacing adversely affects LV structure and function in patients with initially normal LV dimensions and function. These results indicate that, although previous studies show that His bundle ablation is superior to pharmacological treatment in controlling symptoms, His bundle ablation in patients with structurally normal heart and good LV function should be performed only when necessary as it leads to LV remodeling and decreased LV function on the long run.

\section{ACKNOWLEDGMENTS}

The present study was supported by a grant from The Netherlands Organization for Health Research and Development (KV).

\section{REFERENCES}

1 Narasimhan C, Blanck Z, Akhtar M. Atrioventricular nodal modification and atrioventricular junctional ablation for control of ventricular rate in atrial fibrillation. J Cardiovasc Electrophysiol. 1998;9:S146-150.

2 Jensen SM, Bergfeldt L, Rosenqvist M. Long-term follow-up of patients treated by radiofrequency ablation of the atrioventricular junction. Pacing Clin Electrophysiol. 1995;18:16091614.

3 Rodriguez LM, Smeets JL, Xie B, de Chillou C, Cheriex E, Pieters F, Metzger J, den Dulk $\mathrm{K}$, Wellens HJ. Improvement in left ventricular function by ablation of atrioventricular nodal conduction in selected patients with lone atrial fibrillation. Am J Cardiol. 1993;72:11371141. 
4 Edner M, Caidahl K, Bergfeldt L, Darpo B, Edvardsson N, Rosenqvist M. Prospective study of left ventricular function after radiofrequency ablation of atrioventricular junction in patients with atrial fibrillation. Br Heart J. 1995;74:261-267.

5 Twidale N, Sutton K, Bartlett L, Dooley A, Winstanley S, Heddle W, Hassam R, Koutsounis $\mathrm{H}$. Effects on cardiac performance of atrioventricular node catheter ablation using radiofrequency current for drug-refractory atrial arrhythmias. Pacing Clin Electrophysiol. 1993;16:1275-1284.

6 Redfield MM, Kay GN, Jenkins LS, Mianulli M, Jensen DN, Ellenbogen KA. Tachycardiarelated cardiomyopathy: a common cause of ventricular dysfunction in patients with atrial fibrillation referred for atrioventricular ablation. Mayo Clin Proc. 2000;75:790-795.

7 Boriani G, Biffi M, Diemberger I, Martignani C, Branzi A. Rate control in atrial fibrillation: choice of treatment and assessment of efficacy. Drugs. 2003;63:1489-1509.

8 Szili-Torok T, Kimman GP, Theuns D, Poldermans D, Roelandt JR, Jordaens LJ. Deterioration of left ventricular function following atrio-ventricular node ablation and right ventricular apical pacing in patients with permanent atrial fibrillation. Europace. 2002;4:61-65.

9 Szili-Torok T, Bountioukos M, Muskens AJ, Theuns DA, Poldermans D, Roelandt JR, Jordaens LJ. The presence of contractile reserve has no predictive value for the evolution of left ventricular function following atrio-ventricular node ablation in patients with permanent atrial fibrillation. Eur J Echocardiogr. 2005.

10 Badke FR, Boinay P, Covell JW. Effects of ventricular pacing on regional left ventricular performance in the dog. Am J Physiol. 1980;238:H858-867.

11 Kosowsky BD, Scherlag BJ, Damato AN. Re-evaluation of the atrial contribution to ventricular function: study using His bundle pacing. Am J Cardiol. 1968;21:518-524.

12 Wyman BT, Hunter WC, Prinzen FW, McVeigh ER. Mapping propagation of mechanical activation in the paced heart with MRI tagging. Am J Physiol. 1999;276:H881-891.

13 Prinzen FW, Hunter WC, Wyman BT, McVeigh ER. Mapping of regional myocardial strain and work during ventricular pacing: experimental study using magnetic resonance imaging tagging. J Am Coll Cardiol. 1999;33:1735-1742.

14 Andersen HR, Nielsen JC, Thomsen PE, Thuesen L, Mortensen PT, Vesterlund T, Pedersen AK. Long-term follow-up of patients from a randomised trial of atrial versus ventricular pacing for sick-sinus syndrome. Lancet. 1997;350:1210-1216.

15 Nielsen JC, Andersen HR, Thomsen PE, Thuesen L, Mortensen PT, Vesterlund T, Pedersen AK. Heart failure and echocardiographic changes during long-term follow-up of patients with sick sinus syndrome randomized to single-chamber atrial or ventricular pacing. Circulation. 1998;97:987-995.

16 Sweeney MO, Hellkamp AS, Ellenbogen KA, Greenspon AJ, Freedman RA, Lee KL, Lamas GA. Adverse effect of ventricular pacing on heart failure and atrial fibrillation among patients with normal baseline QRS duration in a clinical trial of pacemaker therapy for sinus node dysfunction. Circulation. 2003;107:2932-2937.

17 Vernooy K, Verbeek XA, Peschar M, Crijns HJ, Arts T, Cornelussen RN, Prinzen FW. Left bundle branch block induces ventricular remodelling and functional septal hypoperfusion. Eur Heart J. 2005;26:91-98.

18 Prinzen FW, Cheriex EC, Delhaas T, van Oosterhout MF, Arts T, Wellens HJ, Reneman RS. Asymmetric thickness of the left ventricular wall resulting from asynchronous electric activation: a study in dogs with ventricular pacing and in patients with left bundle branch block. Am Heart J. 1995;130:1045-1053.

19 van Oosterhout MF, Prinzen FW, Arts T, Schreuder JJ, Vanagt WY, Cleutjens JP, Reneman RS. Asynchronous electrical activation induces asymmetrical hypertrophy of the left ventricular wall. Circulation. 1998;98:588-595.

20 Wilkoff BL, Cook JR, Epstein AE, Greene HL, Hallstrom AP, Hsia H, Kutalek SP, Sharma A. Dual-chamber pacing or ventricular backup pacing in patients with an implantable defi- 


\section{$136 \mid$ Chapter 8}

brillator: the Dual Chamber and VVI Implantable Defibrillator (DAVID) Trial. Jama. 2002;288:3115-3123.

21 Spragg DD, Leclercq C, Loghmani M, Faris OP, Tunin RS, DiSilvestre D, McVeigh ER, Tomaselli GF, Kass DA. Regional alterations in protein expression in the dyssynchronous failing heart. Circulation. 2003;108:929-932.

22 Spragg DD, Akar FG, Helm RH, Tunin RS, Tomaselli GF, Kass DA. Abnormal conduction and repolarization in late-activated myocardium of dyssynchronously contracting hearts. Cardiovasc Res. 2005;67:77-86.

23 Schotten U, Neuberger HR, Allessie MA. The role of atrial dilatation in the domestication of atrial fibrillation. Prog Biophys Mol Biol. 2003;82:151-162.

24 Nielsen JC, Kristensen L, Andersen HR, Mortensen PT, Pedersen OL, Pedersen AK. A randomized comparison of atrial and dual-chamber pacing in 177 consecutive patients with sick sinus syndrome: echocardiographic and clinical outcome. J Am Coll Cardiol. 2003;42:614623.

25 Connolly SJ, Kerr CR, Gent M, Roberts RS, Yusuf S, Gillis AM, Sami MH, Talajic M, Tang AS, Klein GJ, Lau C, Newman DM. Effects of physiologic pacing versus ventricular pacing on the risk of stroke and death due to cardiovascular causes. Canadian Trial of Physiologic Pacing Investigators. N Engl J Med. 2000;342:1385-1391.

26 Weerasooriya R, Davis M, Powell A, Szili-Torok T, Shah C, Whalley D, Kanagaratnam L, Heddle W, Leitch J, Perks A, Ferguson L, Bulsara M. The Australian Intervention Randomized Control of Rate in Atrial Fibrillation Trial (AIRCRAFT). J Am Coll Cardiol. 2003;41:1697-1702.

27 Brignole M, Menozzi C, Gianfranchi L, Musso G, Mureddu R, Bottoni N, Lolli G. Assessment of atrioventricular junction ablation and VVIR pacemaker versus pharmacological treatment in patients with heart failure and chronic atrial fibrillation: a randomized, controlled study. Circulation. 1998;98:953-960.

28 Brignole M, Gammage M, Puggioni E, Alboni P, Raviele A, Sutton R, Vardas P, Bongiorni MG, Bergfeldt L, Menozzi C, Musso G. Comparative assessment of right, left, and biventricular pacing in patients with permanent atrial fibrillation. Eur Heart J. 2005;26:712-722. 


\section{Chapter 9}

\section{General discussion}

Kevin Vernooy, MD

Department of Physiology and Cardiology, Cardiovascular Research Institute Maastricht, Maastricht, the Netherlands 
$138 \mid$ Chapter 9

\section{INTRODUCTION}

Over the last decade, cardiac resynchronization therapy (CRT) has become an emerging therapeutic option for patients with heart failure and ventricular conduction disturbances, i.e. left bundle branch block (LBBB). Up to $30 \%$ of patients with heart failure suffer from LBBB. At the beginning of this thesis, there was no consensus whether asynchronous ventricular activation, induced by LBBB, affects myocardial structure and function. Similarly, there was considerable disagreement whether LBBB is a cause or a consequence of HF. In this thesis, we do not answer the question on the cause of LBBB, but we extensively studied the effects of LBBB in an animal model. From the results, we elude to the potential role of LBBB in the origin of heart failure in patients. The animal model also allowed studying to what extent $\mathrm{BiV}$ pacing can reverse the abnormalities caused by LBBB.

A canine model of LBBB, induced by radio-frequency ablation, was used in order to gain more insight into the consequences of long-term LBBB on left ventricular (LV) pump function, inter- and intra-ventricular asynchrony, regional LV contraction, and regional myocardial blood flow as well the effects on LV structure, referred to as LV remodeling. Furthermore, we explored how ventricular resynchronization improves LV pump function, and whether it may reverse the LBBB induced LV remodeling. In addition, the improvement of LV pump function and the effects on inter- and intra-ventricular asynchrony for LV pacing as well as for (sequential) BiV pacing were studied. Finally, we studied the effects of right ventricular (RV) pacing on LV ejection fraction (EF) and LV structure in patients with atrial fibrillation undergoing His bundle ablation. In this chapter, the findings of the present thesis will be put in a wider perspective and some ideas about future research will be discussed.

\section{LBBB ANIMAL MODEL VERSUS LBBB PATIENTS}

The animal studies in this thesis were performed on dogs. LBBB was induced by radio-frequency ablation of the proximal left bundle branch. LV endocardial activation and myocardial shortening maps show that ablation of the left bundle branch was sufficient to force the electrical impulse to be conducted through the LV wall by predominantly slow myocardial conduction as opposed to the rapid conduction through the Purkinje system in the baseline situation (chapter 4 and 6). Studies in patients show a more variable ventricular activation pattern during LBBB. ${ }^{1-3}$ These studies especially showed that left septal activation occurs via pathologically slow conduction through the left bundle branch or via right-to- 
left trans-septal conduction. However, in all patients, the septum was earlyactivated and the postero-lateral basal wall was late-activated, properties which are also typical for our canine LBBB model.

Induction of LBBB doubled the QRS duration in the animal hearts (Chapter 4, 5 and 6). A similar relative increase in QRS duration was found in LBBB patients when compared to healthy controls (table). Also, both in animals and patients, LBBB resulted in significant inter- and intra-ventricular asynchrony (table). The longer QRS duration and larger values of inter- and intraventricular asynchrony in LBBB patients than in our canine LBBB model can be explained by the fact that humans have larger hearts, and that patient hearts may have hypertrophy and increased amounts of fibrosis causing ventricular conduction delay.

Table. Comparisons between canine LBBB model and LBBB patients.

\begin{tabular}{|c|c|c|c|}
\hline & & LBBB Patients & LBBB model \\
\hline QRS Duration & $\begin{array}{l}\text { LBBB } \\
\text { Controls }\end{array}$ & $\begin{array}{l}169 \pm 16 \mathrm{~ms}^{7} \\
80-100 \mathrm{~ms}\end{array}$ & $\begin{array}{l}123 \pm 4 \mathrm{~ms}(\mathrm{Ch} .7) \\
69 \pm 3 \mathrm{~ms}(\mathrm{Ch} .7)\end{array}$ \\
\hline $\begin{array}{l}\text { Inter-ventricular asynchrony } \\
\text { (RV-LV pressure difference) }\end{array}$ & $\begin{array}{l}\text { LBBB } \\
\text { Controls }\end{array}$ & $\begin{array}{l}-50 \pm 17 \mathrm{~ms}^{4} \\
-5 \pm 10 \mathrm{~ms}^{4}\end{array}$ & $\begin{array}{l}-32 \pm 7 \mathrm{~ms}^{4}(\mathrm{Ch} .5) \\
-6 \pm 9 \mathrm{~ms}^{53}(\mathrm{Ch} .5)\end{array}$ \\
\hline $\begin{array}{l}\text { Intra-ventricular asynchrony } \\
\text { (Electrical mapping, } \mathrm{ms} \text { ) }\end{array}$ & $\begin{array}{l}\text { LBBB } \\
\text { Controls }\end{array}$ & $\begin{array}{l}61 \pm 15 \mathrm{~ms}[1] \\
\text { NA }\end{array}$ & $\begin{array}{l}26 \pm 6 \mathrm{~ms}^{4}(\mathrm{Ch} .5) \\
5 \pm 2 \mathrm{~ms}^{53} \text { (Ch.5) }\end{array}$ \\
\hline $\begin{array}{l}\text { Time to first peak systolic shortening } \\
\text { septum to LV lateral wall delay (MR } \\
\text { tagging) }\end{array}$ & $\begin{array}{l}\text { LBBB } \\
\text { Controls }\end{array}$ & $\begin{array}{c}351 \pm 92 \mathrm{~ms}^{6} \\
\text { NA }\end{array}$ & $\begin{array}{l}173 \pm 21 \mathrm{~ms}(\text { Ch.7) } \\
-27 \pm 15 \mathrm{~ms}(\text { Ch.7) }\end{array}$ \\
\hline $\begin{array}{l}\text { Septal to posterior wall motion delay } \\
\text { (SPWMD) }\end{array}$ & $\begin{array}{l}\text { LBBB } \\
\text { Controls }\end{array}$ & $\begin{array}{c}192 \pm 92 \mathrm{~ms}^{7} \\
\text { NA }\end{array}$ & $\begin{array}{c}22 \pm 13 \mathrm{~ms}(\mathrm{Ch} .7) \\
64 \pm 9 \mathrm{~ms}(\mathrm{Ch} .7)\end{array}$ \\
\hline $\begin{array}{l}\text { Echocardiography (\% of controls): } \\
\text { Hypertrophy } \\
\text { LV EDV / wall mass ratio } \\
\text { sep/lat wall mass ratio }\end{array}$ & & $\begin{array}{c}142 \%{ }^{54} \\
114 \% 54 \\
98 \%-90 \%{ }^{54}\end{array}$ & $\begin{array}{c}117 \pm 15 \%(\mathrm{Ch} .4) \\
110 \pm 12 \%(\mathrm{Ch} .4) \\
84 \pm 2 \%(\mathrm{Ch} .4)\end{array}$ \\
\hline $\begin{array}{l}\text { Myocardial blood flow: } \\
\text { (\% of mean } L V) \\
\text { Septum } \\
\text { Lateral wall }\end{array}$ & & $\begin{array}{l}\text { Using PET } \\
93 \%{ }^{10} \\
113 \%{ }^{10}\end{array}$ & $\begin{array}{c}\text { Using microspheres } \\
83 \pm 16 \% \text { (Ch.4) } \\
118 \pm 12 \% \text { (Ch.4) }\end{array}$ \\
\hline
\end{tabular}

In our canine LBBB model, inter-ventricular asynchrony was determined as the time difference between the upslope of the LV and RV pressure, the RV/LV pressure difference. ${ }^{4,5}$ In one clinical study investigating CRT in patients with LBBB and heart failure, inter-ventricular asynchrony was also measured as the $\mathrm{RV} / \mathrm{LV}$ pressure difference. ${ }^{4}$ Verbeek and colleagues showed that the increase in inter-ventricular asynchrony was similar in animals and patients during 


\section{$140 \mid$ Chapter 9}

LBBB (table) and LV pacing (see below). ${ }^{4}$ Other clinical studies using the time delay between opening of the aortic and pulmonary valve, assessed by pulsedwave Doppler echocardiography, showed similar values $(58 \pm 28 \mathrm{~ms})$ as compared to $\mathrm{RV} / \mathrm{LV}$ pressure differences.

Intra-ventricular asynchrony was determined as the duration of LV endocardial electrical activation in our canine LBBB model and was $\sim 30 \mathrm{~ms}$. In agreement with these results, Vassallo and colleagues showed that LV endocardial activation time in LBBB patients was only $\sim 60 \mathrm{~ms}$, considerably shorter than the QRS duration. ${ }^{1}$

Figure 1 shows that the distribution of myocardial strain over the LV circumference was similar for our LBBB model and a LBBB patient. LBBB results in a typical contraction pattern with decreased and irregular shortening in the septum and increased shortening in the LV lateral wall. This typical LBBB contraction pattern could also be observed by M-mode echocardiography. Both the time delay between first peak systolic shortening of the septum and the LV lateral wall, obtained by MR tagging (chapter 7), and the delay between the inward motion of the septum and the LV postero- lateral wall, determined by Mmode echocardiography (SPWMD), were similarly increased in our canine LBBB model as compared to non-ischemic LBBB patients (table) ${ }^{6,7}$ For all measurements, the values are larger in the LBBB patients than in our canine LBBB model, but the relative increase during LBBB as compared to controls is similar.

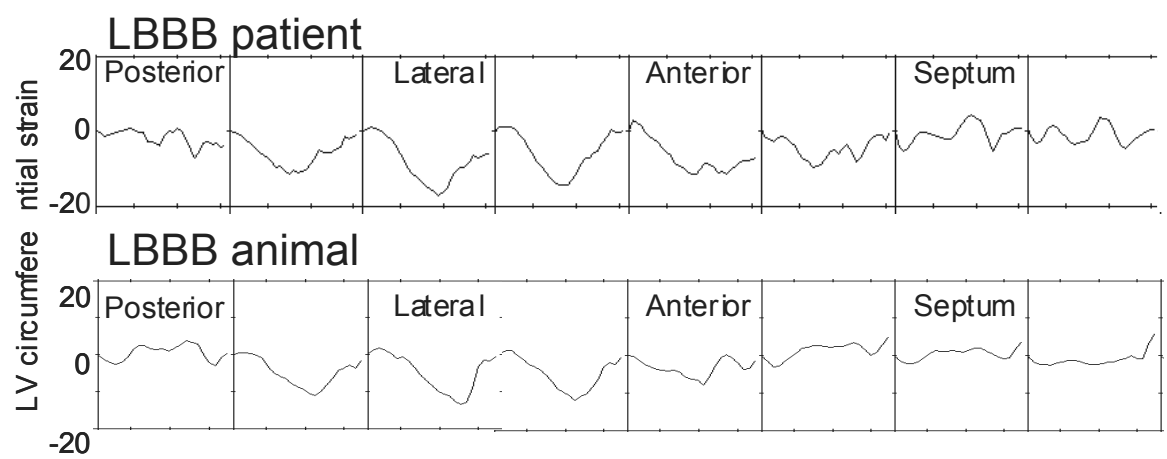

Figure 1. Typical example of myocardial circumferential strain tracings in eight regions along the LV circumference in a mid-basal short-axis slice. The upper tracing is obtained from a patient with LBBB before implantation of a BiV pacemaker (data not published). The lower tracing shows the circumferential strain pattern of a canine LBBB heart. Note the abnormal strain patterns in the septum and pronounced myocardial shortening in the LV lateral wall. Negative strain denotes myocardial shortening. 
This thesis shows the various consequences of asynchronous ventricular activation due to LBBB on myocardial workload and myocardial blood flow distribution. LBBB was shown to induce redistribution of myocardial workload, being reduced in the early activated septum and increased in the late-activated LV lateral wall (chapter 4 and 7). Along with this redistribution, myocardial blood flow was also redistributed proportionally (chapter 4 and 5). ${ }^{8-10}$ In LBBB patients, the redistribution of myocardial blood flow is qualitatively and quantitatively similar, compared to that in our canine LBBB model (table). ${ }^{10} \mathrm{We}$ showed that CRT immediately reversed the redistribution of myocardial workload and myocardial blood flow to a homogenous distribution (chapter 7). A similar homogenous distribution of myocardial blood flow is observed in LBBB patients, ${ }^{10}$ which was, however, investigated several weeks after onset CRT. Turning of CRT, immediately resulted again in redistribution of regional myocardial blood flow in both our canine LBBB model (chapter 7) and LBBB patients. $^{11}$

Besides indices of ventricular asynchrony, the LBBB model has also been shown to be helpful in understanding the mechanism of ventricular resynchronization. Recently, we explored the use of inter-ventricular asynchrony for optimizing CRT. It was shown that the value of inter-ventricular asynchrony at optimum LV pump function could be estimated in our LBBB model. ${ }^{4}$ Also, during CRT in patients with heart failure and LBBB, it was possible to estimate the value of inter-ventricular asynchrony resulting in optimal hemodynamic improvement. $^{4}$

We conclude that the canine LBBB model shows many similarities with LBBB patients and is useful for better understanding of the consequences of LBBB and the mechanisms of improvement of CRT. Considering the important consequences of $\mathrm{LBBB}$, this topic deserves more attention.

\section{DYSSYNCHRONOPATHY AND ITS REVERSAL}

This thesis provides important evidence that long-term asynchronous ventricular activation induces a coherent sequence of events, which are at least partly different from changes by other cardiovascular abnormalities. Therefore, we think it is justified to refer to these abnormalities as dyssynchronopathy (figure $2 \mathrm{~A}$ ). The results from chapter 4,5 , and 7 show that LBBB immediately results in dyscoordinate contraction and reduced pump function. In the long run, LBBB leads to LV dilatation and hypertrophy. Furthermore, the dyscoordinate ventricular contraction results in regional LV mechanical differences, as indicated by the redistribution of myocardial work and myocardial blood flow. Over time, the regional difference in myocardial work resulted in asymmetric hypertrophy. Most hypertrophy developed in the latest-activated, pre-stretched LV lateral 


\section{2 \\ Chapter 9}

wall. Spragg and colleagues showed that, in canine LBBB hearts, the latestactivated LV lateral wall has the most pronounced cellular derangement with respect to conduction velocity and action potential duration. ${ }^{12}$ Moreover, the same group showed a down-regulation of proteins involved in calcium homeostasis in the late-activated regions of dyssynchronous failing hearts. ${ }^{13}$

In our canine LBBB hearts, long-term LBBB does not result in heart failure within four months. Furthermore, we didn't find evidence for development of heart failure during long-term (10 years) RV pacing in healthy patients undergoing pacemaker implantation after His bundle ablation for atrial fibrillation (chapter 8). Nevertheless, permanent ventricular pacing has been identified as an independent risk factor for development of heart failure. Sweeney and colleagues. showed that the patients from the MOST-trial developing heart failure due to RV pacing were more likely to have lower LV EF, myocardial infarction, and worse New York Heart Association function class compared to patients who did not experience heart failure. ${ }^{14,15}$ The experimental and clinical findings suggest that dyssynchronopathy reduces cardiac function reserve, thereby facilitating the development of heart failure in patients with already compromised hearts (figure 3 ). ${ }^{16}$

Recognition of the adverse effects of dyssynchronopathy due to LBBB or RV pacing has stimulated interest to abolish these effects by CRT. In chapter 7, we showed that CRT in canine LBBB hearts not only improves LV function, but also results in a more synchronous electrical activation (chapter 5 and 6 ) and better coordinated contraction (chapter 5) than during LBBB (figure 2B). LV dilatation due to LBBB is thought to be the long-term mechanism compensating for the decreased LV function, thus maintaining normal cardiac output (chapter 4). Therefore, improved LV function by BiV pacing may be the cause of the reversal of LV dilatation as shown in chapter 7 . While this hemodynamic benefit and reduction of LV dilation was also shown in clinical studies, we were the first to show that LV asymmetric hypertrophy, another characteristic of dyssynchronopathy, is reversed by $\mathrm{BiV}$ pacing.

CRT also results in a more coordinated contraction and homogenous distribution of myocardial work, which is reflected by the homogenous distribution of myocardial blood flow during CRT in our canine LBBB model (chapter 7) as well as in LBBB patients ${ }^{10}$. Echocardiographic analysis mainly showed reversal of hypertrophy in the latest activated LV lateral wall, as a consequence of the normalized distribution of myocardial work (chapter 5).

CRT may also reduce path length of ventricular electrical activation after reversal of LV dilatation and hypertrophy, resulting in faster ventricular electrical activation and reduced ventricular asynchrony. Moreover, the decreased LV end-diastolic volume by BiV pacing decreases wall stress ${ }^{17}$ and is favorable for changes in the neurohumoral system in patients ${ }^{18}$. 

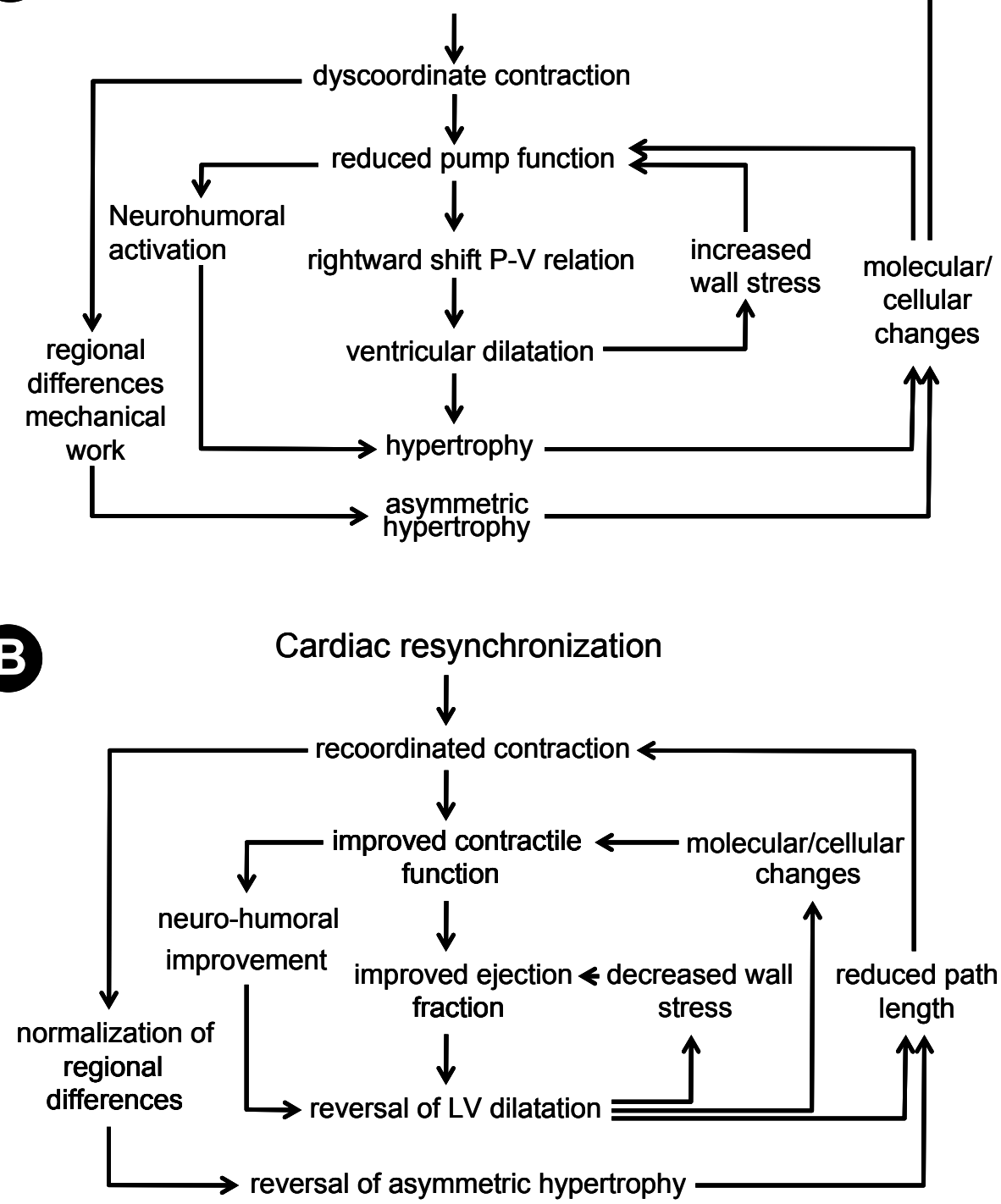

Figure 2. Proposed relation between events following A) onset of asynchronous ventricular activation and $\mathbf{B}$ ) during cardiac resynchronization therapy. For details, see text. 


\section{4 \\ Chapter 9}

The results on the effects of CRT provide evidence for dyssynchronopathy as a separate entity. Further support for the vicious circle of dyssynchronopathy is the increase in LV pump function over time during CRT (chapter 7). ${ }^{19}$ More support is obtained by our finding that the improvement of $\mathrm{LVdP} / \mathrm{dt} \mid \mathrm{max}$ immediately after onset of CRT was related to the reversal of LV dilatation and hypertrophy in the long run (chapter 7). A relation between hemodynamic improvement and LV reverse remodeling has not yet been shown in patients. ${ }^{20}$ Nevertheless, it has recently been shown that LV reverse remodeling, and not improvement in clinical parameters of heart failure, predicts lower mortality and heart failure events, ${ }^{21}$ thereby indicating that predictors of LV reverse remodeling, such as acute improvement of LV function, seem to be very important.

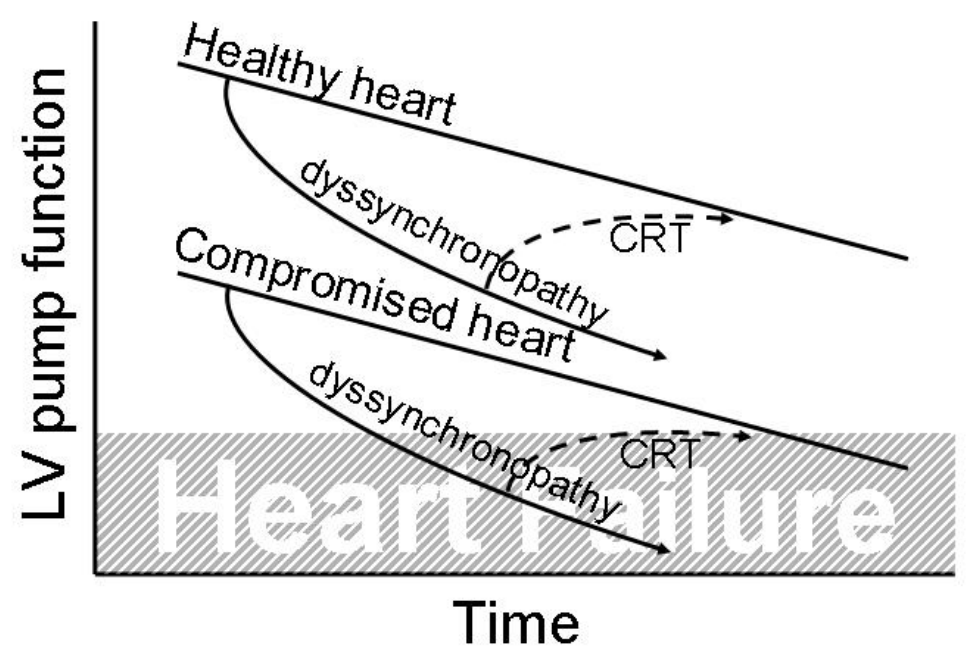

Figure 3. Relationship between duration of ventricular asynchrony by LBBB or RV pacing and development of heart failure. This figure illustrates that attempt to avoid dyssynchronopathy or restoration by cardiac resynchronization therapy may decrease the risk for developing heart failure in healthy subjects and in patients with already reduced LV pump function. Figure modified from reference. ${ }^{15}$

From our findings, we conclude that CRT can be regarded as treatment for dyssynchronopathy. The findings in this thesis were derived from animal experimental studies, and in all of our canine LBBB hearts, LV pump function could be improved by CRT. In patients, however, an important issue remains: "how to identify non-responders to CRT".

Although there is clear evidence for structural and mechanical remodeling, an issue remains whether CRT results in reverse electrical remodeling. In the present thesis CRT only slightly reduced QRS duration and did not reduce QTc 
time (chapter 7). Previous animal experimental studies from our laboratory have also shown absence of electrical remodeling despite structural remodeling. ${ }^{22,23}$ The question whether reverse electrical remodeling is present is important, because many heart failure patients suffer from ventricular arrhythmias and sudden cardiac death is a common cause of death in these patients. ${ }^{24}$ A CRT device is, therefore, often combined with an implantable cardioverter defibrillator (ICD) in patients with heart failure. Although inducibility of ventricular arrhythmias has been shown to become less CRT, ${ }^{25}$ the percentage of sudden cardiac death in the CARE-HF trial was not different in CRT patients as compared to control patients

\section{OPTIMIZATION OF CRT}

In CRT, a great deal of attention is paid to whether a patient is responder or non-responder (see chapter 3). While some patients may be "true nonresponders", it can be argued that others may become responders by better application of CRT. At least two factors can lead to better hemodynamic effects of CRT: pacing site and timing of stimulation.

During LBBB, the LV postero-lateral wall is regarded as the preferred LV pacing site, because it is usually activated latest, ${ }^{2,3}$ In chapter 3 , we showed that maximal improvement in LV pump function could be obtained during intraventricular resynchronization. Intra-ventricular resynchronization could be obtained for all LV pacing sites using the appropriate AV-delays. For the basal LV pacing sites, the appropriate AV-delay in order to merge the LV pacing activation wave front with the intrinsic activation was close to the PQ time during baseline LBBB. LV apex pacing required complete pre-excitation and an AVdelay shorter than PQ time. These findings are in agreement with clinical studies showing that LV pacing improves LV pump function, independent of the LV pacing site. ${ }^{26,27}$ However, it has to be noted that pacing from the lateral wall resulted in a significantly larger increase in LV contractility. ${ }^{27,28}$

Another important aspect for optimization of CRT is timing of stimulation. For understanding the timing of stimulation, Verbeek et al. ${ }^{4}$ have recently proposed a concept for CRT, the path length model (Figure 4). The model assumes that the sequence of electrical LV activation during LV pacing is opposite to that during LBBB. The upper panel shows three situations of LV ventricular activation during $\mathrm{LV}$ pacing at short atrio-ventricular (AV-) delay with complete pre-excitation (situation I). At intermediate AV-delay (situation II) fusion of activation originating from the LV pacing site and intrinsic conduction is present. At long AV-delays (situation III) baseline LBBB activation is present. The other panels show the change in LV pump function, as 
$146 \mid$ Chapter 9

\section{Path lenght model}

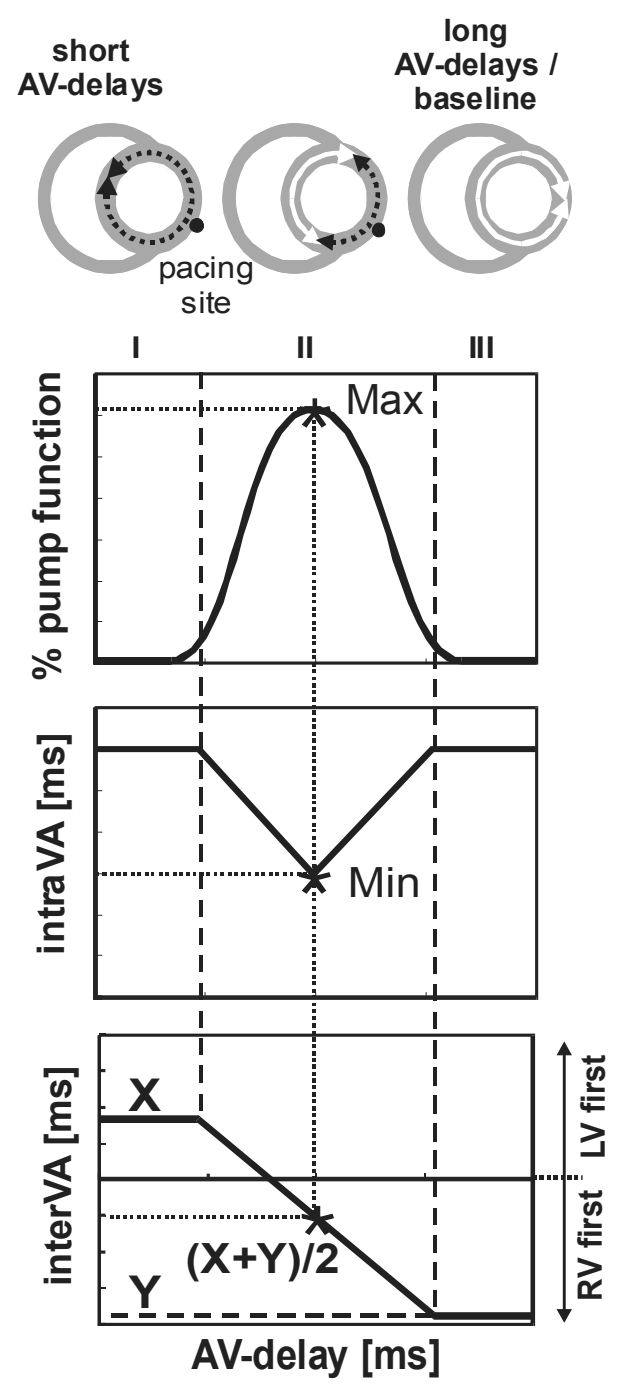

Figure 4. Schematic representation of the path length model (upper panel). Optimal resynchronization is depicted as the wave fronts originating from intrinsic activation (white arrow) and from the LV pacing site (black arrow) merge in the middle. The middle and lower panel show simulated results for intra-ventricular asynchrony (intraVA) and inter-ventricular asynchrony (interVA) as a function of the AV-delay during LV pacing at the LV lateral wall (middle and lower left panel, respectively). Modified from reference. $^{8}$ 
well as change intra- and inter-ventricular asynchrony during LV pacing at various AV-delays. Figure 4 shows that optimal hemodynamic improvement during LV pacing is obtained in situation II. In this situation the value of intraventricular asynchrony should be minimal and the value of inter-ventricular asynchrony halfway its minimal and maximal values, obtained during LBBB (situation III)) and LV pacing (situation I), respectively. It was investigated whether optimal LVdP/dt|max could be predicted by the value of interventricular asynchrony at halfway between its minimal and maximal values. Indeed, the model adequately predicted the value of inter-ventricular asynchrony with optimal LV function for each individual LBBB animal as well as for individual LBBB patients (figure 5). ${ }^{8}$ The wide range of optimal interventricular asynchrony between the animals and patients points out the need for individual optimization of CRT (figure 5A).

The latter study also showed that simultaneous BiV pacing can result in sub-optimal resynchronization because, in $\sim 50 \%$ of the patients, it does not result in values of inter-ventricular asynchrony halfway between its minimal and maximal value. These findings provide insight into why LV pacing is often superior to simultaneous BiV pacing, as reported in several publications. ${ }^{29-32}$ Van Gelder and colleagues showed that fusion of LV pacing and intrinsic activation is superior to $\mathrm{BiV}$ pacing, as predicted from our concept. ${ }^{32}$

The observed sub-optimal improvement of LV function by simultaneous $\mathrm{BiV}$ pacing suggests that $\mathrm{LV}$ function can be improved by sequential $\mathrm{BiV}$ pacing. Indeed, several clinical studies report small, but significant, beneficial hemodynamic effects of sequential over simultaneous BiV pacing. ${ }^{33-36}$ However, optimization of the sequential BiV pacing requires extensive hemodynamic testing during many different combinations of AV-delays and VVintervals. ${ }^{34-36}$ This extensive testing of AV-delay and VV-interval is not feasible for routine clinical practice. Moreover, in clinical practice it is not clear whether priority should be given to AV-delay or VV-interval, because the relation between these two intervals with regard to LV pump function is not clear.

In chapter 7 the abovementioned path length model was extended to incorporate the various combinations of AV-delay and VV-interval. With this model, we tested the hypothesis that the pacing configuration resulting in optimal LV pump function in the animal LBBB model could be predicted for LV pacing as well as simultaneous and sequential BiV pacing. To this purpose, an effective VV-interval (VVeff) was used to incorporate the effect of intrinsic activation as well as RV and LV pacing. With the use of VVeff, optimal resynchronization was predicted for each LBBB animal based on the findings that 1) there was a linear relation between VVeff and inter-ventricular asynchrony, and that 2) optimal LV pump function is achieved at values of inter-ventricular asynchrony halfway between its minimal and maximal values. 
$148 \mid$ Chapter 9
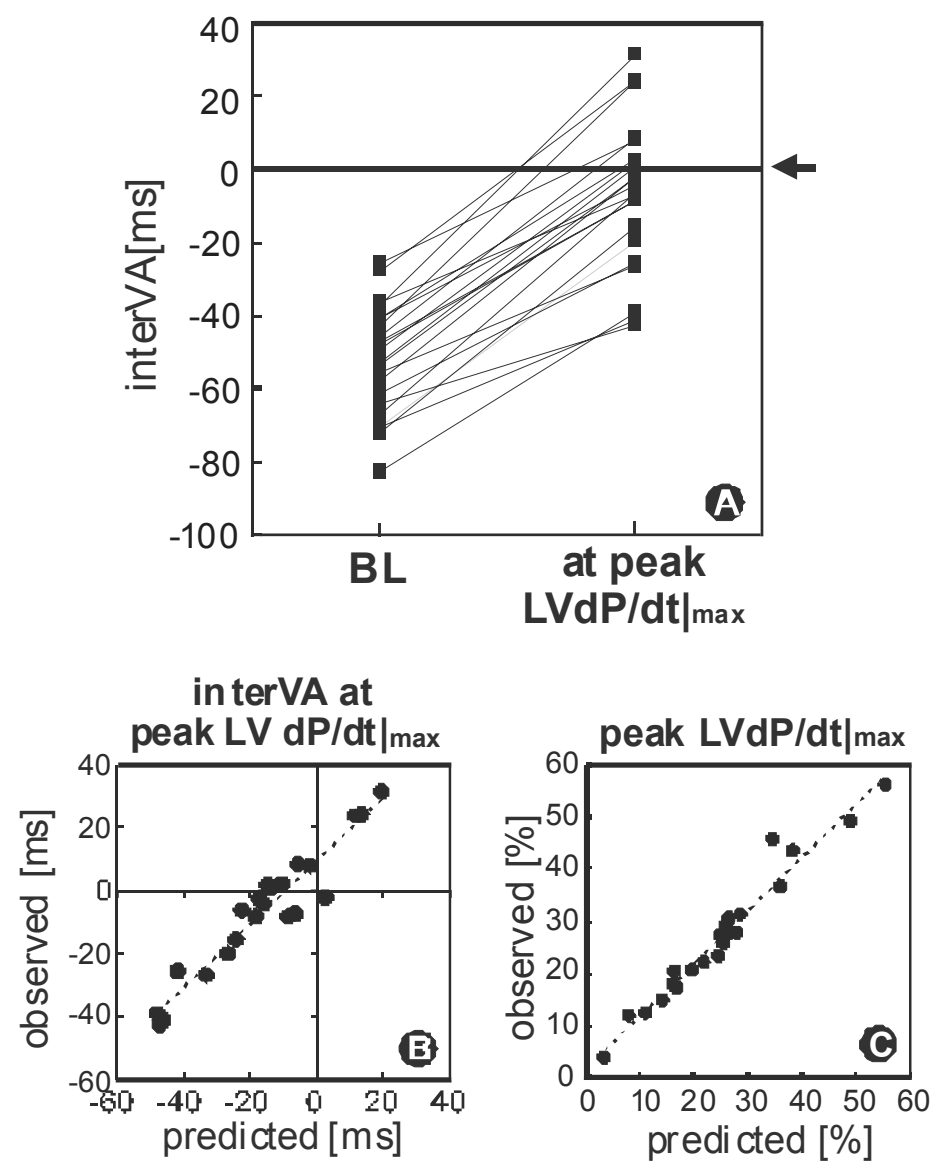

Figure 5. A) Inter-ventricular asynchrony (interVA) values during baseline (LBBB) and at peak LVdP/dt|max of the individual LBBB patients. B) Actual interVA at peak $\mathrm{LVdP} / \mathrm{dt} \mid \mathrm{max}$ versus the predicted interVA at maximal hemodynamic response. (C) Maximum hemodynamic response versus hemodynamic response at predicted interVA. Modified from reference. ${ }^{8}$

Chapter 7 also showed that various methods can be used to optimize VVeff for the best LV pump function. VVeff can be optimized in two ways. A first approach is to achieve optimal VVeff by aiming at fusion with intrinsic activation, using either $\mathrm{LV}$ or BiV pacing at longer AV-delays. A disadvantage of fusion is the inability to adequately cope with the natural variation in AV conduction, resulting in loss of ventricular synchrony. Another approach to optimize VVeff is using $\mathrm{BiV}$ pacing, setting $\mathrm{AV}$-delays shorter than the moment of intrinsic ac- 
tivation through the right bundle branch. The absence of contribution from intrinsic activation provides complete control of timing of RV and LV stimulation, because VVeff equals the programmed VV-interval. Our data further suggest that the use of appropriate VV-interval is hemodynamically more important than optimizing LV filling with longer AV-delays. This finding in LBBB dogs is in agreement with data from CRT patients where optimal LV hemodynamic improvement was found at relatively short AV-delays, i.e. $50 \%$ of intrinsic PR interval $-30 \mathrm{~ms}^{31}$

\section{PACING STRATEGY IN PATIENTS WITH PACING INDICATIONS}

We have previously discussed that, similar to LBBB, RV pacing results in dyssynchronopathy. Since dyssynchronopathy is regarded as a predecessor of heart failure, ${ }^{21}$ pacing strategy in patients with pacemaker indication should be designed to minimize ventricular asynchrony.

Most information related to dyssynchronopathy has been derived from patients and animals in sinus rhythm. However, in patients with symptomatic atrial fibrillation, His bundle ablation and pacemaker implantation is used for rate regulation. In this particular situation, it can be envisioned that rate regulation has some beneficial effects counteracting the negative effects of RV pacing.

In chapter 8 we showed that in this category of patients, especially those patients with structurally normal heart and normal LV EF, long-term RV apex pacing results in decreased LV EF and LV remodeling, i.e. LV dilatation and hypertrophy. In contrast, in patients with initially larger LV dimensions no significant decrease in LV function or LV remodeling occurred during follow-up. Apparently, in these patients the beneficial effects of rate control compensate for the development of dyssynchronopathy.

Various studies have shown that His bundle ablation improves quality of life independent of improvement in LV function. ${ }^{37}$ In a prospective randomized trial in patients with chronic atrial fibrillation and heart failure, it was found that His bundle ablation followed by RV pacing was effective and superior to pharmacological treatment in controlling symptoms. However, the clinical benefit did not coincide with improved LV function or smaller LV dimensions. ${ }^{38}$ Also, the OPSITE study showed that His bundle ablation improved quality of life independent of pacing site (LV, RV or BiV pacing), despite better LV EF during LV and BiV pacing. ${ }^{39}$ On the other, the results of the PAVE study showed small, but significant, beneficial effects of BiV pacing over RV pacing on LV $\mathrm{EF}$ and 6 minute walk test in patients undergoing His bundle ablation for atrial fibrillation. These beneficial effects of BiV pacing were especially present in patients with lower LV EF and worse New York Heart Association function class. 
$150 \mid$ Chapter 9

While BiV pacing is indicated for patients with HF and intrinsic conduction disorders, indications for BiV pacing are less clear in patients with pacemaker indications, so at risk for iatrogenic dyssynchronopathy. Leon and colleagues showed an improved NYHA functional class, increased LV EF, reduced LV end-diastolic, accompanied by a reduction in hospitalization in 20 patients after 17 months of $\mathrm{BiV}$ pacing. ${ }^{40}$ Another study compared RV pacing with BIV pacing in fifty-nine patients with heart failure and atrial fibrillation. BiV pacing improved exercise tolerance, and reduced the number of hospitalizations. ${ }^{41}$ Baker et al. $^{42}$ investigated feasibility, early effects on patient symptoms, and safety of upgrading from a chronically implanted RV pacing system to a BiV system. In 90 percent of patients, upgrading to BiV pacing improved quality of life score, improved NYHA class and increased LV EF. Upgrading from RV pacing to BiV pacing seems feasible, improves LV EF and reduces complaints.

All these data support the idea that, in patients with RV pacing and poor LV EF, CRT should be considered. In order to facilitate decision making about the pacing strategy in pacemaker patients we propose the following decision scheme (Figure 6). The decision tree is based on objective measures: presence of AV-conduction, QRS duration and LV EF. For patients with pacemaker indications who normal AV conduction and narrow QRS complexes, for example sick sinus syndrome, ventricular pacing is not necessary and atrial pacing is recommended, irrespective of LV EF. Because of the substantial risk of developing AV-conduction disturbances in patients with sick sinus, DDD pacemaker implantation with minimal ventricular pacing should be chosen. For patients with AV conduction and wide QRS complex (LBBB), pacing strategy depends on LV EF. While signs of heart failure and LV EF $<35 \%$ fall within the recommendations of CRT, the various studies indicate that all patients with $\mathrm{EF}<40 \%$ are at risk of rapid development of dyssynchronopathy. ${ }^{14,16,43}$ Although we showed that CRT in canine LBBB hearts without heart failure results in reverse remodeling and improvement in LV pump function (chapter 7), there is no evidence that in patients with LBBB and LV EF $>40 \%$ the development of heart failure will be prevented. ${ }^{14,15,43,44}$ Therefore, in these patients atrial pacing would suffice and would at least be better than RV pacing, because this may lead to further widening of the QRS complex. ${ }^{30}$

For patients without AV conduction, permanent ventricular pacing is required. Similar to the situation of patients with normal AV conduction, wide QRS complex, and LV EF $<40 \%$, we recommend CRT for patients without AV conduction and LV EF $<40 \%$. This pacing strategy is based on the clinical studies comparing RV with BiV pacing in patients with heart failure. ${ }^{40,42}$ For $\mathrm{AV}$ block patients with normal LV EF there is not yet sufficient justification for the use of $\mathrm{BiV}$ pacing. ${ }^{14,15,43}$ In order to limit the amount of ventricular 
General discussion

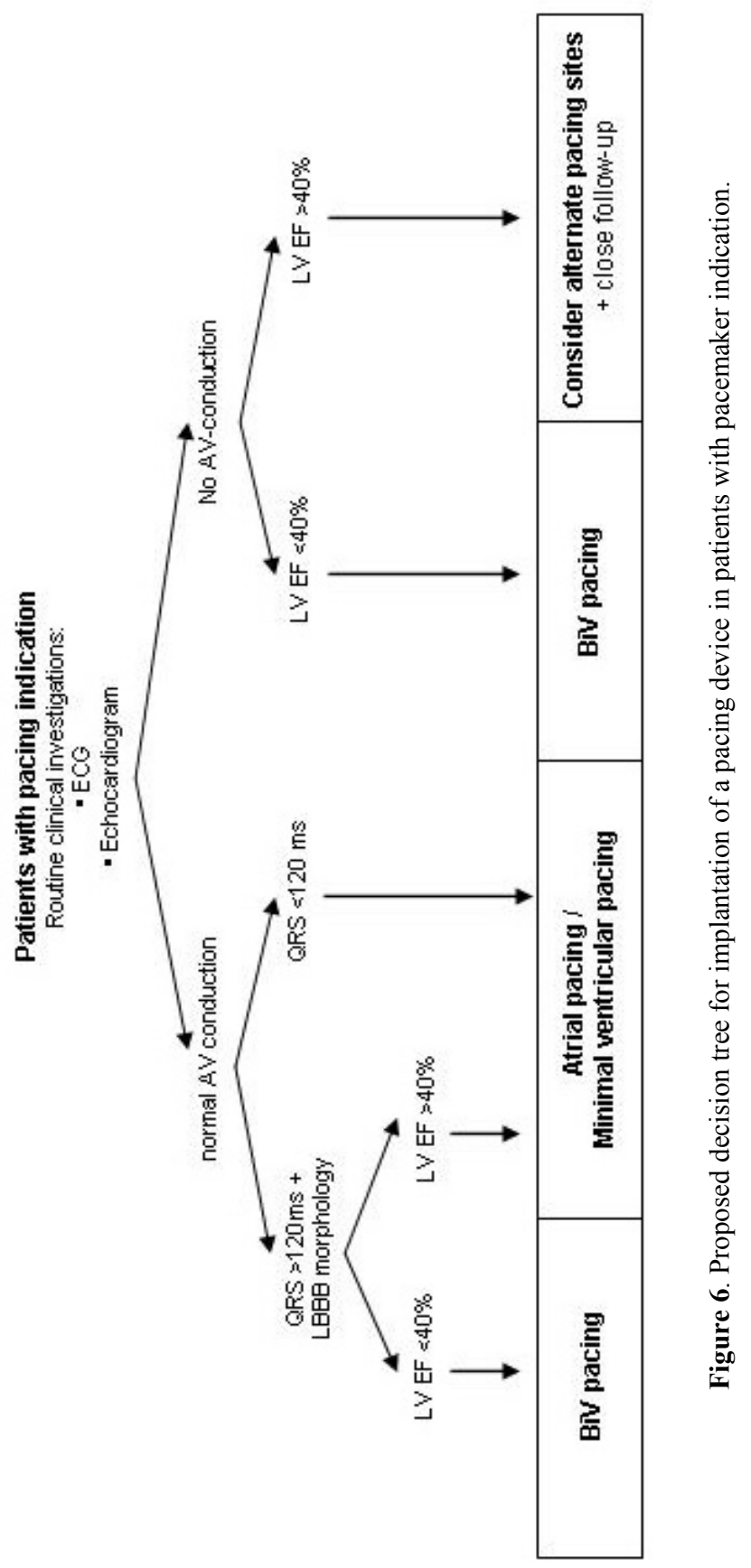




\section{2 \\ Chapter 9}

asynchrony, the use of alternate single ventricular pacing sites should be considered in these patients with normal LV EF and indications for permanent ventricular pacing (RV septal pacing, His bundle pacing, LV apex pacing). ${ }^{45-47}$ It is important to follow these patients using echocardiography, to monitor ventricular function and ventricular remodeling. As shown in chapter 8 , the amount of ventricular remodeling depends on the history of a patient, so individual monitoring may be quite useful. The finding in chapter 7 that CRT reverses LV remodeling in LBBB hearts makes it likely that this may also be the case in patients with permanent RV pacing, thus enabling to recover lost function.

In the light of publications showing that measurements of mechanical dyssynchrony are better predictors of response to CRT, there is a potential role for these measurements in our decision three. However, incorporation of these values is problematic, because currently a large variety of measures is used, each with their own threshold values. Once consensus has been reached on one of these measures, this parameter may replace QRS duration in the decision tree.

\section{UNSOLVED QUESTIONS, FUTURE DIRECTIONS}

While knowledge of the consequences of dyssynchronopathy and resynchronization is rapidly increasing, there are still a number of unsolved questions. Some of them require basic research; others can be investigated in patients.

As mentioned earlier, up to $30 \%$ of patients do not respond to CRT, especially patients with ischemic cardiomyopathy. ${ }^{10}$ The infarcted regions could influence the effect of CRT in at least two ways: local blockade of conduction would prevent $\mathrm{BiV}$ pacing from inducing proper resynchronization, and mechanical interaction between an infarcted region and asynchronously activated region (either early or late activated) is not understood and could lead to complicated interactions. Because of the large variation in location, size and transmural extent of the myocardial infarction in patients, research in animals with LBBB and standardized myocardial infarction could contribute.

More basic understanding of the interaction between ischemic and asynchronously activated regions could be achieved by using mathematical models. Recently, Kerckhoffs and colleagues developed a highly sophisticated model of electro-mechanics. ${ }^{48}$ Estimated values of electrical activation and regional strain, derived from the model, agreed well with those found in canine hearts during $\mathrm{LV}$ and $\mathrm{RV}$ pacing. In the near future, $\mathrm{LBBB}, \mathrm{BiV}$ pacing and infarction will be simulated.

Until now, CRT was evaluated by LV pump function. However, several reports have demonstrated that, in patients with advanced heart failure, the presence of 
RV dysfunction is associated with poor exercise capacity and reduced survival. $^{49,50}$ It is, however, not stated whether this implies that CRT is less effective in RV dysfunction. Possibly, if RV dysfunction is limiting CRT, improvement in LV function does not improve clinical outcome. Also, little or nothing is known about the effects of CRT on RV function. If CRT improves LV function, but reduces RV function, clinical outcome may also not improve. It is therefore interesting and important to study the effects of CRT on RV function in more detail. Preliminary data suggest that BiV pacing can reduce RV pump function while improving LV pump function. ${ }^{51}$

In this thesis, we show that creation of ventricular electrical asynchrony induces dyssynchronopathy, facilitating the development of heart failure. Based on these findings and on other publications in the literature we recommended above to apply $\mathrm{BiV}$ pacing in all patients with dyssynchronopathy and $\mathrm{EF}<40 \%$. However, current guidelines require $\mathrm{EF}<35 \%$ and clinical signs of heart failure. Therefore, there is a gap between the guidelines and our proposed pacing strategy (figure 6). In order to provide further evidence that it is justified to use BiV pacing in patients with less compromised hearts, we recently started a clinical trial. In this trial, patients are included with indications for permanent ventricular pacing resulting in $>70 \%$ ventricular paced beats, and echocardiographic signs of LV systolic dysfunction, i.e. LV EF $<40 \%$ or LV end-diastolic diameter $>55 \mathrm{~mm}$, independent of heart failure symptoms. Primary end-point parameters are LV end-diastolic and end-systolic dimensions as well as LV EF, and New York Heart Association function class. Secondary end-point parameters are quality of life, exercise tolerance and occurrence of atrial and ventricular arrhythmias. This single-blinded randomized cross-over trial is designed to investigate $\mathrm{BiV}$ versus $\mathrm{RV}$ pacing in patients with permanent ventricular pacing. All patients receive a CRT device, which will be randomized to either BiV or RV pacing for 6 months, followed by a 6 months period of pacing in the other pacing setting (figure 7). Moreover, to improve patient selection we will relate mechanical asynchrony with the benefit of BiV pacing. Mechanical asynchrony will be assessed using tissue Doppler imaging (TDI), as previously discussed in chapter 3. 


\section{$154 \mid$ Chapter 9}

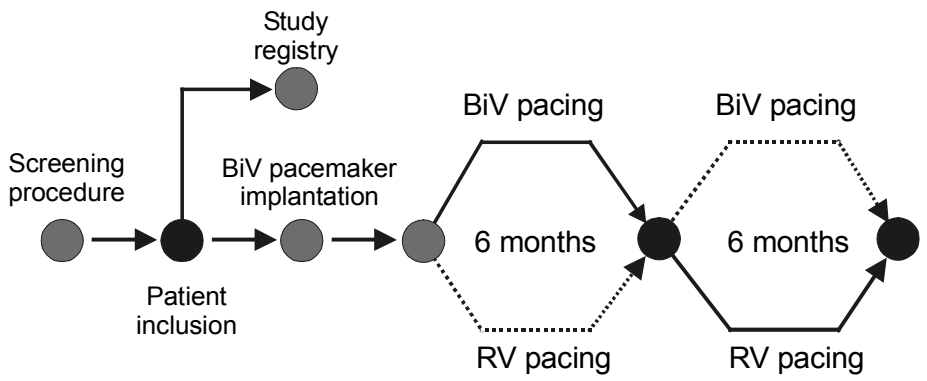

Figure 7. Study design of clinical trial: following inclusion, patients will be implanted with a biventricular $(\mathrm{BiV})$ pacemaker/ICD and randomized to $\mathrm{BiV}$ or right ventricular (RV) pacing for six months, followed by a cross-over period of six months.

Concerning echo measurements of ventricular dyssynchrony: a promising new echocardiographic method that measures regional myocardial circumferential strain has recently been introduced. ${ }^{52}$ This echocardiographic analysis assesses myocardial strain by tracking the "speckles" in the parasternal short axis view (figure 8). Echocardiography has the advantage of being relatively cheap and suitable for follow-up after BiV pacemaker implantation as compared to MRI. However, before clinical implementation of speckle-tracking, proper validation versus MRI-tagging analysis is needed and its feasibility in an unselected population needs to be assessed. To this purpose, we will collaborate with the department of cardiology of Utrecht to validate this speckle-tracking with MRtagging analysis.

Another future direction is to investigate whether it is possible to optimize CRT with an easy non-invasive tool, such as the ECG. Using the path length model we have shown that optimal CRT can be obtained at the halfway values of interventricular asynchrony ${ }^{4}$ and also at the halfway values of VVeff (chapter 7). We also studied whether the heart vector (figure 9), determined by vectorcardiographic analysis, is related to inter-ventricular asynchrony in canine LBBB hearts at various pacing configuration, i.e. various AV-delays and VV-intervals. Figure 8 shows that the heart vector length and inter-ventricular asynchrony are linearly related. Because of this linear relation between heart vector length and inter-ventricular asynchrony, optimal LV pump function and minimal intraventricular asynchrony can be expected to be halfway between the minimal and maximal values of the heart vector length. Preliminary data from eight animals show that heart vector length has a very good correlation with inter-ventricular asynchrony in canine LBBB hearts $(\mathrm{R}=0.96 \pm 0.02)$. 


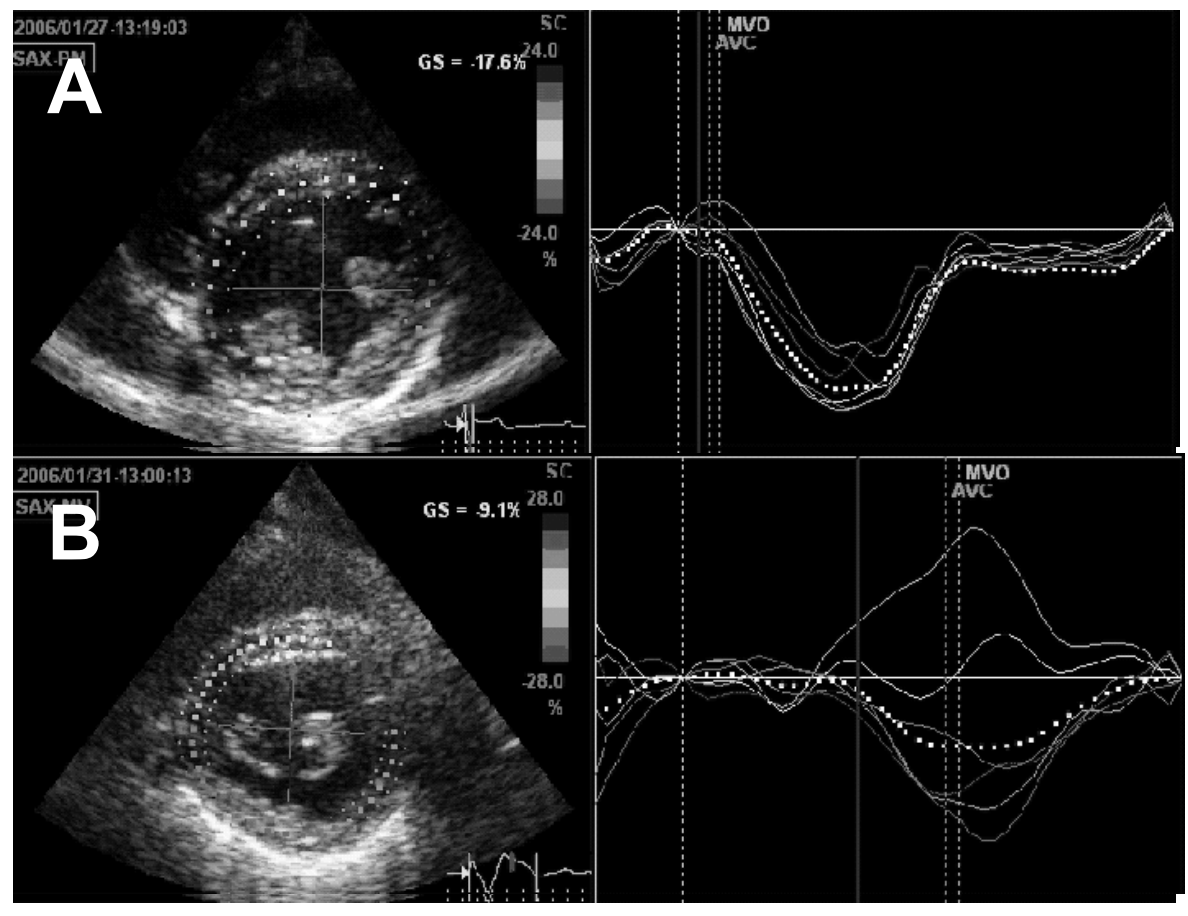

Figure 8. Two parasternal short axis images of a (A) healthy subject and (B) a patient with RV pacing are shown (left column). By tracking the "speckles" (GE, Vivid7) it is possible to determine regional LV circumferential strain (right column). Note the synchronous myocardial shortening patterns in the healthy subject whereas the patient with $\mathrm{RV}$ pacing shows a redistributed strain pattern. The late-activated LV free wall shows normal myocardial shortening (purple and green tracings), but the early-activated septum shows pre-systolic shortening and significant stretch during systole (yellow and blue tracings). Negative strain denotes myocardial shortening, positive strain denotes myocardial stretch. Disregard MVO and AVC in the figures.

Therefore, heart vector length could provide a simple new tool for individual optimization of CRT in the future. To this purpose we have started a clinical study investigating the relation between the heart vector, LV pump function, as well as inter- and intra-ventricular asynchrony in CRT patients during various pacing configurations. 

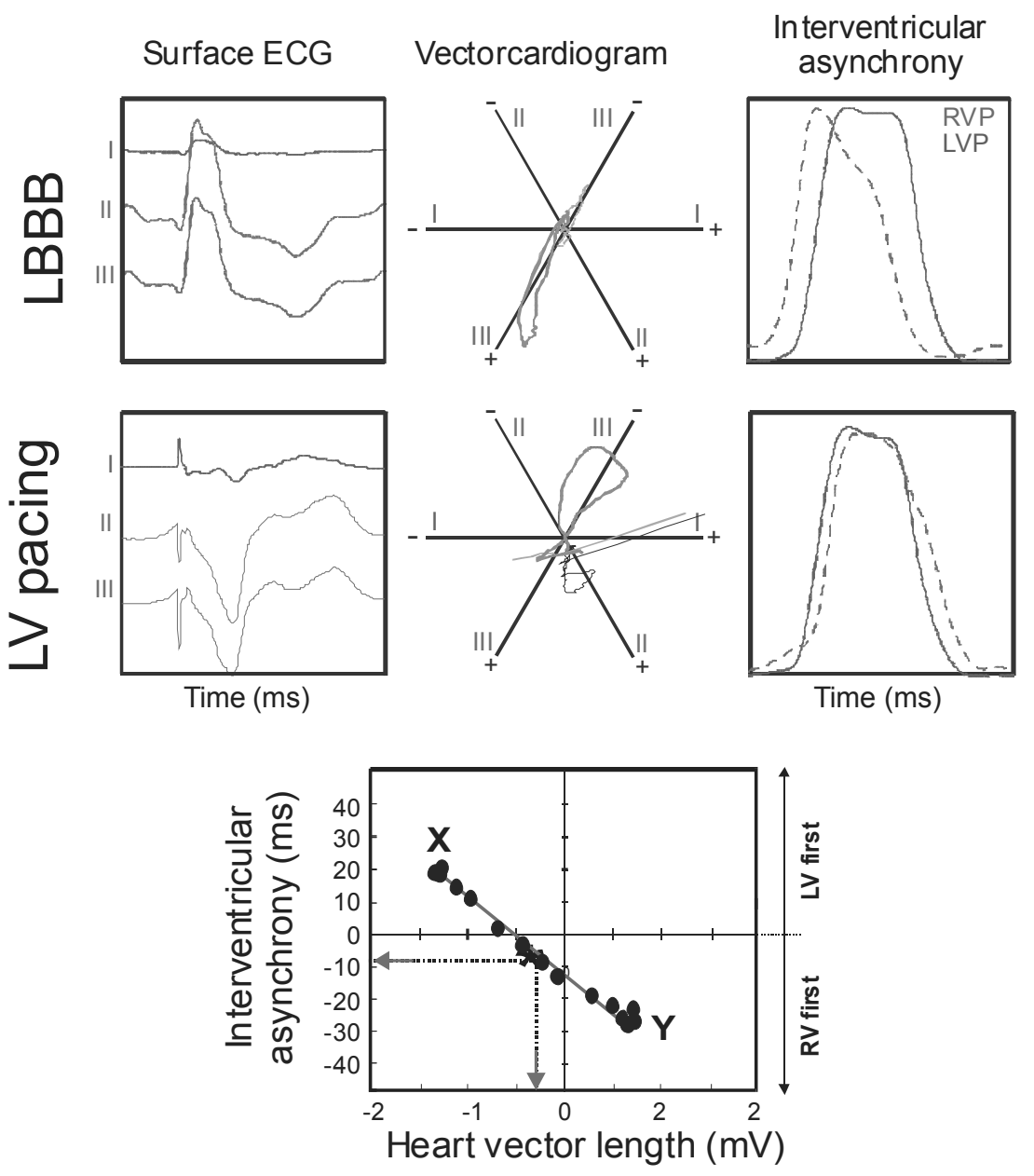

Figure 9. The upper two rows illustrate the surface ECG leads I,II and III (left column), the vectorcardiogram (middle column), and normalized RV and LV pressure curves (PRV and PLV, respectively). PRV and PLV are shown to illustrate inter-ventricular asynchrony which is measured as the time difference between the upslope of PLV and PRV (right column) during LBBB and LV pacing at short AV-delay. The bottom picture shows a typical example of the linear relation between the heart vector length and inter-ventricular asynchrony at various pacing configurations (preliminary data). 


\section{Conclusions}

- Asynchronous ventricular electrical activation by both LBBB and RV apex pacing results in decreased LV pump function, redistribution of myocardial work and blood flow, and LV remodeling in the long run, i.e. asymmetric hypertrophy and LV dilatation. This combination of derangements appears to be one entity that we refer to as dyssynchronopathy.

- Dyssynchronopathy can largely be reversed by BiV pacing

- Optimal hemodynamic improvement is achieved at minimal intraventricular asynchrony.

- The use of VVeff facilitates finding the best combination of AV-delay and $\mathrm{VV}$-interval during BiV pacing.

- In patients undergoing His bundle ablation and pacemaker implantation, the positive effects of rate control interfere with development of dyssynchronopathy.

\section{REFERENCES}

1 Vassallo JA, Cassidy DM, Marchlinski FE, Buxton AE, Waxman HL, Doherty JU, Josephson ME. Endocardial activation of left bundle branch block. Circulation. 1984;69:914-923.

2 Rodriguez LM, Timmermans C, Nabar A, Beatty G, Wellens HJ. Variable patterns of septal activation in patients with left bundle branch block and heart failure. J Cardiovasc Electrophysiol. 2003;14:135-141.

3 Auricchio A, Fantoni C, Regoli F, Carbucicchio C, Goette A, Geller C, Kloss M, Klein H. Characterization of left ventricular activation in patients with heart failure and left bundlebranch block. Circulation. 2004;109:1133-1139.

4 Verbeek XA, Auricchio A, Yu Y, Ding J, Pochet T, Vernooy K, Kramer A, Spinelli J, Prinzen FW. Tailoring cardiac resynchronization therapy using interventricular asynchrony. Validation of a simple concept. Am J Physiol Heart Circ Physiol. 2006;290:H968-977.

5 Verbeek XAAM, Vernooy K, Peschar M, Van Der Nagel T, Van Hunnik A, Prinzen FW. Quantification of interventricular asynchrony during LBBB and ventricular pacing. Am J Physiol Heart Circ Physiol. 2002;283:H1370-1378.

6 Zwanenburg JJ, Gotte MJ, Marcus JT, Kuijer JP, Knaapen P, Heethaar RM, Van Rossum AC. Propagation of onset and peak time of myocardial shortening in ischemic versus nonischemic cardiomyopathy. J Am Coll Cardiol. 2005;46:2215-2222.

7 Pitzalis MV, Iacoviello M, Romito R, Massari F, Rizzon B, Luzzi G, Guida P, Andriani A, Mastropasqua F, Rizzon P. Cardiac resynchronization therapy tailored by echocardiographic evaluation of ventricular asynchrony. J Am Coll Cardiol. 2002;40:1615-1622.

8 Vernooy K, Verbeek XA, Peschar M, Crijns HJ, Arts T, Cornelussen RN, Prinzen FW. Left bundle branch block induces ventricular remodelling and functional septal hypoperfusion. Eur Heart J. 2005;26:91-98.

9 van Oosterhout MF, Prinzen FW, Arts T, Schreuder JJ, Vanagt WY, Cleutjens JP, Reneman RS. Asynchronous electrical activation induces asymmetrical hypertrophy of the left ventricular wall. Circulation. 1998;98:588-595. 


\section{${ }_{158} \mid$ Chapter 9}

10 Lindner O, Vogt J, Kammeier A, Wielepp P, Holzinger J, Baller D, Lamp B, Hansky B, Korfer R, Horstkotte D, Burchert W. Effect of cardiac resynchronization therapy on global and regional oxygen consumption and myocardial blood flow in patients with non-ischaemic and ischaemic cardiomyopathy. Eur Heart J. 2005;26:70-76.

11 Knaapen P, van Campen LM, de Cock CC, Gotte MJ, Visser CA, Lammertsma AA, Visser FC. Effects of cardiac resynchronization therapy on myocardial perfusion reserve. Circulation. 2004;110:646-651.

12 Spragg DD, Akar FG, Helm RH, Tunin RS, Tomaselli GF, Kass DA. Abnormal conduction and repolarization in late-activated myocardium of dyssynchronously contracting hearts. Cardiovasc Res. 2005;67:77-86.

13 Spragg DD, Leclercq C, Loghmani M, Faris OP, Tunin RS, DiSilvestre D, McVeigh ER, Tomaselli GF, Kass DA. Regional alterations in protein expression in the dyssynchronous failing heart. Circulation. 2003;108:929-932.

14 Sweeney MO, Hellkamp AS. Heart Failure During Cardiac Pacing. Circulation. 2006:(in press).

15 Sweeney MO, Prinzen FW. A new paradigm for physiologic ventricular pacing. J Am Coll Cardiol. 2006; $47: 282-288$

16 Wilkoff BL, Cook JR, Epstein AE, Greene HL, Hallstrom AP, Hsia H, Kutalek SP, Sharma A. Dual-chamber pacing or ventricular backup pacing in patients with an implantable defibrillator: the Dual Chamber and VVI Implantable Defibrillator (DAVID) Trial. Jama. 2002;288:3115-3123.

17 D'Ascia C, Cittadini A, Monti MG, Riccio G, Sacca L. Effects of biventricular pacing on interstitial remodelling, tumor necrosis factor-\{alpha\} expression, and apoptotic death in failing human myocardium. Eur Heart J. 2006;27:201-206.

18 Erol-Yilmaz A, Verberne HJ, Schrama TA, Hrudova J, De Winter RJ, Van Eck-Smit BL, De Bruin R, Bax JJ, Schalij MJ, Wilde AA, Tukkie R. Cardiac resynchronization induces favorable neurohumoral changes. Pacing Clin Electrophysiol. 2005;28:304-310.

19 Yu CM, Chau E, Sanderson JE, Fan K, Tang MO, Fung WH, Lin H, Kong SL, Lam YM, Hill MR, Lau CP. Tissue Doppler echocardiographic evidence of reverse remodeling and improved synchronicity by simultaneously delaying regional contraction after biventricular pacing therapy in heart failure. Circulation. 2002;105:438-445.

20 Stellbrink C, Breithardt OA, Franke A, Sack S, Bakker P, Auricchio A, Pochet T, Salo R, Kramer A, Spinelli J. Impact of cardiac resynchronization therapy using hemodynamically optimized pacing on left ventricular remodeling in patients with congestive heart failure and ventricular conduction disturbances(1). J Am Coll Cardiol. 2001;38:1957-1965.

21 Yu CM, Bleeker GB, Fung JW, Schalij MJ, Zhang Q, van der Wall EE, Chan YS, Kong SL, Bax JJ. Left Ventricular Reverse Remodeling but Not Clinical Improvement Predicts LongTerm Survival After Cardiac Resynchronization Therapy. Circulation. 2005.

22 Peschar M, Vernooy K, Cornelussen RN, Verbeek XA, Reneman RS, Vos MA, Prinzen FW. Structural, electrical and mechanical remodeling of the canine heart in AV-block and LBBB. Eur Heart J Suppl. 2004;6D:D61-65.

23 Peschar M, Vernooy K, Vanagt WY, Reneman RS, Vos MA, Prinzen FW. Absence of reverse electrical remodeling during regression of volume overload hypertrophy in canine ventricles. Cardiovasc Res. 2003;58:510-517.

24 Effect of metoprolol CR/XL in chronic heart failure: Metoprolol CR/XL Randomised Intervention Trial in Congestive Heart Failure (MERIT-HF). Lancet. 1999;353:2001-2007.

25 Kies P, Bax JJ, Molhoek SG, Bleeker GB, Zeppenfeld K, Bootsma M, van Erven L, Steendijk P, van der Wall EE, Schalij MJ. Effect of cardiac resynchronization therapy on inducibility of ventricular tachyarrhythmias in cardiac arrest survivors with either ischemic or idiopathic dilated cardiomyopathy. Am J Cardiol. 2005;95:1111-1114. 
26 Gasparini M, Mantica M, Galimberti P, Bocciolone M, Genovese L, Mangiavacchi M, Marchesina UL, Faletra F, Klersy C, Coates R, Gronda E. Is the left ventricular lateral wall the best lead implantation site for cardiac resynchronization therapy? Pacing Clin Electrophysiol. 2003;26:162-168.

27 Butter C, Auricchio A, Stellbrink C, Fleck E, Ding J, Yu Y, Huvelle E, Spinelli J. Effect of resynchronization therapy stimulation site on the systolic function of heart failure patients. Circulation. 2001;104:3026-3029.

28 Dekker AL, Phelps B, Dijkman B, van der Nagel T, van der Veen FH, Geskes GG, Maessen JG. Epicardial left ventricular lead placement for cardiac resynchronization therapy: optimal pace site selection with pressure-volume loops. J Thorac Cardiovasc Surg. 2004;127:16411647.

29 Blanc JJ, Etienne Y, Gilard M, Mansourati J, Munier S, Boschat J, Benditt DG, Lurie KG. Evaluation of different ventricular pacing sites in patients with severe heart failure: results of an acute hemodynamic study. Circulation. 1997;96:3273-3277.

30 Kass DA, Chen CH, Curry C, Talbot M, Berger R, Fetics B, Nevo E. Improved left ventricular mechanics from acute VDD pacing in patients with dilated cardiomyopathy and ventricular conduction delay. Circulation. 1999;99:1567-1573.

31 Auricchio A, Stellbrink C, Block M, Sack S, Vogt J, Bakker P, Klein H, Kramer A, Ding J, Salo R, Tockman B, Pochet T, Spinelli J. Effect of pacing chamber and atrioventricular delay on acute systolic function of paced patients with congestive heart failure. The Pacing Therapies for Congestive Heart Failure Study Group. The Guidant Congestive Heart Failure Research Group. Circulation. 1999;99:2993-3001.

32 Van Gelder BM, Bracke FA, Meijer A, Pijls NH. The Hemodynamic Effect of Intrinsic Conduction During Left Ventricular Pacing as Compared to Biventricular Pacing. J Am Coll Cardiol. 2005;46:2305-2310.

33 Sogaard P, Egeblad H, Pedersen AK, Kim WY, Kristensen BO, Hansen PS, Mortensen PT. Sequential versus simultaneous biventricular resynchronization for severe heart failure: evaluation by tissue Doppler imaging. Circulation. 2002;106:2078-2084.

34 Perego GB, Chianca R, Facchini M, Frattola A, Balla E, Zucchi S, Cavaglia S, Vicini I, Negretto M, Osculati G. Simultaneous vs. sequential biventricular pacing in dilated cardiomyopathy: an acute hemodynamic study. Eur J Heart Fail. 2003;5:305-313.

35 Vanderheyden M, De Backer T, Rivero-Ayerza M, Geelen P, Bartunek J, Verstreken S, De Zutter M, Goethals M. Tailored echocardiographic interventricular delay programming further optimizes left ventricular performance after cardiac resynchronization therapy. Heart Rhythm. 2005;2:1066-1072.

36 Bordachar P, Lafitte S, Reuter S, Sanders P, Jais P, Haissaguerre M, Roudaut R, Garrigue S, Clementy J. Echocardiographic parameters of ventricular dyssynchrony validation in patients with heart failure using sequential biventricular pacing. J Am Coll Cardiol. 2004;44:21572165.

37 Szili-Torok T, Bountioukos M, Muskens AJ, Theuns DA, Poldermans D, Roelandt JR, Jordaens LJ. The presence of contractile reserve has no predictive value for the evolution of left ventricular function following atrio-ventricular node ablation in patients with permanent atrial fibrillation. Eur J Echocardiogr. 2005.

38 Brignole M, Menozzi C, Gianfranchi L, Musso G, Mureddu R, Bottoni N, Lolli G. Assessment of atrioventricular junction ablation and VVIR pacemaker versus pharmacological treatment in patients with heart failure and chronic atrial fibrillation: a randomized, controlled study. Circulation. 1998;98:953-960.

39 Brignole M, Gammage M, Puggioni E, Alboni P, Raviele A, Sutton R, Vardas P, Bongiorni MG, Bergfeldt L, Menozzi C, Musso G. Comparative assessment of right, left, and biventricular pacing in patients with permanent atrial fibrillation. Eur Heart J. 2005;26:712-722. 


\section{$160 \mid$ Chapter 9}

40 Leon AR, Greenberg JM, Kanuru N, Baker CM, Mera FV, Smith AL, Langberg JJ, DeLurgio DB. Cardiac resynchronization in patients with congestive heart failure and chronic atrial fibrillation: effect of upgrading to biventricular pacing after chronic right ventricular pacing. J Am Coll Cardiol. 2002;39:1258-1263.

41 Leclercq C, Walker S, Linde C, Clementy J, Marshall AJ, Ritter P, Djiane P, Mabo P, Levy T, Gadler F, Bailleul C, Daubert JC. Comparative effects of permanent biventricular and right-univentricular pacing in heart failure patients with chronic atrial fibrillation. Eur Heart J. 2002;23:1780-1787.

42 Baker CM, Christopher TJ, Smith PF, Langberg JJ, Delurgio DB, Leon AR. Addition of a left ventricular lead to conventional pacing systems in patients with congestive heart failure: feasibility, safety, and early results in 60 consecutive patients. Pacing Clin Electrophysiol. 2002;25:1166-1171.

43 Sweeney MO, Hellkamp AS, Ellenbogen KA, Greenspon AJ, Freedman RA, Lee KL, Lamas GA. Adverse effect of ventricular pacing on heart failure and atrial fibrillation among patients with normal baseline QRS duration in a clinical trial of pacemaker therapy for sinus node dysfunction. Circulation. 2003;107:2932-2937.

44 Doshi RN, Daoud EG, Fellows C, Turk K, Duran A, Hamdan MH, Pires LA. Left ventricular-based cardiac stimulation post AV nodal ablation evaluation (the PAVE study). J Cardiovasc Electrophysiol. 2005;16:1160-1165.

45 Lieberman R, Grenz D, Mond HG, Gammage MD. Selective site pacing: defining and reaching the selected site. Pacing Clin Electrophysiol. 2004;27:883-886.

46 Gammage MD, Marsh AM. Randomized trials for selective site pacing: do we know where we are going? Pacing Clin Electrophysiol. 2004;27:878-882.

47 Vanagt WY, Verbeek XA, Delhaas T, Gewillig M, Mertens L, Wouters P, Meyns B, Daenen WJ, Prinzen FW. Acute hemodynamic benefit of left ventricular apex pacing in children. Ann Thorac Surg. 2005;79:932-936.

48 Kerckhoffs RC, Faris OP, Bovendeerd PH, Prinzen FW, Smits K, McVeigh ER, Arts T. Electromechanics of paced left ventricle simulated by straightforward mathematical model: comparison with experiments. Am J Physiol Heart Circ Physiol. 2005;289:H1889-1897.

49 Di Salvo TG, Mathier M, Semigran MJ, Dec GW. Preserved right ventricular ejection fraction predicts exercise capacity and survival in advanced heart failure. J Am Coll Cardiol. 1995;25:1143-1153.

50 de Groote P, Millaire A, Foucher-Hossein C, Nugue O, Marchandise X, Ducloux G, Lablanche JM. Right ventricular ejection fraction is an independent predictor of survival in patients with moderate heart failure. J Am Coll Cardiol. 1998;32:948-954.

51 van Kerckhoven R, Storm R, Vernooy K, van Hunnik A, Kuiper M, Prinzen FW. Optimal $\mathrm{RV}$ and LV function require different degree of resynchronization in canine LBBB hearts. Cardiostim abstract. 2006.

52 Amundsen BH, Helle-Valle T, Edvardsen T, Torp H, Crosby J, Lyseggen E, Stoylen A, Ihlen H, Lima JA, Smiseth OA, Slordahl SA. Noninvasive myocardial strain measurement by speckle tracking echocardiography: validation against sonomicrometry and tagged magnetic resonance imaging. J Am Coll Cardiol. 2006;47:789-793.

53 Verbeek XAAM, Vernooy K, Peschar M, Cornelussen RNM, Prinzen FW. Intra-ventricular resynchronization for optimal left ventricular function during pacing in experimental left bundle branch block. J Am Coll Cardiol. 2003;42:558-567.

54 Prinzen FW, Cheriex EC, Delhaas T, van Oosterhout MF, Arts T, Wellens HJ, Reneman RS. Asymmetric thickness of the left ventricular wall resulting from asynchronous electric activation: a study in dogs with ventricular pacing and in patients with left bundle branch block. Am Heart J. 1995;130:1045-1053. 
Summary 
Summary

162 
Synchronous, coordinate ventricular contraction is an important determinant of cardiac pump function. The coordinate ventricular contraction is achieved by ventricular activation through the specialized ventricular rapid-conduction system, the Purkinje fibers. Conduction through these Purkinje fibers is approximately 4 times faster than in the normal myocardium.

Abnormal ventricular impulse conduction, such as left bundle branch block (LBBB), Wolff-Parkinson-White syndrome or ventricular pacing, results in asynchronous ventricular activation and contraction, because the Purkinje system is largely bypassed, and activation spreads by slow conduction through the myocardium. The resulting asynchronous ventricular activation and dyscoordinate contraction leads to adverse hemodynamic effects and abnormal distribution of myocardial workload and blood flow. Animal studies have shown that long-term LV pacing induces LV remodeling, including LV dilatation and asymmetric hypertrophy, processes that predispose for heart failure. Various clinical studies indicate that long-term right ventricular (RV) pacing as well as LBBB are associated with LV dilatation, and increased morbidity and mortality. In chapter 2, the literature on the contribution of the effect of asynchronous ventricular activation to the development of heart failure is discussed.

Chapter 3 reviews the literature on cardiac resynchronization therapy (CRT). During the last decade, CRT has emerged as a new therapeutic option for patients with advanced systolic heart failure in combination with ventricular conduction disturbances, mainly LBBB. CRT restores a synchronous ventricular activation and contraction using combined right ventricular and LV pacing, also referred to as biventricular (BiV) pacing. Large clinical trials in thousands of patients have shown that CRT improves symptoms, quality of life, and exercise tolerance and lowers mortality in patients with refractory heart failure. Despite the clear evidence for the benefits of CRT in the majority of patients with heart failure and ventricular conduction disturbances, about one-third of the patients do not respond to this therapy. Clearly, more insight is required about the cause of lack of response to CRT as well as about how to improve patient selection, positioning of pacing electrodes and timing of RV and LV stimulation.

In chapter 4, we investigated to what extent LBBB alone leads to regional and global structural changes. LV dilatation, hypertrophy, and septal perfusion defects are frequently observed in patients with LBBB. However, patients with LBBB often suffer from co-morbidity, such as hypertension, myocardial infarction, and valvular insufficiencies, making it impossible to study the effects of LBBB in patients. Therefore, we investigated whether isolated LBBB causes dyssynchronopathy in healthy canine hearts. To this purpose, LBBB was induced in eight dogs by radio frequency ablation. Echocardiography showed that 16 weeks of LBBB decreased LV ejection fraction and induced LV dilatation and hypertrophy. In addition, LBBB resulted in maintained regional differences in myocardial workload and blood flow. Myocardial workload and blood flow 


\section{4 \\ Summary}

increased in the LV lateral wall and decreased in the septum. This redistribution in myocardial workload coincided with regional differences in LV wall mass. After several weeks, hypertrophy was more pronounced in the late-activated LV lateral wall as compared to the early-activated septum. The derangements in regional workload and blood flow as well as ventricular remodeling, found in this study, were similar to those found during ventricular pacing. Therefore, we think it is justified to refer to this combination of derangements as dyssynchronopathy. The observed changes in our study, in combination with recent evidence from other laboratories, make us believe that dyssynchronopathy puts the myocardium at risk for development of heart failure.

As mentioned above, cardiac resynchronization therapy (CRT) improves LV pump function in patients with heart failure and LBBB, supposedly due to ventricular resynchronization. However, the relation between LV pump function and measures of asynchrony was not well established. Therefore, in chapter 5, we explored to what extent intra- and inter-ventricular resynchronization determine LV function in canine LBBB hearts during ventricular pacing. To this purpose, canine LBBB hearts were paced at the RV apex, four LV sites (anterior, lateral, posterior, apex), and simultaneously at the RV and LV apex (BiV pacing), at a large number of AV-delays. The results showed that induction of LBBB increased values of both intra- and inter-ventricular asynchrony, while $\mathrm{LVdP} / \mathrm{dt} \mid \max$ and LV stroke work, measures of LV pump function, decreased. Many configurations of LV and BiV pacing immediately improved LV pump function. However, optimal improvement in LV function during ventricular pacing occurred consistently when intra-ventricular asynchrony was minimal. Normalization of intra-ventricular asynchrony required AV-delays shorter than baseline PQ-time during LV apex and BiV pacing thus excluding endogenous $\mathrm{LV}$ activation, but AV-delays virtually equal to baseline PQ-time during pacing at lateral LV sites in order to obtain fusion between pacing induced and endogenous activation. This study showed that intra-ventricular asynchrony around the LV circumference is an important determinant of LV pump function during LBBB and ventricular pacing, and that the pacing strategy for intraventricular resynchronization depends on pacing site and on baseline PQ time.

BiV pacemakers have the option to adjust not only timing between atrium and ventricles, the AV-delay, but also the time interval between RV and LV stimulation, the VV-interval. Currently, finding of the optimum combination of $\mathrm{AV}$-delay and VV-interval requires extensive hemodynamic testing and is therefore often not feasible for clinical practice. In chapter 5, we showed that during LV pacing in canine LBBB hearts, LV pump function is determined by intra-ventricular asynchrony, irrespective of the source of RV activation (RV pacing or intrinsic conduction through the right bundle). For the purpose of the study, described in chapter $\mathbf{6}$, we hypothesize that the same holds true for BiV pacing at any AV-delay and VV-interval. We investigated the relation between 
AV-delay, VV-interval and the improvement of LV pump function in canine LBBB hearts. We showed that the AV-delay is important for fusion of endogenous activation via normal conduction through the right bundle with activation from the pacing electrodes. To correct for the timing of ventricular activation for the intrinsic activation, we calculated, the effective VV-interval. Intrinsic consduction time was derived from measurements of surface ECG during BiV pacing at various $\mathrm{AV}$-delays. Calculation of this effective VV-interval enabled to estimate the combination(s) of AV-delay and VV-interval leading to the best hemodynamic effect in a non-invasive way.

In chapter 5 and 6 we showed that CRT can improve LV pump function immediately in the canine LBBB heart. We hypothesized that the dyssynchronopathy, induced by LBBB as described in chapter 4, can be restored by ventricular resynchronization. In order to test this hypothesis, in eight dogs with chronic (eight weeks) LBBB BiV pacing was applied for another eight weeks. CRT immediately and persistently improved LV pump function and restored the regional differences in myocardial blood flow and myocardial contraction almost completely. Moreover, the LV dilatation and asymmetric hypertrophy that were present after 8 weeks of LBBB, largely disappeared after eight weeks of $\mathrm{BiV}$ pacing. The most pronounced reduction in hypertrophy was observed in the LV lateral wall, the region that was hypertrophied most due to LBBB. These results indicate that CRT is able to "cure" dyssynchronopathy, even in hearts without overt heart failure.

As mentioned above, dyssynchronopathy can be induced by LBBB, but also by ventricular pacing. So far, no study has investigated the consequences of long-term ventricular pacing in patients on ventricular remodeling. Because conventional RV apex pacing results in a ventricular activation pattern, similar to LBBB, we hypothesized the presence of dyssynchronopathy after long-term RV pacing in these patients. Chapter 8 describes a retrospective echocardiographic analysis on data from patients during long-term RV pacing following His bundle ablation for atrial arrhythmias. We sought to gain insight into the balance between adverse effects of long-term RV pacing and beneficial hemodynamic effects of heart rate regularization by His bundle ablation and tried to identify those patients who deteriorate as a consequence RV pacing. In patients with normal cardiac function and normal LV dimensions, RV pacing resulted in dilatation and decreased cardiac function within 2-5 years. This data is consistent with the remodeling mentioned above in dogs with LBBB. However, in patients with decreased cardiac pump function at the time pacemaker implantation, cardiac function and structure did not change during long-term RV pacing. An possible explanation for the lack of changes in the latter group is that in this group cardiac function had already been decreased by the atrial arrhythmias and that the positive effects of appropriate rate control counterbalanced the negative effects of RV pacing. Therefore, we conclude that in patients with structurally 


\section{$166 \mid$ Summary}

normal heart and normal cardiac function, His bundle ablation should be avoided in healthy subjects in order to prevent development of dyssynchronopathy.

Chapter 9 is the general discussion, where results of the previous chapters are discussed in a broader perspective. Moreover, current and future research topics, initiated by this thesis work, are mentioned. First of all, a prospective randomized clinical trial has been performed our hospital. It is the aim of this study to investigate whether biventricular pacing can reverse or prevent the possible adverse effects of single right ventricular pacing in patients with indications for chronic ventricular pacing therapy. This single (patient) blinded randomized crossover trial is designed to investigate $\mathrm{BiV}$ versus $\mathrm{RV}$ pacing in patients with class I or II indications for permanent pacing therapy. We hypothesize that ventricular asynchrony predicts the positive effects of BiV pacing, independent of the severity heart failure. Patients were eligible for the study if having class I or II indications for permanent pacemaker indications resulting in $>70 \%$ RV paced beats. Furthermore, echocardiographic signs of systolic LV dysfunction were required: LV ejection fraction $<40 \%$ or LV end-diastolic diameter $>55 \mathrm{~mm}$, independent of heart failure symptoms. All patients received a $\mathrm{BiV}$ pacing device, randomized to either BiV or RV pacing for 6 months, followed by 6 months of pacing in the other pacing setting. At the beginning of the study and after each period of 6 months, the patients will undergo the following investigations: clinical status, echocardiogram, electrocardiogram, exercise test, blood sample and heart failure questionnaire. 37 patients have been included in the study. So far, 12 patients have finished the complete study protocol. Another 18 patients have finished their first half year after randomization. The study is supposed to finish in august 2007.

In addition, a study has been initiated on the possibility of using vectorcardiography for optimization of cardiac resynchronization therapy in animals and patients. Also, speckple tracking is currently being studied for measurements of circumferential regional myocardial strain. Echocardiography has the advantage of being relatively cheap and suitable for follow-up after BiV pacemaker implantation as compared to MRI. However, before clinical implementation of speckle tracking, proper validation versus MRI-tagging analysis is needed. 
Samenvatting 
Samenvatting 
Voor een goede pompfunctie van het hart is het van belang dat de hartspiercellen goed samenwerken. Deze samenwerking wordt gemedieerd door het geleidingssysteem in het hart. Het geleidingssysteem bestaat uit een aantal banen waarlangs de elektrische prikkel in het hart snel voortgeleid wordt, waardoor de hartspiercellen in de hartkamers bijna overal tegelijkertijd elektrisch geactiveerd worden en daardoor ook gelijktijdig samentrekken.

In het geval van een geleidingsstoornis, is de geleiding langs een van de snelle geleidingsbanen geblokkeerd. Bij het linker bundeltak blok (LBTB) is de geleiding over de linker bundeltak, naar de linker hartkamer, geblokkeerd. De elektrische prikkel kan dan nog wel in de linker kamer terecht komen, maar dit vindt dan plaats via de veel tragere cel-op-cel geleiding vanuit de rechter hartkamer. Door deze trage prikkelgeleiding naar en binnen de linker hartkamer zal de activatie van de linker kamer en daarmee de duur van totale activatie van het hart toenemen.

Trage geleiding met verlengde activatietijd van het hart is ook aanwezig bij elektrische stimulatie van de hartkamers door middel van een pacemaker (ventriculair pacen). Tijdens ventriculair pacen vindt geen prikkel geleiding plaats via de snelle geleidingsbanen, maar wordt de elektrische activatie vanuit de pacemaker-electrode door middel van cel-op-cel geleiding doorgegeven door de hartkamers. Tijdens een pacemaker implantatie worden de pacemaker draden door de aders opgeschoven in de rechter boezem en rechter hartkamer. Activatie van de hartkamers vindt dan plaats vanuit de rechter hartkamer naar de linker hartkamer, een volgorde van activatie, die veel lijkt op het eerder beschreven activatie tijdens LBTB.

Doordat, tijdens ventriculair pacen of bij LBTB, de activatie van de hartkamers vertraagd is, trekken de verschillende gebieden van de hartkamer niet tegelijkertijd samen (asynchrone samentrekking). Uit eerdere studies is bekend dat asynchrone samentrekking een duidelijk nadelige invloed heeft op de pompfunctie van het hart, vandaar dat ook wel gesproken wordt over dyssynchronie.

Geleidingsstoornissen komen in verhouding veel voor bij patiënten met hartfalen. Een veel voorkomende geleidingsstoornis is het LBTB. Deze geleidingsstoornis komt voor bij ongeveer 25 procent van de patiënten met hartfalen. Het mag duidelijk zijn dat dyssynchronie in een toch al slecht hart extra nadelige gevolgen kan hebben. Het staat echter nog ter discussie of het LBTB oorzaak of gevolg van hartfalen is.

Sinds enkele jaren wordt een nieuwe behandeling gebruikt bij patiënten met hartfalen en LBTB. Deze therapie heet "cardiale resynchronisatie therapie (CRT)". Door het gelijktijdig stimuleren van zowel de linker als de rechter hartkamer worden de samentrekking van beide kamers gesynchroniseerd en wordt de pompfunctie van het hart verbeterd. Gedurende de laatste 10 jaar heeft onderzoek bij duizenden patiënten aangetoond dat deze therapie de symptomen van hartfalen vermindert, de kwaliteit van het leven verbetert en ook de prog- 


\section{$170 \mid$ Samenvatting}

nose van overleving verbetert. Er bestaan echter nog een groot aantal vragen rond deze therapie. Zo wordt onvoldoende begrepen waarom een aanzienlijk deel van de patiënten (20-30\%) zich niet beter voelt met CRT. Ook lijkt CRT nog niet overal optimaal te worden toegepast, bijvoorbeeld met betrekking tot plaatsing van de pacemaker-electroden en de timing van stimulatie van de rechter en linker kamer. Hiertoe worden steeds geavanceerder technieken gebruikt.

Het onderzoek in dit proefschrift besteedt aandacht aan de pathofysiologie van de boven gedefinieerde dyssynchronopathie, de gevolgen van resynchronisatie en systematiek van het optimaal resynchroniseren.

Het is bekend een spier zich aanpast aan de mechanische belasting: spiergewicht neemt toe (hypertrofie) bij langdurig zware belasting en neemt af (atrofie) bij inactiviteit. Dit is ook bekend voor het hart: de hartspier wordt dikker wanneer, bijvoorbeeld door hoge bloeddruk, de belasting van de hartkamers hoog is. Bij aanvang van dit promotieonderzoek was de verwachting dat het hart zich zou aanpassen aan de veranderde elektrische activatie op grond van regionale verschillen in belasting. Hierbij worden laat-geactiveerde gebieden van het hart meer belast en worden vroeg geactiveerde gebieden minder belast. Daarnaast was de verwachting dat door de dyssynchrone activatie van de hartkamers, de pompfunctie van het hart achteruit zou gaan wat op de lange termijn zou kunnen leiden tot een vergroting van het hele hart (dilatatie). Omdat deze cascade uniek is voor een dyssynchrone activatie definiëren we het als dyssynchronopathie.

Om deze reden wilden we onderzoeken in hoeverre dyssynchronopathie optreedt als gevolg van LBTB. In patiënten is dit lastig te onderzoeken omdat veel patiënten met LBTB ook andere afwijkingen aan het hart hebben, zoals hypertrofie, klepproblemen, hartinfarcten en pompfunctiestoornissen. Dit was voor ons de reden om in hoofdstuk $\mathbf{4}$ de gevolgen van linker bundeltak blok op de structuur en functie in het gezonde hondenhart te bestuderen. LBTB werd geïnduceerd door met behulp van een katheter in de linker hartkamer, de linker bundeltak "door te branden" met radiofrequente straling. De structuur en functie van het hart werd bij deze honden vervolgens gedurende 16 weken gevolgd met echo en MRI van het hart. We konden zien dat vrijwel onmiddellijk de pompfunctie van het hart afnam en er binnen enkele weken dilatatie van de linker hartkamer optrad. Ook ontstonden er regionale verschillen in belasting van de linker hartkamer, wat binnen enkele weken leidde tot een sterkere hypertrofie in de laat-geactiveerde vrije wand van de linker kamer ten op zichte van het vroeggeactiveerde septum. In gezonde hondenharten leidde LBTB binnen 4 maanden niet tot hartfalen, maar wel tot dyssynchronopathie met afwijkingen die zouden kunnen bijdragen tot het ontstaan van hartfalen.

In hoofdstuk 5 onderzochten we of het mogelijk was om de pompfunctie van het hart in honden met linker bundeltak blok te verbeteren, alsmede welke 
factoren verband houden met de verbetering van pompfunctie. Hiertoe werden er, bij de honden die een linker bundeltak blok hadden, pacemakerdraden geplaatst op verschillende plaatsen op de linker hartkamerwand. Door het plaatsen van een catheter met 64 electroden in de linker kamer, werd de volgorde van elektrische activatie binnen de linker kamer gemeten (asynchronie binnen de linker kamer). Door het plaatsen van drukcatheters in de linker en rechter kamer werd het tijdsverschil in stijging van de bloeddruk in beide kamers gemeten (asynchronie tussen linker en rechter kamer). De pompfunctie van het hart werd gemeten door meting van druk en volume in de linker hartkamer. Het bleek dat onafhankelijk van de plaats van stimuleren, de verbetering van pompfunctie sterk gerelateerd was aan de asynchronie binnen de linker hartkamer. Steeds als de asynchronie binnen de linker hartkamer minimaal was, bleek de pompfunctie van de linker hartkamer optimaal.

Met moderne CRT pacemakers kan, naast het tijdverschil tussen boezems en hartkamers (AV-delay), ook een tijdverschil tussen de linker en rechter hartkamer (VV-interval) geprogrammeerd worden. Sommige studies suggereren dat de pompfunctie van het hart nog verder verbeterd kan worden door, bij CRT, de linker en rechter kamer electrode niet gelijktijdig te stimuleren. Optimale instelling van zowel $\mathrm{AV}$-delay als $\mathrm{VV}$-interval vereist echter uitgebreide metingen, ook al omdat er tot nu toe geen logica te ontdekken is hoe AV-delay en VVinterval met elkaar samenhangen . Daarom onderzochten we in hoofdstuk 6 systematisch de relatie tussen AV-delay, VV-interval en de verbetering in pompfunctie van het hart. Dit onderzoek in honden met LBTB toonde, dat AVdelay en VV-interval niet los van elkaar te zien zijn. Het AV-delay is van belang voor de mate van fusie van de elektrische activatie via de normale geleiding door de rechter bundeltak en de activatie vanuit de pacemaker electroden in rechter en linker kamer. Om te corrigeren voor de normale geleiding door de rechter bundeltak hebben we met behulp van het hartfilmpje (elektrocardiogram=ECG), een effectief VV-interval berekend. Met behulp van dit effectief VV-interval, kon de optimale combinatie van AV-delay and VV-interval gemakkelijk en non-invasief (geen katheter nodig in de linker hartkamer) bepaald konden worden.

Uit hoofdstuk 5 en 6 werd duidelijk dat CRT, in het gezonde hondenhart met linker bundeltak blok, de pompfunctie van het hart onmiddellijk kan verbeteren. De vraag die we ons stelden in hoofdstuk 7 was, in hoeverre CRT de structurele en functionele veranderingen van het hart ten gevolge van linker bundeltak blok (hoofdstuk 4) kan herstellen op de lange termijn. Kortom, in hoeverre CRT de dyssynchronopatie door het LBTB kan "genezen". Hiertoe werd er bij honden met 8 weken LBTB een CRT pacemaker geïmplanteerd. De structuur en functie van het hart werd bij deze honden vervolgens gedurende de 8 weken LBTB en 8 weken CRT vervolgd met echo en MRI van het hart. Na 8 weken CRT bleken de dilatatie en asymmetrische hypertrofie, veroorzaakt door 


\section{$172 \mid$ Samenvatting}

het LBTB, nagenoeg verdwenen. Dit alles ging gepaard met een nagenoeg compleet herstel van het patroon van samentrekking van de hartspier (gemeten met MRI, echo) en van de doorbloeding. Deze gegevens zijn een sterke aanwijzing dat CRT dyssynchronopatie, veroorzaakt door het LBTB, kan herstellen, zelfs in de afwezigheid van hartfalen.

Tot op heden heeft niemand systematisch de structurele en functionele aanpassingen van het hart ten gevolge van rechter hartkamer stimulatie onderzocht. Omdat bij rechter kamer stimulatie de activatie van het hart veel lijkt op die bij LBTB, achtten wij het mogelijk dat bij patiënten met een dergelijke pacemaker ook dyssynchronopathie voorkomt. Dit is de reden dat we in hoofdstuk 8, bij patiënten met een pacemaker, de gegevens van reeds gemaakte echo's van het hart na implantatie van de pacemaker, hebben bestudeerd. De patiënten in dit onderzoek kregen de pacemaker in verband met boezemritmestoornissen die niet goed onder controle gekregen konden worden met medicijnen. Bij deze patiënten wordt dan de verbinding tussen de boezems en hartkamers onderbroken en wordt het ritme van de hartkamers overgenomen door de pacemaker. Het onderzoek toonde dat, bij patiënten die bij implantatie een normale structuur en functie van het hart hadden, het rechter kamer stimuleren resulteerde in verminderde pompfunctie en dilatatie van het hart binnen 2-5 jaar. Dit zijn dus veranderingen die lijken op die gevonden in de hondenharten met LBTB. Echter, bij patiënten die ten tijde van de pacemaker implantatie reeds een verminderde pompfunctie van het hart hadden, nam de pompfunctie van het hart niet verder af en trad er geen dilatatie van het hart op. Een mogelijke verklaring hiervoor is dat, bij de patiënten uit deze laatste groep, de pompfunctie van het hart al verminderd was door de boezemritmestoornissen. Mogelijk wegen de nadelen van asynchrone activatie van het hart door chronische hartstimulatie niet op tegen de voordelige effecten van het reguleren van het hartritme.

Naar aanleiding van bovengenoemde studies, zijn we in het academisch ziekenhuis Maastricht een prospectieve studie gestart. Het doel van deze studie is te onderzoeken in hoeverre CRT de dyssynchronopathie ten gevolge van chronische rechter kamer stimulatie kan voorkomen of zelfs kan herstellen. Hierbij is de hypothese dat het herstel van de dyssynchronopathie voorspeld kan worden door de mate van asynchronie tijdens rechter kamer stimulatie en dat het herstel onafhankelijk is van de ernst van hartfalen. Hiertoe zijn patiënten met een pacemaker een "upgrade" naar een biventriculaire pacemaker ondergaan. De patiënten werden deze studie geselecteerd op basis van aanwezigheid van verminderde pompfunctie van het hart en dilatatie van het hart, ongeacht klachten van hartfalen. De studie heeft een "cross-over" ontwerp. Dit houdt in dat de patiënt, na de upgrade naar de biventriculaire pacemaker, een half jaar rechter kamer stimulatie en een half jaar biventriculaire stimulatie zal ondergaan, of visa versa. De patiënt weet echter niet welke instelling de pacemaker gedurende de 2 perioden heeft. In het begin van de studie en na elk half jaar, zal 
de patiënt geëvalueerd worden door middel van een echo van het hart, een vragenlijst, een inspanningstest, bloedonderzoek en gesprek met de cardioloog. Op dit moment zijn alle patiënten geincludeerd en de eerste resultaten zullen in 2007 bekend worden. 
Dankwoord 
Dankwoord 176 
Tot slot wil ik iedereen, die heeft bijgedragen aan het tot stand komen van dit proefschrift, heel hartelijk bedanken. Sommigen wil ik hierbij in het bijzonder noemen.

Allereerst wil ik Frits Prinzen, mijn co-promotor en directe begeleider, bedanken. Frits, in 1998 werd ik als 2e jaars student aan je voorgesteld. Ik wist toen al dat ik cardioloog wilde worden en dat ik graag in deze richting onderzoek wilde doen. Jij hebt mij hier destijds bij geholpen. Na enkele jaren als student-assistent bij je te hebben gewerkt, vroeg je me in 2001 of ik promotieonderzoek wilde doen. Toen in 2003 de mogelijkheid bestond om mijn promotieonderzoek te combineren met de opleiding cardiologie, heb je me geholpen bij het schrijven van de subsidieaanvraag. $\mathrm{Nu}, 2006$, zit mijn promotieonderzoek er op en zal ik de komende jaren in de kliniek verdwijnen. Frits, heel erg bedankt voor de leuke, leerzame en inspirerende tijd. Ik hoop dat we in de toekomst nog veel zullen samenwerken waarbij we de lijn van preklinisch naar klinisch onderzoek kunnen onderhouden.

De promotoren prof.dr.H.J.G.M. Crijns en prof.dr.T. Arts.

Beste Harry, bedankt voor de kritische pen waarmee je mijn werk gecorrigeerd hebt. Daarnaast wil ik je bedanken voor mogelijkheid om mijn promotieonderzoek kunnen combineren met de opleiding cardiologie. Deze combinatie is helaas niet vaak mogelijk en ik waardeer het daarom des te meer.

Beste Theo, met name het laatste jaar ben je erg betrokken geweest bij mijn proefschrift. Bedankt voor het kritisch doornemen van mijn proefschrift. Je commentaar inspireerde me om, vlak voor de eindstreep, nog even extra mijn best te doen.

Co-promoter dr. B. Dijkman.

Beste Barbara, toen mijn onderzoek meer klinisch georienteerd raakte, ben je betrokken geraakt bij mijn onderzoek. Ik wil je graag bedanken voor je steun, vertrouwen en inzet waarmee je mijn klinische onderzoek hebt begeleid. Ondanks dat onze BV-RV studie nu niet meer binnen dit proefschrift valt., ben ik ervan overtuigd dat we dit onderzoek succesvol zullen afronden en dat dit slechts het begin is van onze samenwerking.

De leden van de beoordelingscommissie, prof.dr.G.J. van der Vusse, prof.dr.M.A. Allessie, dr.A. Auricchio, prof.dr.J.J. Bax en prof.dr.J.G. Maessen, wil ik bedanken voor het beoordelen van het manuscript.

Maaike, jij hebt mij ingewijd in het onderzoek toen ik als student-assistent bij je begon. Jarenlang hebben we lief en leed gedeeld en ik wil je graag bedanken voor je gezelligheid en collegialiteit. 
$178 \mid$ Dankwoord

Xander, omdat onze projecten veel overlap hadden, hebben we veel samengewerkt. Ik wil je bedanken voor die samenwerking. Ik heb altijd gevonden dat de combinatie van technicus en medicus uiterst zinvol was, ondanks dat jij de gedachtekronkels van medici niet altijd begreep.

Richard, graag wil je bedanken voor je directheid en kritische blik. Jij wist altijd precies de vinger op de zere plek te leggen. Je hebt me daarmee geholpen een kritischer onderzoeker te worden.

Ward, toen jij je bij de groep voegde hebben we, als "room mates", lief en leed met elkaar gedeeld. Ik ben blij dat je mijn paranimf wilt zijn. Hopelijk zullen we we samen nog veel artikelen blijven publiceren. Aan de case-reports zal het in ieder geval niet liggen.

Arne, Marion en Theo, ik wil jullie graag bedanken voor de hulp tijdens de experimenten met de proefdieren. Dit proefschrift zou nooit tot stand zijn gekomen zonder jullie inzet.

Beste Tammo, Luz-Maria en Carl. Jullie wil ik graag bedanken voor de mogelijkheid die jullie geboden hebben om mijn wetenschappelijk interesse te verruimen. Met jullie hulp was het mogelijk om een aantal maanden naar het lab van Ramon Brugada en Charles Antzelevitch te gaan. Deze periode was uiterst leerzaam voor mij.

Verder wil ik iedereen bedanken die mij heeft geholpen dit proefschrift tot stand te laten komen en die ik niet heb genoemd.

Beste Rogier, bedankt voor je vriendschap. Ik vind het erg fijn dat jij als paranimf aan mijn zij zal staan tijdens de verdediging van mijn proefschrift.

Ten slotte wil ik mijn vrouw en familie bedanken. Ik wil jullie heel erg bedanken voor jullie steun en liefde. 


\section{Curriculum Vitae}


Curriculum vitae 


\section{Kevin Vernooy}

Geboren 29 juli 1978 te St.Oedenrode

\section{Opleiding}

1990-1996 Gymnasium, R.K. Gymnasium Beekvliet, St.Michielsgestel

1996-2003 Geneeskunde, Universiteit Maastricht (cum laude)

\section{Relevante werkervaring}

1998-2001 Student-assistent, vakgroep Fysiologie, Universiteit Maastricht (dr.F.W. Prinzen)

Aug. '01 Assistent in opleiding (AIO), vakgroep Fysiologie, Universiteit Maastricht (dr.F.W.Prinzen, prof.dr.T.Arts)

Aug.'03 Assistent geneeskunde in opleiding tot klinisch onderzoeker (AGIKO), vakgroep cardiologie, academisch ziekenhuis Maastricht (prof.dr.H.J.G.M.Crijns)

Aug.'03 Onderzoek, vakgroep Fysiologie/Cardiologie

Aug.'04 Arts in opleiding tot specialist, vakgroep Cardiologie, academisch ziekenhuis Maastricht

Aug.'05 Onderzoek, vakgroep Fysiologie/Cardiologie

Okt.'06 Arts in opleiding tot specialist, stage interne geneeskunde in het kader van de opleiding cardiologie, Atrium Medisch Centrum Heerlen (dr.P.Voogt)

\section{Buitenlandse stage}

Mrt-jun. '04 Moleculaire genetica, Masonic medical research institute, Utica, New York, USA (dr.R.Brugada, dr.C.Antzelevitch)

\section{Beurzen/prijzen}

2003

ZonMW (NWO) AGIKO-stipendium toekenning, voor het project "Ventricular remodeling due to asynchronous activation and reversal by resynchronization therapy"

Aug '06 Winner Sagawa Young Investigator's Award, Cardiovascular System Dynamics Society 2006 
182 


\section{Publications}


Publications 
1. Verbeek XAAM, Vernooy K, Peschar M, Van Der Nagel T, Van Hunnik A, Prinzen FW. Quantification of interventricular asynchrony during LBBB and ventricular pacing. Am J Physiol Heart Circ Physiol 2002 Oct; 283(4):H1370-8.

2. Peschar M, Vernooy K, Vanagt WYR, Reneman RS, Vos MA, Prinzen FW. Absence of reverse electrical remodeling during regression of volume overload hypertrophy in canine ventricles. Cardiovascular Research 2003 58;2003:510-17.

3. Verbeek XAAM, Vernooy K, Peschar M, Cornelussen RNM, Prinzen FW. Intra-ventricular resynchronization for optimal left ventricular function during pacing in experimental left bundle branch block. JACC 2003, Vol 42(3): 558-67.

4. Vernooy K, Verbeek XAAM, Peschar M, Prinzen FW. Relation between abnormal ventricular impulse conduction and heart failure. J Interv Cardiol. 2003 Dec;16(6):557-62.

5. Peschar M, Vernooy K, Cornelussen RN, Reneman R, Vos M, Prinzen FW. Structural, electrical and mechanical remodeling of the heart in AV-block and LBBB. Eur Heart J Suppl 2004; 6: D61-D65

6. Prinzen FW, Vernooy K, Cornelussen RN. Cardiac memory and cortical memory. Circulation. 2004 May 25;109(20):e226 (letter to the editor)

7. Vernooy K, Verbeek XAAM, Peschar M, Crijns HJGM, Arts T, Cornelussen RNM, Prinzen FW. Ventricular remodeling and septal hypoperfusion in chronic experimental left bundle branch block. Eur Heart J 2005 Jan;26(1):91-8

8. Oliva A, Vernooy K, Cooter R, David DJ, Pascali V. Helmet-induced neck degloving in a motorcyclist. J Trauma. 2005 Feb;58(2):370-1. (case-report)

9. Vanagt WY, Pulles-Heintzberger CF, Vernooy K, Cornelussen RN, Delhaas T. Asystole during outbursts of laughing in a child with Angelman syndrome. Pediatr Cardiol. 2005 Nov-Dec;26(6):866-8. (case report)

10. Verbeek XA, Auricchio A, Yu Y, Ding J, Pochet T, Vernooy K, Kramer A, Spinelli J, Prinzen FW. Tailoring cardiac resynchronization therapy using interventricular asynchrony. Validation of a simple model. Am J Physiol Heart Circ Physiol. 2006 Mar;290(3):H968-77 
$186 \mid$ Publications

11. Vernooy K, Delhaas T, Cremer OL, Di Diego JM, Oliva A, Timmermans C, Volders PG, Prinzen FW, Crijns HJGM, Antzelevitch C, Kalkman CJ, Rodriguez LM, Brugada R. Electrocardiographic changes predicting sudden death following long-term high-dose propofol sedation. Heart Rhythm. 2006 Feb;3(2):131-7

12. Vernooy K, Dijkman B, Cheriex E, Prinzen FW, Crijns HJGM. Ventricular remodeling during long-term right ventricular pacing following His bundle ablation in patients with atrial fibrillation. Am J Cardiol. 2006 Apr 15;97(8):1223-7.

13. Vanagt WY, Cornelussen RN, Poulina QP, Blaauw E, Vernooy K, Cleutjens JP, van Bilsen M, Delhaas T, Prinzen FW. Pacing-induced dyssynchrony preconditions rabbit myocardium against ischemia/reperfusion injury. Circulation. 2006 Jul 4;114(1 Suppl):I264-9.

14. Vernooy K, Sicouri S, Dumaine R, Hong K, Oliva A, Burashnikov E, Timmermans C, Delhaas T, Crijns HJGM, Antzelevitch C, Rodriguez LM, Brugada R. Genetic and Biophysical Basis for Bupivacaine-induced ST Segment Elevation and VT/VF. Anesthesia Unmasked Brugada Syndrome. Heart Rhythm 2006 Sep;3(9):1074-8.

15. Vernooy K, Verbeek XAAM, Cornelussen RNM, Dijkman B, Crijns HJGM, Arts T, Prinzen FW. Calculation of effective VV-interval facilitates optimization of AV-delay and VV-interval in cardiac resynchronization therapy. Heart Rhythm (in press) 